\title{
Zeitaufgelöste Laserspektroskopie
}

\author{
Dissertation \\ zur Erlangung des Doktorgrades \\ der Fakultät für Physik \\ der Universität Bielefeld
}

vorgelegt von

Tim Nielsen

Mai 1999 


1. Gutachter: Prof. Dr. Peter Andresen

2. Gutachter: Prof. Dr. Katharina Kohse-Höinghaus

Tag der Disputation: 13. Juli 1999

Gedruckt auf alterungsbeständigem Papier nach DIN-ISO 9706. 


\title{
Zeitaufgelöste Laserspektroskopie
}

\author{
Dissertation \\ zur Erlangung des Doktorgrades \\ der Fakultät für Physik \\ der Universität Bielefeld
}

vorgelegt von

Tim Nielsen

Mai 1999 


\section{Kurzzusammenfassung}

In dieser Arbeit wird das Potential der zeitaufgelösten LIF in drei beispielhaften Fällen, die in je einem Kapitel vorgestellt werden, untersucht. Die behandelten Systeme sind recht unterschiedlich, was die Vielfalt der Probleme, die mit Hilfe der Laserspektroskopie analysiert werden können, zeigt.

\section{ps-LIF an zweiatomigen Molekülen}

Im ersten Kapitel werden $\mathrm{OH}-$ Moleküle in atmosphärischen Flammen untersucht. Nach Anregung eines einzelnen Rotationszustands mit einem schmalbandigen und abstimmbaren ps-UV-Laser wurde die Fluoreszenzemission mit hoher zeitlicher und spektraler Auflösung detektiert. Durch eine detaillierte Analyse der Spektren konnte die durch Stöße mit umgebenden Molekülen induzierte Dynamik in einem Vibrationszustand des elektronisch angeregten Zustands verfolgt werden. Mit diesem Aufbau war es erstmalig möglich, einige RET Raten direkt in einer atmosphärischen Flamme zu messen. Es konnte die totale RET Rate für das angeregte Rotationsniveau bestimmt werden. Desweiteren konnte die Rotationsverteilung innerhalb des angeregten Vibrationszustands durch ein einfaches Modell für zustandsspezifischen RET beschrieben werden.

\section{ps-LIF in Flüssigkeiten}

Im zweiten Kapitel wird die Bindung von fluoreszenzmarkiertem GTP an ein GProtein mit spektroskopischen Methoden untersucht. Das Bindungsereignis konnte sowohl an einer Änderung der Fluoreszenzintensität als auch an einer Änderung der Fluoreszenzlebensdauer festgestellt werden. Die untersuchte Reaktion stellt ein Modellsystem für ein Screening-System dar. Die durchgeführten Messungen zeigen, daß sich der Aufbau zu einem leistungsfähigen HTS-System erweitern läßt, das sich gegenüber bestehenden Systemen durch einige Vorteile auszeichnen würde.

\section{Parallelprocessing in der Zweiphotonenmikroskopie}

Im dritten Kapitel wird der Aufbau und die Erprobung eines Zweiphotonenmikroskops dargestellt. Im Unterschied zu üblichen Zweiphotonenmikroskopen, die mit einem Strahl arbeiten, wurden zur Anregung der Fluoreszenz 64 Laserstrahlen simultan verwendet. Es wird ein neues Verfahren der Strahlaufteilung vorgestellt.

Die Art der Datenaufnahme mit einer CCD-Kamera ist ebenfalls eine Neuerung in der Zweiphotonenmikroskopie. Sie hat den Vorteil, daß, auch wenn die Fluoreszenz beim Austritt aus dem untersuchten Objekt gestreut wird, ohne Einschränkung der Auflösung gearbeitet werden kann, solange die Signale der einzelnen Strahlen noch voneinander getrennt werden können. 


\section{Inhaltsverzeichnis}

$\begin{array}{ll}\text { Einleitung } & 1\end{array}$

1 Zeitaufgelöste Messung des Rotationsenergietransfers in $\mathrm{A}^{2} \Sigma^{+}$( $\left.\mathbf{v}^{\prime}=\mathbf{2}\right)$ beim OH-Molekül in atmosphärischen Flammen $\mathbf{5}$

1.1 Laserinduzierte Fluoreszenz zur Konzentrationsmessung in Flammen 5

1.2 Der experimentelle Aufbau . . . . . . . . . . . . . . . 7

1.2.1 Die Kalibrierung des Aufbaus . . . . . . . . . . . 10

1.3 Die Berechnung der Besetzung in $v^{\prime}=2$ aus den Emissionsspektren 10

1.3.1 Polarisationseffekte . . . . . . . . . . . . . 13

1.3.2 Die Zeitabhängigkeit der Besetzung . . . . . . . . . . . 16

1.4 Die Modellierung der Dynamik des angeregten Zustands . . . . . . 16

1.5 Diskussion . . . . . . . . . . . . . . . . 22

1.5.1 Vergleich mit Raten für $v^{\prime}=0,1 \ldots \ldots \ldots 22$

1.5.2 Vergleich mit anderen Meßverfahren . . . . . . . . . . 23

1.6 Zusammenfassung ..................... 24

2 Zeitaufgelöste Fluoreszenzspektroskopie in Flüssigkeiten zur Erkennung chemischer Reaktionen $\quad 25$

2.1 Das Modellsystem: Rab3A und mantGTP . . . . . . . . . . . . 26

2.1.1 Allgemeines über G-Proteine . . . . . . . . . . . . . . 26

2.1.2 Die Struktur von mantGTP . . . . . . . . . . . . . . 29

2.1.3 Das Meßprinzip . . . . . . . . . . . . . . . . . . . . 29

2.2 Der experimentelle Aufbau . . . . . . . . . . . . . . . 31

2.2.1 Die Triggerung des Experiments . . . . . . . . . . 33

2.2.2 Die Charakterisierung des Meßsystems . . . . . . . . . 34

2.3 Die Durchführung der Messung . . . . . . . . . . . . . . . . . 35

2.3.1 Die Herstellung der Lösungen . . . . . . . . . . . . . . 35

2.3.2 Die Aufnahme zeitaufgelöster Spektren . . . . . . . . . . 36

2.3.3 Die Auswertung der Fluoreszenzabklingkurven . . . . . . . . 37

2.4 Die Spektren der Substanzen . . . . . . . . . . . . . . . . 37

2.4.1 Küvette und Puffer . . . . . . . . . . . . . . . . . 38

2.4 .2 GTP und Rab3A . . . . . . . . . . . . . . . . 39

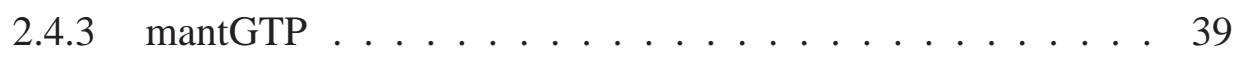

2.5 Diskussion. . . . . . . . . . . . . . . 45 
2.5.1 Die Intensitätsänderung bei der Bindung an Rab3A . . . . . 46

2.5.2 Die Fluoreszenzlebensdauern . . . . . . . . . . . . 47

2.5.3 Die Ratenkonstante für die Spaltung des Rab3A-mantGTP

Komplexes . . . . . . . . . . . . . . . . . . . 48

2.5.4 Nachweisgrenzen . . . . . . . . . . . . . . . . 48

2.6 Zusammenfassung . . . . . . . . . . . . . . . 48

3 Parallelprocessing in der Zweiphotonenmikroskopie $\quad 50$

3.1 Laserscanningmikroskopie . . . . . . . . . . . . . . . . 51

3.1 .1 Konfokale LSM . . . . . . . . . . . . . . . . . . . 52

3.1 .2 Zweiphotonen LSM . . . . . . . . . . . . . 53

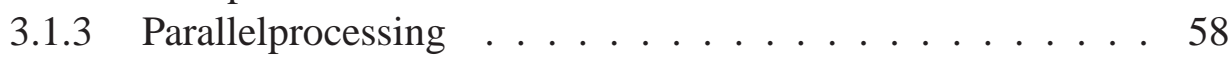

3.2 Der experimentelle Aufbau . . . . . . . . . . . . . . . . . . 59

3.2.1 Das Lasersystem . . . . . . . . . . . . . . . . . . . . 59

3.2.2 Der Strahlvervielfacher . . . . . . . . . . . . . . 67

3.2.3 Das Mikroskop . . . . . . . . . . . . . . . . . 74

3.2 .4 Der Detektor . . . . . . . . . . . . . . . . . . . . 82

3.2.5 Die Steuerung der Messungen . . . . . . . . . . . . . 91

3.3 Die Messungen . . . . . . . . . . . . . . . . . . 93

3.3.1 Zweiphotonenanregung . . . . . . . . . . . 93

3.3.2 Die Zeitauflösung . . . . . . . . . . . . . . . . . . . . . . . 94

3.3.3 Die Berechnung der Bilder aus den Rohdaten . . . . . . . . 95

3.3.4 Die Ortsauflösung . . . . . . . . . . . . . . . . 101

3.3.5 Messungen mit fluoreszenzmarkierten Bakterien . . . . . 104

3.4 Diskussion . . . . . . . . . . . . . . . . . 112

3.4.1 Die Auflösung . . . . . . . . . . . . . . . . 112

3.4.2 Gegenseitige Beeinflussung der Teilstrahlen in der Probe . . 112

3.4.3 Die Signalstärke . . . . . . . . . . . . . . . . 113

3.4.4 Die Scangeschwindigkeit . . . . . . . . . . . . . . 115

3.5 Zusammenfassung . . . . . . . . . . . . 116

$\begin{array}{lr}\text { Zusammenfassung } & 118\end{array}$

$\begin{array}{ll}\text { A Lösung der Ratengleichung } & 121\end{array}$

$\begin{array}{lr}\text { Literaturverzeichnis } & 124\end{array}$

$\begin{array}{lr}\text { Danksagung } & 130\end{array}$ 


\section{Einleitung}

Die Laserspektroskopie ist eine Meßtechnik, die zur Analyse verschiedenster Prozesse in Physik, Chemie, Biologie aber auch in technischen Anwendungen verwendet wird. Parallel zur Entwicklung der Laser wurden in den letzten Jahrzehnten (zum Teil sehr spezielle) Lasermeßverfahren entwickelt, in denen die besonderen Eigenschaften des Laserlichts eingesetzt wurden. Den Verfahren gemeinsam ist, daß Laser benutzt werden, um das zu untersuchende Objekt mit Licht zu bestrahlen und daß dann die Absorption des Laserlichts, am Objekt gestreutes oder von ihm als Fluoreszenz emittiertes Licht detektiert wird. Die Verfahren sind berührungslos, das heißt, das untersuchte Objekt wird durch die Messung nicht gestört. Durch Fokussierung des Laserlichts kann eine gute Ortsauflösung $(<1 \mu \mathrm{m})$ und durch Verwendung von gepulsten Lasern eine hohe Zeitauflösung $(<10 \mathrm{fs})$ erreicht werden.

Darüber hinaus zeichnet sich besonders laserinduzierte Fluoreszenz (LIF) dadurch aus, daß sie sehr empfindlich und selektiv ist. Über die Fluoreszenzintensität können Molekülverteilungen bildgebend visualisiert werden oder auch absolute Konzentrationen gemessen werden. Anhand des Fluoreszenzspektrums kann die Spezies identifiziert oder bei kleinen Molekülen sogar der Quantenzustand angegeben werden. Die Polarisation der Fluoreszenz enthält Informationen über die Beweglichkeit bzw. Diffusionsgeschwindigkeit der Moleküle. Die Fluoreszenzlebensdauer wird von der Umgebung, in der sich die Moleküle befinden, beeinflußt. Es kann also eine Vielzahl von spektroskopischen Merkmalen ausgenutzt werden, um verschiedene Informationen über das untersuchte Objekt zu erhalten.

Durch die ständige Weiterentwicklung sowohl der Laser als auch der Detektoren wird der Einsatzbereich der Laserspektroskopie kontinuierlich erweitert. Einen Überblick über verschiedene Verfahren findet man in [1].

In dieser Arbeit wird das Potential der zeitaufgelösten LIF in drei beispielhaften Fällen, die in je einem Kapitel vorgestellt werden, untersucht. Die behandelten Systeme - damit verbunden auch die spezielle Fragestellung jedes Kapitels — sind recht unterschiedlich, was die Vielfalt der Probleme, die mit Hilfe der Laserspektroskopie analysiert werden können, zeigt. In allen Fällen wird jedoch ein Kurzpulslaser mit Pulsdauern im ps- bzw. fs-Bereich zur Anregung verwendet und die anschließende Fluoreszenzemission zeitaufgelöst detektiert. Aus dem zeitlichen Verlauf der Emission können dann Rückschlüsse auf die Umgebung der angeregten Moleküle gezogen werden. Die zur Anregung verwendeten Laser sind jeweils speziell an das untersuchte System angepaßt und sind daher in den drei Experimenten 
unterschiedlich. Die Detektion der Fluoreszenz erfolgt in allen Fällen über intensivierte CCD-Kameras mit extrem kurzen Verschlußzeiten $(\leq 200 \mathrm{ps})$, die erst in jüngster Zeit entwickelt wurden.

\section{Der Einfluß von Stößen mit Molekülen der Umgebung auf das Fluoreszenzspektrum}

Im ersten Kapitel wird ein zweiatomiges Molekül in der Gasphase untersucht genauer gesagt das OH-Radikal in einer atmosphärischen Flamme. OH-Moleküle kommen als Zwischenprodukt bei den chemischen Reaktionen, die bei der Verbrennung ablaufen, vor und sind deshalb von grundlegendem Interesse für das Verständnis der Vorgänge in Flammen. Besonders die Konzentration der OH-Moleküle ist wichtig für einen Vergleich mit Modellrechnungen. Ein qualitatives Bild der $\mathrm{OH}-$ Verteilung kann man relativ leicht mit Hilfe von LIF erhalten. Bei einer Quantifizierung der Fluoreszenzintensität, d. h. der Umrechnung des Signals in eine Konzentration, kommen aber Effekte, die durch Stöße der angeregten Moleküle mit anderen Molekülen der Umgebung hervorgerufen werden, erschwerend hinzu: Durch einen Stoß können die angeregten Moleküle die durch die Absorption des Laserphotons gewonnene Energie teilweise oder ganz verlieren - also den Quantenzustand wechseln —, ohne dabei Fluoreszenz zu emittieren. Das heißt, von den ursprünglich angeregten Molekülen trägt ein von der jeweiligen Umgebung der Moleküle abhängiger Bruchteil nicht zur Fluoreszenz bei. Um für die jeweilige Umgebung aus dem Fluoreszenzsignal die Konzentration berechnen zu können, müssen die Raten, mit denen die verschiedenen Energietransferprozesse ablaufen, bekannt sein. Im Kapitel 1 wird ein neues Verfahren, mit dem Raten für Rotationsenergietransfer, d. h. die stoßinduzierte Änderung der Rotationsquantenzahl, gemessen werden können, vorgestellt.

Da hier ein einzelner Quantenzustand angeregt werden sollte, mußte ein schmalbandiger und abstimmbarer ps-Laser zur Anregung verwendet werden. Dieser Laser wurde an der Universität Bielefeld entwickelt. Durch hohe spektrale Auflösung bei der Detektion konnten die Emissionen einzelnen Quantenzuständen zugeordnet werden und so die Besetzung im angeregten Zustand rotationsaufgelöst bestimmt werden. Anhand der Veränderung der Spektren konnte die Veränderung der Besetzung und daraus die Raten für Rotationsenergietransfer ermittelt werden.

Das Hauptziel dieses Kapitels ist die Erläuterung des Meßprinzips — nämlich die Gewinnung der Besetzungsdynamik aus der detaillierten Analyse transienter Spektren. Daher ist der Vergleich der Ergebnisse mit anderen Messungen und die Beziehung der Technik zu in der Flammenspektroskopie üblichen Meßverfahren knapp gehalten. Der an den speziellen Problemen der Flammenspektroskopie interessierte Leser, sei auf die angegebenen Referenzen verwiesen. Eine Einführung in die Spektroskopie des OH-Moleküls und insbesondere die Notation der Zustände und Übergänge findet man u. a. in [2] und [3]. Der wesentliche Teil des ersten Kapitels ist in [4] veröffentlicht. 


\section{Die Erkennung chemischer Reaktionen anhand spektroskopi- scher Merkmale}

Im Unterschied zum ersten Kapitel, werden im zweiten Kapitel größere Moleküle ${ }^{1}$ in Flüssigkeiten untersucht. Die Größe der Moleküle und die starke Wechselwirkung mit dem Lösungsmittel bringen es mit sich, daß die Absorptions- und Emissionsspektren kontinuierlich sind. Der Laser brauchte also nicht mehr schmalbandig und abstimmbar zu sein, sondern hier kam es eher auf moderate Intensitäten pro Puls, um die Moleküle nicht zu dissoziieren, und hohe Pulswiederholfrequenz, um trotzdem ein gutes Signal zu bekommen, an.

Ziel, der im zweiten Kapitel dargestellten Messungen, ist es, anhand der Fluoreszenz festzustellen, ob es zu einer spezifischen Bindung zwischen zwei bestimmten Molekülen kommt. Der Grundgedanke ist auch hier — ähnlich wie oben —, daß die Fluoreszenzemission von der Umgebung der Moleküle abhängt. In diesem Fall entstehen die unterschiedlichen Umgebungen nicht durch die verschiedenen Bereiche der Flamme, sondern dadurch, daß die Moleküle, wenn sie nicht binden, ganz von Lösungsmittelmolekülen umgeben sind, während sie, wenn sie aneinander binden, durch den Reaktionspartner teilweise vom Lösungsmittel abgeschirmt werden, oder sogar ihre eigene Konformation ändern.

Die Erkennung spezifischer chemischer Reaktionen ist von großem Interesse bei Grundlagenfragen der Biologie, z. B. bei der Untersuchung von Protein-Ligand Interaktionen, aber auch bei angewandten Fragen, wie in der Pharmakologie bei der Suche nach neuen Medikamenten. Ein optisches Verfahren ist hier besonders vorteilhaft, weil es schnell ist und durch den Einsatz bildgebender Verfahren parallelisiert, d. h. für viele verschiedene Substanzen simultan durchgeführt werden kann.

\section{Zeitaufgelöste Spektroskopie mit hoher, dreidimensionaler Orts- auflösung}

Die Möglichkeit, Informationen über die Umgebung der angeregten Moleküle oder Reaktionen mit anderen Molekülen, aus spektroskopischen Merkmalen zu erhalten, macht es reizvoll, die Spektroskopie mit hoher Ortsauflösung zu kombinieren, um z. B. in lebenden Zellen Reaktionen, die bei physiologischen Vorgängen ablaufen, direkt beobachten zu können.

Im dritten Kapitel wird der Aufbau eines Laserscanningmikroskops beschrieben, mit dem die dreidimensionale Verteilung der Fluoreszenzlebensdauer in einem Objekt mit einer Ortsauflösung im Mikrometerbereich gemessen werden kann. Mit einem solchen Mikroskop ist es z. B. möglich, die Aufnahme und Wirkung von Arzneistoffen an einzelnen Zellen zu verfolgen.

Dieses Kapitel nimmt den größten Raum der Arbeit ein, weil der experimentelle Aufwand hier am höchsten ist. Zur Steigerung der Bildaufnahmegeschwindigkeit,

${ }^{1}$ Für Physiker-Verhältnisse schon sehr große Moleküle mit einem Molekulargewicht von 25 kDa. 
die relativ gering ist, weil es sich um ein Raster-Verfahren handelt, wurde der Laserstrahl in mehrere Teilstrahlen aufgespalten und die Probe simultan mit allen Teilstrahlen abgerastert. Dies und die Art der Detektion sind wesentliche Neuerungen und Unterschiede des hier aufgebauten Systems gegenüber anderen Laserscanningmikroskopen.

Die einzelnen Kapitel sind jeweils mit einer Einleitung versehen, in der die zugrundeliegende Fragestellung genauer erläutert wird. Ebenso schließt jedes Kapitel mit einer Zusammenfassung, in der die wichtigsten Ergebnisse wiedergegeben werden. Am Schluß der Arbeit befindet sich eine Zusammenfassung aller Kapitel. Die Reihenfolge der Kapitel entspricht der zeitlichen Abfolge der Experimente und der sich aus den jeweiligen Ergebnissen weiter entwickelnden Fragen. 


\section{Kapitel 1}

\section{Zeitaufgelöste Messung des Rotationsenergietransfers in $\mathbf{A}^{2} \Sigma^{+}$ $\left(v^{\prime}=2\right)$ beim OH-Molekül in atmosphärischen Flammen}

\subsection{Laserinduzierte Fluoreszenz zur Konzentrations- messung in Flammen}

Laserinduzierte Fluoreszenz (LIF) ist eine häufig eingesetzte Technik beim Nachweis von Minoritätenspezies in Flammen [5, 6]. Die Vorteile dieser Methode liegen in der hohen Sensitivität, Selektivität und der Möglichkeit, zweidimensionale Bilder der Verteilung der Moleküle aufzunehmen. Es ist allerdings schwierig, die Fluoreszenzintensität mit der Konzentration der Moleküle, an der man interessiert ist, in Verbindung zu bringen, weil Stöße mit den Molekülen der Umgebung den LIF-Prozeß stören. Dies gilt für die Fluoreszenzemission, da die angeregten Moleküle Rotations- und Vibrationsenergietransfer (RET/VET), Depolarisation und Quenching ausgesetzt sind. Aber auch RET im Grundzustand kann die Zahl der angeregten Moleküle beeinflussen, wenn z. B. hohe Laserintensitäten, die die Anregung sättigen, verwendet werden [7]. Die verschiedenen stoßinduzierten Prozesse im angeregten Zustand sind in Abbildung 1.1 schematisch dargestellt. Um den störenden Einfluß der Stöße auf das Fluoreszenzsignal auszuschalten, müssen sowohl Anregung als auch Detektion der Fluoreszenz auf Zeitskalen stattfinden, die kurz gegenüber der mittleren Stoßzeit sind. Dies macht bei atmosphärischem oder höherem Druck den Einsatz von Pikosekunden-Technik nötig. Pikosekunden-LIF wurde sowohl für den eindimensionalen $[8,9]$ als auch zweidimensionalen Nachweis $[10,11]$ von $\mathrm{OH}$ in Flammen eingesetzt.

Eine Strategie den Einfluß der Stöße auf das LIF Signal zu berücksichtigen, wenn die apparativ aufwendige Pikosekunden-LIF nicht eingesetzt werden kann, ist es, die Konzentrationen aller Majoritätenspezies simultan zum Fluoreszenzsignal zu 


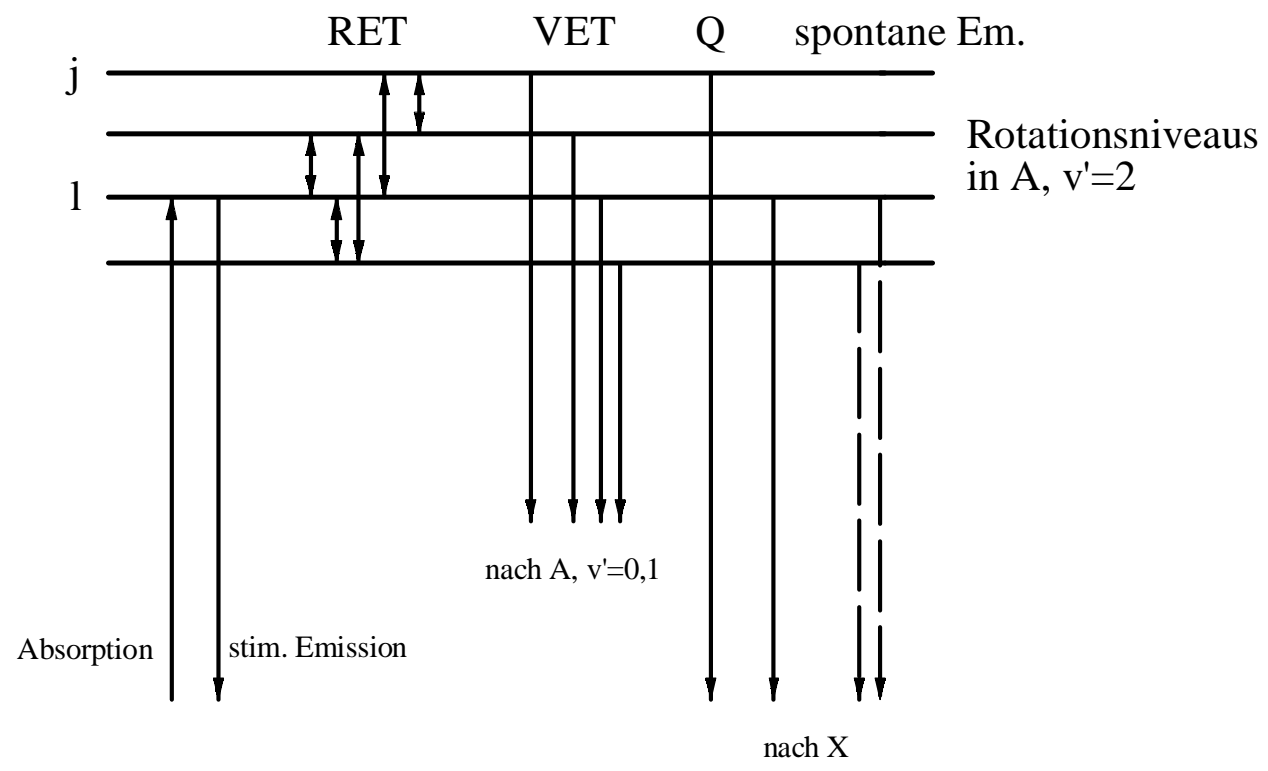

Abbildung 1.1: Schematische Darstellung der Energietransferprozesse im A ${ }^{2} \Sigma^{+}$ Zustand $\left(v^{\prime}=2\right)$ des OH-Moleküls. Q steht für Quenching. Der elektronische Grundzustand ist mit $\mathrm{X}$ bezeichnet.

messen und anschließend das Fluoreszenzsignal auf der Basis von gemessenen oder berechneten Ratenkonstanten für die verschiedenen Stoßprozesse zu korrigieren.

Im Falle des OH-Moleküls wurden detaillierte Ratengleichungsmodelle zur Simulation der Dynamik des angeregten Zustands entwickelt [12]. Diesen Modellen liegen allerdings wenige experimentell bestimmte Ratenkonstanten zugrunde.

RET Ratenkonstanten wurden für den A-Zustand des OH-Moleküls $\left(v^{\prime}=0,1\right)$ bei Temperaturen von $300 \mathrm{~K}$ oder in der Nähe von $1500 \mathrm{~K}$ gemessen; alle Messungen wurden bei niedrigem Druck $(<100$ mbar) durchgeführt. Ein Überblick über diese Messungen wird in [12] gegeben.

Da die Ratengleichungsmodelle typischerweise 40 Rotationszustände für jeden Vibrationszustand des elektronisch angeregten Zustands berücksichtigen, müssen mindestens 1600 zustandsspezifische Ratenkonstanten für jeden Stoßpartner bekannt sein. Bisher sind weniger als $1 \%$ dieser Konstanten gemessen worden, und dies zumeist unter Bedingungen, die stark von den Bedingungen, wo sie benutzt werden, abweichen. Daher werden in den detaillierten Modellen Annahmen über das Verhalten der Ratenkonstanten, z. B. Skalierungsregeln wie IOS (infinite order sudden [13, 14]) oder ECS (energy corrected sudden [15]), benutzt. Diese Regeln beschreiben die Abhängigkeit der Ratenkonstanten von anderen Größen wie der Temperatur und dem Quantenzustand. Mit Hilfe der Regeln werden die vielen zustandsspezifischen Ratenkonstanten aus wenigen Basiskonstanten berechnet.

In diesem Abschnitt wird die erste Messung von RET Ratenkonstanten $\left(v^{\prime}=2\right)$ beim $\mathrm{OH}-M o l e k u ̈ l$, die in atmosphärischen Flammen durchgeführt wurde, darge- 
stellt. Untersucht wurden eine vorgemischte, stöchiometrische Methan-Luft- und Methan-Sauerstoff-Flamme.

Angeregt wurden die $P_{11}(12.5)$ und $Q_{11}(16.5) A-X$ Übergänge der (2,0)Bande des $\mathrm{OH}-$ Moleküls mit einem Pikosekundenlaser. Die Emissionsspektren wurden zeit- und spektralaufgelöst mit einer Kombination aus hochauflösendem Spektrometer und intensivierter CCD-Kamera, die eine sehr kurze Verschlußzeit hatte, detektiert. Die Auflösung des Spektrometers reichte aus, um die Emissionen einzelner Rotationszustände zu trennen. Durch eine genaue Analyse des zu einem bestimmten Zeitpunkt aufgenommenen Spektrums konnte die Rotationsverteilung der Besetzung des angeregten Zustands zu diesem Zeitpunkt ermittelt werden. Anhand der Abfolge der Spektren, die zu verschiedenen Zeiten aufgenommen wurden, konnte die Dynamik des angeregten Zustands verfolgt werden. Aus diesen Daten konnten zustandsspezifische RET Ratenkonstanten berechnet werden.

Die einzelnen Schritte (1.) der Aufnahme der Spektren, (2.) der Berechnung der Besetzung aus den Spektren und (3.) der Berechnung der Ratenkonstanten aus der Besetzung werden in den folgenden Abschnitten (1.2 - 1.4) beschrieben. Anschließend werden die so erhaltenen Werte mit Daten aus der Literatur verglichen, sowie die Vor- und Nachteile des Meßverfahrens, das an sich schon eine Neuerung darstellt, gegenüber anderen Verfahren zur Bestimmung von Ratenkonstanten diskutiert (1.5). Das Kapitel schließt mit einer Zusammenfassung (1.6).

\subsection{Der experimentelle Aufbau}

Abbildung 1.2 zeigt den experimentellen Aufbau. Zur Anregung der Fluoreszenz wurde ein Pikosekunden-Raman-Excimerlaser, der an der Universität Bielefeld entwickelt wurde, verwendet. Der Laser ist im Detail in anderen Arbeiten [16, 17, 18] beschrieben; daher soll hier nur das Funktionsprinzip dargestellt werden:

Der Strahl eines abstimmbarern, schmalbandigen KrF-Excimerlasers (EMG 150, Lambda Physik) wird in eine Hochdruckgaszelle (30 bar Kr) fokussiert. Dort wird der Puls durch stimulierte Brillouinstreuung (SBS, [19]) reflektiert; der reflektierte Puls hat eine steile Anstiegsflanke ( $<1 \mathrm{~ns}$ ). Gegenüber [16] wurde der Excimerlaser in zwei Punkten modifiziert, um das Strahlprofil des SBS-Pulses zu optimieren. Zum einen wurde die Cassegrain-Optik entfernt, zum anderen wurde der Oszillator-Strahl mit einem Teleskop vergrößert und in einem einfachen Durchlauf durch die Verstärkerröhre verstärkt. Diese beiden Maßnahmen führen zu geringerer Strahldivergenz und einem besseren Verhältnis von schmalbandiger Laserstrahlung zu breitbandigem Untergrund.

Die steile Anstiegsflanke des SBS-Pulses wird in einem Zweifachdurchgang durch einen weiteren KrF-Verstärker (EMG 101, Lambda Physik) verstärkt, reduziert aber den Gain des Verstärkers dabei so sehr, daß der nachfolgende Teil des Pulses nur wenig verstärkt wird. Das Ergebnis ist ein Puls mit einer intensiven, kurzen Spitze am Beginn und einem etwa 10ns langen, schwachen Schwanz. Die Spitze wird vom Rest des Pulses durch stimulierte Ramanstreuung in Methan abgetrennt 


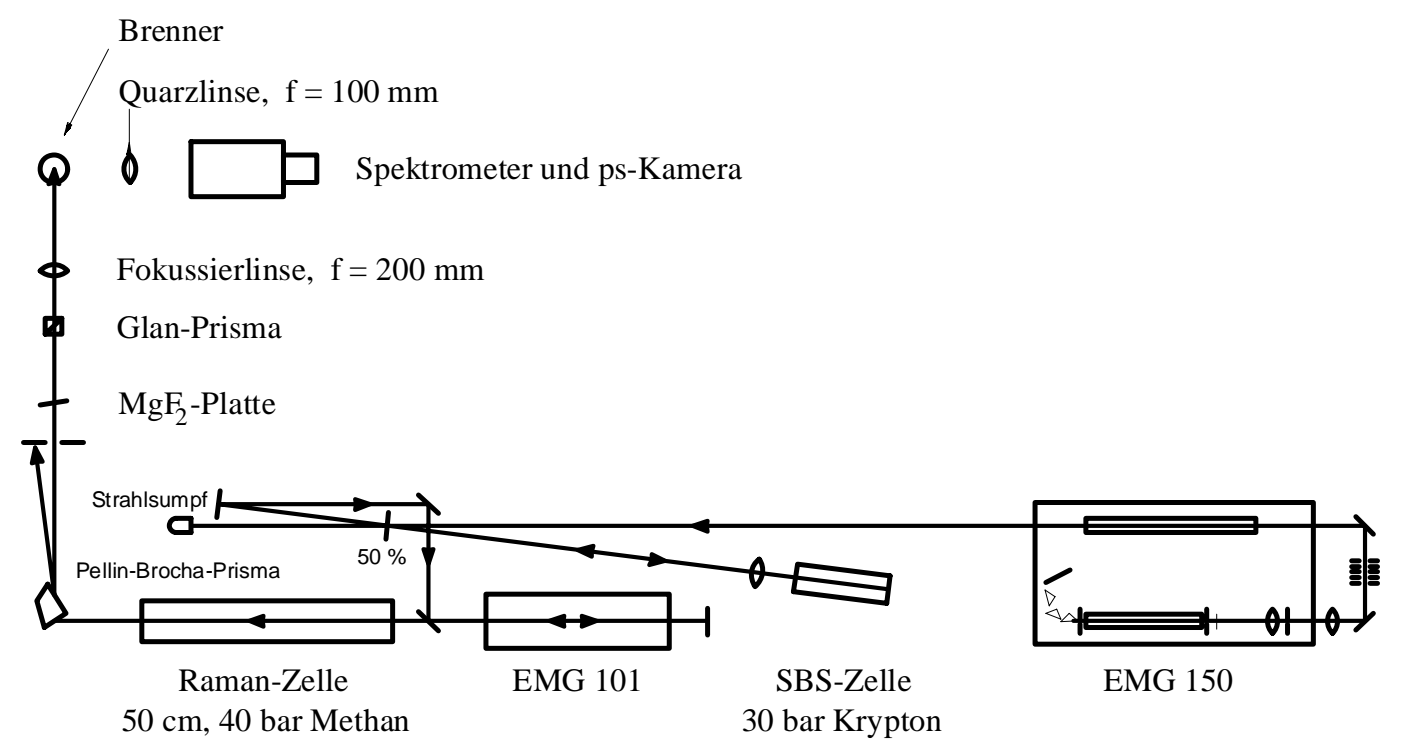

Abbildung 1.2: Experimenteller Aufbau zur Aufnahme der zeitaufgelösten Emissionsspektren.

und über ein Pellin-Brocha-Prisma zum Experiment geleitet. Dieser Aufbau liefert schmalbandige, durchstimmbare Laserpulse mit 300 ps Dauer und $0.5 \mathrm{~mJ}$ Energie bei Wellenlängen um 268nm und einer Pulsrate von 10Hz. Die Strahlung ist zu 80\% linear polarisiert. Die Polarisationsrichtung kann mit einer $\mathrm{MgF}_{2}$-Platte eingestellt werden; ein drehbares Glan-Thompson-Prisma polarisiert den Strahl vollständig.

Der Strahl wurde mit einer sphärischen Linse $(f=200 \mathrm{~mm})$ in das Abgas einer vorgemischten, stöchiometrischen Methan-Luft- oder Methan-Sauerstoff-Flamme, die bei Atmosphärendruck brannte, fokussiert. Die Flammen wurden mit folgenden Gasflüssen ${ }^{1}$ betrieben: $0.12 \operatorname{slm} \mathrm{CH}_{4}, 1.2 \mathrm{slm}$ Luft bzw. $1.0 \mathrm{slm} \mathrm{CH}_{4}, 2.0 \operatorname{slm~} \mathrm{O}_{2}$. Die Temperatur der Flammen wurde mittels Rayleigh/Raman-Streuung gemessen (siehe z. B. [17]).

Die Fluoreszenz wurde mit einer $100 \mathrm{~mm}$ Linse auf den Eintrittsspalt (100 $\mu \mathrm{m})$ eines Spektrometers (Acton Research, $f_{\#}=3.8,3600$ Linien $/ \mathrm{mm}$, geblazed für $240 \mathrm{~nm}$ ) abgebildet. Als Detektor wurde eine intensivierte ps-CCD Kamera (LaVision PicoStar) verwendet. Die Kamera besteht aus einem schnellen Bildverstärker [20], der faseroptisch an eine 12bit CCD-Kamera gekoppelt ist. Der Bildverstärker hat eine minimale Öffnungsdauer von 80 ps.

Um das Öffnen des Bildverstärkers mit den ps-Laserpulsen zu synchronisieren, ist eine präzise Triggerung des Bildverstärkers nötig. Dazu wird ein schwacher Reflex des SBS-Strahls auf eine schnelle Photodiode gelenkt, die dann den Triggerpuls für den Bildverstärker liefert. Der Jitter zwischen Laser und Bildverstärker betrug in diesem Experiment \pm 150 ps [21]. Die Zeitdifferenz zwischen Laserpuls und Öff-

\footnotetext{
${ }^{1} \operatorname{slm}=$ Standardliter $/$ Minute
} 


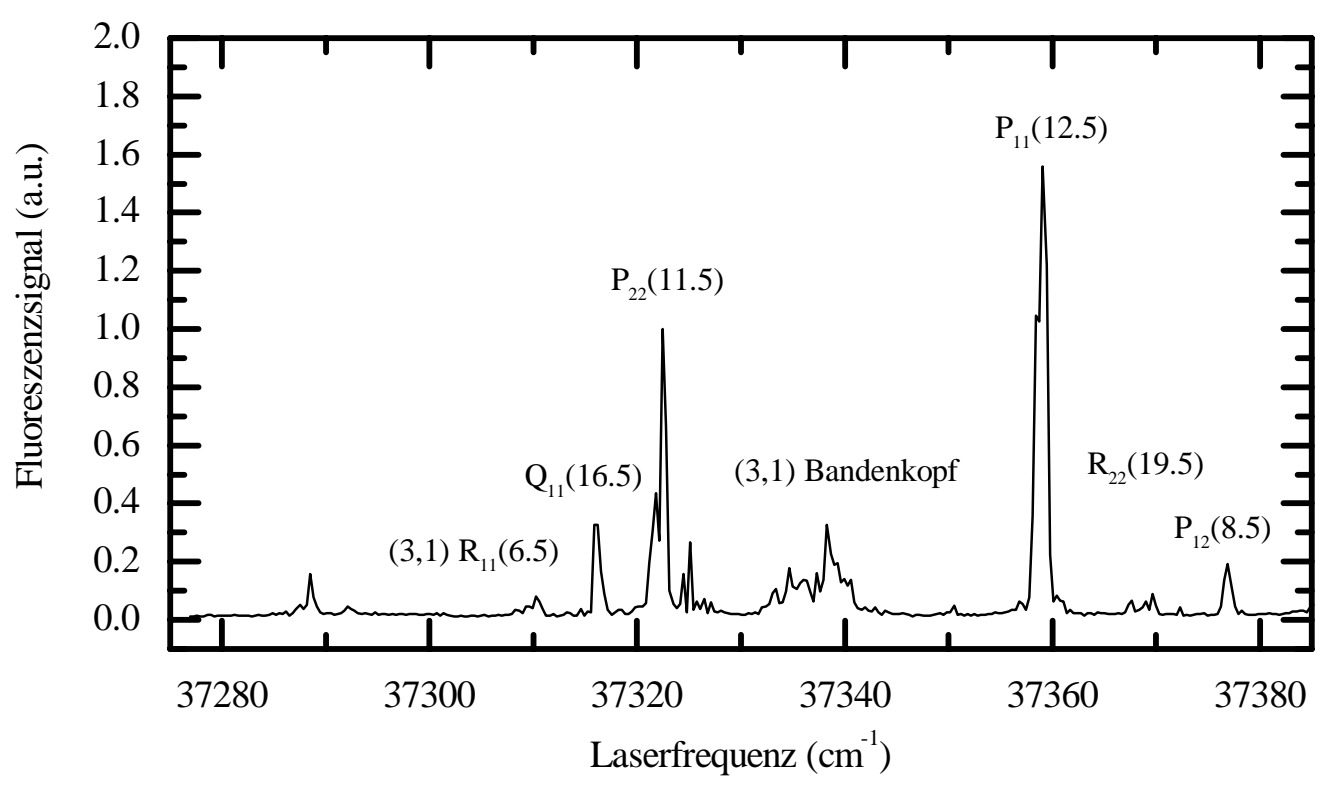

Abbildung 1.3: Anregungsspektrum des OH-Moleküls, das mit dem ps-Laser in einer Methan-Sauerstoff-Flamme aufgenommen wurde. Die beobachteten Linien konnten der (2,0)- bzw. (3,1)-Bande des $A^{2} \Sigma \leftarrow X^{2} \Pi$ Übergangs des OH-Moleküls zugeordnet werden.

nen des Bildverstärkers konnte in 500 ps Schritten mit einem passiven Kabeldelay, das in die Triggerleitung geschaltet war, eingestellt werden. Eine Feineinstellung an der Bildverstärkerelektronik erlaubte kleinere Schritte von $\approx 120 \mathrm{ps.}$

Die Öffnungsdauer des Bildverstärkers wurde nicht auf den minimalen Wert sondern auf 400 ps (FWHM) eingestellt, um das Fluoreszenzsignal zu erhöhen. Zur Aufnahme eines Emissionsspektrums wurden 20 Laserpulse pro Kamerabild integriert und jeweils 50 Bilder gemittelt, d. h. 1000 Laserpulse trugen zu einem Spektrum bei. Die Mittelung über viele Laserpulse verbreiterte die effektive Pulsdauer, die über den Zeitverlauf des Rayleighstreulichts gemessen wurde, auf 700 ps. Zwei Effekte tragen dazu bei: Zum einen ist der Mittelwert vieler Pulse breiter als ein einzelner Puls, wegen des Jitters zwischen Laser und Kamera, zum anderen ist das Signal die Faltung aus dem Zeitverlauf des Rayleighstreulichts und der Öffnungsdauer des Detektors.

Es befinden sich mehrere Rotationslinien der (2,0)- und (3,1)-Bande des $A^{2} \Sigma \leftarrow$ $X^{2} \Pi$ Übergangs des OH-Moleküls im Abstimmbereich des Lasers. Ein Anregungsspektrum ist in Abbildung 1.3 dargestellt. In den folgenden Messungen wurden die $P_{11}(12.5)$ und $Q_{11}(16.5)$ Übergänge der $(2,0)$-Bande angeregt.

Wegen der langen Mittelungsdauer mußte bei der Aufnahme der Spektren auf Wellenlängendrifts des Lasers geachtet werden. Daher wurde die Wellenlänge des Lasers bei den Messungen ständig mit einem Etalon beobachtet, um zu gewährleisten, daß sie exakt der Molekülabsorption entsprach. 


\subsubsection{Die Kalibrierung des Aufbaus}

Um die Emissionsspektren analysieren zu können, ist es nötig, die Form der Spektrometerfunktion exakt zu kennen. Sie wurde mit einer Quecksilberdampflampe gemessen. Die Form konnte gut durch einen gaußförmigen Peak mit exponentiell abklingenden Flügeln beschrieben werden [17] - Funktionen wie $\operatorname{sinc}^{2}$, GaußProfil oder Voigt-Profil, die häufig zur Modellierung von Spektrometerfunktionen eingesetzt werden, stimmten nicht mit dem beobachteten Profil überein.

Auch die wellenlängen- und polarisationsabhängige Nachweiswahrscheinlichkeit muß bei der Auswertung der Spektren berücksichtigt werden. Sie wurde mit einer Deuteriumlampe und einem Polarisator gemessen. Da der nachgewiesene Spektralbereich allerdings recht klein war $(\approx 10 \mathrm{~nm})$, war die Nachweiswahrscheinlichkeit fast konstant ( $<2 \%$ Variation über den gesamten Bereich). Wichtiger war die chromatische Aberration der Quarzlinse, mit der die Fluoreszenz auf das Spektrometer abgebildet wurde. Sie führte zu einer wellenlängenabhängigen Vergrößerung, die ebenfalls die gemessenen Spektren beeinflußte. Die Größe dieses Effekts $(\approx 10 \%)$ wurde mit einem feinen Drahtgitter bestimmt, das mit der Deuteriumlampe beleuchtet und auf den Eintrittsspalt des Spektrometers abgebildet wurde. Wurde nun ein Bild mit der Kamera aufgenommen, hing der Abstand der Gitterdrähte (in Pixel) von der Wellenlängenposition ab. Diese Werte der $\lambda$-abhängigen Vergrößerung wurden zur Korrektur der Spektren verwendet. Eine Rechnung, in die die Geometrie des Aufbaus sowie die bekannte Dispersion von Quarz eingingen, lieferte dieselben Ergebnisse.

\subsection{Die Berechnung der Besetzung in $v^{\prime}=2$ aus den Emissionsspektren}

Abbildung 1.4 zeigt zwei typische Emissionsspektren der (2,1)-Bande, die zu verschiedenen Zeiten nach der Anregung des $P_{11}(12.5)$ Übergangs aufgenommen wurden, zusammen mit einer Simulation. Neben der spektralen Nachweiswahrscheinlichkeit wurden die Spektren noch bezüglich Polarisationseffekten korrigiert — dies wird im folgenden Abschnitt beschrieben. Die kleine Graphik in Abbildung 1.4 zeigt die Detektionszeitpunkte relativ zum Zeitverlauf des anregenden Laserpulses. Diese Kurve wurde aus dem Rayleigh-Signal erhalten und kann gut durch ein Gauß-Profil angepaßt werden. Die Zeitachse ist so gewählt, daß $t=0 \mathrm{~ns}$ dem Maximum des Laserpulses entspricht. Die Zeitpunkte, bevor der Laserpuls sein Maximum erreicht, sind daher negativ angegeben. Das obere Spektrum in Abbildung 1.4 ist zu einem frühen Zeitpunkt ( $t=-0.5 \mathrm{~ns}$ ), wo noch wenig RET stattgefunden hat, aufgenommen worden. Man erkennt drei starke Linien, die den $P$-, $Q$ - und $R$-Übergängen, die von dem einen durch den Laser bevölkerten Rotationszustand ausgehen, entsprechen. Die kleineren Linien entstehen durch RET und gehen von anderen Rotationszuständen aus.

Die Struktur des Emissionsspektrums ändert sich rasch, wie an dem unteren 

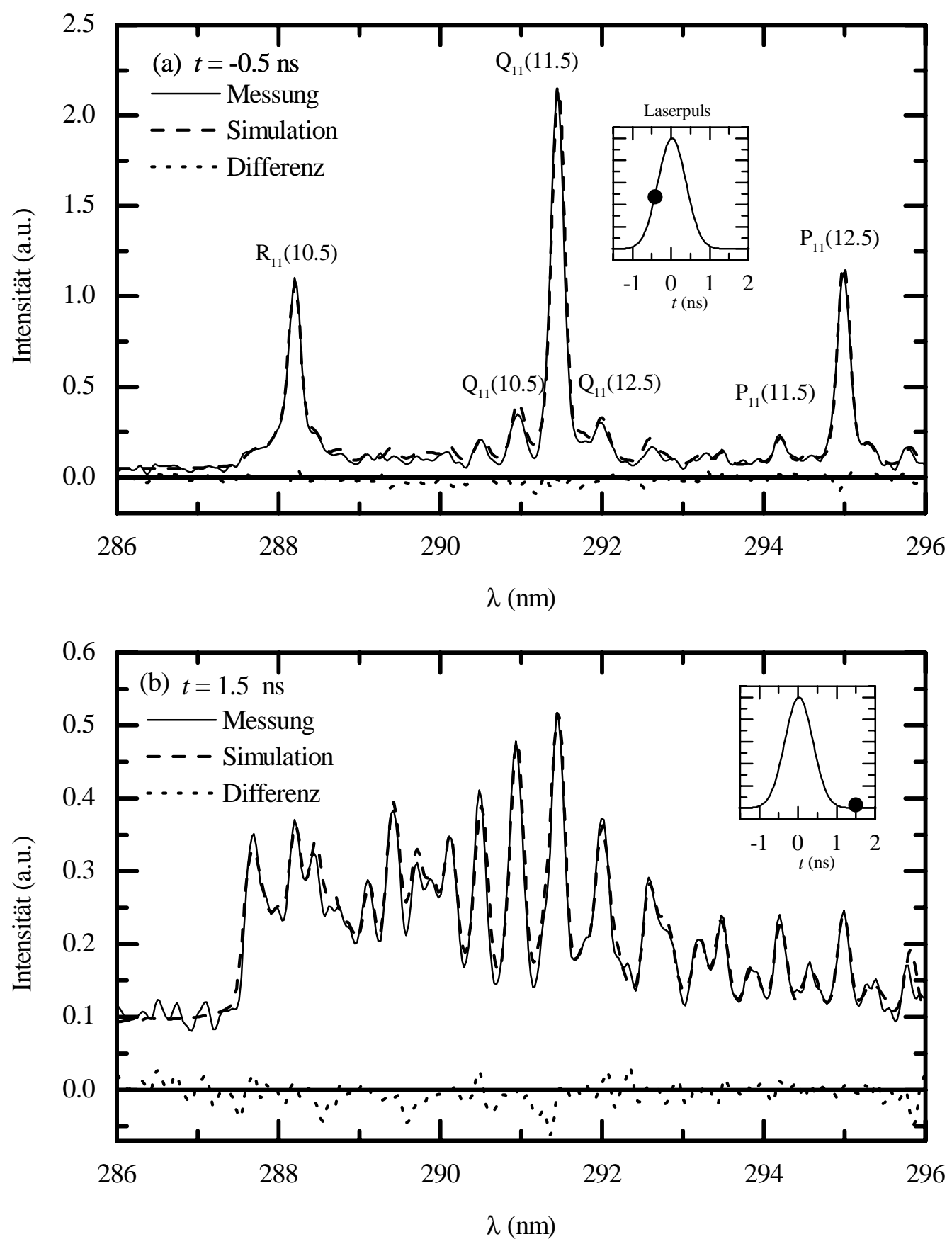

Abbildung 1.4: Typische Emissionsspektren der (2,1)-Bande nach Anregung des $P_{11}(12.5)$ Übergangs: (a) zu einem frühen Zeitpunkt, wo noch wenig RET stattgefunden hat, (b) 2 ns später, wo RET die Struktur der Emission stark geändert hat. 
Spektrum in Abbildung 1.4, das bei $t=1.5 \mathrm{~ns}$ aufgenommen wurde, zu sehen ist. Obwohl das Spektrum recht kompliziert ist, stimmen Simulation und Messung sehr gut überein.

Für die Simulation der Emissionsspektren $I(\lambda)$ wurden die Linienpositionen $\lambda_{0}$ und Einstein $A$-Koeffizienten aus dem Lifbase-Programm [22] verwendet. Jede Linie wurde mit der Spektrometerfunktion $f$ gefaltet und entsprechend der Population des Rotationszustands $n$ gewichtet:

$$
I(\lambda)=\sum_{i=\text { alle Linien }} n\left(N^{\prime}(i), F^{\prime}(i)\right) \cdot A(i) \cdot f\left(\lambda-\lambda_{0}(i)\right) .
$$

$N^{\prime}$ und $F^{\prime}$ stehen hier für die Rotations- und Spinquantenzahl des Niveaus des angeregten Zustands.

Die Besetzung des angeregten Zustands wurde mit linearen und nicht-linearen Fitalgorithmen aus dem gemessenen Spektrum berechnet. Die lineare Ausgleichsrechnung wurde mit Hilfe von Singulärwertzerlegung (s. u.) durchgeführt. Für die nichtlineare Ausgleichsrechnung wurde ein spezieller Algorithmus [23] verwendet, der lineare und nicht-lineare Parameter unterschiedlich behandelt. Dieser Algorithmus ist beim Fitten von Emissionsspektren, wo viele lineare und wenige nichtlineare Parameter im Modell auftauchen, stabiler als die üblichen Verfahren zur Lösung der Normalengleichungen.

Die lineare Ausgleichsrechnung läuft auf das Lösen eines linearen Gleichungssystems hinaus. Ein gemessenes Spektrum, d. h. ein Vektor, der die für jedes Wellenlängenintervall ${ }^{2}$ gemessene Intensität enthält, wird durch Multiplikation mit einer geeigneten Matrix in den Vektor der Besetzung der einzelnen Niveaus überführt. Die Rechnung läßt sich sehr schnell durchführen und das Ergebnis ist eindeutig. Die physikalischen Details des Problems, wie z. B. Linienpositionen und Spektrometerfunktion, sind in der Matrix enthalten. Beim Fitten der Emissionsspektren wurden die Niveaus mit $N^{\prime}=0-17$ und $F^{\prime}=1,2$ (=36 Parameter) berücksichtigt. Die übrigen Fitparameter waren ein für alle Wellenlängen konstanter Untergrund sowie, im Falle des nicht-linearen Algorithmus, Ursprung und Skalierung der Wellenlängenachse.

Schwierigkeiten ergeben sich beim Fitten, wenn zwei Parameter nicht eindeutig sind, was z. B. auftritt, wenn sich die zugehörigen Linien im Spektrum stark überlappen. Dies ist insbesondere am Bandenkopf um $288 \mathrm{~nm}$ der Fall. Glücklicherweise sendet jeder Rotationszustand aber nicht nur eine sondern drei starke Emissionslinien aus. Selbst wenn eine davon sich mit einer anderen Linie überlagert, sind die anderen ungestört oder werden von Linien eines dritten Zustands überlagert; dies verhindert zum großen Teil Uneindeutigkeiten der Parameter. Man kann den Effekt der Linienüberlagerung - ungenügende Auflösung des Spektrometers führt zu denselben Problemen - quantitativ durch Singulärwertzerlegung (SVD = singular value decomposition) der Matrix $M$, die die Besetzung mit dem Spektrum verbindet, analysieren. Mit Hilfe der SVD kann die Matrix $M$ geschrie-

\footnotetext{
${ }^{2}$ Das sind die Wellenlängen, die vom Spektrometer auf ein Pixel der Kamera abgebildet werden.
} 
ben werden als

$$
M=U W V^{\mathrm{T}},
$$

wobei $W$ eine Diagonalmatrix und $U$ und $V$ orthogonale Matrizen sind. Die Einträge von $W$ werden Singulärwerte genannt. Sehr kleine Werte (im Extremfall Nullen) werden durch schlechte Auflösung des Spektrometers oder Uneindeutigkeiten wegen der Überlappung der Linien verursacht (oder mathematisch: durch eine schlechte Konditionszahl der Matrix $M$ ). Diese kleinen Werte erzeugen mehrdeutige oder numerisch instabile Lösungen bei der Berechnung der Besetzung aus dem Spektrum. Die Kehrwerte der Singulärwerte sind mit den Fehlern der Besetzungen verknüpft, d. h. mit Hilfe der SVD kann direkt überprüft werden, wieviele signifikante Informationen aus einem Spektrum gewonnen werden können. So wurde die Zahl der Rotationszustände, deren Besetzung sinnvoll aus dem beobachteten Spektralbereich bestimmt werden konnte, und damit die Zahl der Fitparameter mit Hilfe der SVD ermittelt. Außerdem können die Fehler der berechneten Besetzungen durch Fehlerfortpflanzung aus der Unsicherheit der Meßdaten abgeschätzt werden. ${ }^{3}$ Eine Einführung in die Verwendung von SVD bei der Lösung linearer Ausgleichsprobleme findet man in [24].

\subsubsection{Polarisationseffekte}

Bei der Interpretation der Spektren muß der Einfluß des linear polarisierten Laserstrahls, der zur Anregung verwendet wurde, berücksichtigt werden.

Regt man einen Dipolübergang eines Moleküls mit linear polarisiertem Licht an, so ist der angeregte Zustand entlang der Polarisationsrichtung ausgerichtet [25], d. h. Zustände, die sich in ihrer $m_{J^{\prime}}$ Quantenzahl unterscheiden, haben nicht die gleiche Besetzung. ${ }^{4}$ Der angeregte Zustand ist nicht isotrop und demzufolge ist auch die emittierte Fluoreszenz zu einem gewissen Grad polarisiert [26]. Eine andere Folge ist, daß die üblichen Einstein $A$-Koeffizienten, die für isotrope Zustände gelten, nicht mehr die korrekten Linienstärken wiedergeben. Die Linienstärken müssen dann durch zusätzliche Polarisationsfaktoren korrigiert werden. Diese Polarisationseffekte sind bei Anregung eines $Q$-Übergangs besonders stark.

Abbildung 1.5a zeigt Spektren, die nach Anregung des $Q_{11}(16.5)$ Übergangs mit horizontal bzw. vertikal polarisiertem Laser aufgenommen wurden. Man erkennt, daß sich die Intensität der $Q$-Emissionslinie mehr als verdoppelt, wenn man von horizontaler zu vertikaler Polarisation wechselt, während sich die Intensität der $R$-Linie nur wenig ändert. Ein Effekt dieser Größenordnung muß natürlich berücksichtigt werden, wenn aus den Linienstärken die Besetzungen des angeregten Zustands berechnet werden sollen.

Die Situation wird dadurch erschwert, daß der Grad der Ausrichtung von mehreren Größen beeinflußt wird. Zum einen reduziert sich die Ausrichtung bei hohen

\footnotetext{
${ }^{3}$ Wurde der nicht-lineare Fitalgorithmus verwendet, wurden die Fehler der Besetzung mit Hilfe der Kovarianzmatrix berechnet.

${ }^{4}$ Ausrichtung soll hier bedeuten, die Besetzung hängt nur von $\left|m_{J^{\prime}}\right|$ ab - im Unterschied zu Orientierung, wo die Besetzung für $+m_{J^{\prime}}$ und $-m_{J^{\prime}}$ unterschiedlich sein kann.
} 

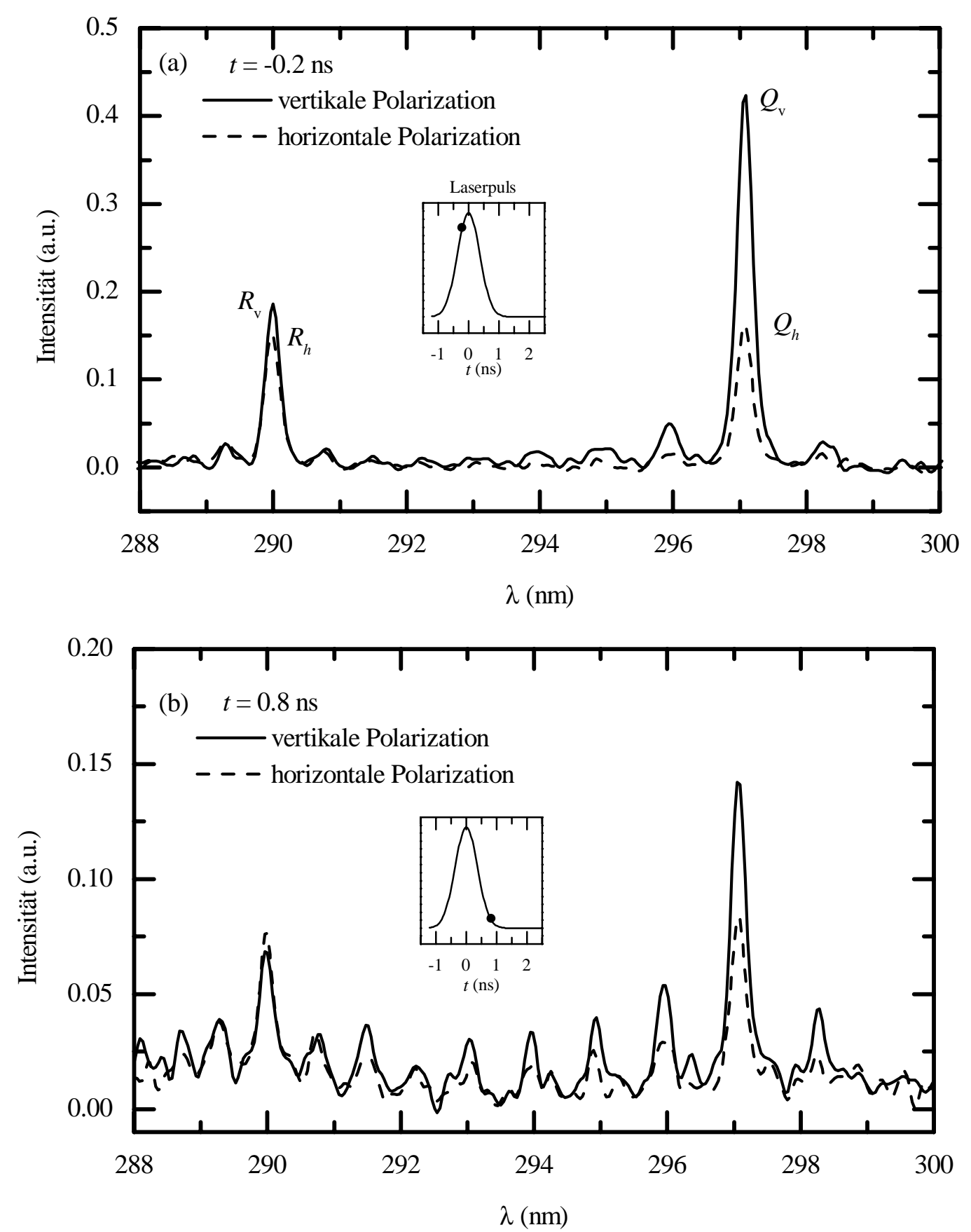

Abbildung 1.5: Spektren, die mit unterschiedlicher Laserpolarisation nach Anregung des $Q_{11}(16.5)$ Übergangs aufgenommen wurden: (a) bei frühen Spektren beobachtet man eine sehr starke Ausrichtung, (b) auch Zustände, die durch RET bevölkert wurden, sind noch ausgerichtet. 
Laserintensitäten durch Sättigungseffekte bei der Anregung. Darüber hinaus ist die Ausrichtung auch zeitabhängig, da Stöße mit Molekülen der Umgebung auch den $m_{J^{\prime}}$ Zustand des OH-Moleküls ändern können [27]. Dieses Phänomen wird mit Depolarisation bezeichnet. Weil Depolarisation und RET simultan ablaufen, können die Effekte schwer getrennt behandelt werden, da sie beide die Intensität der emittierten Linien beeinflussen.

Abbildung 1.5b zeigt Spektren, die mit unterschiedlicher Laserpolarisation bei $t=0.8 \mathrm{~ns}$ aufgenommen wurden. Die Linien, die vom laserangeregten Niveau emittiert werden, zeigen nun eine geringere Ausrichtung, während die Linien der durch RET bevölkerten Niveaus ebenfalls Ausrichtungseffekte zeigen!

Theoretisch gibt es drei Möglichkeiten, Ausrichtungseffekte zu vermeiden:

1. Vollständige Sättigung bei der Anregung,

2. Anregung unter dem sog. magischen Winkel, d. h. Anregung mit einem linear polarisierten Laser, mit einem Winkel von $54.7^{\circ}$ zwischen dem elektrischen Feld und der vertikalen Achse, und Detektion der horizontal polarisierten Komponente der Emission.

3. Die Aufnahme dreier Spektren, wobei der Laser jeweils entlang der $x, y, z-$ Achse polarisiert ist. Addiert man die Spektren mit gleichen Gewichten (1/3), erhält man ein Spektrum, das frei von Polarisationseffekten ist.

Die Verwendung eines unpolarisierten Lasers führt nicht zum Ziel, sondern verursacht eine Ausrichtung entlang der Ausbreitungsrichtung des Strahls. Dies wurde bei zahlreichen Messungen, die der Literatur entnommen werden können, außer acht gelassen.

Hier wurde der dritte Weg, die Polarisationseffekte zu beseitigen, gewählt. Dazu wurden Spektren mit vertikal und horizontal polarisierter Anregung aufgenommen. Die fehlende dritte Polarisationsrichtung ist die Ausbreitungsrichtung des Strahls. Aus Symmetriegründen - die Emission wurde nicht polarisationsaufgelöst nachgewiesen — ist diese Polarisationsrichtung der vertikalen äquivalent. Daraus folgt, daß die Summe aus horizontalem und vertikalem Spektrum, wenn die Spektren mit $1 / 3$ bzw. 2/3 gewichtet werden, frei von Polarisationseffekten sein sollte.

Es zeigte sich allerdings, daß ein zusätzlicher Skalierungsfaktor $c$, der die absoluten Signalstärken aller horizontalen und vertikalen Spektren aufeinander skaliert, benötigt wurde. Die Ursache für die Notwendigkeit des Faktors ist vermutlich die polarisationsabhängige Transmission des Spektrometers. $c$ wurde aus der Gesamtintensität von Spektren berechnet, die zu einem frühen Zeitpunkt aufgenommen wurden, wo die Einflüsse der Stöße auf das Spektrum minimal waren:

$$
c=\frac{\left(I_{v} / I_{h}\right)_{\mathrm{gem} .}}{\left(I_{v} / I_{h}\right)_{\mathrm{theor} .}}
$$

Hier steht $\left(I_{v} / I_{h}\right)_{\text {theor. }}$ für das Intensitätsverhältnis, das man theoretisch für lineare LIF ohne Berücksichtigung von Stößen erwartet (= 0.94 bei $P$-Anregung [28]). 
Dann wurden die Spektren für horizontale (1/3c gewichtet) und vertikale $(2 / 3$ gewichtet) Laserpolarisation für jeden einzelnen Zeitpunkt addiert. Die so erhaltenen Spektren wurden für die Berechnung der Besetzung verwendet.

\subsubsection{Die Zeitabhängigkeit der Besetzung}

Die Ergebnisse des Fits sind in Abbildung 1.6 für die Methan-Sauerstoff-Flamme in logarithmischer Darstellung gezeigt. Die Abbildung enthält für verschiedene Zeitpunkte die Besetzung in den einzelnen Rotationszuständen in $v^{\prime}=2$; dabei sind die Werte für beide Spinzustände $F^{\prime}=1,2$ getrennt dargestellt. Qualitativ sind die Ergebnisse bei der Methan-Luft-Flamme ähnlich, weshalb nur die Daten der Sauerstoff-Flamme gezeigt werden.

Im folgenden sollen unter dem Begriff „Bad“ alle Niveaus des $A$-Zustands ( $v^{\prime}=$ 2), außer dem durch den Laser angeregten, zusammengefaßt werden. Die Besetzung des laserangeregten Niveaus wird mit $n_{l}$ bezeichnet.

Drei Dinge lassen sich direkt aus Abbildung 1.6 ablesen:

- Zu Beginn ist nur ein Rotationszustand besetzt. Von diesem Zustand ausgehend werden die übrigen Zustände bevölkert. Solange die Anregung andauert, ist der Transfer von $n_{l}$ in das Bad der dominierende Prozess; RET innerhalb des Bads oder Rücktransfer in $n_{l}$ ist von geringer Bedeutung.

- RET Prozesse, die den Spinzustand ändern, laufen deutlich langsamer ab, als die, die den Spinzustand erhalten. Dieses Verhalten ist schon theoretisch vorhergesagt [29] und auch in anderen Experimenten beobachtet worden [30] - besonders bei Stößen mit Wasser, das den wichtigsten Stoßpartner in einer Methan-Sauerstoff-Flamme darstellt.

- Nach der Anregung beginnt sich die Besetzung einer Boltzmannverteilung anzunähern. Allerdings wird die gesamte Besetzung dabei gleichzeitig auch durch Verlustprozesse wie Quenching und VET verringert. Zu der Zeit, zu der eine Verteilung nahe dem thermischen Gleichgewicht erreicht wird, ist das gesamte Signal auf 10\% des Maximums abgefallen. D. h. ohne Detektion mit kurzer Belichtungszeit wird immer eine nicht-thermische Rotationsverteilung beobachtet, weil elektronisches Quenching und RET gleichzeitig (und mit vergleichbarer Geschwindigkeit) ablaufen.

\subsection{Die Modellierung der Dynamik des angeregten Zustands}

Man kann die Dynamik im angeregten Zustand mit einem Ratengleichungsmodell beschreiben [12]:

$$
\frac{d n}{d t}=(R+V+Q+P+A+\gamma(t) X) n
$$




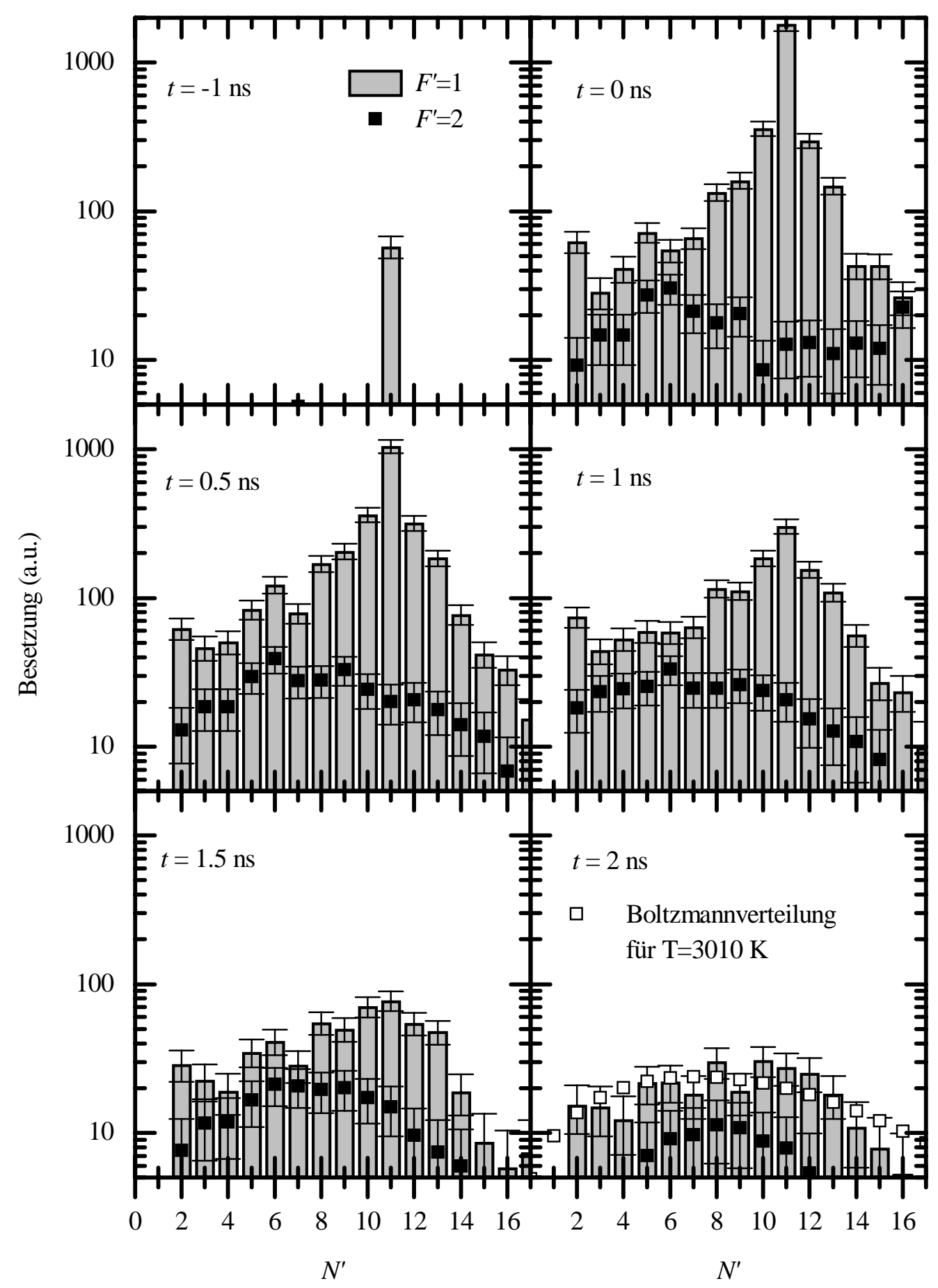

Abbildung 1.6: Die Besetzung einzelner Rotationszustände des OH-Moleküls in $v^{\prime}=2 \mathrm{zu}$ verschiedenen Zeiten. Die Besetzungen wurden aus Spektren, die in einer stöchiometrischen Methan-Sauerstoff-Flamme aufgenommen wurden, berechnet. 


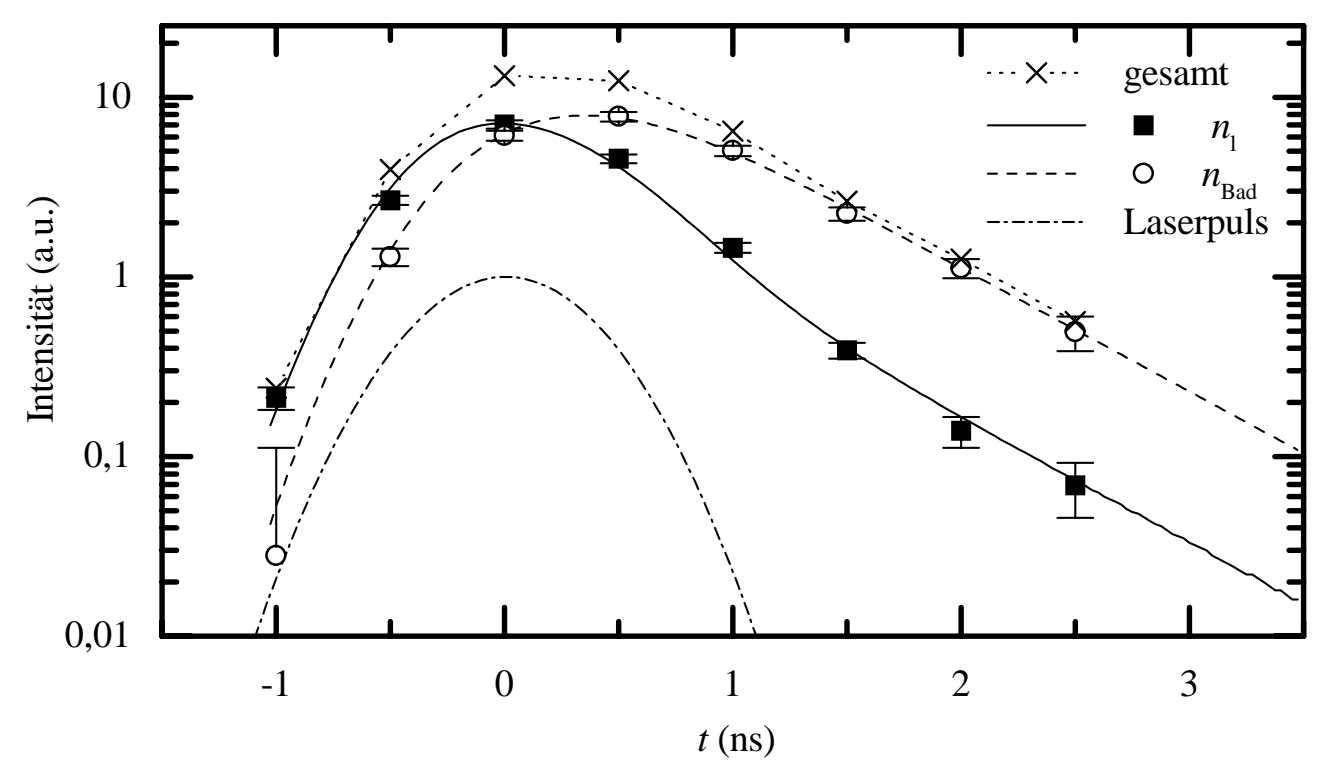

Abbildung 1.7: Zeitverlauf der Besetzung im durch den Laser angeregten Niveau $n_{l}$ und den übrigen Niveaus in $v^{\prime}=2 n_{\text {Bad }}$ bei der Methan-Sauerstoff-Flamme.

Hier steht $n$ für einen Vektor, der je einen Eintrag für die Besetzung jedes berücksichtigten Niveaus enthält. Für die Modellierung wurden Zustände aus $v^{\prime}=2$ mit $N^{\prime}=0 \ldots 20$ und $F^{\prime}=1,2$ verwendet. Zusätzlich wurde noch ein Niveau des Grundzustands, das mit $n_{x}$ bezeichnet wird, aufgenommen. Es ist nicht nötig, weitere Niveaus des Grundzustands in das Modell mit einzubeziehen, da es nur um die Modellierung der Dynamik im $A$-Zustand geht.

Es wurden keine Niveaus aus anderen Vibrationszuständen neben $v^{\prime}=2$ berücksichtigt. Das heißt, in diesem Modell wird Rücktransfer von $v^{\prime}=0,1$ nach $v^{\prime}=2$ vernachlässigt. Dies ist aber wegen der großen Energielücke zwischen den Vibrationszuständen und dem starken Quenching keine ernsthafte Einschränkung. Zum Beispiel ist beim Wasser der Wirkungsquerschitt für VET etwa zehnmal kleiner als der Wirkungsquerschnitt für Quenching [31].

$R, V, Q, P$ und $A$ sind Matritzen für RET, VET, Quenching, Prädissoziation und spontane Emission. Ein Eintrag dieser Matrizen z. B. $R_{f, i}$ steht für die Ratenkonstante für RET von einem Ausgangsniveau $i$ zu einem Endniveau $f .{ }^{5}$ Die Diagonalelemente der Matrizen geben die totale Verlustrate, der ein Niveau aufgrund des zugehörigen Prozesses ausgesetzt ist, an.

Die Matrix $X$ beschreibt die Laseranregung. Sie hat nur vier von Null verschiedene Einträge:

$$
X_{x, x}=X_{l, l}=-1, \quad X_{x, l}=X_{l, x}=1 .
$$

\footnotetext{
${ }^{5} \mathrm{Im}$ Vergleich zu [12] ist die Reihenfolge der Indices vertauscht.
} 
$\gamma(t)$ ist die Anregungsrate und ist durch

$$
\gamma(t)=g_{\nu} B_{x, l} I(t)
$$

gegeben. Wobei $g_{\nu}$ für das Überlappungsintegral zwischen spektralem Laserprofil und Molekülabsorption steht. $B_{x, l}$ ist der Einstein Koeffizient für Absorption und $I(t)$ die Laserintensität. Das zeitliche Profil von $I(t)$ wurde durch ein Gauß-Profil, das an den Zeitverlauf des Rayleigh-Signals angepaßt wurde, dargestellt. Im Maximum hatte $\gamma$ einen typischen Wert von $5 \cdot 10^{9} \mathrm{~s}^{-1}$. Der Einfluß der Mittelung der Meßdaten auf die Lösung der Differentialgleichung wird im Anhang diskutiert.

Da keine Endniveaus für VET, Quenching, Prädissoziation und Fluoreszenz in das Modell aufgenommen wurden, sind diese Matrizen diagonal. Das bedeutet, diese Prozesse können von diesem Standpunkt aus nicht voneinander unterschieden werden. Die Daten für $P$ und $A$ wurden dem Lifbase Programm entnommen. Beide Matrizen sind allerdings von geringer Bedeutung, da die Prozesse verglichen mit VET und Quenching sehr langsam ablaufen.

Die kombinierten Verluste durch VET und Quenching wurden aus der Abnahme der Gesamtbesetzung in $v^{\prime}=2$ berechnet. Die Gesamtbesetzung ist in Abbildung 1.7 dargestellt. Man erkennt, daß die Gesamtbesetzung nach der Anregung exponentiell mit einer Zeitkonstante von 675 ps abklingt.

Auch wenn der Zerfall einfach exponentiell erscheint, heißt das noch nicht, daß Quenching und VET für alle beteiligten Niveaus gleich sind, weil so viele Niveaus zur Gesamtbesetzung beitragen, daß es unmöglich ist, individuelle Lebensdauern zu bestimmen.

In der Tat wurde eine Abnahme der Quenchingrate mit zunehmender Rotationsquantenzahl in einigen Untersuchungen beobachtet [32] - [35]. Die Variation hängt von der Temperatur ab und geht bei steigender Temperatur zurïck [36]. Trotzdem wurde hier ein Wert von $(Q+V)_{i, i}=-(675 \mathrm{ps})^{-1}$ für alle Zustände $i \neq x$ verwendet, da wenig über die Abhängigkeit des VET von der Rotationsquantenzahl bekannt ist [37]. Im Falle der Methan-Luft-Flamme ergab dasselbe Verfahren einen Wert von $(Q+V)_{i, i}=-(730 \mathrm{ps})^{-1}$.

Als Modell für die zustandsspezifischen RET Ratenkonstanten wurde eine einfache Skalierungsregel, die im wesentlichen vom Energieabstand der beteiligten Niveaus abhängt, verwendet:

$$
\begin{aligned}
R_{j, i} & =\left(2 J_{j}^{\prime}+1\right) \exp \left(-\frac{E_{j}}{k_{B} T}\right) \cdot R_{0} \exp \left(-\alpha\left|E_{j}-E_{i}\right|\right) \quad i \neq j \\
R_{i, i} & =-\sum_{k \neq i} R_{k, i}
\end{aligned}
$$

Hier steht $E_{j}$ für Energie und $J_{j}^{\prime}$ für den Drehimpuls des Niveaus $j$. Die ersten beiden Faktoren in Gleichung (1.7) sind eine Konsequenz des principle of detailed balancing, das eine Boltzmannverteilung mit der richtigen Temperatur als Gleichgewichtsverteilung gewährleistet [15]. Dieses Modell wurde zur Beschreibung der Dynamik innerhalb des Spinzustands $F^{\prime}=1$ verwendet. Der andere Spinzustand $F^{\prime}=2$ wurde vernachlässigt, da seine Besetzung klein gegenüber $F^{\prime}=1$ war. 


\begin{tabular}{|c|c|c|c|c|}
\hline Flamme & $T[\mathrm{~K}]$ & $\alpha\left[10^{-3} \mathrm{~cm}\right]$ & $R_{0}[1 / \mathrm{s}]$ & $\left|R_{11,11}\right|\left[\mathrm{ns}^{-1}\right]$ \\
& & & & $(\mathrm{a})$ \\
\hline $\begin{array}{c}\text { Methan-Sauerstoff } \\
\text { Methan-Luft }\end{array}$ & 3010 & $-2.9 \pm 0.5$ & $2.34 \cdot 10^{16}$ & $3.2 \pm 0.3$ \\
& 2170 & $-2.5 \pm 0.8$ & $3.2 \cdot 10^{19}$ & $3.3 \pm 0.3$ \\
\hline
\end{tabular}

Tabelle 1.1: Werte für $\alpha$ und $R_{0}$ für die RET-Matrix sowie Raten für totalen RET $\left(v^{\prime}=2, N^{\prime}=11, F^{\prime}=1\right)$.

Die einzigen freien Parameter, die in Gleichung (1.4), die die Besetzungsdynamik im angeregten Zustand beschreibt, enthalten sind, befinden sich in $R: R_{0}$ und $\alpha$. Diese beiden Werte wurden durch einen Fit der Rechnung an die Ergebnisse der Messung bestimmt. Das Ergebnis dieser Anpassung liefert eine totale RET Rate für das angeregte Niveau $N^{\prime}=11, F^{\prime}=1$ von $\left|R_{l, l}\right|=(310 \pm 30 \mathrm{ps})^{-1}$ für die Methan-Sauerstoff-Flamme und $\left|R_{l, l}\right|=(300 \pm 30 \mathrm{ps})^{-1}$ für die Methan-LuftFlamme. Die zugehörigen Werte von $\alpha$ und $R_{0}$ sind in Tabelle 1.1 dargestellt. Aus diesen Werten können die zustandsspezifischen RET Raten für beliebige Niveaus berechnet werden.

Die berechneten Zeitverläufe für $n_{l}$ und das Bad sind zusammen mit den experimentellen Daten in Abbildung 1.7 dargestellt. $n_{l}$ steigt stark an, sobald die Anregung einsetzt. Nach der Anregung fällt $n_{l}$ zunächst schnell ab, weil sowohl RET als auch VET/Quenching Verlustprozesse sind. Nähert sich die Rotationsverteilung dem Gleichgewicht an, verlangsamt sich die Abnahme von $n_{l}$ und verläuft parallel zum Bad.

Die gleichzeitige Messung der Besetzung vieler Rotationszustände erlaubt es im Prinzip, die Skalierungsregeln für die zustandsspezifischen RET Raten zu testen und zu optimieren. In Abbildung 1.8 sind die nach Gleichung (1.4) berechneten Besetzungen einzelner Rotationszustände zusammen mit den Ergebnissen der Messung für drei Zeiten dargestellt. Die absoluten Werte der Simulation wurden dabei nur in einem Wert $\left(t=0 \mathrm{~ns}, N^{\prime}=11\right)$ auf den Wert der Messung skaliert d. h. in allen Graphen sind alle simulierten Werte mit demselben Faktor multipliziert worden. Messung und Simulation passen recht gut zueinander. Abweichungen treten bei kleinen Werten für $N^{\prime}$ auf. Dies könnte eine Folge der einfachen Skalierungsregel sein. Es bliebe zu überprüfen, ob andere Regeln, wie IOS oder ECS, oder kompliziertere Beziehungen, wie das von Kienle et. al. [38] vorgeschlagene energy-corrected-sudden exponential-and-power-gap law, zu einer besseren Übereinstimmung führen. Eine andere Ursache für die Abweichungen wären $N^{\prime}$ abhängige Verluste (Quenching oder VET). 


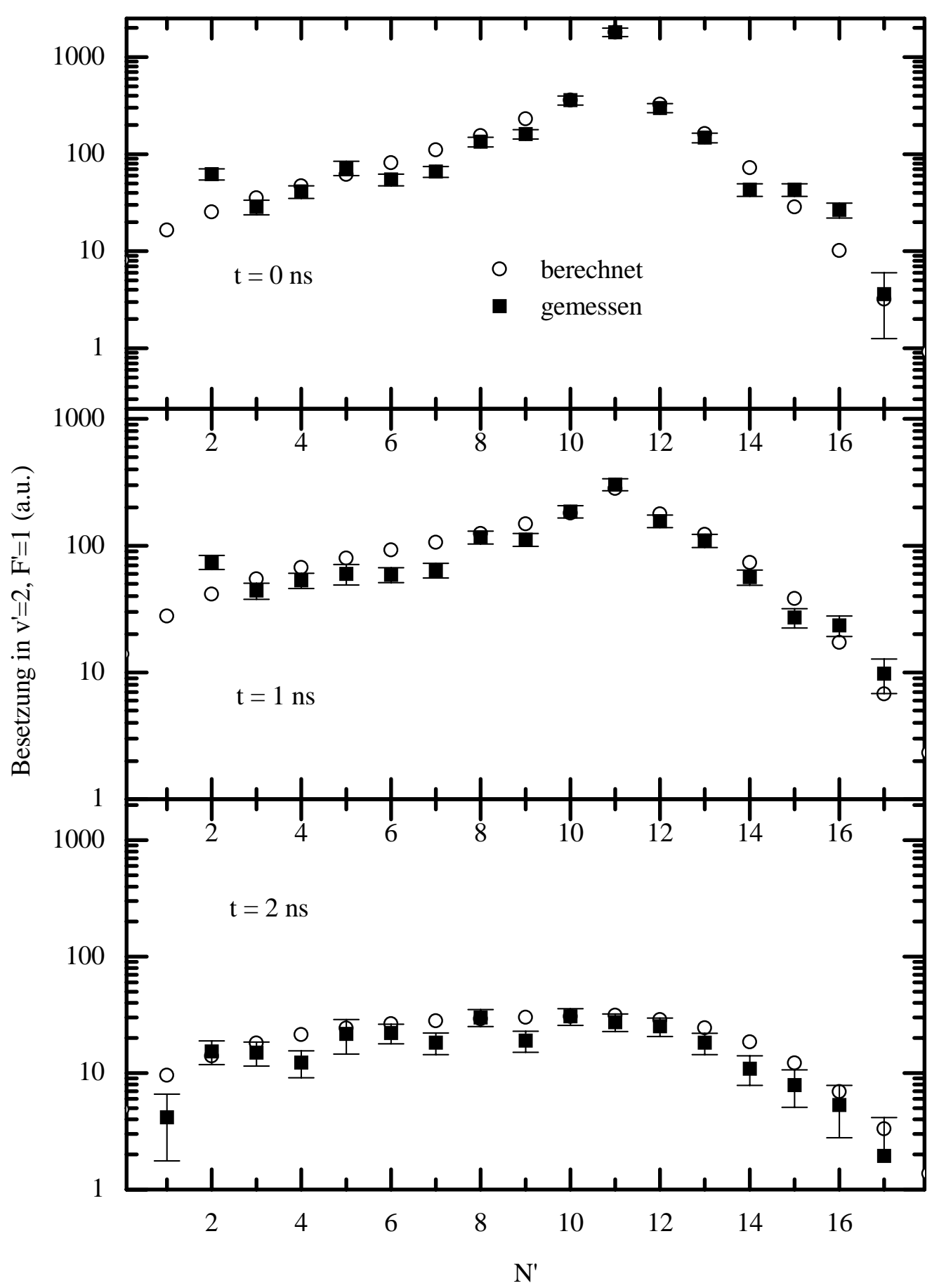

Abbildung 1.8: Vergleich der berechneten und experimentell bestimmten Besetzung einzelner Rotationszustände für drei verschiedene Zeiten. Die Daten beziehen sich auf die Methan-Sauerstoff-Flamme. 


\begin{tabular}{|c|c|}
\hline Niveau & $\sigma \mathrm{H}_{2} \mathrm{O}\left[\AA^{2}\right]$ \\
\hline$v^{\prime}=2, N^{\prime}=11, F^{\prime}=1$ [diese Arbeit] & $106 \pm 15(<130)$ \\
$v^{\prime}=0, N^{\prime}=10, F^{\prime}=2[45]$ & $110 \pm 30$ \\
$v^{\prime}=0, N^{\prime}=10, F^{\prime}=1[38]$ & $107 \pm 15$ \\
$v^{\prime}=0, N^{\prime}=12, F^{\prime}=1[38]$ & $98 \pm 20$ \\
\hline
\end{tabular}

Tabelle 1.2: Wirkungsquerschnitte für totalen RET von $\mathrm{OH} \mathrm{A}{ }^{2} \Sigma$ für Stöße mit Wasser.

\subsection{Diskussion}

\subsubsection{Vergleich mit Raten für $v^{\prime}=0,1$}

Beim OH-Molekül sind bisher nur RET Raten und Wirkungsquerschnitte für $v^{\prime}=$ 0,1 gemessen worden. Die Werte für beide Vibrationszustände unterscheiden sich nur geringfügig. Um die hier gemessene totale RET Rate mit diesen Werten vergleichen zu können, wird zunächst eine obere Grenze für den RET Wirkungsquerschnitt von Wasser berechnet.

Das Abgas der Methan-Sauerstoff-Flamme setzt sich im wesentlichen aus folgenden Bestandteilen zusammen [39]: Wasser (39\%), $\mathrm{CO}_{2}(11 \%), \mathrm{CO}(15 \%)$. Wasser ist dabei der wichtigste Stoßpartner, nicht nur weil es den größten Anteil stellt, sondern auch weil sein Wirkungsquerschnitt etwa dreimal größer als der des $\mathrm{CO}_{2}$ ist [12]. Querschnitte für das CO sind unbekannt.

Berücksichtigt man nur das Wasser als Stoßpartner, bekommt man folgenden Wirkungsquerschnitt:

$$
\begin{aligned}
\sigma & =\frac{R_{l, l}}{v n \chi}=130 \pm 15 \AA^{2}, \\
n & =\frac{p}{k T}, \\
v & =\sqrt{\frac{8 k T}{\pi \mu}} \quad \mu=\frac{m_{\mathrm{H}_{2} \mathrm{O}} \cdot m_{\mathrm{OH}}}{m_{\mathrm{H}_{2} \mathrm{O}}+m_{\mathrm{OH}}}
\end{aligned}
$$

wobei $n$ die absolute Anzahldichte in der Flamme, $v$ die Relativgeschwindigkeit der Stoßpartner und $\chi$ der Molenbruch des Wassers ist. Dieser Wert für $\sigma$ stellt eine obere Grenze dar, weil alle anderen Stoßpartner vernachlässigt wurden. Verwendet man den $\mathrm{N}_{2}$ Wirkungsquerschnitt für $\mathrm{CO}_{2}$ und $\mathrm{CO}$ - was in Ermangelung besserer Daten gelegentlich getan wird (z. B. [40]) — kommt man auf $\sigma=106 \AA^{2}$. Dies ist im Rahmen der Meßgenauigkeit derselbe Wert wie für vergleichbare Rotationszustände in $v^{\prime}=0$. In Tabelle 1.2 werden die verfügbaren Werte miteinander verglichen.

Es ist auf den ersten Blick überraschend, daß der RET in der Methan-LuftFlamme schneller als in der Sauerstoff-Flamme ist, weil hier das Wasser durch 


\begin{tabular}{|c|c|c|c|}
\hline Flamme & $T[\mathrm{~K}]$ & $\begin{array}{c}k_{\text {eff }}\left[10^{-10} \mathrm{~cm}^{3} / \mathrm{s}\right] \\
(\mathrm{a})\end{array}$ & $\begin{array}{c}k_{\text {eff }}\left[10^{-10} \mathrm{~cm}^{3} / \mathrm{s}\right] \\
(\mathrm{b})\end{array}$ \\
\hline $\begin{array}{c}\text { Methan-Sauerstoff } \\
\text { Methan-Luft }\end{array}$ & 3010 & $13.3 \pm 1.4$ & 13.0 \\
\hline
\end{tabular}

Tabelle 1.3: Effektive Geschwindigkeitskoeffizienten $k_{\text {eff }}$, die aus diesen Messungen gewonnen wurden (a) und mit Werten aus [38] für $v^{\prime}=0$ berechnet wurden (b). Definition und Bedeutung der Geschwindigkeitskoeffizienten findet man in [40].

den großen Stickstoffanteil verdünnt wird $\left(\chi_{\mathrm{H}_{2} \mathrm{O}}=0.17, \chi_{\mathrm{N}_{2}}=0.72\right)$. Die LuftFlamme ist jedoch kälter, was zu einer höheren Stoßrate führt. Für Stickstoff wurden Wirkungsquerschnitte für totalen RET für $\mathrm{OH} \mathrm{A}{ }^{2} \Sigma^{+}\left(v^{\prime}=0\right)$ von etwa $40 \AA^{2}$ gemessen [41] - [44]. Verwendet man diesen Wert, bekommt man einen effektiven Geschwindigkeitskoeffizienten für die Luft-Flamme von $10.1 \cdot 10^{-10} \mathrm{~cm}^{3} / \mathrm{s}$. Dies stimmt gut mit dem hier beobachteten Wert von $(9.9 \pm 1) \cdot 10^{-10} \mathrm{~cm}^{3} / \mathrm{s}$ überein. In Tabelle 1.3 sind die Werte für beide Flammen gegenübergestellt.

\subsubsection{Vergleich mit anderen Meßverfahren}

Die hier verwendete Methode, die Emissionsspektren zu analysieren, ist direkt. Die spektrale Auflösung wird benutzt, um die Besetzung des angeregten Zustands zu einer bestimmten Zeit zu bestimmen. Die Zeitauflösung erlaubt es, die Dynamik der Besetzung zu verfolgen. Diese Technik ist effizienter als andere Verfahren, wo entweder zeitlich integrierte Spektren aufgenommen werden, oder der Zeitverlauf in einem engen spektralen Fenster registriert wird. Die hier verwendete Auswertetechnik führt von den Meßwerten zu den Raten und nicht umgekehrt, wie andere Methoden, wo ein Satz von Raten angenommen wird und dann auf dieser Grundlage mit Hilfe eines Modells versucht wird, ein Spektrum zu simulieren, das den Meßdaten gleicht. Die hier benutzte Technik erlaubt es, durch Fehlerfortpflanzung die Ungenauigkeit der berechneten Raten aus der Ungenauigkeit der Meßdaten zu bestimmten. So kann sofort erkannt werden, ob ein Ergebnis signifikant ist oder nicht. Bei der anderen Methode kann nur eine Sensitivitätsanalyse aller Parameter des Modells zeigen, welcher Parameter signifikant ist und welcher nicht. Denn die bloße Übereinstimmung der Simulation mit der Messung heißt noch nicht, daß der zugehörige Parametersatz bedeutungsvoll ist, solange nicht ausgeschlossen werden kann, daß auch andere Parameter genauso gut sein könnten.

Limitierungen durch den experimentellen Aufbau können bei dieser Methode anhand der Fehlerfortpflanzung erkannt werden. Z. B. läßt sich der Einfluß des Signal/Rausch-Verhältnisses oder der Spektrometerauflösung analysieren. So können die Einflußgrößen, die die Genauigkeit der Raten bestimmen, erkannt werden und entschieden werden, wo sich eine Optimierung lohnt. 


\subsection{Zusammenfassung}

In diesem Kapitel wurde die Aufnahme von LIF von OH-Molekülen in atmosphärischen Flammen mit hoher zeitlicher und spektraler Auflösung beschrieben. Es wurden vorgemischte, stöchiometrische Methan-Luft und Methan-Sauerstoff-Flammen untersucht. Es wurde ein Einfluß der Laserpolarisation auf die beobachteten Spektren festgestellt, der bei der anschließenden Auswertung berücksichtigt werden mußte.

Durch Analyse und Modellierung der Emissionsspektren konnte der Zeitverlauf der Besetzung der einzelnen Rotationszustände in $v^{\prime}=2$ ermittelt werden. Totale sowie zustandsspezifische RET Raten konnten aus diesen Besetzungsdaten auf der Grundlage eines Ratengleichungsmodells berechnet werden. Die Ergebnisse dieser Rechnung waren:

1. Übergänge, die den Spinzustand ändern $\left(F^{\prime}=1 \leftrightarrow 2\right)$ sind deutlich langsamer (ca. zehnfach) als die, die den Spinzustand erhalten.

2. Der Wirkungsquerschnitt für totalen RET von Wasser $\sigma=106 \pm 15 \AA^{2}$ ist gleich dem für $v^{\prime}=0$. Das heißt, daß der RET beim $\mathrm{OH}$ nicht stark vom Vibrationszustand abhängt, was schon Messungen in $v^{\prime}=0,1$ zeigten.

3. Die zustandsspezifischen Raten konnten durch eine einfache Skalierungsregel beschrieben werden.

4. Wird keine Detektion mit kurzer Öffnungsdauer verwendet, wird immer eine nicht-thermische Rotationsverteilung beobachtet, da Quenching und RET simultan ablaufen. 


\section{Kapitel 2}

\section{Zeitaufgelöste Fluoreszenzspektroskopie in Flüssigkeiten zur Erkennung chemischer Reaktionen}

Die Erkennung chemischer, speziell biochemischer Reaktionen spielt eine große Rolle in der Biologie, Medizin und Pharmazie. Insbesondere bei der Suche nach neuen Arzneimitteln besteht zur Zeit ein großer Bedarf an Verfahren, die in der Lage sind, die Bindung zwischen zwei Molekülen schnell zu erkennen.

Oft interessiert man sich für ein bestimmtes Zielmolekül (z. B. ein Protein), das durch Bindung eines anderen Moleküls in seiner Funktion blockiert oder aktiviert werden soll. Die Bindung soll dabei hoch spezifisch sein, d. h. ausschließlich das Zielmolekül soll gebunden werden. Das Molekül, das diesen Zweck erfüllt, wird häufig „Hit“ genannt; um es zu finden, müssen sehr viele Testsubstanzen auf ihre Reaktivität hin untersucht werden.

Im Gegensatz zur traditionellen Chemie werden die Testsubstanzen dabei nicht mehr gezielt synthetisiert sondern durch zufällige Reaktionen erzeugt (kombinatorische Chemie). Auf diese Weise erhält man eine große Zahl verschiedener Moleküle, unter denen dann der Hit gesucht wird. Alternativ dazu kann der Hit auch in einer Sammlung verschiedener Naturstoffe gesucht werden.

Allgemein steht man also vor dem Problem, daß eine große Bibliothek von Testsubstanzen auf ihre Reaktivität mit einer Zielsubstanz untersucht werden soll. Verfahren, die dieses Problem angehen, werden unter dem Begriff „Hochdurchsatzscreening" (HTS = high throughput screening) zusammengefaßt. Angestrebt sind dabei Verfahren, die in der Lage sind, etwa $10^{7}$ Testsubstanzen pro Jahr, d. h. einige zehntausend pro Tag, zu untersuchen. Dies läßt sich nur erreichen, wenn sowohl die Verarbeitung der Proben als auch die Analyse der Reaktionen so parallelisiert werden kann, daß viele Proben gleichzeitig untersucht werden können.

Werden die Reaktionen in Lösung untersucht, kommen dabei Mikrotiterplatten zum Einsatz, die ca. 96, 400 oder 1000 Reaktionsgefäße auf einer Fläche von 
$8 \times 12 \mathrm{~cm}^{2}$ haben. Kann einer der Reaktionspartner fest an eine Oberfläche gebunden werden, ohne daß dadurch die Reaktivität beeinträchtigt wird, können deutlich höhere Integrationsdichten durch Verwendung sogenannter Biochips erreicht werden. Dabei werden zum Beispiel zuerst die Testsubstanzen geordnet an verschiedene Bereiche mikrostrukturierter Substrate gebunden, und anschließend wird das Zielmolekül über das gesamte Substrat gegeben. Auf diese Weise konnten Reaktionen zwischen Oligonukleotiden mit $10^{6}$ Substanzen pro $\mathrm{cm}^{2}$ untersucht werden [49].

Die Verarbeitung wird durch Roboter weitgehend automatisiert. Die Analyse kann durch den Einsatz bildgebender optischer Verfahren ebenfalls parallelisiert werden.

In diesem Kapitel soll ein Verfahren, das zum Einsatz beim Hochdurchsatzscreening geeignet ist, vorgestellt werden. Als Modellsystem dient dabei ein menschliches G-Protein und dessen Bindung an GTP.

Im ersten Abschnitt wird die Bedeutung des Modellsystems und das Meßprinzip erläutert. Danach wird der experimentelle Aufbau, mit dem es möglich war, Spektrum und Zeitverhalten der Fluoreszenz zu messen, dargestellt (2.2). Die folgenden Abschnitte beschreiben die Durchführung der Messungen (2.3), sowie die dabei erhaltenen Spektren und Fluoreszenzabklingkurven der Substanzen (2.4). Im Abschnitt 2.5 werden die Ergebnisse diskutiert und mit anderen Verfahren verglichen. Das Kapitel schließt mit einer Zusammenfassung (2.6).

\subsection{Das Modellsystem: Rab3A und mantGTP}

\subsubsection{Allgemeines über G-Proteine}

Dieser Abschnitt soll die Bedeutung des hier untersuchten Modellsystems erläutern. Dabei ist es unumgänglich, einige Begriffe der molekularen Zellbiologie zu verwenden. Eine allgemeine Einführung in die Molekularbiologie der Zelle wird in [50] gegeben.

Unter dem Begriff G-Proteine werden eine große Zahl verschiedener Proteine, die in der Lage sind, GTP ${ }^{1}$ zu binden und zu GDP umzuwandeln, zusammengefaßt. Sie spielen eine wesentliche Rolle bei der Steuerung verschiedener Zellfunktionen (u. a. Signaltransduktion, Proliferation, Proteinsynthese, Vesikeltransport). Allen gemeinsam ist, daß sie in zwei Zuständen auftauchen, in einer inaktiven Form, wenn GDP an das Protein gebunden ist, und einer aktiven Form, wenn GTP gebunden ist. Diese zwei Zustände machen die G-Proteine zu molekularen Schaltern.

Man unterscheidet zwei große Gruppen nach Molekulargewicht und Aufbau (Monomer oder Trimer). Das hier untersuchte G-Protein gehört zu den sogenannten kleinen GTP-bindenden Proteinen, die aus einer einzelnen Aminosäurekette mit einem Molekulargewicht zwischen 21 und $36 \mathrm{kDa}$ bestehen. Diese werden wiederum in mehrere Familien unterteilt (u. a. ras, rab, rho). Einen Überblick über die

\footnotetext{
${ }^{1} \mathrm{GTP}=$ Guanosintriphosphat, $\mathrm{GDP}=$ Guanosindiphosphat
} 


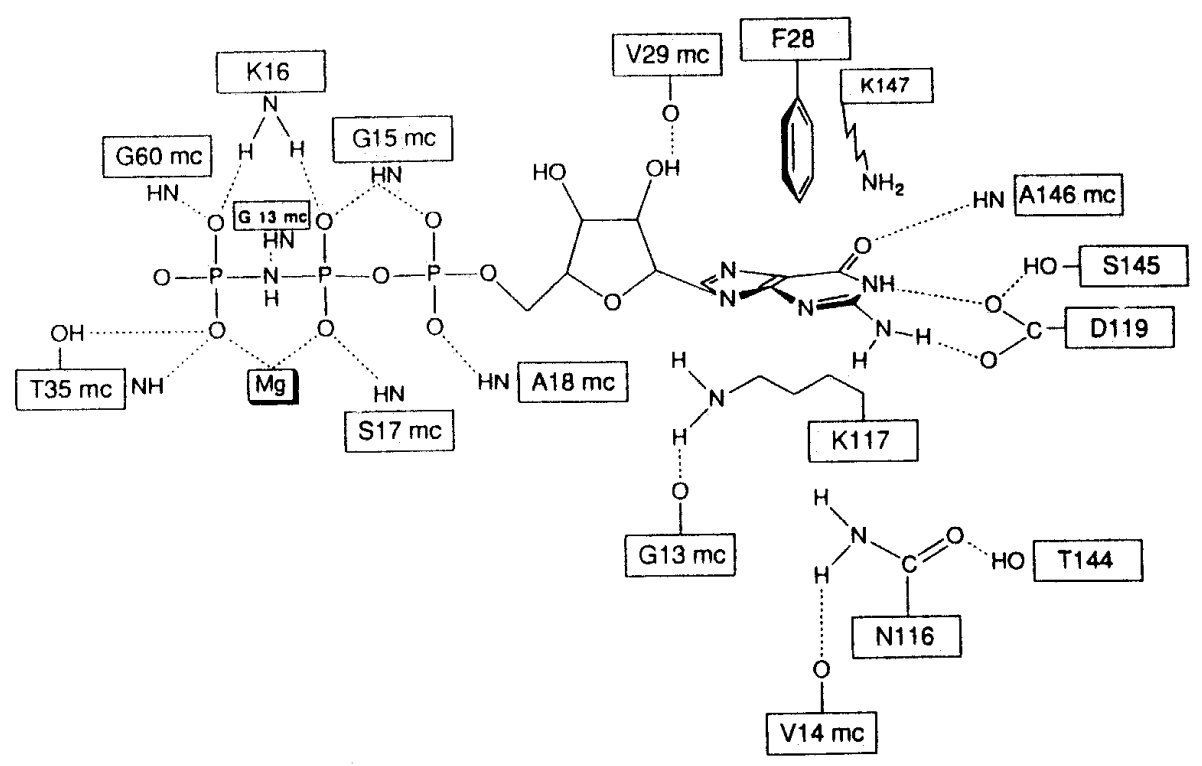

Abbildung 2.1: Die Aminosäuren beim p21 ${ }^{\text {ras }}$, die an der GTP-Bindung beteiligt sind (aus [54]).

Funktion der kleinen GTP-bindenden Proteine findet man in [52, 53, 54].

Der genaue Ablauf der Prozesse, an denen die G-Proteine mitwirken, ist zur Zeit noch Gegenstand intensiver Forschung. Am besten untersucht sind bisher die p2 $1^{\text {ras }}$ Proteine, weil Mutationen der ras Gene mit Krebserkrankungen in Verbindung gebracht werden. Ihre Struktur wurde durch Röntgenbeugung bestimmt.

Die Aminosäuresequenzen vieler kleiner G-Proteine wurden analysiert und man fand in allen Fällen 5 Bereiche mit charakteristischer Sequenz, die anhand der dreidimensionalen Struktur von p21 $1^{\text {ras }}$ für die GDP/GTP-Bindung und die GTPase Aktivität des Proteins verantwortlich gemacht werden. Abbildung 2.1 zeigt die Lage von GTP und die an der Bindung beteiligten Aminosäuren beim p2 $1^{\text {ras }}$.

In eukariontischen Zellen werden die G-Proteine nach der Translation noch am C-terminalen Ende der Aminosäurekette modifiziert. Diese Modifikation scheint für die Lokalisation der G-Proteine in der Zelle entscheidend zu sein. Z. B. wird beim Rab3A eine stark hydrophobe Geranylgeranyl-Kette an die letzte und drittletzte Aminosäure (jeweils Cystein) angefügt. Diese Kette scheint dafür verantwortlich zu sein, daß Rab3A gut an Membranen binden kann.

Neben den G-Proteinen gibt es weitere für jedes G-Protein spezifische Proteine, die die Aktivität der G-Proteine beeinflussen, indem sie den Austausch von GDP und GTP hemmen (GDI) bzw. fördern (GEF) oder die GTPase Aktivität hemmen (GIP) bzw. steigern (GAP) ${ }^{2}$. Diese Proteine können auch in die Verteilung der G-Proteine eingreifen, indem sie Bindungen zu einer Membran lösen, oder selbst

\footnotetext{
${ }^{2} \mathrm{GDI}=\mathrm{GDP}$ dissociation inhibitor, GEF $=$ guanine nucleotide exchange factor, GAP $=$ GTPaseactivating protein, GIP $=$ GTPase-inhibiting protein .
} 


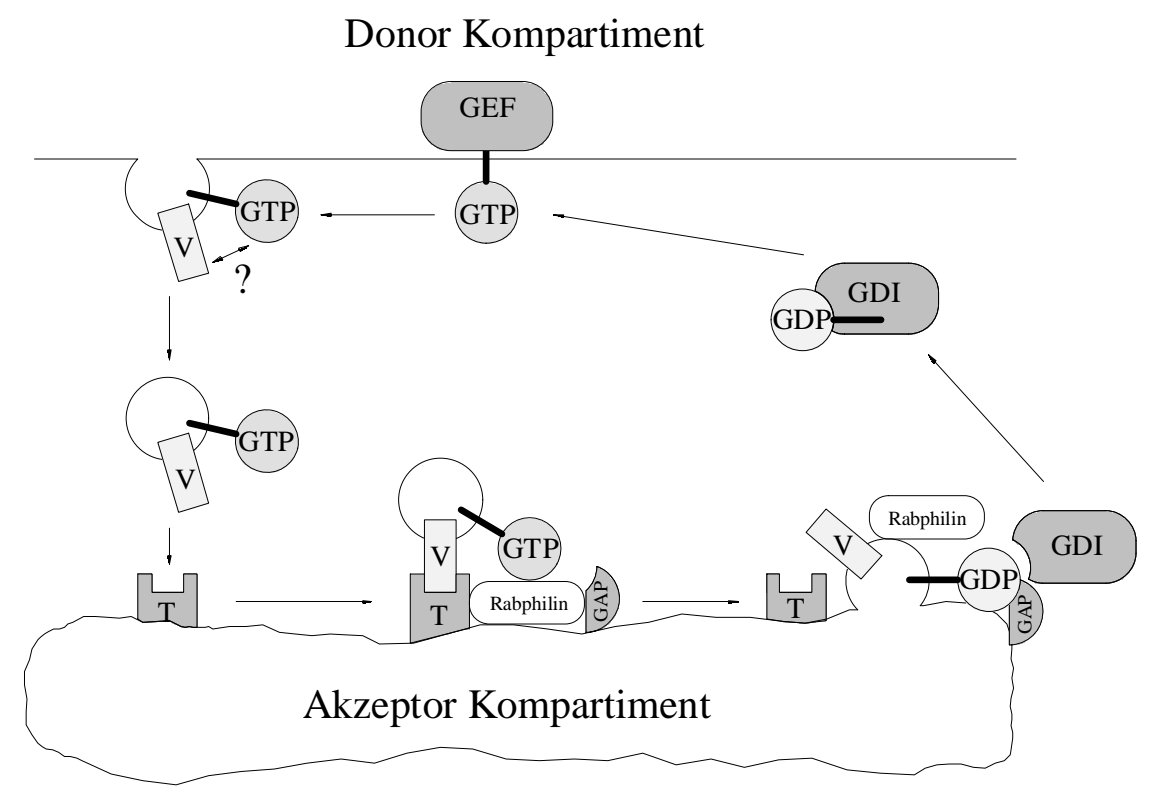

Abbildung 2.2: Hypothetisches Modell zur Funktionsweise der rab-Proteine (aus [55]). Das rab-Protein (dicker, schwarzer Strich) wird auf der Donorseite durch GEF aktiviert und bindet an ein Vesikel, das zur Akzeptorseite wandert. Dort wird das rab-Protein durch GAP deaktiviert und bindet an die Akzeptormembran. Durch GDI wird das rab-Protein von der Membran gelöst und wandert durch das Cytoplasma zurück zur Donorseite, wo es wieder aktiviert wird. V und T sind Moleküle, die das spezifische Andocken des Vesikels an das richtige Kompartiment gewährleisten. Es wird vermutet, daß die Bindung von $\mathrm{V}$ an $\mathrm{T}$ nur bei aktiviertem rab-Protein stattfinden kann. Eine direkte Wechselwirkung von V und dem rab-Protein konnte aber bisher nicht nachgewiesen werden.

an der Membran lokalisiert sind und nur dort ihre Aktivität entfalten. Die lokale Konzentration von aktiven und inaktiven G-Proteinen wird also auch von diesen Proteinen beeinflußt.

Das hier untersuchte G-Protein, Rab3A oder auch smg p25A genannt, gehört zur rab Familie und kommt beim Menschen im wesentlichen im Gehirn vor. Es spielt beim Vesikeltransport in Synapsen eine Rolle. Abbildung 2.2 zeigt ein hypothetisches Modell seiner Funktionsweise. Das rab-Protein wird auf der Donorseite durch GEF aktiviert und bindet an ein Vesikel, das zur Akzeptorseite wandert. Dort wird das rab-Protein durch GAP deaktiviert und bindet an die Akzeptormembran. Durch GDI wird das rab-Protein von der Membran gelöst. Dies kann z. B. dadurch geschehen, daß GDI die hydrophobe Geranylgeranyl-Kette umhüllt. Dann wandert das rab-Protein durch das Cytoplasma zurück zur Donorseite, wo es wieder aktiviert wird.

Die Untersuchung von G-Proteinen ist von grundlegendem Interesse, um zu einem besseren Verständnis der Organisation der Abläufe in einer Zelle zu kommen. 
Moleküle, die das Verhalten der G-Proteine beeinflussen und so in ihre regulatorische Funktion eingreifen, sind potentiell von pharmakologischer Bedeutung. Ein Screening-System, mit dem die Protein-Ligand Interaktion untersucht werden kann, ist daher auch für Anwendungen interessant.

Optische Methoden haben den Vorteil, schnell und berührungslos, d. h. ohne Eingriff in das zu untersuchende System, zu arbeiten. Die Kinetik der GTP/GDPBindung kann mit fluoreszenzmarkiertem GTP oder anhand der Eigenfluoreszenz der Proteine untersucht werden. In dieser Arbeit wird fluoreszenzmarkiertes GTP (mantGTP) verwendet.

\subsubsection{Die Struktur von mantGTP}

Man erhält mantGTP aus GTP, wenn am 2' oder 3'-Kohlenstoff der Ribose, eine N-Methyl-Anthranilolyl-Gruppe (mant) angefügt wird [56]. Es gibt 2'- und 3'Isomere, die bei Raumtemperatur imVerhältnis 40:60 vorliegen [57]. Die Umwandlungsrate zwischen beiden Formen ist klein $\left(<1 \mathrm{~s}^{-1}\right)$. In Abbildung 2.3 ist die 2' Konfiguration gezeigt.

Das Absorptionsspektrum ist in Abbildung 2.4 gezeigt. Der breite Peak um $350 \mathrm{~nm}$ ist dabei charakteristisch für die mant-Gruppe [58]. Der Peak bei 250nm und die Schulter bei $280 \mathrm{~nm}$ sind auf das Guanin zurückzuführen [59]. Die mant-Gruppe zeigt eine starke Fluoreszenz. Die Quantenausbeute hängt von der Polarität des Lösungsmittels ab und liegt bei Anregung mit $350 \mathrm{~nm}$ zwischen 0.24 (Wasser) und 0.93 (N,N-Dimethylformamid)[56]. Diese starke Abhängigkeit macht mantGTP zu einem guten Sensor für die Umgebung, in der es sich befindet.

Die Farbstoffmarkierung darf die Bindung des GTP an das G-Protein nicht behindern. Dies ist nicht ohne weiteres gegeben, da das GTP selbst ein recht kleines Molekül ist. In Abbildung 2.1 sieht man, daß die OH-Gruppe am 2'-Kohlenstoff der Ribose (im Falle von p21 ${ }^{\text {ras }}$ ) nicht an der Bindung an das G-Protein beteiligt ist, d. h. eine Farbstoffmarkierung an dieser Stelle sollte die Bindung nicht behindern.

\subsubsection{Das Meßprinzip}

Zum Nachweis der Bindung des mantGTP an das G-Protein wird die starke Umgebungsabhängigkeit der Quantenausbeute des mantGTP ausgenutzt. Solange das mantGTP frei ist, ist es im wesentlichen von Wassermolekülen umgeben und die Quantenausbeute ist klein. Man kann also ein niedriges Signal erwarten. Bindet es an das G-Protein, wird es zum Teil vor Stößen mit dem Lösungsmittel abgeschirmt, das Signal sollte also steigen. Außerdem ist es dann den Gegebenheiten an der Bindungsstelle am G-Protein ausgesetzt, d. h. man kann das mantGTP als Probe für die lokale Polarität ansehen. Insbesondere der Unterschied zwischen mantGTP und mantGDP ist interessant, weil dies Rückschlüsse auf Konformationsunterschiede zwischen der aktiven und inaktiven Form des Proteins ermöglicht.

Am Signalanstieg kann man also nicht nur das Bindungsereignis als solches 


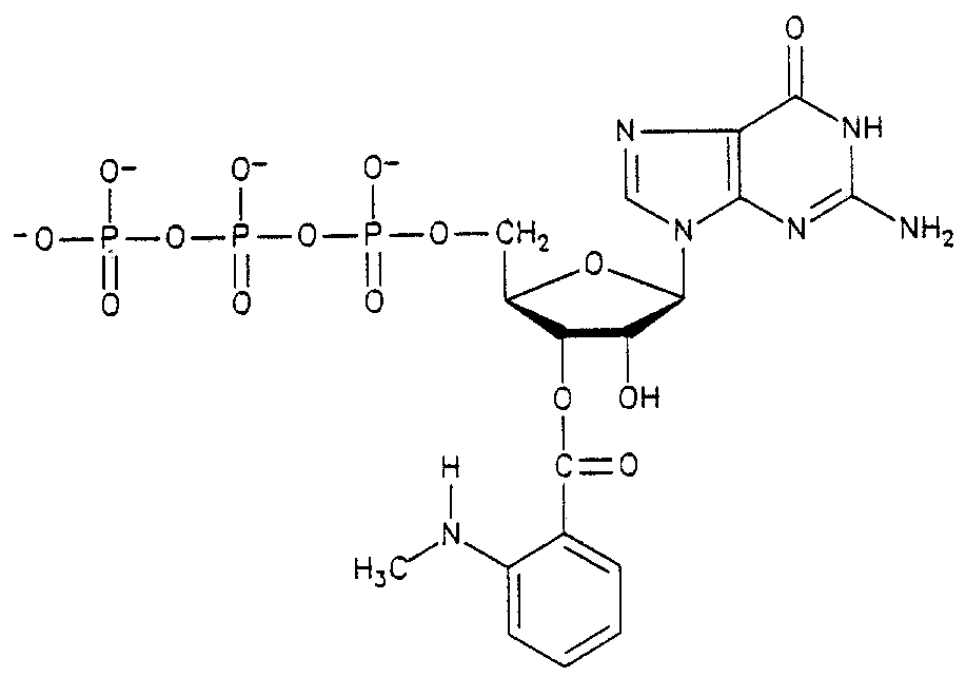

Abbildung 2.3: Die Struktur des mantGTP Moleküls.

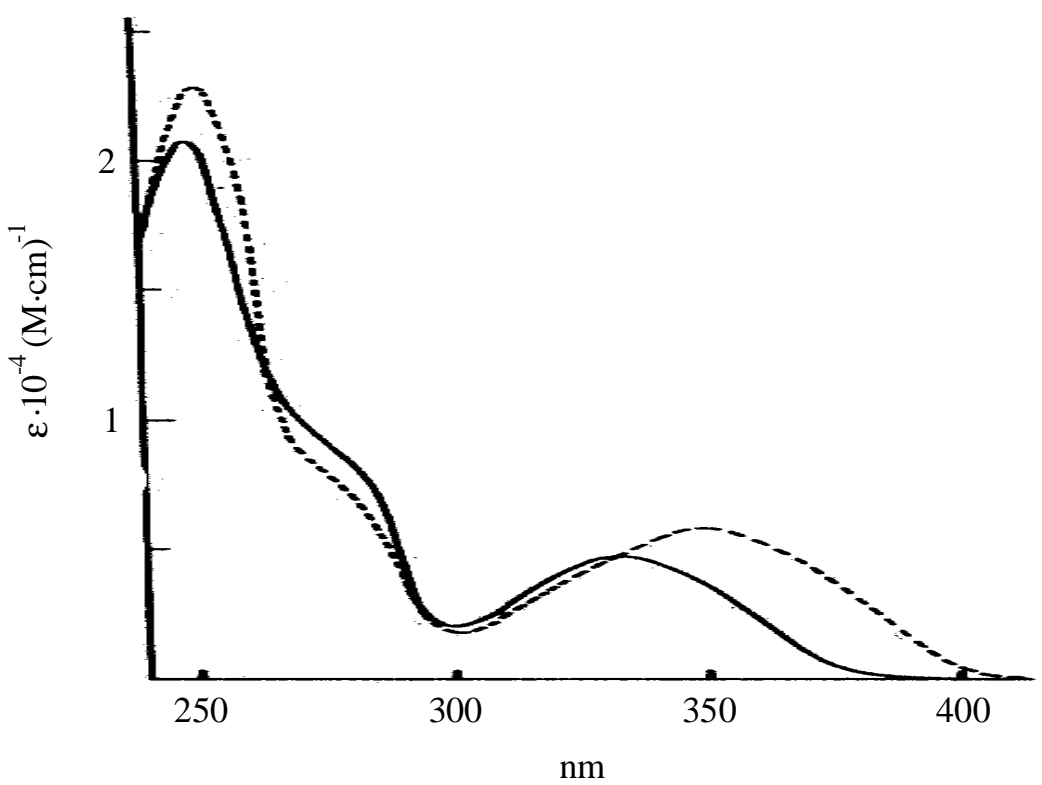

Abbildung 2.4: Das Absorptionsspektrum von mantGTP (- - ) (aus [56]). Der Absorptionskoeffizient hat folgende Werte: $\epsilon=22600 \mathrm{M}^{-1} \mathrm{~cm}^{-1}(\lambda=252 \mathrm{~nm})$ und $\epsilon=5700 \mathrm{M}^{-1} \mathrm{~cm}^{-1}(\lambda=350 \mathrm{~nm})$. Die durchgezogene Linie zeigt das Absorptionsspektrum von Anthraninolyl-GTP. 
erkennen, sondern aus der Höhe des Anstiegs auch etwas über das G-Protein lernen.

Im folgenden Abschnitt wird beschrieben, wie die Unterschiede in der Fluoreszenz zwischen gebundenem und ungebundenem mantGTP aufgenommen wurden.

\subsection{Der experimentelle Aufbau}

Der gesamte Aufbau ist in Abbildung 2.5 schematisch dargestellt. Zur Anregung wurde ein modengekoppelter Nd:YAG-Laser (Coherent Antares), der bereits intern frequenzverdoppelt wird, verwendet. Der austretende $532 \mathrm{~nm}$ Strahl wurde in einem BBO-Kristall nochmals verdoppelt. Mit Hilfe eines Pellin-Broca-Prismas wurde der $266 \mathrm{~nm}$ Strahl von den $532 \mathrm{~nm}$ getrennt und über zwei Umlenkspiegel zum Experiment gelenkt. Der Laser liefert Pulse von 100 ps Dauer mit einer Repetitionsrate von $76 \mathrm{MHz}$. Die mittlere Leistung des $266 \mathrm{~nm}$ Strahls betrug $1.5 \mathrm{~mW}$. Durch einen Fresnel-Rhombus konnte die Polarisationsrichtung des Laserstrahls eingestellt werden. Bei den folgenden Messungen wurde mit vertikaler Laserpolarisation gearbeitet. Die Stabilität des Lasers ist nur mäßig. Sowohl die Strahllage, als auch die Intensität sind Schwankungen unterworfen. Dies führt zu Signalschwankungen von ca. 15\% (siehe Abbildung 2.6).

Der Strahl wurde mit einer Quarzlinse $(f=200 \mathrm{~mm})$ in eine Quarzküvette fokussiert. Die Küvette hat Abmessungen von $30 \times 20 \times 2 \mathrm{~mm}^{3}$, sie wurde unter einem Winkel von ca. $40^{\circ}$ in den Strahlengang gestellt, so daß der direkte Reflex von der Oberfläche in Richtung auf das Spektrometer jedoch deutlich neben den Eintrittsspalt fiel. Der Strahldurchmesser am Meßort betrug $0.5 \mathrm{~mm}$ der Weg durch die Küvette $2.5 \mathrm{~mm}$, d. h. das angeregte Volumen ist $0.5 \mu \mathrm{l}$ groß.

Die Fluoreszenz wurde mit einem Aluminiumspiegel (Ø250 mm, $f=350 \mathrm{~mm}$ ), der im rechten Winkel zum Laserstrahl stand, auf den Eintrittsspalt eines Spektrometers (Oriel Multispec) abgebildet. Vor dem Spektrometer befand sich ein Kantenfilter zur Unterdrückung von Laserstreulicht (Schott WG 295) und ein Glan-Prisma zur Analyse der Fluoreszenzpolarisation. Das Glan-Prisma hat eine nutzbare Öffnung von $2 \times 2 \mathrm{~cm}^{2}$ und einen Akzeptanzwinkel von $\pm 5^{\circ}$. Die Stellung wurde so gewählt, daß entweder horizontal polarisiertes Licht (E-Feld in Spaltrichtung) oder vertikal polarisiertes Licht (E-Feld senkrecht zur Streuebene) durchgelassen wurde.

Im Spektrometer wurde ein Gitter mit 400 Linien pro mm, das für $500 \mathrm{~nm}$ geblazed ist, benutzt, mit dem sich ein sichtbarer Spektralbereich von etwa $130 \mathrm{~nm}$ ergab. Die Spaltbreite betrug bei allen Messungen $0.2 \mathrm{~mm}$. Als Detektor wurde der psBildverstärker und die CCD-Kamera, die im Abschnitt 3.2.4 genauer beschrieben werden, verwendet. Die Kamera war dabei so orientiert, daß die Wellenlängenachse in x-Richtung (0-640 Pixel) und die Ortsachse in y-Richtung (480 Pixel) lag. Da keine Ortsauflösung nötig war, wurde in dieser Richtung mit maximalem Binning (ybin $=32$ ) gearbeitet. In x-Richtung konnte das Bild ohne Verlust an spektraler Auflösung um einen Faktor 4 komprimiert werden. Die Rohdaten haben also ein Format von $160 \times 15$ Pixeln. Durch das Binning verbessert sich das Signal/RauschVerhältnis deutlich. 


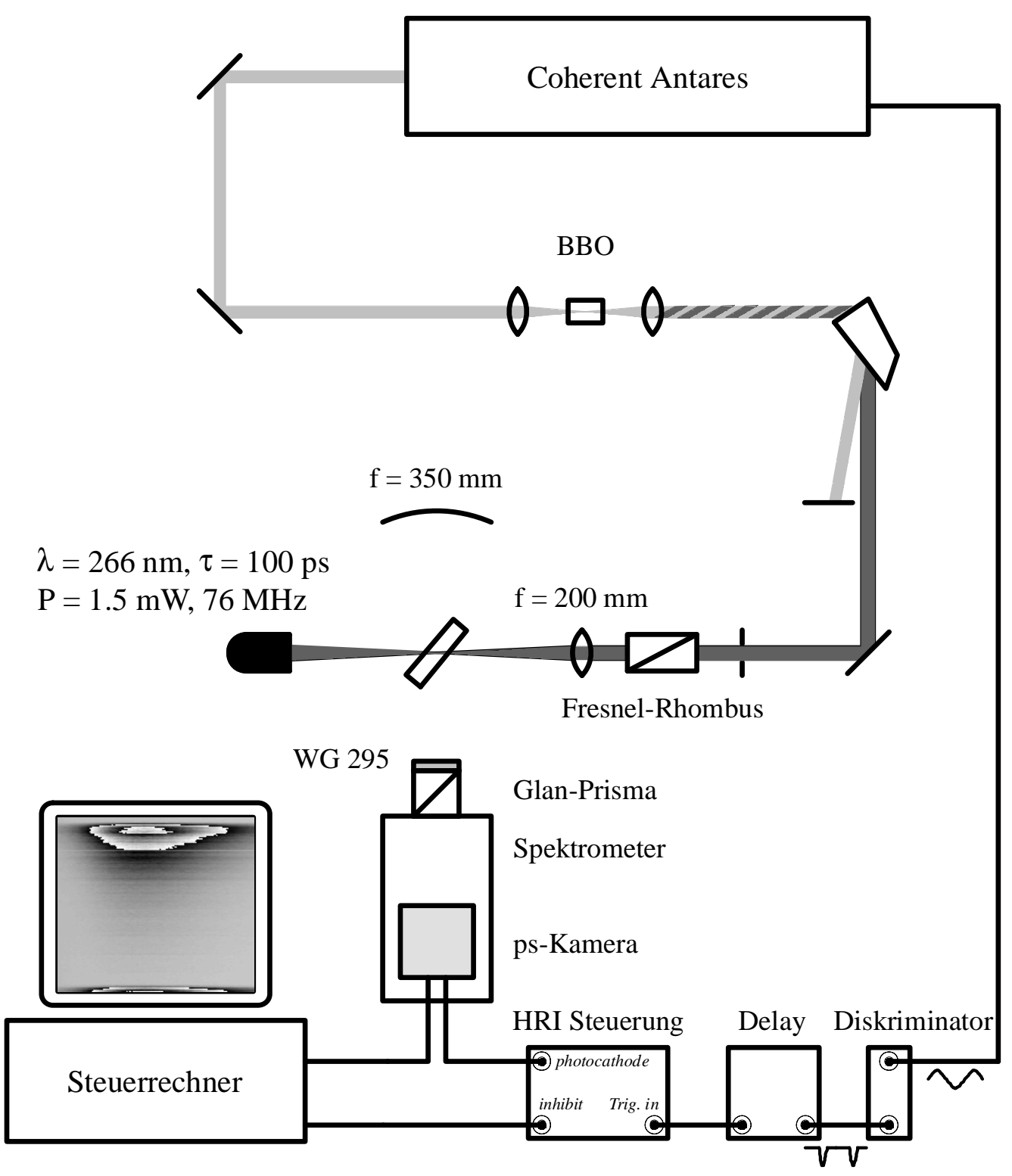

Abbildung 2.5: Der experimentelle Aufbau. 


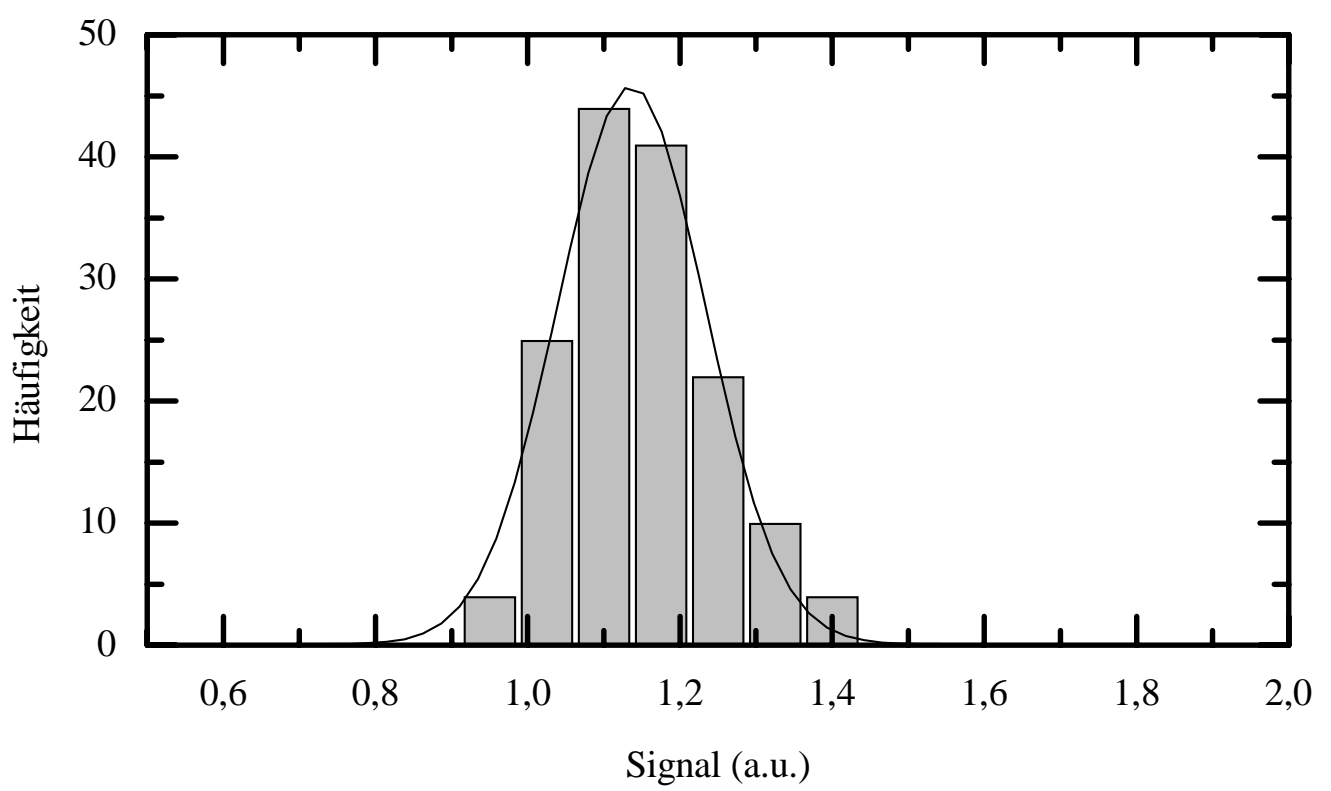

Abbildung 2.6: Histogramm der Signalschwankungen. Die Standardabweichung beträgt $15 \%$.

\subsubsection{Die Triggerung des Experiments}

Zur Triggerung des Bildverstärkers, die mit hoher Genauigkeit erfolgen muß, um eine gute Zeitauflösung zu erreichen, wurde ein $38 \mathrm{MHz}$ Sinussignal des optoakustischen Modulators, der die Modenkopplung im Laser herbeiführt, verwendet. Die Laserpulse werden synchron zu den Nulldurchgängen der Sinuskurve emittiert. Dieses Signal wurde durch einen Diskriminator (Ortec $100 \mathrm{MHz}$ ) in $38 \mathrm{MHz}$ ECLPulse umgewandelt, die über das programmierbare passive Kabeldelay geleitet werden und den Bildverstärker triggern. Der Bildverstärker wird also nur mit $38 \mathrm{MHz}$ getriggert, so daß nur jeder zweite Laserpuls zur nachgewiesenen Fluoreszenz beiträgt. Der Bildverstärker wurde unabhängig von der Bildaufnahme kontinuierlich getriggert. Allerdings wurde die MCP nur für die Dauer der Bildaufnahme unter Hochspannung gelegt. Die Öffnungsdauer des Bildverstärkers betrug bei allen Messungen 200 ps.

Die inhibit Leitung, über die der Bildverstärker ein- und ausgeschaltet wurde, sowie die CCD-Kamera wurden mit einer programmierbaren, digitalen Ein/Ausgabe-Karte (Bestec buffered PIO) gesteuert. Dabei wurde die inhibit Leitung jeweils $50 \mathrm{~ms}$ vor Beginn der CCD-Belichtungszeit auf $0 \mathrm{~V}$ gelegt (d.h. der Bildverstärker wurde eingeschaltet), damit die MCP voll aufgeladen war, bevor die CCD-Belichtungszeit begann. Die Spannung an der MCP betrug bei allen Messungen $800 \mathrm{~V}$, die Belichtungszeiten je nach Signalstärke zwischen 10 und 500 ms.

Die Steuerung des Experiments wurde mit der Davis Software (LaVision) unter Windows durchgeführt; die Aufnahme der Daten konnte damit weitgehend automa- 

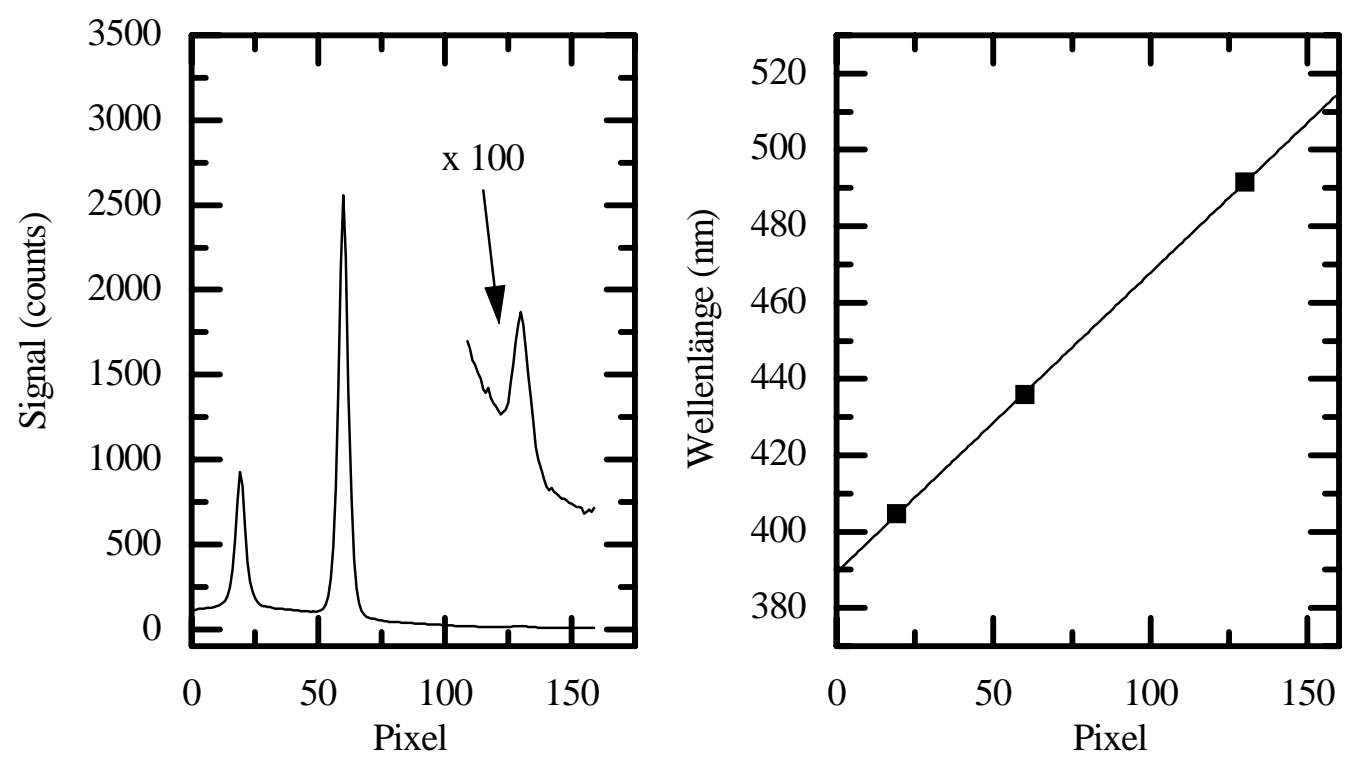

Abbildung 2.7: Der linke Graph zeigt das Spektrum einer Hg-Lampe. Rechts ist die Wellenlängenzuordnung der beobachteten Linien und die Regressionsgerade dargestellt.

tisiert werden.

\subsubsection{Die Charakterisierung des Meßsystems}

Um die Wellenlängenskala festzulegen, wurde das Spektrum einer Quecksilberdampflampe aufgenommen und die beobachteten Linien Werten aus der Literatur [51] zugeordnet (Abbildung 2.7). Drei Linien lagen im Sichtbereich des Spektrometers. Die Wellenlängenskala wurde mittels linearer Regression bestimmt.

Die Nachweiswahrscheinlichkeit der Fluoreszenz ist abhängig von der Wellenlänge. Mehrere Faktoren tragen dazu bei: die Reflektivität des Spiegels und des Gitters sowie die Quanteneffizienz der Photokathode. Die Effizienz des Gitters hängt darüber hinaus auch von der Polarisation des einfallenden Lichts ab. Um die gemessenen Spektren korrigieren zu können, wurde das kontinuierliche Spektrum einer Halogen Eichlampe (Oriel) für beide Stellungen des Glan-Prismas aufgenommen. Das Spektrum der Eichlampe ist an einigen Stützstellen bekannt - Zwischenwerte wurden mittels Spline-Interpolation berechnet. Die Korrekturfaktoren für jede Wellenlänge wurden ermittelt, indem das interpolierte Spektrum der Eichlampe durch das gemessene Spektrum dividiert wurde. So wurden für beide Polarisationsrichtungen Korrekturprofile erhalten, mit denen im folgenden alle gemessenen Spektren multipliziert wurden (siehe Abbildung 2.8).

Die Zeitauflösung wurde analysiert, indem ein Zeitprofil des Rayleighstreulichts 

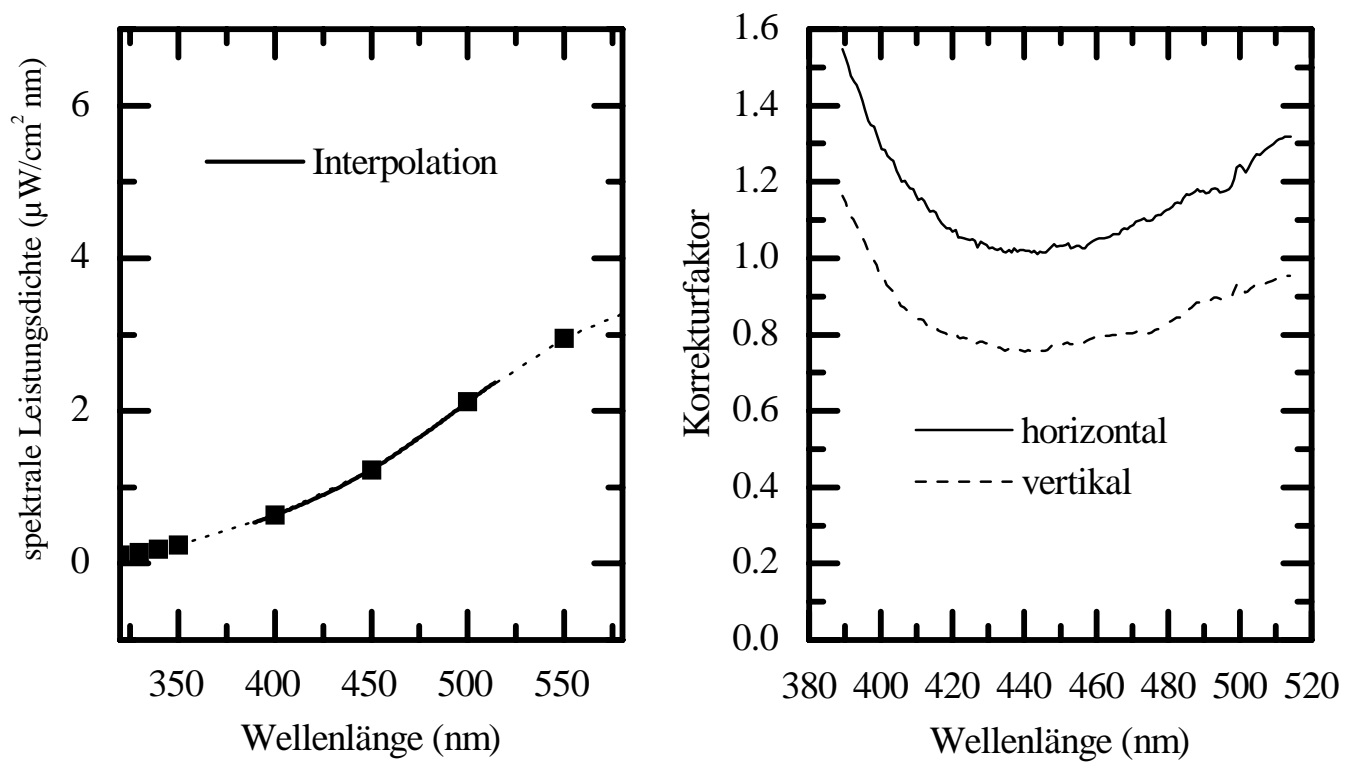

Abbildung 2.8: Der linke Graph zeigt das vom Hersteller angegebene Spektrum der Halogenlampe mit der Interpolation. Rechts sind die beiden Profile zur Korrektur der spektralen Nachweiswahrscheinlichkeit dargestellt.

des Lasers aufgenommen wurde. ${ }^{3}$ Abbildung 2.9 zeigt das erhaltene Profil. Die Halbwertsbreite beträgt etwa 200 ps, was den Herstellerangaben zum Bildverstärker entspricht. Der Jitter bei der Triggerung muß also deutlich kleiner sein, da er die Zeitauflösung nicht reduziert.

\subsection{Die Durchführung der Messung}

\subsubsection{Die Herstellung der Lösungen}

Die Experimente wurden in Lösungen mit folgenden Konzentrationen durchgeführt: mantGTP $10 \mu \mathrm{M}$, GTP $10 \mu \mathrm{M}$ und $10 \mathrm{mM}$, Rab3A $5 \mu \mathrm{M}$. Alle Lösungen wurden mit einem Endvolumen von $100 \mu 1$, die in die Küvette gegeben wurden, hergestellt. Die Küvette wurde bevor eine Lösung hineingegeben wurde mehrmals mit Wasser gespült und danach getrocknet. Zur Zugabe der Substanzen wurde die Küvette aus dem Aufbau herausgenommen. Die Halterung war allerdings so reproduzierbar, daß die Meßwerte direkt miteinander verglichen werden können. Alle Messungen wurden bei $20{ }^{\circ} \mathrm{C}$ durchgeführt. Im folgenden wird beschrieben, wie die Lösungen hergestellt wurden.

Als Puffer wurde eine wässrige Lösung von $50 \mathrm{mM}$ Hepes, $0.5 \mathrm{mM} \mathrm{MgCl}_{2}$,

\footnotetext{
${ }^{3}$ Dazu wurde der Kantenfilter vor dem Spektrometer entfernt und ein entsprechender Wellenlängenbereich eingestellt.
} 


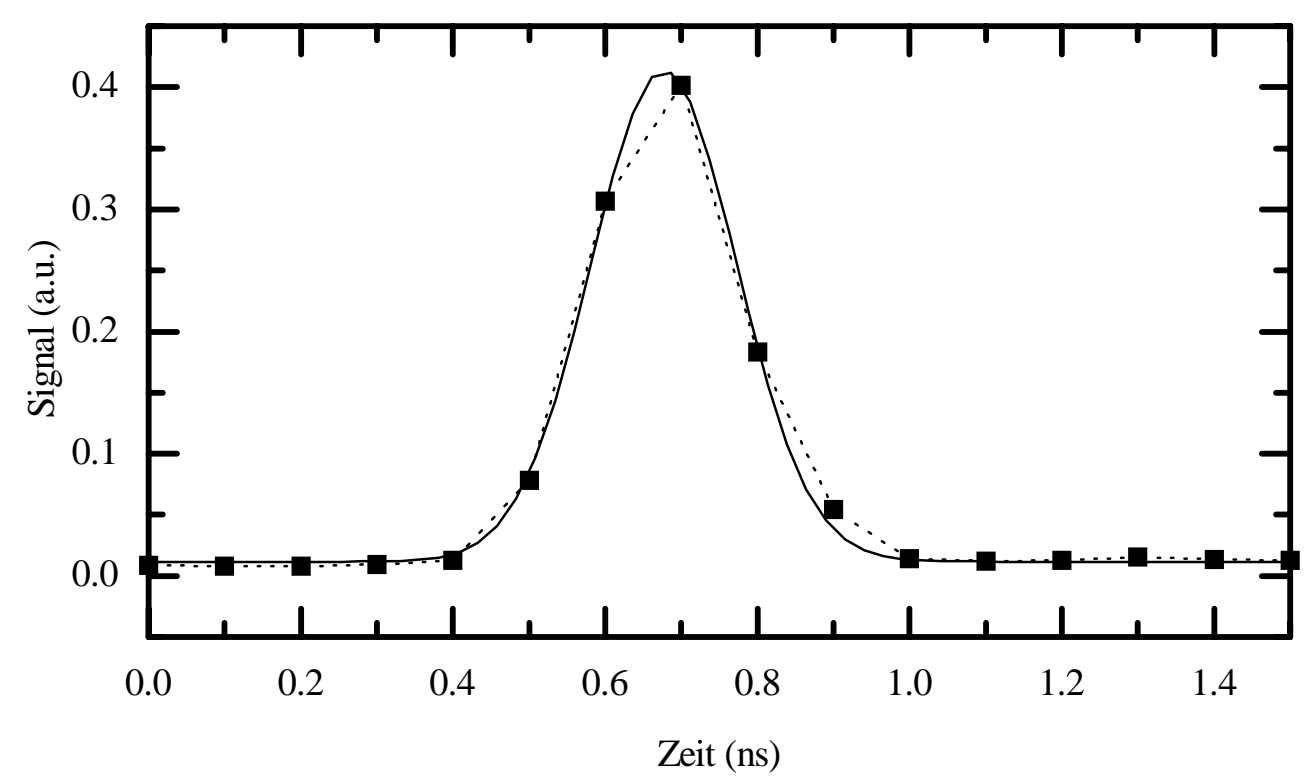

Abbildung 2.9: Gemessener Zeitverlauf des Rayleighstreulichts zur Charakterisierung der Zeitauflösung. Die Halbwertsbreite des Signals beträgt etwa 200 ps. Die durchgezogene Linie ist ein angepaßtes Gauß-Profil.

$100 \mathrm{mM} \mathrm{NaCl}$ und $1 \mathrm{mM}$ DTT verwendet.

Das G-Protein [68] war in einem Puffer aus $20 \mathrm{mM}$ Tris-HCl (pH 8.0), $45 \mathrm{mM}$ $\mathrm{NaCl}, 5 \mathrm{mM} \mathrm{MgCl} 2,1 \mathrm{mM}$ DTT und 50\% Glycerin gelöst. Die Konzentration betrug $360 \mu \mathrm{M}$. Von der G-Protein Lösung wurden $1.38 \mu \mathrm{l}$ in die Meßlösung gegeben, so daß sich eine Konzentration von $5 \mu \mathrm{M}$ ergab.

MantGTP [69] lag in einer Lösung von $5 \mathrm{mM}$ vor. Diese Lösung wurde mit Wasser bis zu einer Konzentration von $100 \mu \mathrm{M}$ verdünnt. Von dieser Lösung wurden $10 \mu \mathrm{l}$ in die Meßlösung gegeben, um die gewünschte Konzentration von $10 \mu \mathrm{M}$ zu erhalten.

Um eine $100 \mathrm{mM}$ GTP Lösung zu erhalten, wurden $5.2 \mathrm{mg}$ GTP $(10 \mu \mathrm{mol})$ in $100 \mu \mathrm{l}$ Wasser gelöst. $10 \mu \mathrm{l}$ dieser Lösung wurden weiter mit Wasser verdünnt, und so eine zweite GTP Lösung mit einer Konzentration von $100 \mu \mathrm{M}$ hergestellt.

\subsubsection{Die Aufnahme zeitaufgelöster Spektren}

Um das Zeitverhalten der Substanzen zu untersuchen, wurde bei verschiedenen Einstellungen des Kabeldelays jeweils ein Kamerabild aufgenommen. In der Regel wurden 150 Bilder in Zeitschritten von $0.1 \mathrm{~ns}$ aufgenommen. Der insgesamt aufgenommene Zeitbereich von $15 \mathrm{~ns}$ ist ausreichend, da der Abstand der Laserpulse nur rund 13 ns beträgt.

Für jedes Bild wurde ein über alle Zeilen gemitteltes Profil berechnet und als Zeile in einem Datenpuffer abgelegt. Man erhält so eine Matrix, in der eine Zeile 
das Emissionsspektrum zu einem bestimmten Zeitpunkt und eine Spalte den Zeitverlauf bei einer bestimmten Wellenlänge darstellt.

Zur Korrektur der Rohdaten wurde zunächst das Dunkelbild der CCD-Kamera abgezogen. Dann wurde jede Zeile mit dem Profil für die entsprechende Polarisationsrichtung zur Korrektur der spektralen Nachweiswahrscheinlichkeit multipliziert. Schließlich wurden die Daten durch die Belichtungszeit der CCD-Kamera dividiert, um die Messungen unabhängig von der Belichtungszeit vergleichen zu können.

Die Zeitprofile, die im folgenden verwendet werden, wurden berechnet, indem über alle Spalten der Datenmatrix, d. h. über alle Wellenlängen, gemittelt wurde, nachdem alle Korrekturen angebracht waren. Die Spektren (Abbildung 2.14 ausgenommen) sind über alle Zeilen, d. h. über alle Zeitintervalle, gemittelt.

\subsubsection{Die Auswertung der Fluoreszenzabklingkurven}

Zur Bestimmung der Fluoreszenzlebensdauern wurde eine doppelt exponentielle Abklingkurve mit Hilfe eines nicht linearen Fit-Algorithmus an die Meßwerte angepaßt.

$$
I_{\mathrm{Fit}}(t)=A_{1} e^{-t / \tau_{1}}+A_{2} e^{-t / \tau_{2}}+C
$$

Als Maß der Güte des Fits wurde die $\chi^{2}$-Funktion herangezogen. Für die Fehler $\Delta I$ wurden jeweils $15 \%$ des Meßwerts angesetzt.

$$
\chi^{2}=\frac{1}{N} \sum_{i=1}^{N}\left(\frac{I_{\mathrm{gem}}\left(t_{i}\right)-I_{\mathrm{Fit}}\left(t_{i}\right)}{\Delta I\left(t_{i}\right)}\right)^{2}
$$

Um die Fehler der Fitresultate abzuschätzen, wurde die Bootstrap-Methode [24] verwendet. Dabei werden aus dem Datensatz, der untersucht wird, zufällig $N$ Wertepaare ausgewählt und so ein ,neuer“ Datensatz, bei dem einige Meßwerte doppelt vorkommen und einige fehlen, konstruiert. An diesen Datensatz wird die Fitfunktion angepaßt und man bekommt einen neuen Satz von Fitparametern. Dies wird für viele zufällig aus den Originaldaten ausgewählte Datensätze wiederholt. Die Standardabweichung der dabei erhaltenen Fitparameter ist als Fehler der Fitparameter angegeben.

Die erhaltenen Fluoreszenzlebensdauern sind in den Tabellen 2.2 und 2.3 in der Diskussion zusammengestellt.

\subsection{Die Spektren der Substanzen}

Bei allen Messungen konnte keine Polarisation der Fluoreszenz nachgewiesen werden, d. h. die Messwerte waren im Rahmen der Meßgenauigkeit für beide Stellungen des Glan-Prismas gleich. Für das GTP und mantGTP ist dies nicht verwunderlich, da die Moleküle sehr klein sind. Überraschend ist, daß keine Anisotropie beim Rab3A-mantGTP Komplex beobachtet wurde. Allerdings sind die Messungen durch die Laserschwankungen verrauscht, so daß Anisotropien unter 0.07 nicht 


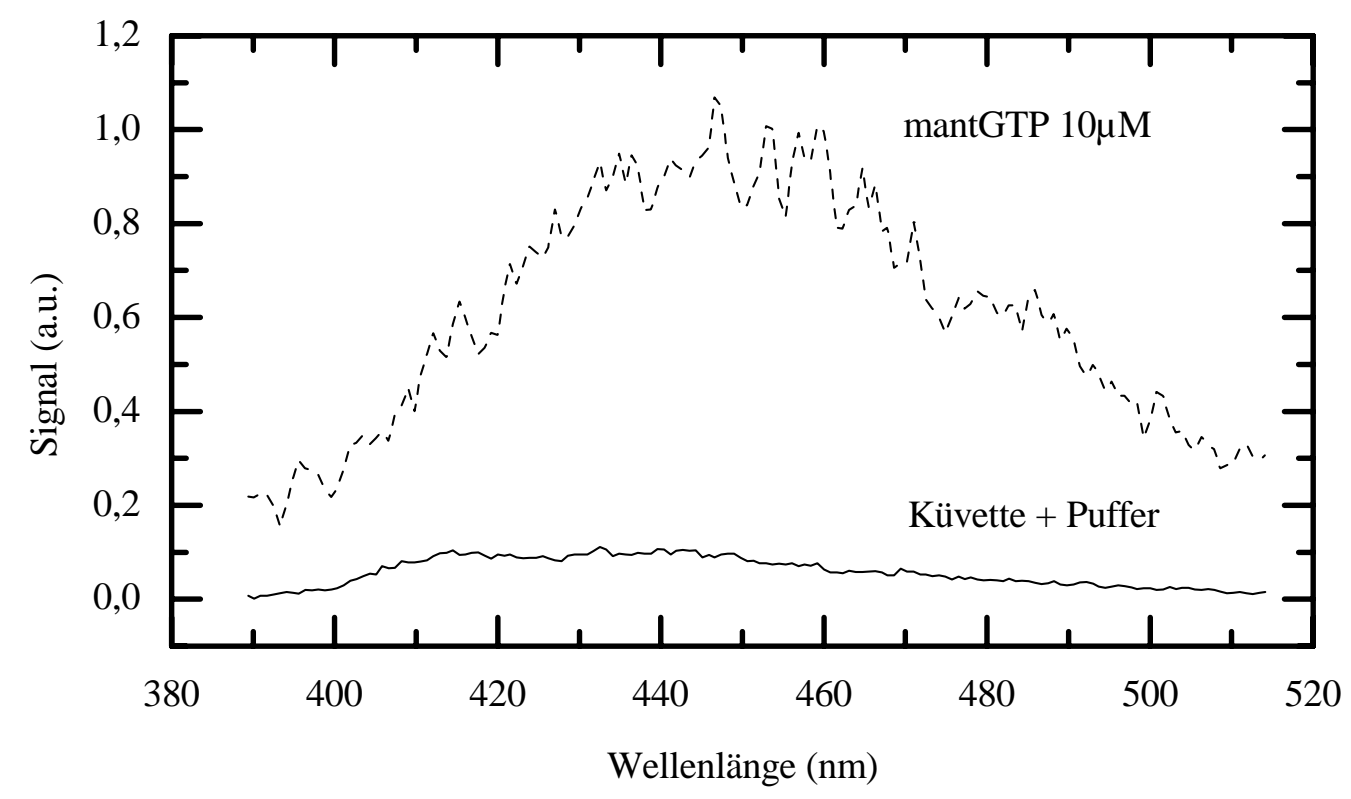

Abbildung 2.10: Eigenfluoreszenz der Küvette. Im Vergleich dazu ist das Spektrum von $10 \mu \mathrm{M}$ mantGTP dargestellt.

nachgewiesen werden können. Eine mögliche Erklärung für die fehlende Anisotropie ist, daß die Methyl-Antranilolyl-Gruppe (mant), die für die Fluoreszenz verantwortlich ist, unabhängig vom GTP und damit auch unabhängig vom Protein um die C-O oder C-C Bindung zwischen GTP und mant rotieren kann.

Im folgenden sind nur die Ergebnisse für vertikal polarisierte Fluoreszenz dargestellt.

\subsubsection{Küvette und Puffer}

Zunächst wurden die leere Küvette und die Pufferlösung untersucht. Die Küvette zeigte eine deutliche Eigenfluoreszenz, die allerdings nicht so stark war, daß sie die folgenden Messungen behinderte. Das Spektrum der Eigenfluoreszenz ist in Abbildung 2.10 gezeigt. Wurde die Küvette mit Pufferlösung gefüllt, ergab sich keine Änderung der Fluoreszenz, d. h. eine Pufferfluoreszenz ist nicht nachzuweisen.

Die Eigenfluoreszenz tritt in allen weiteren Messungen auf und wird von den Daten abgezogen. Da die Küvettenfluoreszenz aber eine kurze Abklingzeit von $0.92 \mathrm{~ns}$ hat, die deutlich unter der des mantGTP (5.4ns) liegt, ist der Untergrund nur in den ersten $4 \mathrm{~ns}$ nach der Anregung relevant. Der Zeitverlauf der Küvettenfluoreszenz ist zusammen mit der mantGTP Fluoreszenz in Abbildung 2.13 dargestellt. 


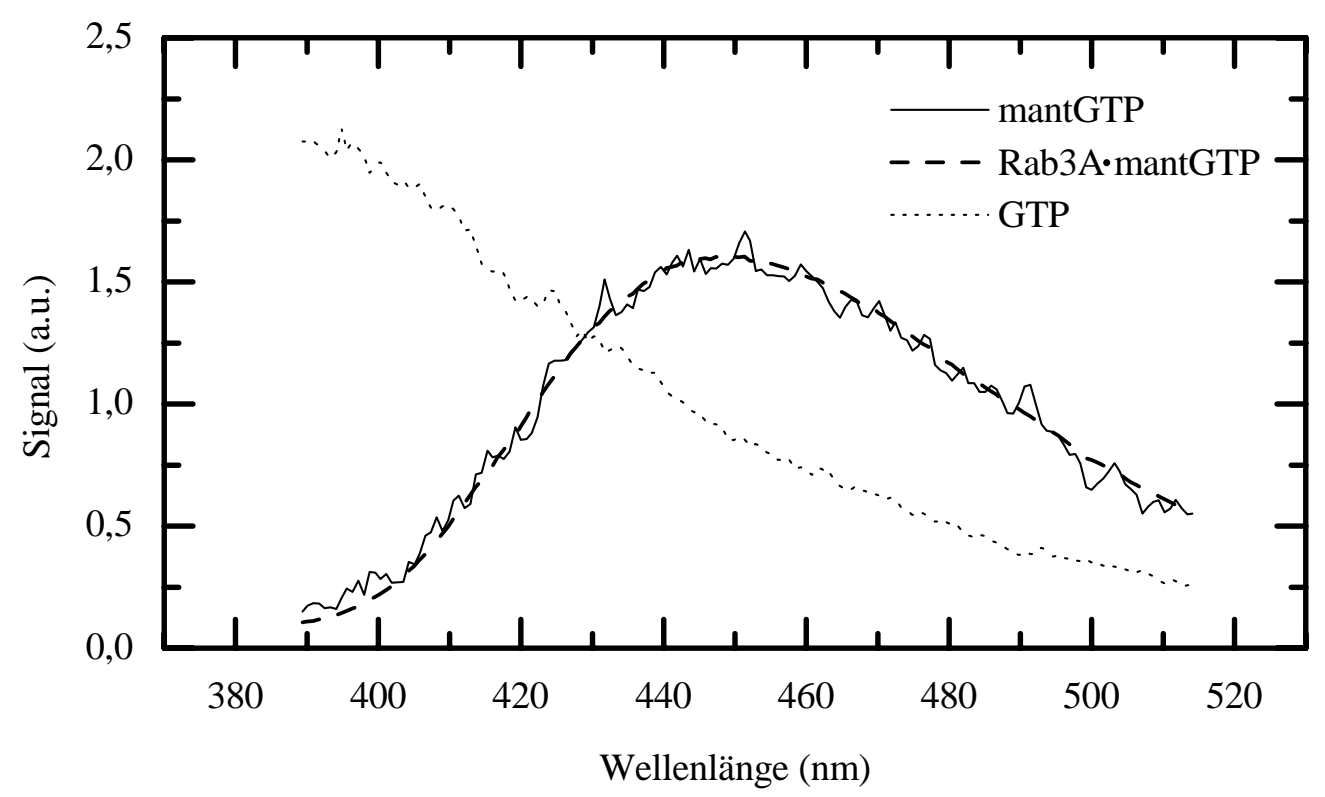

Abbildung 2.11: Spektren von GTP, mantGTP und Rab3A-mantGTP. Um die Form besser vergleichen zu können, sind die Spektren auf einen Mittelwert von Eins normiert.

\subsubsection{GTP und Rab3A}

Bei den Messungen zur Interaktion des mantGTP mit dem G-Protein kommt GTP in zwei Konzentrationen zum Einsatz: $10 \mathrm{mM}$ und $10 \mu \mathrm{M}$. In diesen Konzentrationen wurde GTP zunächst allein untersucht.

Bei einer Konzentration von $10 \mu \mathrm{M}$ wurde keine GTP Fluoreszenz beobachtet. Bei der 10 mM GTP Lösung konnte eine kurzlebige Fluoreszenz, die zum blauen Ende des Spektrums hin ansteigt, beobachtet werden. Das Spektrum ist in Abbildung 2.11 dargestellt, das Zeitverhalten in Abbildung 2.12. Die Fluoreszenz ist im Maximum etwa so stark wie die mantGTP Fluoreszenz, allerdings ist die Lebensdauer so kurz und das Spektrum so unterschiedlich, daß die Störung zu vernachlässigen ist (siehe auch Abbildung 2.14).

Das Protein wurde nur in einer Konzentration von $5 \mu \mathrm{M}$ verwendet. Bei dieser Konzentration wurde keine Fluoreszenz des Proteins in dem gewählten Wellenlängenbereich beobachtet.

\subsection{3 mantGTP}

Die Fluoreszenz des mantGTP soll als Indikator für eine Bindung des mantGTP an das G-Protein dienen. Daher wurde das mantGTP sowohl allein, als auch in verschiedenen Mischungen mit dem G-Protein und GTP untersucht. Bei der Bindung an das G-Protein treten zwei Veränderungen der mantGTP Fluoreszenz auf: 1. die Intensität steigt um den Faktor 25 an. 2. die Lebensdauer fällt von 5.4ns auf 4.38ns. 


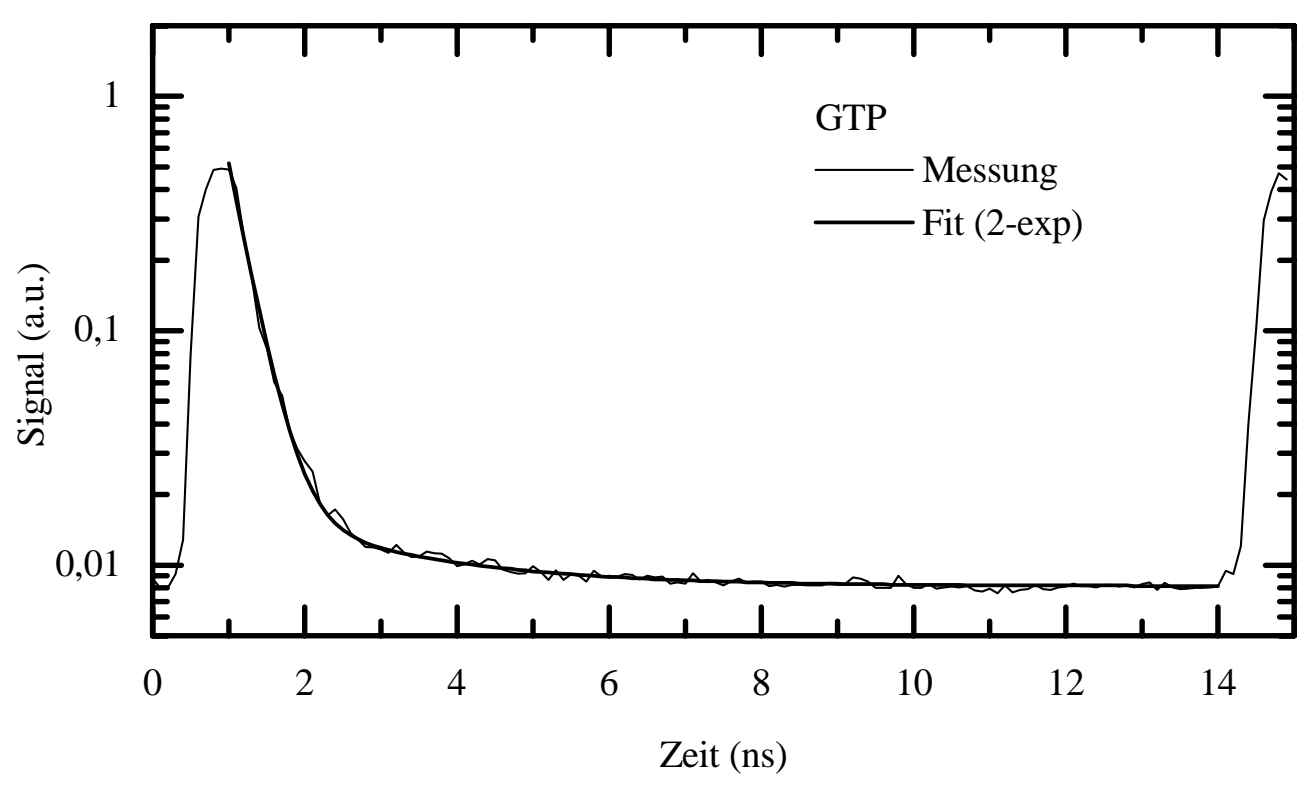

Abbildung 2.12: Zeitverhalten der GTP Fluoreszenz und doppelt exponentieller Fit.

\begin{tabular}{|c|r|r|r|r|}
\hline & Ansatz I & Ansatz II & Ansatz III & Ansatz IV \\
\hline mantGTP & $10 \mu \mathrm{M}$ & $10 \mu \mathrm{M}$ & $10 \mu \mathrm{M}$ & $\approx 10 \mu \mathrm{M}$ \\
GTP & $10 \mathrm{mM}$ & $10 \mu \mathrm{M}$ & $10 \mu \mathrm{M}$ & $\approx 10 \mathrm{mM}$ \\
Rab3A & $5 \mu \mathrm{M}$ & & $5 \mu \mathrm{M}$ & $\approx 5 \mu \mathrm{M}$ \\
\hline
\end{tabular}

Tabelle 2.1: Zusammensetzung der verschiedenen Ansätze, mit denen die Bindung des mantGTP an das G-Protein untersucht wurde.

Die Spektren, die für mantGTP allein und an das G-Protein gebunden aufgenommen wurden, sind in Abbildung 2.11 dargestellt. Dabei sind die Spektren, um ihre Form besser vergleichen zu können, so normiert, daß sie den gleichen Mittelwert von Eins haben. Es ist kein Unterschied im Spektrum zwischen gebundenem und freiem mantGTP festzustellen. Das Maximum der Fluoreszenz liegt bei $\lambda=450 \pm 1 \mathrm{~nm}$. Das Zeitverhalten der mantGTP-Fluoreszenz ist in Abbildung 2.13 (ungebunden) und in Abbildung 2.15 (gebunden) dargestellt.

Eine Übersicht der verschiedenen Ansätze, die untersucht wurden, ist in Tabelle 2.1 dargestellt. Ansatz I enthält mantGTP und das G-Protein in etwa gleichen Konzentrationen aber einen tausendfachen GTP Überschuß. Da GTP und mantGTP um dieselbe Bindungsstelle am G-Protein konkurrieren und etwa gleiche Bindungskonstanten haben, sollten praktisch alle mantGTP Moleküle ungebunden sein, da die Bindungsstellen im Verhältnis der Konzentrationen besetzt werden. Tatsächlich wurde im wesentlichen dasselbe Verhalten wie bei reinem mantGTP beobachtet. Abweichungen wurden nur unmittelbar nach der Laseranregung festgestellt. Sie lassen sich aber auf Fluoreszenz vom GTP zurückführen. 


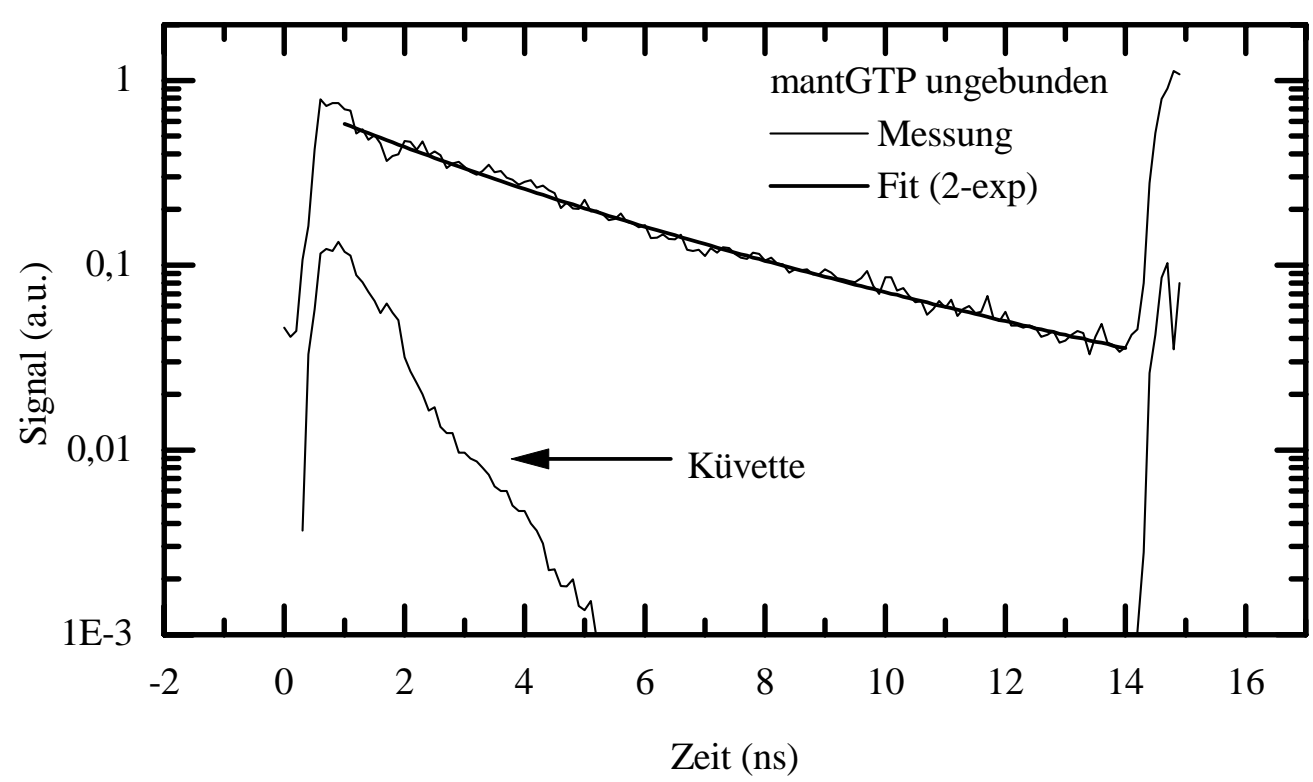

Abbildung 2.13: Zeitverhalten der mantGTP-Fluoreszenz zusammen mit einem doppelt exponentiellen Fit. Zusätzlich ist noch das Zeitverhalten der Eigenfluoreszenz der Küvette angegeben.

Abbildung 2.14 zeigt den Verlauf der Fluoreszenzemission von Ansatz I innerhalb einer Nanosekunde. Zusätzlich sind die Spektren von reinem mantGTP und GTP sowie deren Summe, die das gemessene Spektrum von Ansatz I recht gut reproduziert, dargestellt. Das erste Spektrum $(t=0.4 \mathrm{~ns})$ ist zu Beginn der Laseranregung aufgenommen, wo noch kaum Fluoreszenz emittiert wird. 200 ps später ist die Fluoreszenz in voller Stärke vorhanden und wird auf der kurzwelligen Seite des Spektrums vom GTP dominiert. Die GTP Fluoreszenz klingt allerdings schnell ab und das Spektrum gleicht sich immer mehr dem von reinem mantGTP an. Zwei Nanosekunden nach der Anregung sind keine Unterschiede zwischen mantGTP und Ansatz I feststellbar; die Lebensdauer entspricht der von ungebundenem mantGTP. Es liegt also nahe, daß das mantGTP nicht vom GTP und dem G-Protein beeinflußt wird.

\subsubsection{Rab3A-mantGTP}

Ansatz III enthält GTP, mantGTP und das G-Protein in etwa gleichen Konzentrationen, d. h. hier sollte ein Komplex aus mantGTP und dem G-Protein (Rab3A-mantGTP) vorliegen. Im Vergleich zu reinem mantGTP wird eine deutlich stärkere Emission (ca. 25mal stärker) beobachtet. Außerdem ändert sich die Fluoreszenzlebensdauer von 5.4 ns auf 4.38 ns (Abbildung 2.15). Man kann die Bindung also sowohl an der Stärke der Emission als auch an deren Zeitverhalten erkennen. 


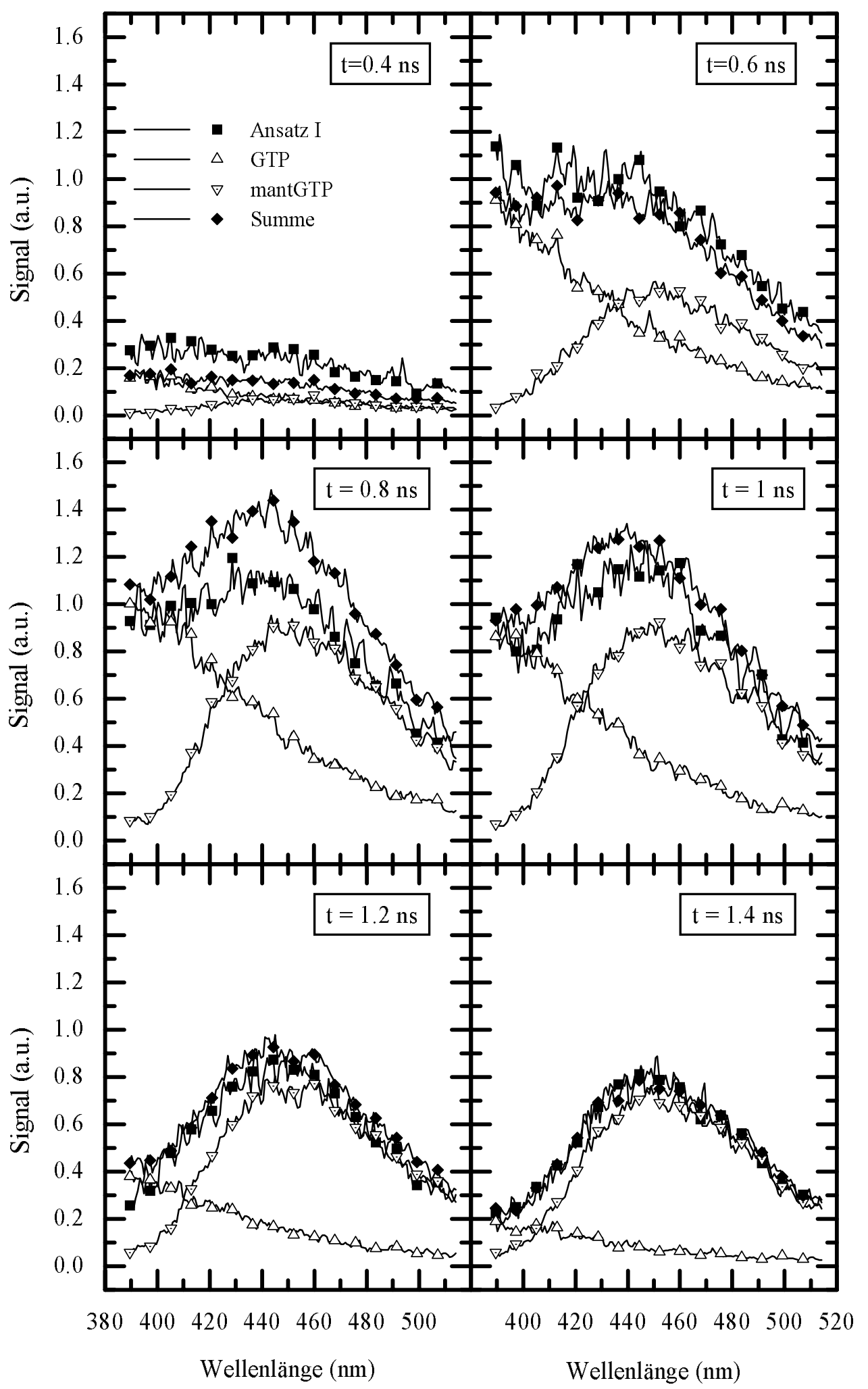

Abbildung 2.14: Entwicklung der Emission von Ansatz I unmittelbar nach der Laseranregung. Das beobachtete Spektrum entsteht durch Überlagerung von GTPund mantGTP-Fluoreszenz. 


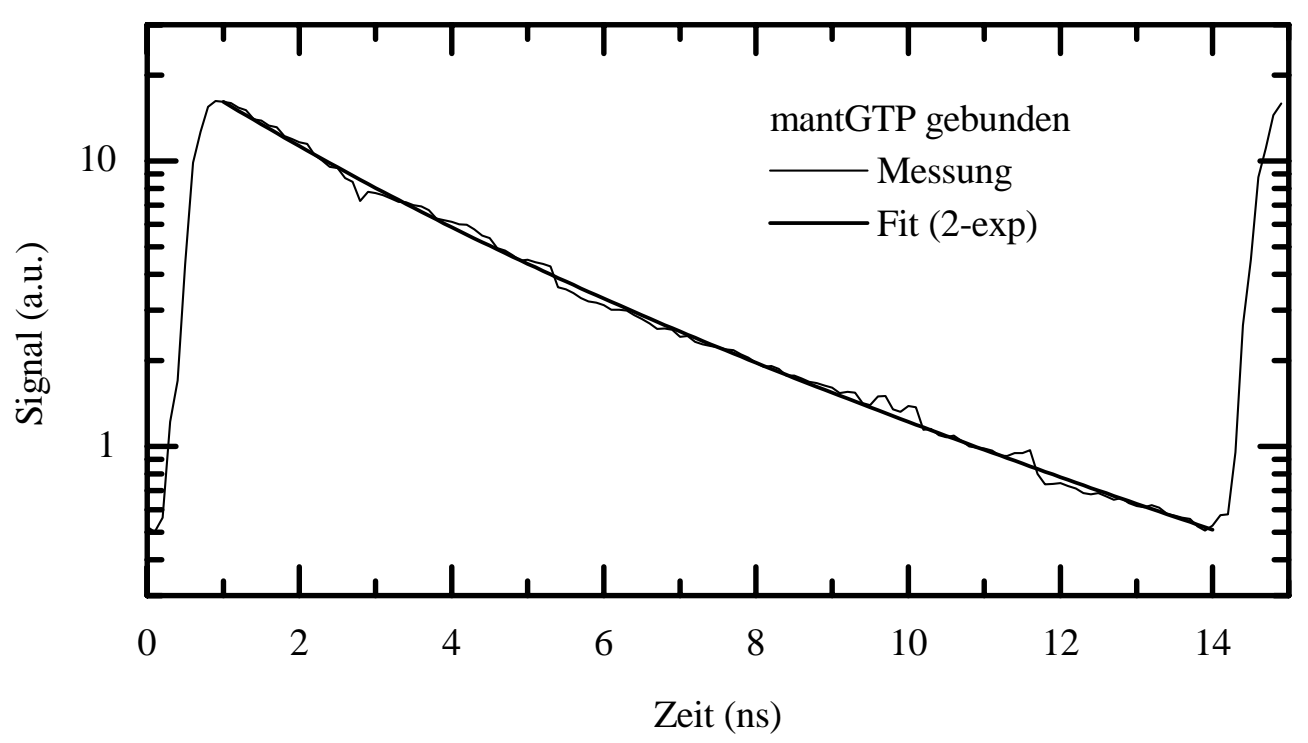

Abbildung 2.15: Zeitverhalten der Rab3A·mantGTP Fluoreszenz.

Hat das mantGTP an das G-Protein gebunden, wird es von diesem hydrolysiert und zu mantGDP umgewandelt. Dabei wurde in einer anderen Arbeit (mit einem anderen G-Protein [57]) ein Rückgang der Fluoreszenz um 10\% beobachtet.

Die Fluoreszenzintensität von Ansatz III wurde daher über eine Stunde in Abständen von 5 Minuten gemessen. Dazu wurden jeweils 100 Bilder bei einer Belichtungszeit von $20 \mathrm{~ms}$ gemittelt. Zwischen den Messungen wurde der Laserstrahl geblockt. Es wurde keine Abnahme der Fluoreszenz beobachtet (siehe Abbildung 2.17), allerdings liegt die relative Standardabweichung bezogen auf den Mittelwert der Intensität bei 0.09 , d. h. ein Effekt von $10 \%$ wäre schwer nachzuweisen. Diese hohe Schwankung wird durch die Instabilität des Lasers verursacht. Um genauere Ergebnisse zu bekommen, müßte die Laserleistung simultan mitgemessen werden.

Zusätzlich zur Intensität wurde während dieser Stunde auch die Fluoreszenzlebensdauer gemessen. Abbildung 2.16 zeigt die dabei erhaltenen Werte. Die in Tabelle 2.2 angegebene Lebensdauer ist der Mittelwert aus diesen Messungen.

\subsubsection{Verdrängung des mantGTP durch GTP}

In den Ansatz III wurden zusätzlich noch $10 \mu 1$ der 100 mM GTP-Lösung gegeben, so daß - abgesehen von der Änderung des Gesamtvolumens von 100 auf $110 \mu \mathrm{l}-$ dieselben Konzentrationen wie im Ansatz I vorlagen. Da jetzt wieder ein großer Überschuß an GTP vorhanden ist, sollte das mantGTP aus der Bindung mit dem G-Protein verdrängt werden. Um diesen Effekt zu untersuchen, wurde die Fluoreszenzintensität eine halbe Stunde lang aufgenommen - zuerst in Abständen von $15 \mathrm{~s}$, dann in Schritten von 30, 60 und 300 s. Die Werte sind in Abbildung 2.17 zusam- 


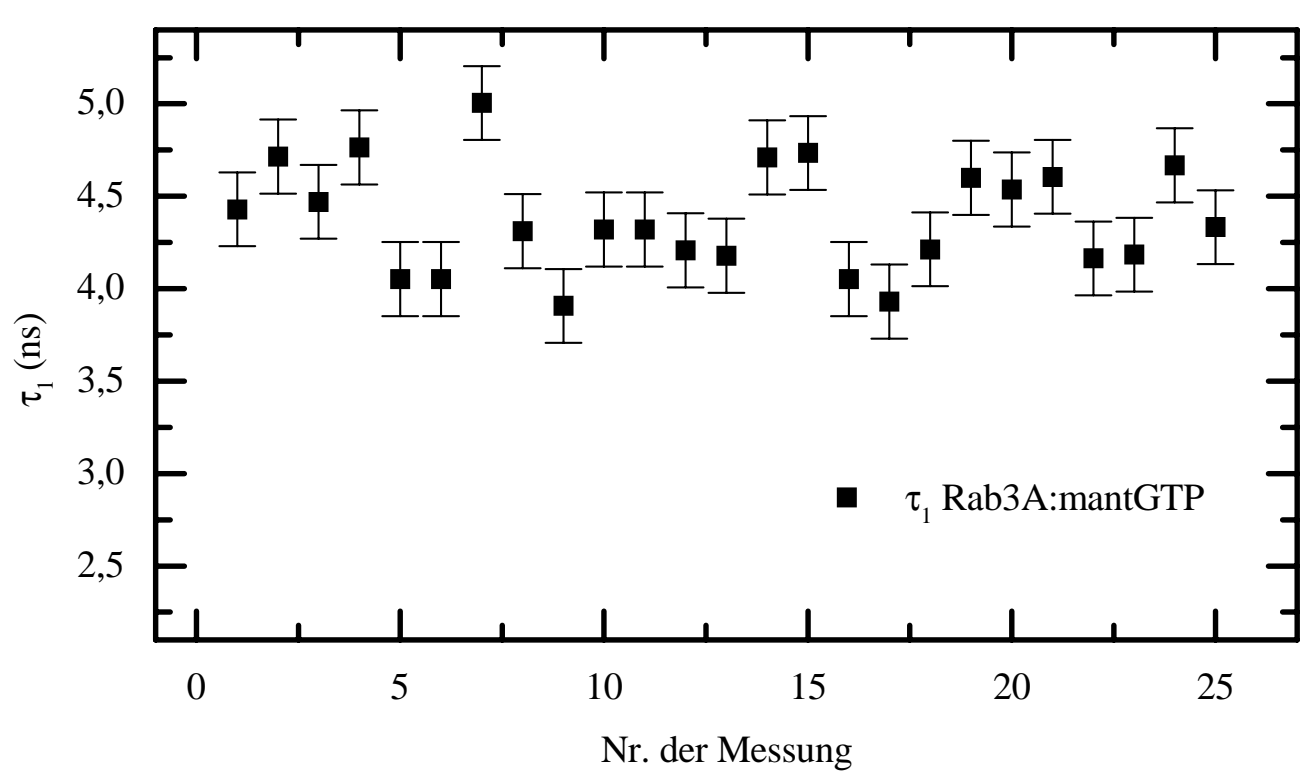

Abbildung 2.16: Schwankungen der Fluoreszenzlebensdauer beim Rab3A·mantGTP bei wiederholter Messung.

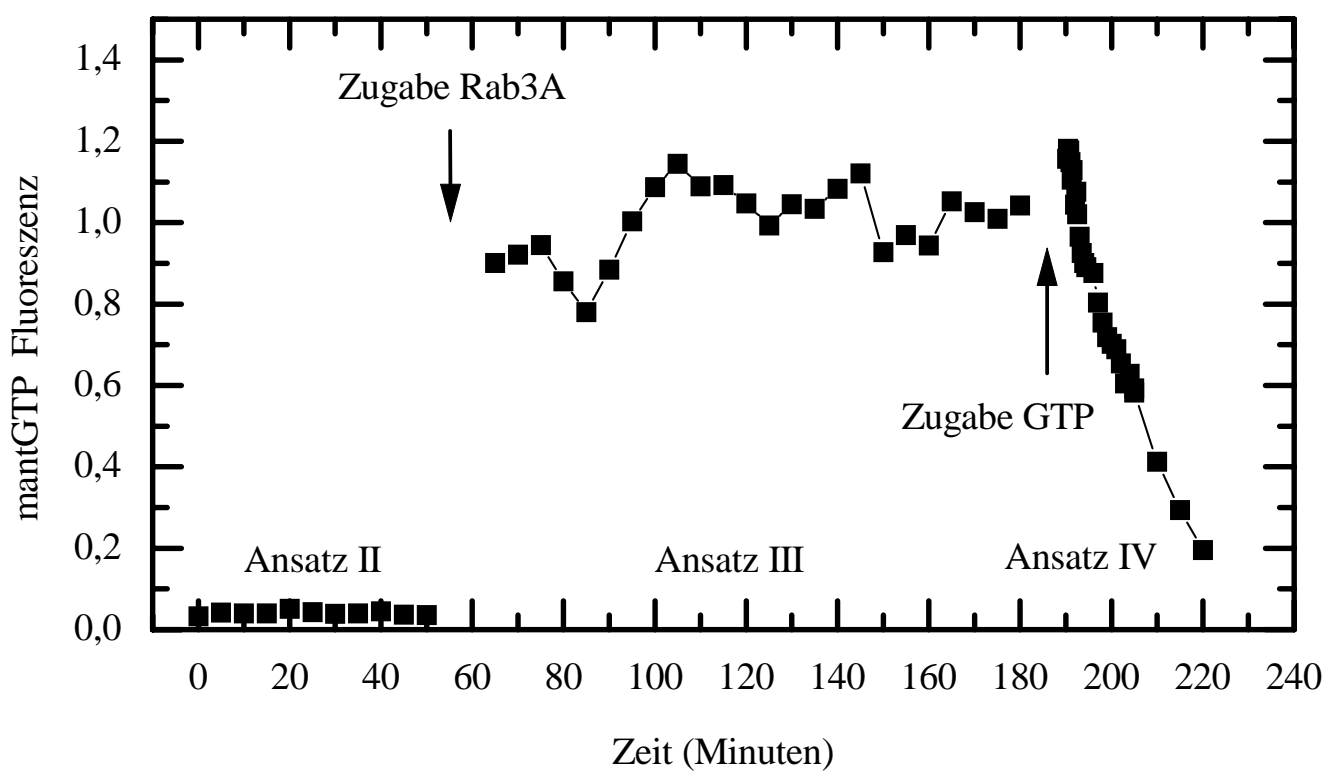

Abbildung 2.17: Stärke der mantGTP Fluoreszenz unter verschiedenen Bedingungen. Links ungebunden, in der Mitte an das G-Protein gebunden, rechts Verdrängung des mantGTP durch GTP. Das Signal ist auf das mittlere Signal des Rab3A-mantGTP Komplexes normiert. Der Mittelwert des ungebundenen mantGTP liegt bei 0.041 . 


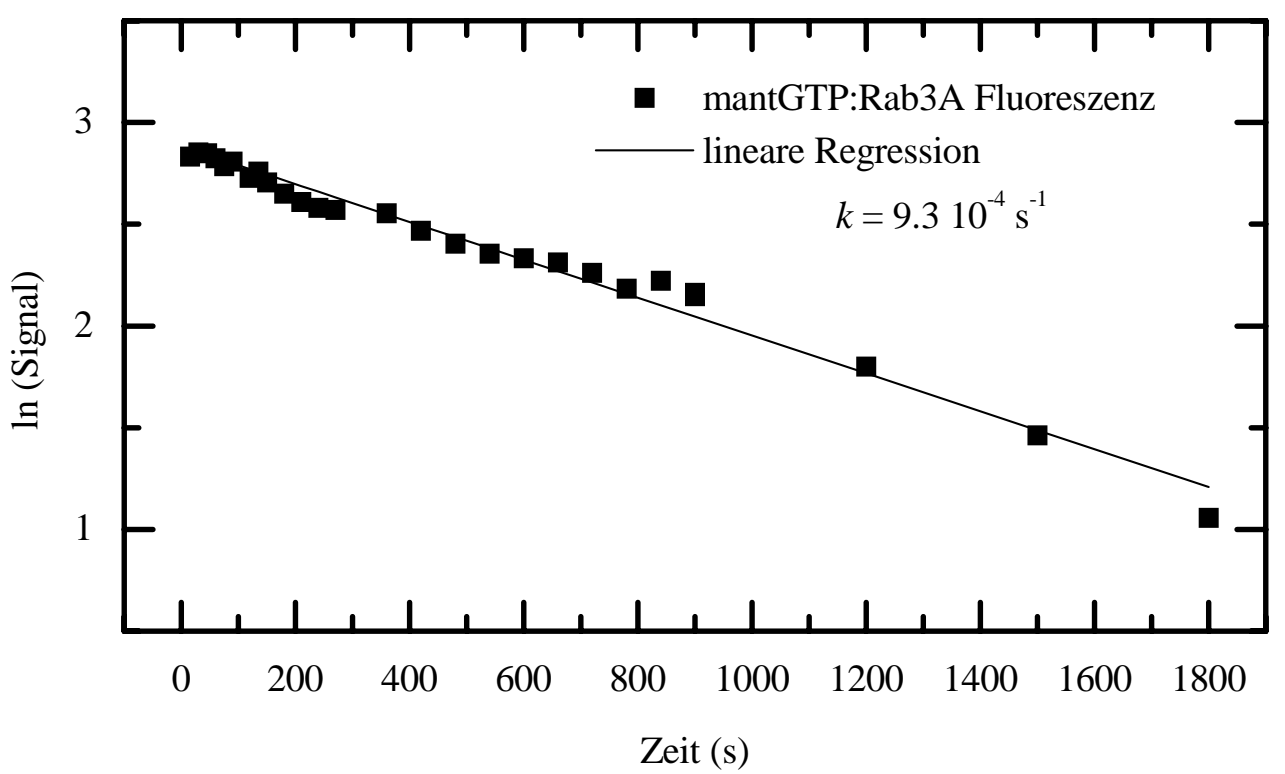

Abbildung 2.18: Abnahme der Fluoreszenz bei der Verdrängung von mantGTP durch GTP aus der Bindung mit dem G-Protein $\left(T=20^{\circ} \mathrm{C}\right)$.

men mit den Werten für ungebundenes und gebundenes mantGTP dargestellt. Die drei Bereiche in der Graphik entsprechen den Ansätzen II, III und IV.

Die Fluoreszenz nimmt nach Zugabe des GTP schnell ab und ist eine halbe Stunde später auf ein Fünftel des Anfangswertes abgeklungen. Nimmt man die Fluoreszenz als ein Maß für die Menge des gebundenen mantGTP, kann aus dem Zeitverlauf der Fluoreszenz die Ratenkonstante für die Spaltung des Rab3A-mantGTP Komplexes berechnet werden. In Abbildung 2.18 ist die Fluoreszenz logarithmisch gegenüber der Zeit aufgetragen. Man erkennt, daß die Fluoreszenz exponentiell abklingt, wie es für eine einfache Verdrängungsreaktion zu erwarten ist, bei dem ein Partner in großem Überschuß vorhanden ist. Lineare Regression liefert eine Ratenkonstante von $k=9.3 \cdot 10^{-4} \mathrm{~s}^{-1}$ (bei einer Temperatur von $20^{\circ} \mathrm{C}$ ).

\subsection{Diskussion}

In diesem Abschnitt sollen die beobachteten Effekte, wie die Intensitäts- und Lebensdaueränderung, mit Daten aus der Literatur verglichen werden. Bisher wurde Rab3A noch nicht mit mantGTP untersucht. Es gibt jedoch Arbeiten zum mantGTP, in denen andere G-Proteine (u. a. p21 ${ }^{\text {ras }}, \mathrm{G}_{o}$ ) verwendet wurden. Diese Experimente kommen den hier vorgestellten Messungen am nächsten. Daher wird im folgenden meist auf diese Experimente Bezug genommen. 


\subsubsection{Die Intensitätsänderung bei der Bindung an Rab3A}

Neal et. al. [57] haben die Kinetik der Bindung von mantGTP an p21 ${ }^{\text {NRAS }}$ und Mutanten dieses G-Proteins untersucht. Dabei wurde zur Anregung des mantGTP eine Wellenlänge von $350 \mathrm{~nm}$ benutzt. Bei Bindung an das G-Protein wurde ein 3.2facher Anstieg der Fluoreszenz beobachtet. Dieser Wert liegt deutlich unter dem hier gemessenen Faktor von 25.

Der deutlich höhere Faktor hängt wahrscheinlich mit der hier verwendeten Anregungswellenlänge von $266 \mathrm{~nm}$ zusammen. Es gibt zwei mögliche Erklärungen:

1. Mit $266 \mathrm{~nm}$ wird nicht die mant-Gruppe, deren Absorptionsmaximum bei $350 \mathrm{~nm}$ liegt, sondern das Guanin angeregt. Die Energie muß also zunächst auf die mant-Gruppe transferiert werden, bevor Fluoreszenz emittiert wird. Es ist möglich, daß dieser Proze $ß$ - ebenso wie die Fluoreszenzemission der mant-Gruppe - dem Quenching durch das Lösungsmittel unterworfen ist. Dadurch könnte die Quantenausbeute bei Anregung mit $266 \mathrm{~nm}$ noch viel stärker als bei Anregung mit $350 \mathrm{~nm}$ (Faktor 4) vom Lösungsmittel abhängen. Die Quantenausbeute des mantGTP bei Anregung mit $266 \mathrm{~nm}$ ist bisher nicht gemessen worden.

2. Mit $266 \mathrm{~nm}$ kann man auch die Aminosäuren Tryptophan (W) und Tyrosin (Y) anregen, die im G-Protein enthalten sind $(3 \times \mathrm{W}, 9 \times \mathrm{Y}$ [61]). Die Energie kann von den Aminosäuren auf das mantGTP übertragen werden, wenn sich die Aminosäuren nah genug beim mantGTP befinden. Remmers et. al. [60] haben bei dem heterotrimeren G-Protein $\mathrm{G}_{o}$ bei der Bindung von mantGTP $\gamma \mathrm{S}^{4}$ eine Zunahme der Fluoreszenz um einen Faktor 16 beobachtet $\left(\lambda_{e x}=280 \mathrm{~nm}\right)$ und zum Teil auf Energietransfer vom Tryptophan zurückgeführt. In Untersuchungen mit mutierten ras G-Proteinen, in denen gezielt an einer Stelle der Aminosäurensequenz Tryptophan durch Phenylalanin ersetzt wurde, konnte Energietransfer vom Tryptophan auf das mantGTP nachgewiesen werden [62]. Auch Experimente mit Transducin liefern Hinweise auf Energietransfer vom Tryptophan auf GTP [63]. Weil der Energietransfer aber stark von der genauen Konformation des Proteins und insbesondere der Bindungsstelle für das GTP abhängt, kann der Einfluß des Tryptophans beim Rab3A nur vermutet werden, da keine genauen Daten zur Struktur bekannt sind.

Für die Proteine, bei denen der Energietransfer nachgewiesen wurde, lagen detaillierte Informationen zur Konformation aus Kristalluntersuchungen vor. Mit Hilfe dieser Daten und dem Vergleich mit gezielt mutierten Proteinen konnte das Verhalten der Fluoreszenz konsistent gedeutet werden.

Fehlen diese Strukturdaten können aus dem Verhalten der Fluoreszenz Rückschlüsse auf die Umgebung der Bindungsstelle gezogen werden. Insbesondere die Unterschiede zwischen mantGTP und mantGDP können Hinweise auf die Dynamik des Proteins bei Aktivierung liefern. Hier gibt es kein einheitliches Bild; es wurden verschiedene G-Proteine untersucht und sowohl keine [57], kleine — die oben erwähnten 10\% [57] — oder große [60] Unterschiede zwischen der mantGTP und mantGDP Fluoreszenz gefunden.

${ }^{4} \mathrm{~N}-$ Methyl, 2'-O-Anthranilolyl-Guanosin 5'-O-Thiotriphosphat 


\begin{tabular}{|c|r|r|r|}
\hline & GTP & mantGTP & Rab3A.mantGTP \\
\hline$A_{1}$ & 0.5 & 0.33 & 6.66 \\
$A_{2}$ & $9.5 \cdot 10^{-3}$ & 0.25 & 7.82 \\
$\tau_{1}[\mathrm{~ns}]$ & $0.26 \pm 0.01$ & $5.4 \pm 0.2$ & $4.38 \pm 0.06$ \\
$\tau_{2}[\mathrm{~ns}]$ & 2 & 2.2 & $2.0 \pm 0.3$ \\
$\chi^{2}$ & 0.16 & 0.31 & 0.30 \\
\hline
\end{tabular}

Tabelle 2.2: Ergebnisse der zweifach exponentiellen Fits an die Zeitverläufe der Substanzen.

\begin{tabular}{|c|r|r|r|}
\hline & Küvette & mantGTP & Rab3A·mantGTP \\
\hline$A$ & $0.103 \pm 5 \cdot 10^{-3}$ & $0.50 \pm 0.01$ & $12.2 \pm 0.3$ \\
$\tau$ [ns] & $0.92 \pm 0.02$ & $4.7 \pm 0.06$ & $3.86 \pm 0.04$ \\
$\chi^{2}$ & 1.2 & 0.50 & 0.56 \\
\hline
\end{tabular}

Tabelle 2.3: Ergebnisse der einfach exponentiellen Fits an die Zeitverläufe der Substanzen.

\subsubsection{Die Fluoreszenzlebensdauern}

Die hier gemessenen Fluoreszenzlebensdauern der einzelnen Substanzen sind in Tabelle 2.2 und 2.3 zusammengefaßt.

Hazlett et. al. [64] haben Fluoreszenzlebensdauern und Anisotropien von mantGTP allein und bei der Bindung an verschiedene $\mathrm{p} 21^{\text {ras }}$ Proteine mit modulierter Anregung $\left(\lambda_{e x}=351 \mathrm{~nm}\right)$ und phasensensitiver Detektion gemessen. Aufgrund dieser Meßmethode wurden alle Daten im Frequenzraum analysiert; als Modell zur Bestimmung der Fluoreszenzlebensdauer wurde einfach-exponentielles Abklingen benutzt. Zum Vergleich wurden die hier gemessenen Abklingkurven von mantGTP und Rab3A-mantGTP durch einen einfach-exponentiellen Zerfall angefittet. Dabei ergab sich ein $\chi^{2}$-Wert, der etwa doppelt so groß ist wie bei den Fits mit zweifachexponentiellem Zerfall.

Die Ergebnisse sind in Tabelle 2.3 angegeben. Der Wert von $4.7 \mathrm{~ns}$ für das mantGTP weicht etwas vom Wert von Hazlett ab, der für freies mantGTP in wässriger Lösung bei $5{ }^{\circ} \mathrm{C}$ eine Lebensdauer von 4.22 ns angibt. Angesichts der Tatsache, daß die Werte mit völlig unterschiedlichen Meßverfahren unter etwas anderen Bedingungen (Lösungsmittel und Temperatur) gewonnen wurden, ist die Differenz zwischen den Werten nicht erstaunlich.

Beachtet werden sollte auch der Unterschied zwischen den Werten in Tabelle 2.2 und 2.3, der den Einfluß des Modells, das an die Daten angepaßt wird, verdeutlicht. Hier wird die Schwierigkeit klar, das richtige Modell zu wählen, in Fällen, wo die Vorgänge so komplex sind, daß kein Modell aus der Physik heraus gerechtfertigt werden kann. Auch Lacowicz [65] weist darauf hin, daß die bloße Übereinstimmung eines Modells mit den Daten noch nicht bedeutet, daß die Parameter des 
Modells eine physikalische Bedeutung haben. So sollten die Werte für $\tau$ nicht mit den mittleren Lebensdauern eines Zustands im mantGTP identifiziert werden.

Unabhängig vom Modell liegen die Werte für Rab3A-mantGTP unter denen für mantGTP. Dies steht im Gegensatz zu den Messungen von Hazlett, wo ein Anstieg der Fluoreszenzlebensdauer auf $8-9$ ns abhängig vom Protein beobachtet wurde.

\subsubsection{Die Ratenkonstante für die Spaltung des Rab3A-mantGTP Komplexes}

Für Rab3A ist die Ratenkonstante für die Spaltung des Rab3A-mantGTP Komplexes bisher nicht gemessen worden. Der hier bestimmte Wert für die Spaltung des Rab3A-mantGTP Komplexes von $k=9.3 \cdot 10^{-4} \mathrm{~s}^{-1}$ liegt in derselben Größenordnung wie Werte, die für p2 $1^{\text {ras }}$ Proteine (zwischen 1.6 und $4 \cdot 10^{-4} \mathrm{~s}^{-1}[57,66]$ ) und $\mathrm{G}_{o}$ (ca. $\left.3 \cdot 10^{-3} \mathrm{~s}^{-1}[67]\right)$ angegeben wurden.

\subsubsection{Nachweisgrenzen}

Die Messungen wurden alle mit jeweils $100 \mu$ l Lösung durchgeführt. Tatsächlich vom Laserstrahl angeregt wurden aber nur etwa $0.5 \mu \mathrm{l}$, d. h. das Probenvolumen könnte ohne Signalverlust auf $0.5 \mu \mathrm{l}$ verkleinert werden. In $0.5 \mu \mathrm{l}$ befinden sich bei einer Konzentration von $10 \mu \mathrm{M}$ etwa $3 \cdot 10^{12}$ Moleküle.

Die Eigenfluoreszenz der Küvette und die Schwankungen des Lasersystems stellen die größten Fehlerquellen in diesem Experiment dar. Wenn die Laserleistung simultan mitgemessen würde und die Küvette durch eine mit geringerer Eigenfluoreszenz ersetzt würde, könnte mit deutlich kleineren Konzentrationen gearbeitet werden.

\subsection{Zusammenfassung}

In diesem Kapitel wurde gezeigt, wie mit Hilfe zeitaufgelöster Spektroskopie chemische Reaktionen nachgewiesen werden können. Die Bindung konnte sowohl an einer Änderung der Fluoreszenzintensität als auch der Lebensdauer erkannt werden. Dabei hat die Messung der Fluoreszenzlebensdauer gegenüber einer Intensitätsmessung den Vorteil, daß sie unabhängig von der Konzentration der Substanz ist. Außerdem wurde die Ratenkonstante für die Spaltung des Rab3A-mantGTP Komplexes erstmals bestimmt.

Im Unterschied zu früheren Messungen zum mantGTP, die mit Photomultipliern und scannenden Monochromatoren durchgeführt wurden, konnte das gesamte Emissionsspektrum simultan mit einer intensivierten CCD-Kamera aufgenommen werden. Durch sehr kurze Verschlußzeiten des Bildverstärkers, der synchron zu einem modengekoppelten ps-Laser mit $38 \mathrm{MHz}$ getriggert wurde, konnte die Fluoreszenzlebensdauer direkt gemessen werden. 
Um mehr über die Dynamik der G-Proteine zu erfahren, wäre es sinnvoll, simultan die mantGTP- und die Eigenfluoreszenz der Proteine aufzunehmen. Möglichst noch mit verschiedenen Anregungswellenlängen, mit denen man dann wahlweise Tryptophan, Tyrosin und Phenylalanin anregen kann.

Der hier benutzte Aufbau könnte zu einem Screening-System für Moleküle, die an die GTP Bindungsstelle eines G-Proteins binden, erweitert werden, indem auf die spektrale Auflösung verzichtet wird und stattdessen die Fluoreszenz bildgebend aufgenommen wird. Dann könnten viele Reaktionsgefäße (z. B. eine Mikrotiterplatte) gleichzeitig beobachtet werden. Durch Lichtleiter zur Beleuchtung und Detektion ließe sich ein sehr kompakter Aufbau realisieren, bei dem auch kleine Substanzmengen untersucht werden können.

Eine Messung würde so ablaufen, daß zunächst mantGTP und das G-Protein in gleichen Konzentrationen in die Gefäße gegeben werden, so daß das mantGTP an das G-Protein bindet. Dann könnte in einem zweiten Schritt in jedes der Gefäße eine andere Testsubstanz im Überschuß hinzugegeben werden. Kommt es zur Verdrängung des mantGTP, sollte dies an einer Änderung der Fluoreszenz zu erkennen sein. Es sind keine Waschschritte und keine Immobilisierung erforderlich, sofern die Testsubstanzen nicht selbst fluoreszieren. Dieses Verfahren wäre deutlich einfacher als sogenannte Enzym-Assays. 


\section{Kapitel 3}

\section{Parallelprocessing in der Zweiphotonenmikroskopie}

Optische Mikroskopie zählt auch heute noch zu einem der wichtigsten Untersuchungsverfahren in der Biologie, obwohl inzwischen mit elektronenmikroskopischen und nahfeldmikroskopischen Verfahren bessere Ortsauflösung erreicht wird.

Der Grund hierfür liegt darin, daß die optische Mikroskopie wichtige Vorteile gegenüber den anderen Verfahren hat: Es können mit relativ geringem Aufwand bei der Probenvorbereitung lebende Objekte betrachtet werden. Die optische Fernfeldmikroskopie ist schonend, so daß in gewissen Grenzen physiologische Vorgänge bei lebenden Zellen beobachtet werden können, ohne die Zellen dabei zu beschädigen. Es können nicht nur Oberflächen, sondern auch Strukturen aus dem Volumen abgebildet werden. Die Fluoreszenzmikroskopie bietet durch sehr spezifische Anfärbetechniken, die sich in den letzten Jahren stark weiterentwickelt haben und auch jetzt noch verbessert werden, hervorragende Kontrastmöglichkeiten. Mit empfindlichen Detektoren können auch Spezies, die nur in geringen Konzentrationen (bis hin zu einzelnen Molekülen) vorliegen, nachgewiesen werden.

Spektroskopische Merkmale der Farbstoffe können dazu benutzt werden, nicht nur die Strukturen des Objekts zu visualisieren, sondern auch Informationen über die Umgebung der Farbstoffmoleküle zu liefern. So gibt es z. B. spezielle Farbstoffe, die auf den $\mathrm{pH}$-Wert oder die $\mathrm{Ca}^{2+}$-Konzentration sensitiv sind.

Meist wird heute nur die Intensität der Fluoreszenz oder das Spektrum aufgenommen. Die Fluoreszenzlebendauer kann jedoch zusätzliche Merkmale liefern, so konnten z. B. Membran, Cytoplasma, Nucleoli und Zellkern einer Zelle, die mit den Farbstoffen DiO und EtBr gefärbt wurde, anhand der Fluoreszenzlebensdauern voneinander unterschieden werden [71].

Ein Nachteil der Epifluoreszenzmikroskopie ist, daß nur dünne Objekte kontrastreiche Bilder liefern, da das gesamte Objekt zur Fluoreszenz angeregt wird. Die Fluoreszenz der Teile des Objekts, die nicht in der Fokalebene des Objektivs liegen, wird unscharf abgebildet und verteilt sich diffus über das Bild. Hochauflösende Bilder dicker Objekte können nur aufgenommen werden, wenn das Objekt in dünne Schichten geschnitten wird, die dann nacheinander untersucht werden. Die- 
ser Nachteil tritt bei Laserscanningmikroskopen (LSM), mit denen dreidimensionale Bilder von bis zu einigen hundert Mikrometer dicken Objekten aufgenommen werden können, nicht auf. Es konnte z. B. intaktes Nervengewebe mit einem LSM untersucht werden [72].

In diesem Kapitel wird ein LSM beschrieben, mit dem sowohl dreidimensionale Bilder der Fluoreszenzintensität als auch der Lebensdauer aufgenommen werden können. Im Gegensatz zu üblichen Mikroskopen wird die Probe hier mit mehreren Strahlen simultan abgerastert, um die Scangeschwindigkeit zu erhöhen. Die Aufteilung des Laserstrahls in viele Teilstrahlen und die simultane Detektion der Fluoreszenz stellen wesentliche Unterschiede und Neuerungen des hier beschriebenen Aufbaus gegenüber anderen LSM dar.

Im ersten Abschnitt wird die Funktionsweise eines LSM allgemein beschrieben. Daran schließt sich ein Abschnitt an, in dem das in dieser Arbeit aufgebaute LSM dargestellt wird (3.2). Im Abschnitt 3.3 werden die Messungen, die zur Charakterisierung des Mikroskops durchgeführt wurden, beschrieben. Das Kapitel schließt mit einer Diskussion (3.4) und einer Zusammenfassung (3.5).

\subsection{Laserscanningmikroskopie}

Das Prinzip eines LSM ist in Abbildung 3.1 dargestellt. Der Laserstrahl wird aufgeweitet und über einen Umlenkspiegel in das Mikroskopobjektiv gelenkt. Das Objektiv fokussiert den Strahl in das Objekt hinein, wo Farbstoffmoleküle, mit denen das Objekt angefärbt wurde, oder Substanzen, die natürlich im Objekt vorkommen, zur Fluoreszenz angeregt werden. Das Fluoreszenzlicht wird mit demselben Objektiv wieder aufgenommen und auf einen Detektor abgebildet. Das Objekt wird punktweise vermessen, indem entweder der Strahl oder das Objekt rasterartig bewegt wird.

Die Fähigkeit optische Schnitte durch das Objekt zu legen, die den Hauptvorteil gegenüber der Epifluoreszenzmikroskopie darstellt, kann auf zwei Arten realisiert werden:

1. Konfokales LSM: Eine Lochblende vor dem Detektor sorgt dafür, daß nur die Fluoreszenz aus dem Fokus des Laserstrahls nachgewiesen wird. Die Fluoreszenz, die in den Ebenen unterhalb und oberhalb der Brennebene des Objektivs entsteht, wird defokussiert auf die Lochblende abgebildet und von ihr aufgefangen. Dieser Mikroskoptyp ist in Abbildung 3.1 dargestellt.

2. Multiphotonen LSM: Die Farbstoffmoleküle werden nur mit zwei oder mehr Photonen $(n \geq 2)$ zur Fluoreszenz angeregt. Diese Art der Anregung hängt stark von der Intensität der Laserstrahlung ab $\left(\sim I^{n}\right)$ und findet daher nur im Laserfokus effizient statt. Da die Anregung schon auf ein kleines Volumen beschränkt ist, ist die Lochblende vor dem Detektor zur Unterdrückung ungewünschter Fluoreszenz nicht nötig. 


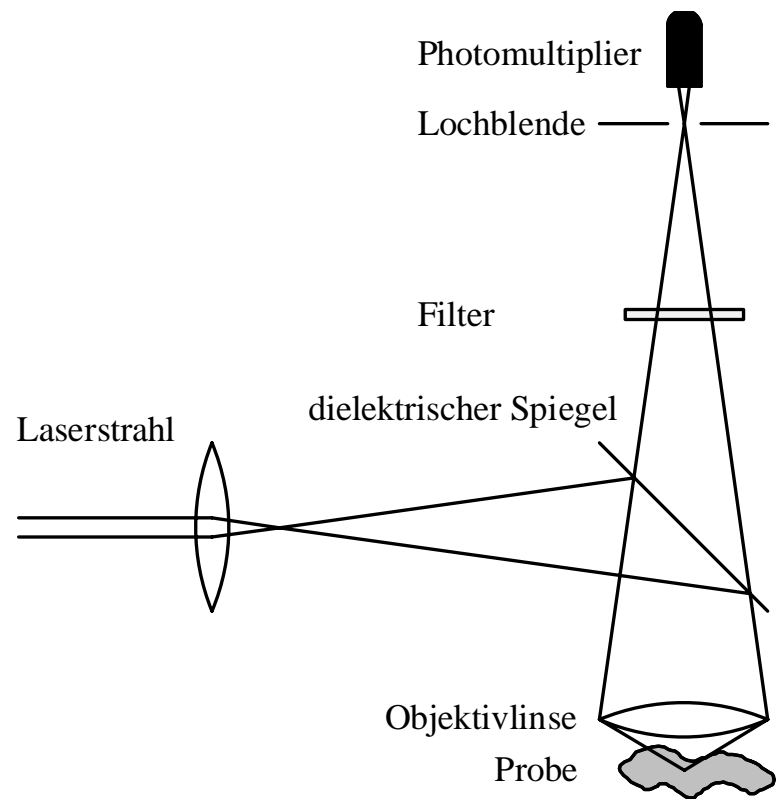

Abbildung 3.1: Prinzip eines Laserscanningmikroskops.

Diese beiden Methoden werden in den folgenden Abschnitten näher dargestellt und miteinander verglichen. Einen Überblick über die Laserscanningmikroskopie findet man in [73].

\subsubsection{Konfokale LSM}

Ein wichtiger Parameter eines Mikroskops ist die Ortsauflösung. Da es sich bei der Laserscanningmikroskopie um eine Fernfeldtechnik handelt, sind hier, genau wie bei der klassischen Mikroskopie, die numerische Apertur des Objektivs NA und die Wellenlänge des Lichts $\lambda$ die entscheidenden Parameter. Die laterale Auflösung eines konfokalen Mikroskops ist durch

$$
\Delta r=\frac{0.8 \lambda}{2 \mathrm{NA}}
$$

gegeben [73].

Die axiale Auflösung hängt von der Größe der Lochblende vor dem Detektor ab. Eine untere Grenze stellt aber die Schärfentiefe des Objektivs dar [74, 75]:

$$
\Delta z=\frac{1.4 \eta \lambda}{\mathrm{NA}^{2}}
$$

Wobei $\eta$ der Brechungsindex im Objekt ist. Typische Werte für die Wellenlänge und die numerische Apertur sind: $\lambda \approx 500 \mathrm{~nm}$ (Argon-Ionen-Laser), NA $=1.4$ (Öl-Immersions Objektiv). Damit läßt sich theoretisch eine Auflösung von $0.14 \mu \mathrm{m}$ lateral und $0.36 \mu \mathrm{m}$ axial erreichen; praktisch wird meist eine Auflösung von etwa $0.3 \mu \mathrm{m}$ lateral, $0.7 \mu \mathrm{m}$ axial erreicht. 
Ein Nachteil der konfokalen Mikroskopie ist, daß das gesamte vom Laser durchstrahlte Volumen zur Fluoreszenz angeregt wird, aber nur ein kleiner Bruchteil der Fluoreszenz genutzt wird. Dies hat einige unerwünschte Konsequenzen.

- Es führt zu einem relativ schlechten Signal/Rausch-Verhältnis, da das Signal auf einem hohen Pegel von Fluoreszenz aus anderen Tiefen des Objekts detektiert werden muß. Erschwert wird die störungsfreie Detektion der Fluoreszenz auch noch dadurch, daß sich die Wellenlängen von Laserstrahlung und Fluoreszenz meist nur wenig voneinander unterscheiden, so daß Filter mit sehr steilen Kanten nötig sind, um zwar das Laserstreulicht, nicht aber die Fluoreszenz zu unterdrücken.

- Wird die Fluoreszenz aus dem Fokus auf dem Weg zum Detektor im Objekt gestreut, trägt sie nicht mehr zum Signal bei, da sie nicht scharf auf die Lochblende abgebildet wird.

- Der Farbstoff wird auch außerhalb des Fokus ausgebleicht. Dies hat einerseits zur Folge, daß bei Anwendungen, wo das Ausbleichen die Meßzeit beschränkt, nur eine begrenzte Anzahl von Schnitten in verschiedenen Tiefen aufgenommen werden können. Denn beim Abrastern einer Ebene werden auch die Teile des Objekts in anderen Tiefen ausgebleicht. Andererseits erhöht es die Schädigungsrate des Objekts. Die genauen Vorgänge bei der Schädigung von Organismen durch Licht sind noch nicht verstanden. Eine Ursache scheint jedoch die Bildung von $\mathrm{O}_{2}\left({ }^{1} \Delta\right)$ aus Grundzustands $\mathrm{O}_{2}$ durch Quenching der Triplet-Zustände des Farbstoffs zu sein. Die angeregten Sauerstoffmoleküle sind sehr reaktiv und führen wahrscheinlich zur Schädigung des Farbstoffs und der Probe. Durch Entfernung des Sauerstoffs bei fixierten (toten) Zellen [76] oder die Zugabe von Substanzen, die den SingletSauerstoff quenchen [77], konnte das Ausbleichen bzw. die Schädigung deutlich verlangsamt werden.

- Da die Laserstrahlung entlang des gesamten Strahls absorbiert wird, ist die Eindringtiefe bei stark angefärbten Präparaten nur begrenzt.

Diese Nachteile treten bei der Zweiphotonenmikroskopie nicht oder nur in schwächerer Form auf.

\subsubsection{Zweiphotonen LSM}

Zum ersten Mal demonstriert wurde die Zweiphotonenmikroskopie von Denk et. al. [78]. Im Unterschied zum konfokalen LSM werden die Farbstoffmoleküle bei einem Zweiphotonenmikroskop nur durch Absorption von zwei Photonen angeregt. Die Anregungswahrscheinlichkeit $p$ eines Moleküls ist für Intensitäten unterhalb der Sättigungsintensität quadratisch von der Laserintensität $I$ abhängig:

$$
p=\sigma\left(\frac{I}{h \nu}\right)^{2} t
$$


Wobei $\sigma$ der Querschnitt für Zweiphotonenabsorption, $\nu$ die Frequenz und $t$ die Pulsdauer des Lasers ist. Es sind bisher wenige Querschnitte für Zweiphotonenanregung gemessen worden, doch sie liegen in der Größenordung von $\sigma \approx 10^{-50} \mathrm{~cm}^{4} \mathrm{~s}$. Die Intensität ist proportional zur Anzahl der Photonen in einem Puls $N_{p h}$ und umgekehrt proportional zur Fläche des Strahls $A$ und der Pulsdauer $t$ :

$$
I=\frac{h \nu N_{p h}}{A t} .
$$

Nimmt man eine homogene Verteilung der Farbstoffmoleküle mit einer Dichte $n_{F}$ an, so ist die Anzahl der in einer Tiefe $z$ in einer Schicht der Dicke dz angeregten Moleküle gleich

$$
N_{a b s}(z)=n_{F} V p=n_{F} A(z) \mathrm{dz} p=n_{F} \sigma \frac{N_{p h}^{2}}{A(z) t} \mathrm{dz} .
$$

Das heißt, die Absorption ist umgekehrt proportional zur Strahlfläche. Daher findet die Anregung bei der Zweiphotonenmikroskopie im wesentlichen im Fokus statt. Eine zweite wichtige Abhängigkeit, die charakteristisch für Zweiphotonenabsorption ist, kann man in Gleichung (3.5) erkennen: Bei konstanter Pulsenergie $\left(\sim N_{p h}\right)$ ist die Absorption umgekehrt proportional zur Pulsdauer.

\subsubsection{Abschätzung der Signalstärke}

In diesem Abschnitt soll anhand von Gleichung (3.5) die Signalstärke in einem Zweiphotonenmikroskop abgeschätzt werden, um einerseits einen Überblick über die Größenordnungen der einzelnen Parameter zu geben, und andererseits die Zeit, die zur Aufnahme eines Bildes nötig ist, zu berechnen.

\section{Einfluß der Anregung}

Nimmt man an, daß der Fokus beugungsbegrenzt ist und mit einem Objektiv mit numerischer Apertur NA erzeugt wird, kann man die Fokusfläche abschätzen:

$$
A=2 \pi r^{2}=2 \pi\left(\frac{0.8 \lambda}{2 \mathrm{NA}}\right)^{2} \approx \frac{\lambda^{2}}{\mathrm{NA}^{2}}
$$

Für dz kann man

$$
\mathrm{dz} \approx \frac{2 \lambda}{\mathrm{NA}^{2}}
$$

ansetzen [73]. Damit erhält man für die Zahl der pro Laserpuls angeregten Moleküle

$$
N_{a b s}=2 n_{F} \sigma \frac{N_{p h}^{2}}{\lambda t}
$$

Da meist Laser mit hoher Repetitionsrate $f$ (in $\mathrm{Hz}$ ) verwendet werden, ist es praktischer, statt der Photonenzahl pro Puls die Durchschnittsleistung $P=h \nu N_{p h} f$ zu benutzen. Man bekommt damit für den Fluoreszenzphotonenfluß

$$
\Phi=\gamma N_{a b s} f=\frac{2 n_{F} \gamma \sigma \lambda P^{2}}{h^{2} c^{2} f t},
$$


wobei $\gamma$ für die Quanteneffizienz für Fluoreszenzemission des Farbstoffs steht.

Typische Werte für die einzelnen Parameter sind: Farbstoffkonzentration $1 \mu \mathrm{M}$, das entspricht einer Dichte von $n_{F}=3 \cdot 10^{16} \mathrm{~cm}^{-3}, \gamma=1, P=1 \mathrm{~mW}, f=76 \mathrm{MHz}$, $t=50$ fs. Damit erhält man einen Fluoreszenzphotonenfluß von $\Phi \approx 3 \cdot 10^{7} \mathrm{~s}^{-1}$.

Offenbar kann man $\Phi$ durch Erhöhung der Durchschnittsleistung steigern. Bei zu hohen Werten kommt es allerdings zu unerwünschten Effekten, wie Zellschädigung, Selbstfokussierung und Plasmabildung. Diese Effekte setzen der nutzbaren Leistung eine obere Grenze. Einen konkreten Wert für diese Grenze anzugeben, ist jedoch schwer, da insbesondere die Schädigung von lebenden Zellen noch kaum verstanden ist. Die oben angenommenen $1 \mathrm{~mW}$ geben die Erfahrung von König et. al. [79] wieder, wonach eine Leistung von $1 \mathrm{~mW}$ bei $\lambda=700-800 \mathrm{~nm}$ und $t=150 \mathrm{fs}$ verwendet werden konnte, ohne daß Veränderungen im Stoffwechsel der dort untersuchten Zellen nachgewiesen werden konnten.

Bei Leistungen von $2-3 \mathrm{~mW}$ wurden Veränderungen in den Mitochondrien nachgewiesen und die Zellteilungsrate war reduziert. Wurden Leistungen von $\geq$ $6 \mathrm{~mW}$ benutzt, waren $100 \%$ der Zellen nicht mehr fähig, sich zu teilen; Leistungen von $\geq 10 \mathrm{~mW}$ führten zu sofortigem Tod und Fragmentation der Zellen.

Die gesamte Lichtenergie, mit der die Zellen bestrahlt werden, hat keinen Einfluß auf die Schädigungsrate, da Zellen z. B. mehr als hundertmal mit $1 \mathrm{~mW}$ untersucht werden konnten, ohne daß Veränderungen auftraten, während sie bei $10 \mathrm{~mW}$ schon während des ersten Scans abstarben. Bisher ist noch nicht geklärt, ob die Durchschnittsleistung, die Pulsleistung oder die Pulsintensität die Schädigungsrate bestimmen. Daher ist es schwer, diese Ergebnisse auf Experimente mit anderen Parametern (Pulsdauer, Fokussierung) zu übertragen.

Eine andere Möglichkeit, das Signal zu steigern, ist eine Erhöhung der Farbstoffkonzentration. Diese Möglichkeit ist allerdings ebenfalls begrenzt, da die meisten Farbstoffe giftig sind und in hohen Konzentrationen die Zellen schädigen.

\section{Einfluß der Detektion}

Das gemessene Signal $S$ hängt von der Sammeleffizienz der Optik $\epsilon$, der Nachweiswahrscheinlichkeit $q$ und der Integrationszeit $t_{\text {det }}$ des Detektors ab.

$$
S=\Phi \epsilon q t_{\text {det }}
$$

Da für den Nachweis der Fluoreszenz dasselbe Objektiv wie zum Fokussieren verwendet wird, kann die Lichtsammeleffizienz $\epsilon$ aus der numerischen Apertur des Objektivs berechnet werden. $\epsilon$ ist durch das Verhältnis des Raumwinkels $\Omega$, der vom Objektiv aufgenommen wird, zum vollen Raumwinkel gegeben. Ist $\alpha$ der halbe Akzeptanzwinkel des Objektivs, so gilt für $\Omega$ :

$$
\Omega=2 \pi(1-\cos (\alpha))
$$

Mit der Definition der numerischen Apertur NA $=\eta \sin (\alpha)$ ergibt sich daraus für die Sammeleffizienz:

$$
\epsilon=\frac{\Omega}{4 \pi}=\frac{1-\cos (\alpha)}{2}=\frac{1-\sqrt{1-\sin ^{2}(\alpha)}}{2}=\frac{1-\sqrt{1-(\mathrm{NA} / \eta)^{2}}}{2}
$$


Für eine kleine numerische Apertur $(\mathrm{NA} / \eta \ll 1)$ bekommt man daraus die bekannte Formel:

$$
\epsilon=\frac{(\mathrm{NA} / \eta)^{2}}{4}
$$

Für eine hohe numerische Apertur $(\mathrm{NA} / \eta \approx 1)$ kann man Gleichung (3.12) so nähern:

$$
\epsilon=\frac{1}{2}-\sqrt{\frac{\Delta}{2}},
$$

mit $\Delta=1-\mathrm{NA} / \eta$. Das heißt insbesondere, daß die Effizienz nicht mehr quadratisch mit der numerischen Apertur ansteigt. Für das hier verwendete Objektiv bekommt man $\epsilon=0.3$.

Eine genauere Diskussion der Nachweiswahrscheinlichkeit, in der die Art der Detektion berücksichtigt wird, befindet sich in Abschnitt 3.4. Für diese Abschätzung soll zunächst ein Wert von $\epsilon q=0.01$ angenommen werden.

Um ein Signal von $S=10-100$ Photonen aufzunehmen, was für brauchbare Bilder etwa die minimale Anzahl darstellt, sind demnach $100 \mu$ s Integrationszeit pro Punkt nötig.

Typischerweise besteht ein Scan aus ca. $300 \times 300$ Bildpunkten. Für ein komplettes zweidimensionales Bild müssen also $\approx 10^{5}$ Punkte aufgenommen werden, d. h. die Meßzeit für ein Bild beträgt $10 \mathrm{~s}$.

Wie die Meßgeschwindigkeit gesteigert werden kann, wird im Abschnitt 3.1.3 beschrieben.

\subsubsection{Die Auflösung bei der Zweiphotonen-LSM}

Die nichtlineare Absorption erzeugt ein dreidimensional begrenztes Anregungsvolumen und legt damit die Auflösung des Mikroskops fest. Geht man von einem beugungsbegrenzten Strahl aus, kann man die Auflösung berechnen. Man erhält dabei Werte, die mit der Auflösung eines konfokalen Mikroskops, das mit der halben Wellenlänge wie das Zweiphotonenmikroskop arbeitet, vergleichbar sind (siehe Z. B. [73]).

Eine weitere Erhöhung der Auflösung ist - abgesehen von einer Erniedrigung der Wellenlänge - durch Erhöhung der numerischen Apertur oder durch den Einsatz anderer nichtlinearer Techniken möglich.

Vergrößerung der Apertur Die numerische Apertur der verwendeten Objektive stellt ein Maximum dar. Die effektive numerische Apertur kann aber durch die gleichzeitige Verwendung von mehreren Objektiven, deren Brennpunkte sich überlagern, gesteigert werden. Verwendet man zwei Objektive, die mit einem Winkel von $180^{\circ}$ gegeinander gerichtet sind, spricht man von 4Pi-Mikroskopie [80], bei zwei oder mehr Objektiven mit anderen Winkeln zueinander von $\vartheta$-Mikroskopie [81]. 
Ausnutzung nichtlinearer Effekte: Durch die Nichtlinearität bei der Zweiphotonenanregung erreicht man eine Auflösung, die etwa doppelt so gut ist, wie es nach der Beugungsbegrenzung bei der verwendeten Laserwellenlänge zu erwarten wäre. Auf ähnliche Weise erhöht Dreiphotonenanregung die Auflösung. Andere nichtlineare Effekte, die zur Erhöhung der Auflösung vorgeschlagen wurden, sind das Ausbleichen des Grundzustands [82] oder Fluoreszenzlöschung durch stimulierte Emission [83]. Dadurch, daß diese Prozesse gesättigt werden können, sind aufgrund von Rechnungen trotz beugungsbegrenzter Laserstrahlen sehr starke Gradienten der Fluoreszenzemission zu erwarten.

\subsubsection{Vorteile der größeren Anregungswellenlänge:}

Üblicherweise werden bei der Zweiphotonenmikroskopie gepulste Laser im nahen Infrarot $(\lambda \approx 700-1200 \mathrm{~nm})$ eingesetzt. Dieser Wellenlängenbereich hat gegenüber den kürzeren Wellenlängen, die bei der konfokalen Mikroskopie verwendet werden, einige Vorteile:

- Die Streuung und Absorption im Gewebe ist geringer. Daher ist die Tiefe, in der noch Bilder aufgenommen werden können, größer als bei der konfokalen Mikroskopie. Es spielt auch keine Rolle, ob das Fluoreszenzlicht auf dem Weg zum Detektor gestreut wird, da das Anregungsvolumen die 3DAuflösung festlegt.

- Da nur im Fokus Laserenergie absorbiert wird, ist das Ausbleichen sowie die Schädigung durch das Licht auf die Fokalregion beschränkt. Dies ermöglicht es, lebende Organismen deutlich länger (>60fach [84]) als bei der konfokalen Mikroskopie zu beobachten.

- Die Wellenlänge der Fluoreszenz unterscheidet sich stark von der Anregungswellenlänge. Daher ist es leicht, das Laserstreulicht zu unterdrücken.

- Werden Wellenlängen im sichtbaren Spektralbereich zur Zweiphotonenanregung genutzt, können damit Zellbestandteile zur Eigenfluoreszenz angeregt werden, was sonst nur durch Bestrahlung mit UV-Licht, das die Zellen sehr stark schädigt, möglich ist.

Die verwendeten Laser liefern Pulse im Femto- bis wenige Pikosekundenbereich mit Repetitionsraten von typischerweise $80 \mathrm{MHz}{ }^{1}$ Hinderlich bei der Verbreitung der Zweiphotonenmikroskopie, trotz der Vorteile, die sie gegenüber der konfokalen Mikroskopie bietet, war bisher die Komplexität der fs-Laser. Durch die Entwicklung neuer, komplett festkörperbasierter Laser sind in den letzten Jahren die Voraussetzungen für eine weitere Verbreitung der Zweiphotonenmikroskopie geschaffen worden. Einen Überblick über neuere Festkörperlaser, die zum Einsatz in der Zweiphotonenmikroskopie geeignet sind, findet man in [86].

\footnotetext{
${ }^{1}$ Auch cw-Laser wurden in der Zweiphotonenmikroskopie verwendet [85].
} 


\subsubsection{Parallelprocessing}

Im Abschnitt 3.1.2.1 wurde abgeschätzt, daß etwa $10 \mathrm{~s}$ nötig sind, um ein Bild bei einer Laserleistung von $1 \mathrm{~mW}$ aufzunehmen. Diese Zeit ist zu groß, um schnelle physiologische Vorgänge beobachten zu können. Ein Beispiel ist die Untersuchung der Reizleitung in Nervenzellen [72]. Hier wurden die Vorteile der Zweiphotonenmikroskopie benutzt, um hochauflösende Bilder aus intaktem Nervengewebe zu erhalten. Andererseits verhinderte es die langsame Aufnahmegeschwindigkeit bei der Zweiphotonenmikroskopie, die Reizleitung bildgebend zu verfolgen. ${ }^{2}$ Gelingt es, die Aufnahmegeschwindigkeit zu steigern, stellt dies eine Erweiterung des Einsatzbereichs der Laserrastermikroskopie dar.

Eine Möglichkeit, die Bildaufnahmegeschwindigkeit zu steigern, liegt in einer effizienteren Ausnutzung des Laserlichts. Die Laser, die in der Zweiphotonenmikroskopie eingesetzt werden, liefern Durchschnittsleistungen im Bereich von $100-1000 \mathrm{~mW}$ - in die Probe fokusiert werden davon üblicherweise $1-10 \mathrm{~mW}$, d. h. 99\% der verfügbaren Laserleistung werden nicht genutzt. Man kann die Effizienz steigern, indem man den Laserstrahl in viele Teilstrahlen, die an unterschiedliche Orte der Probe fokussiert werden, aufteilt.

Das Prinzip der simultanen Verwendung vieler Strahlen ist in Abbildung 3.2 dargestellt. Die Probe wird dann nicht mit einem Strahl, sondern mit allen Teilstrahlen gleichzeitig abgerastert. Dabei werden die Bereiche so gewählt, daß jeder Teilstrahl ein anderes Gebiet des Objekts erfaßt. Die Daten der einzelnen Strahlen werden anschließend zu einem Gesamtbild kombiniert. Die Meßzeit sinkt proportional zur Anzahl der Teilstrahlen.

Die optimale Anzahl der Teilstrahlen bekommt man, wenn jeder Teilstrahl die maximal erlaubte Leistung hat, denn die Meßzeit ist umgekehrt proportional zum Quadrat der Leistung (dies folgt aus Gl. (3.9)). Eine Erhöhung der Anzahl der Strahlen reduziert die Meßzeit nur linear.

Die Erweiterung eines konventionellen Zweiphotonenmikroskops zum Vielstrahlmikroskop macht neben der Aufteilung des Strahls auch eine andere Detektion der Fluoreszenz nötig, da jetzt nicht mehr nur ein Signal sondern die Signale aller Teilstrahlen simultan aufgenommen werden müssen. Dies bedeutet insbesondere, daß Photomultiplier, die anderen Detektoren hinsichtlich des erreichten Signal/Rausch-Verhältnisses überlegen sind (siehe auch [73] Kapitel 12) und die bisher den Standard darstellen, nicht verwendet werden können.

In dieser Arbeit wird in den folgenden Abschnitten ein Zweiphotonenmikroskop beschrieben, bei dem der Strahl eines Ti:Sa-Lasers in 64 Teilstrahlen aufgespalten wird. Die Detektion erfolgt mit einer (bildverstärkten) CCD-Kamera. Der Bildverstärker ermöglicht es durch sehr kurze Verschlußzeiten, die Fluoreszenzlebensdauer zu messen.

\footnotetext{
${ }^{2}$ In der zitierten Arbeit wurde so verfahren, daß zunächst anhand eines langsam aufgenommen Bildes der interessante Bereich festgelegt wurde. Bei der Verfolgung der Reizleitung wurde dann eine Zeile in diesem Bereich mit maximaler Geschwindigkeit abgerastert, so daß nur Ortsprofile entlang dieser Zeile aufgenommen wurden.
} 

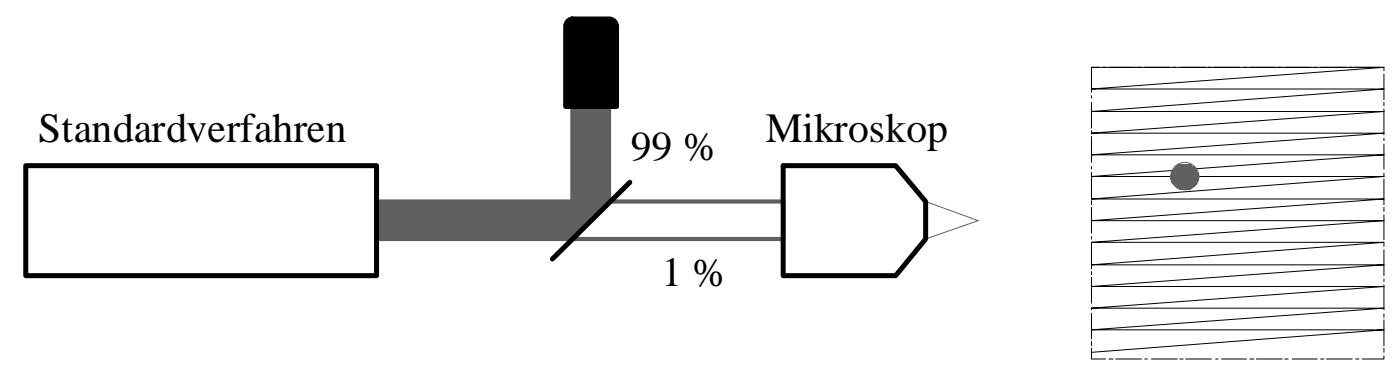

$$
\text { mit paralleler Rasterung }
$$

Mikroskop
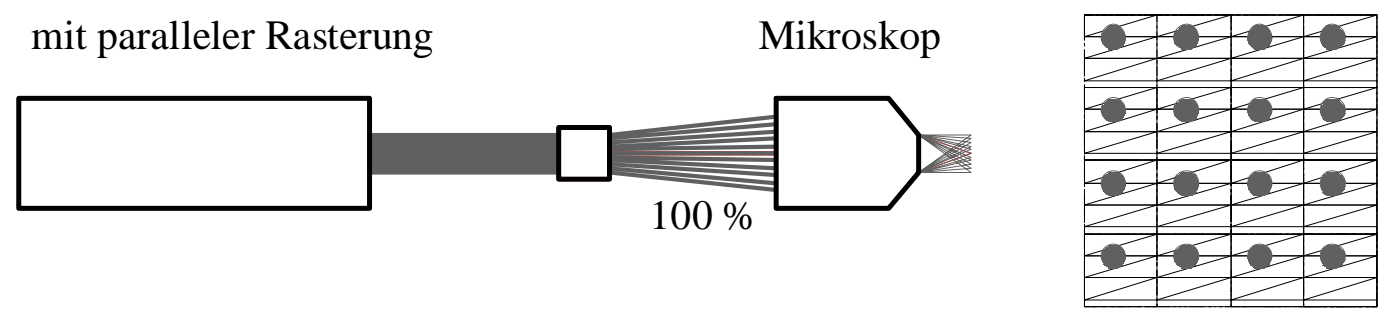

Abbildung 3.2: Die Erhöhung der Meßgeschwindigkeit durch Parallelprocessing.

\subsection{Der experimentelle Aufbau}

Abbildung 3.3 zeigt einen Überblick über den gesamten Aufbau des VielstrahlMikroskops, das aus vier Komponenten besteht. Als Strahlquelle dient ein Femtosekundenlaser, dessen Strahl im Strahlvervielfacher in mehrere Teilstrahlen aufgespalten wird. Die Laserstrahlen werden mit einem Mikroskopobjektiv in die Probe fokussiert, wo sie durch Zweiphotonenanregung Fluoreszenz auslösen, die dann von einem flächigen Detektor registriert wird. Die einzelnen Komponenten werden in den folgenden Abschnitten genauer beschrieben.

\subsubsection{Das Lasersystem}

In Abbildung 3.4 ist das Lasersystem dargestellt. Dazu gehört neben dem eigentlichen Laser ein Autokorrelator, ein Spektrumanalysator und eine Prismenstrecke zur Dispersionskompensation.

\subsubsection{Der fs-Oszillator}

Bei dem Laser handelt es sich um einen passiv modengekoppelten Titan-Saphir Femtosekundenlaser, der an der Universität Bielefeld gebaut wurde [87]. Gepumpt wird er mit 5 W Strahlung eines Argon-Ionenlasers (Coherent Innova 200) im Multiline Betrieb. Der Laser ist passiv modengekoppelt, d. h. in den Resonator sind Elemente eingebaut, die die Verluste im Resonator abhängig von der Intensität der Laserstrahlung machen. Hier sind dies ein Spalt vor dem Endspiegel (harte Blende) 


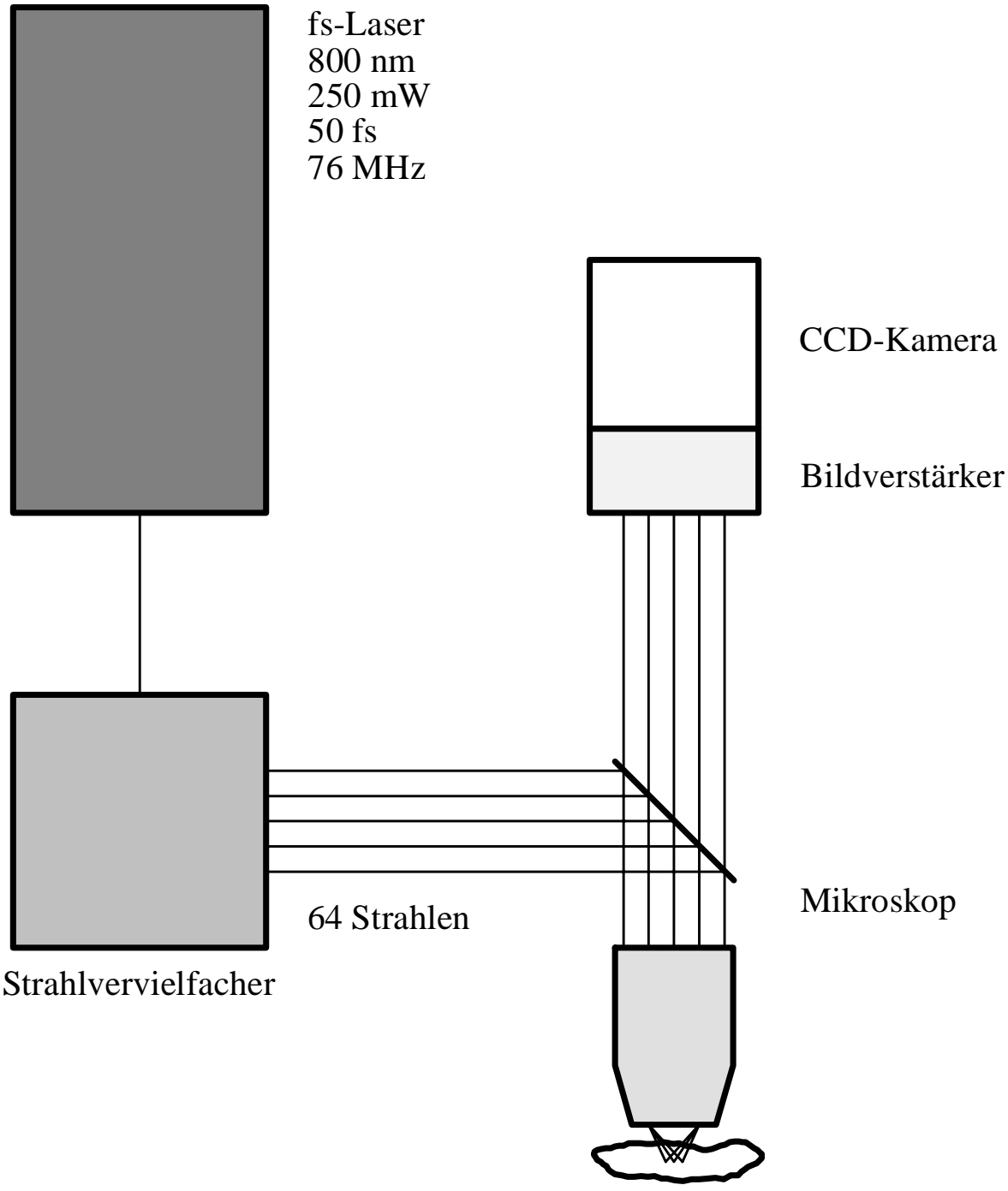

Abbildung 3.3: Überblick über den gesamten Aufbau zum Zweiphotonenmikroskop. Der Strahlengang ist nur schematisch gezeichnet. Die einzelnen Komponenten sind in den Abbildungen 3.4, 3.11 und 3.13 detaillierter dargestellt. 


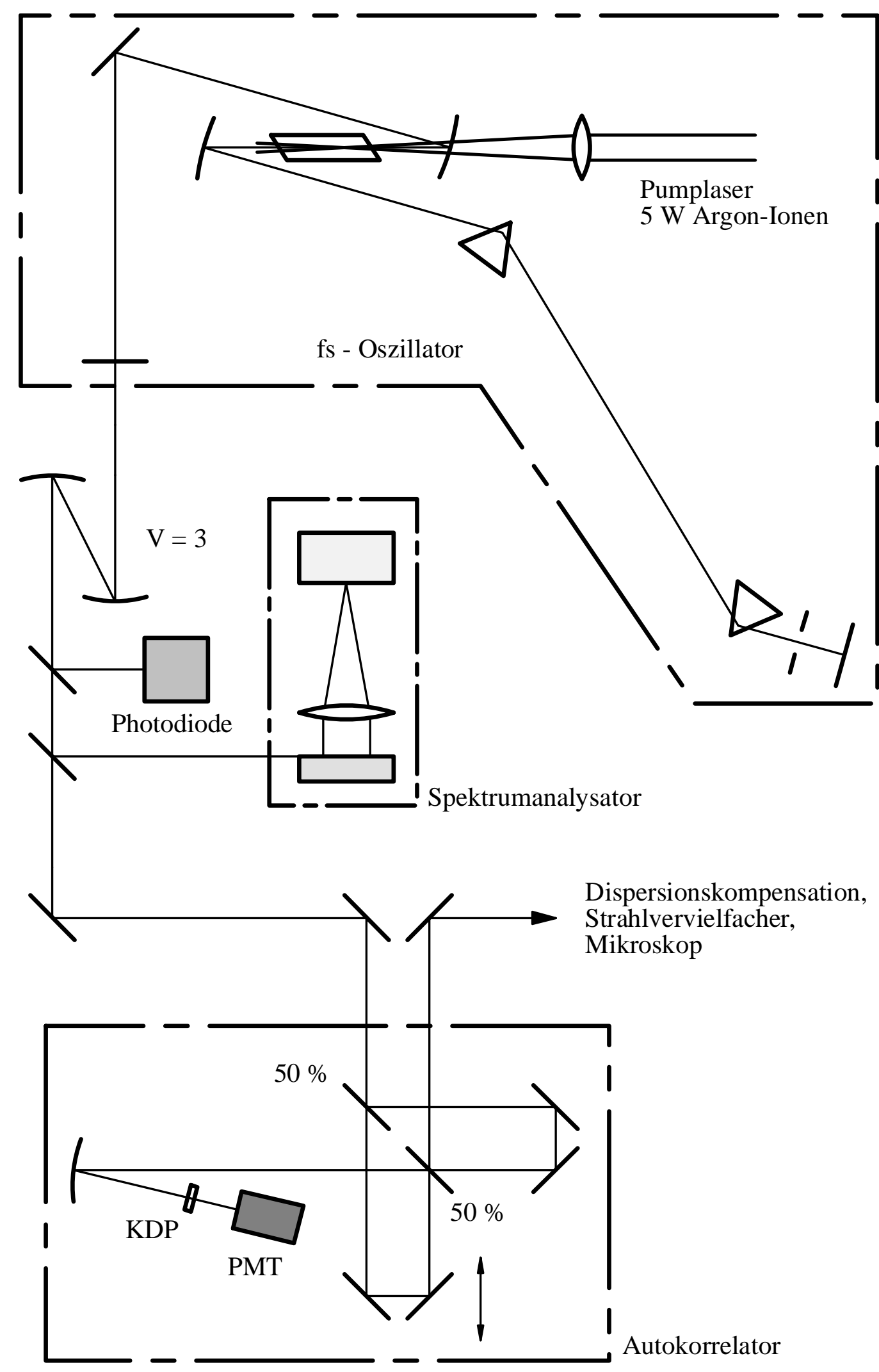

Abbildung 3.4: Der Ti:Sa-Laser mit Autokorrelator und Spektrumanalysator. Die Dispersionskompensation ist nicht eingezeichnet. 
und das gepumpte Volumen im Ti:Sa-Kristall selbst (weiche Blende). Bei hoher Laserintensität, wie sie im gepulsten Betrieb erreicht wird, kommt es durch nichtlineare Effekte zur Selbstfokussierung im Ti:Sa-Kristall, wodurch die Verluste an den Blenden verringert werden. Diese Art der Modenkopplung wird mit Kerr-LensModenkopplung bezeichnet und ist heute das Standardverfahren bei Ti:Sa-Lasern. Zur Kompensation der Dispersion und der Selbstphasenmodulation wird eine Prismenstrecke mit zwei Quarzprismen verwendet.

Voraussetzung für einen erfolgreichen Betrieb eines solchen Lasers sind ein stabiler Pumplaser mit gutem Strahlprofil ${ }^{3}$ und ein mechanisch stabiler Aufbau. Der gesamte Aufbau befindet sich daher auf einem schwingungsgedämpften optischen Tisch (Newport). Der Laser reagiert wegen der großen Resonatorlänge empfindlich auf Temperaturschwankungen und muß in möglichst staubfreier Luft betrieben werden, weil Teile des Resonators (Prismen und Endspiegel) offen sind. Das Labor ist daher mit einer Klimaanlage temperaturstabilisiert. Der optische Tisch befindet sich unter einem Zelt, das über eine Flowbox mit gefilterter Luft gespült wird.

Um die Modenkopplung zu starten, ist es nötig, eine Fluktuation der Lasermoden zu erzeugen, die sich gegen die cw-Moden ${ }^{4}$, die sonst aktiv sind, durchsetzen kann. Dies geschieht dadurch, daß der Endspiegel, der auf einem Piezo montiert ist, kurzzeitig in Schwingungen versetzt wird. Sowohl im gepulsten als auch im cw-Betrieb hat der Laser jeweils ein charakteristisches Strahlprofil, an dem der Betriebszustand sofort erkannt werden kann, auch ohne Spektrum oder Zeitstruktur zu analysieren. Der Laser ist im gepulsten Betrieb bei guter Justierung über viele Stunden stabil, sofern der Resonator nicht durch Erschütterung des Tisches gestört wird.

Der Laser liefert Pulse von 50 fs Dauer mit einer Zentralwellenlänge von 800nm. Die Repetitionsrate beträgt $76 \mathrm{MHz}$, die durchschnittliche Leistung $250 \mathrm{~mW}$. Unmittelbar hinter dem Auskoppelspiegel wird der Laserstrahl zur Verringerung der Divergenz durch ein Spiegelteleskop um den Faktor 3 vergrößert. Der Strahl hat dann einen Durchmesser von 3 mm und eine Divergenz von $130 \mu$ rad (halber Winkel). Das Strahlprofil ist gaußförmig.

Ein kleiner Teil des Laserstrahls wird zur Triggerung des Experiments auf eine schnelle Photodiode (Hamamatsu S5973) ausgekoppelt, ein weiterer Reflex dient dazu, das Spektrum des Lasers zu registrieren. Dazu wird das Licht unter streifendem Einfall auf ein Gitter gelenkt. Das Spektrum wird mit einer Linse $(f=200 \mathrm{~mm})$ auf eine Zeilenkamera (Vistek), die sich in der Brennebene der Linse befindet, fokussiert. Die Kamera wird unabhängig vom Laser mit $10 \mathrm{~Hz}$ ausgelesen. Die Daten werden von einem Rechner (Atari ST) aufgenommen und in Echtzeit dargestellt, so daß Bandbreite und Wellenlänge der Laserstrahlung jederzeit abgelesen werden können. Ein typisches Profil ist in Abbildung 3.5 dargestellt; die Bandbreite beträgt $15 \mathrm{~nm}$.

\footnotetext{
${ }^{3}$ Ein Argon-Ionenlaser stellt hier noch nicht das Optimum dar; deutlich besser sind diodengepumte Festkörperlaser.

${ }^{4}$ Im nicht modengekoppelten Betrieb wurden in der Regel mehrere, stark fluktuierende cwModen simultan beobachtet.
} 


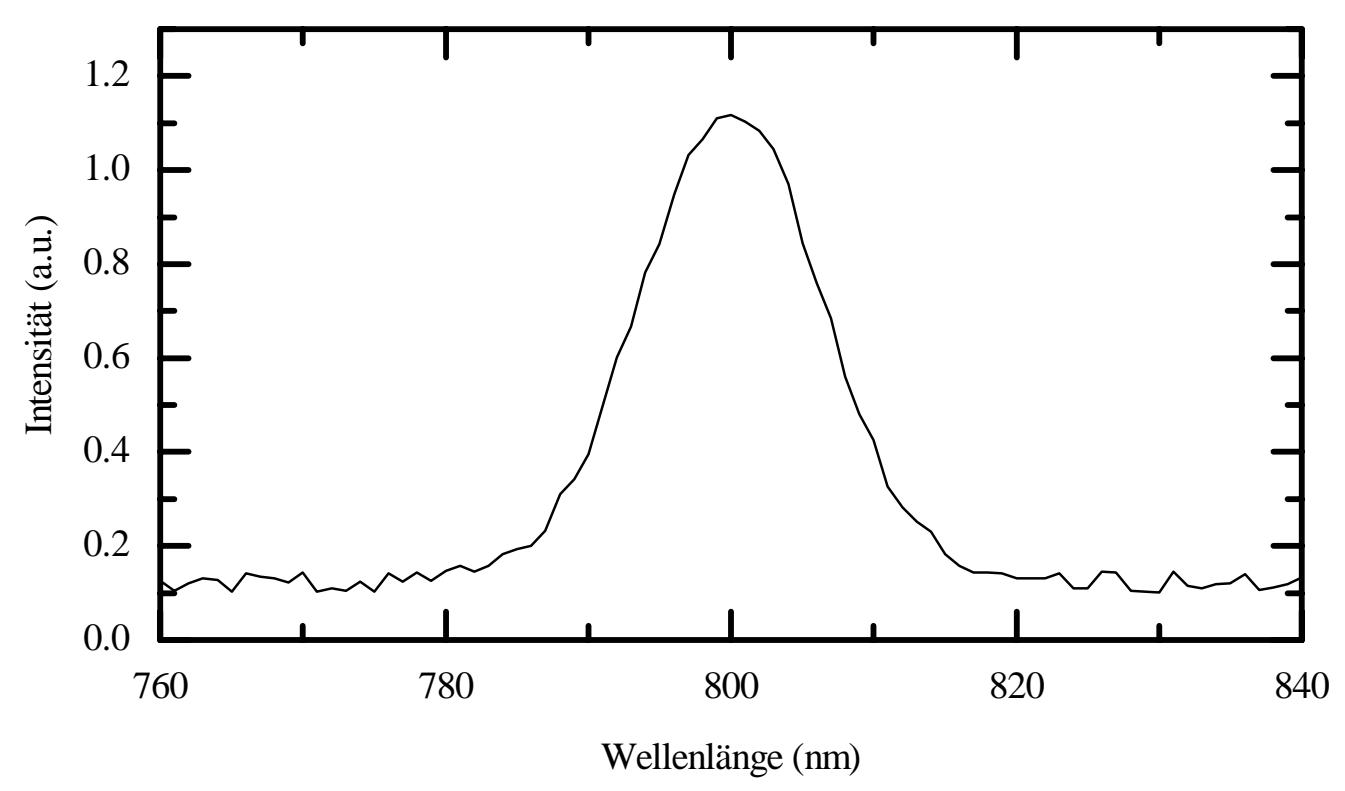

Abbildung 3.5: Typisches Spektrum des fs-Lasers. Die volle Halbwertsbreite beträgt $15 \mathrm{~nm}$.

Verschiebt man den Spalt im Resonator senkrecht zum Strahlengang, kann die Zentralwellenlänge um $\pm 20 \mathrm{~nm}$ variiert werden. Die größte Stabilität hat der Laser allerdings bei einer Zentralwellenlänge von $800 \mathrm{~nm}$, weshalb bei allen Messungen diese Wellenlänge verwendet wurde.

Zur genaueren Charakterisierung der Laserpulse stand ein Autokorrelator zur Verfügung, mit dem Pulsdauer und Chirp gemessen werden konnten.

\subsubsection{Der Autokorrelator}

Der Autokorrelator ist ähnlich wie ein Michelson-Interferometer aufgebaut. Der einfallende Strahl wird zunächst in zwei Strahlen gleicher Intensität aufgespalten. Die beiden Teilstrahlen durchlaufen dann jeweils einen Arm des Interferometers und werden mit Hilfe eines zweiten Strahlteilers wieder überlagert. Das eine Strahlenbündel tritt aus dem Autokorrelator aus und kann zum Experiment geleitet werden, das andere Bündel wird mit einem dielektrisch beschichteten Hohlspiegel in einen KDP-Kristall fokussiert und dort frequenzverdoppelt. Die Strahlen werden dabei so justiert, daß sie sich räumlich im Kristall überlappen. Die frequenzverdoppelte Strahlung wird mit einem Photomultiplier, dessen Spannung über eine A/D-Karte in einen Steuerrechner eingelesen wird, registriert. Der eine Arm des Interferometers ist auf einem Piezotranslator montiert und kann in seiner Länge um etwa $100 \mu \mathrm{m}$ verändert werden. Dadurch können die Pulse im KDP-Kristall zeitlich überlagert werden.

Details zur Aufnahme und Auswertung von Autokorrelationskurven können der 


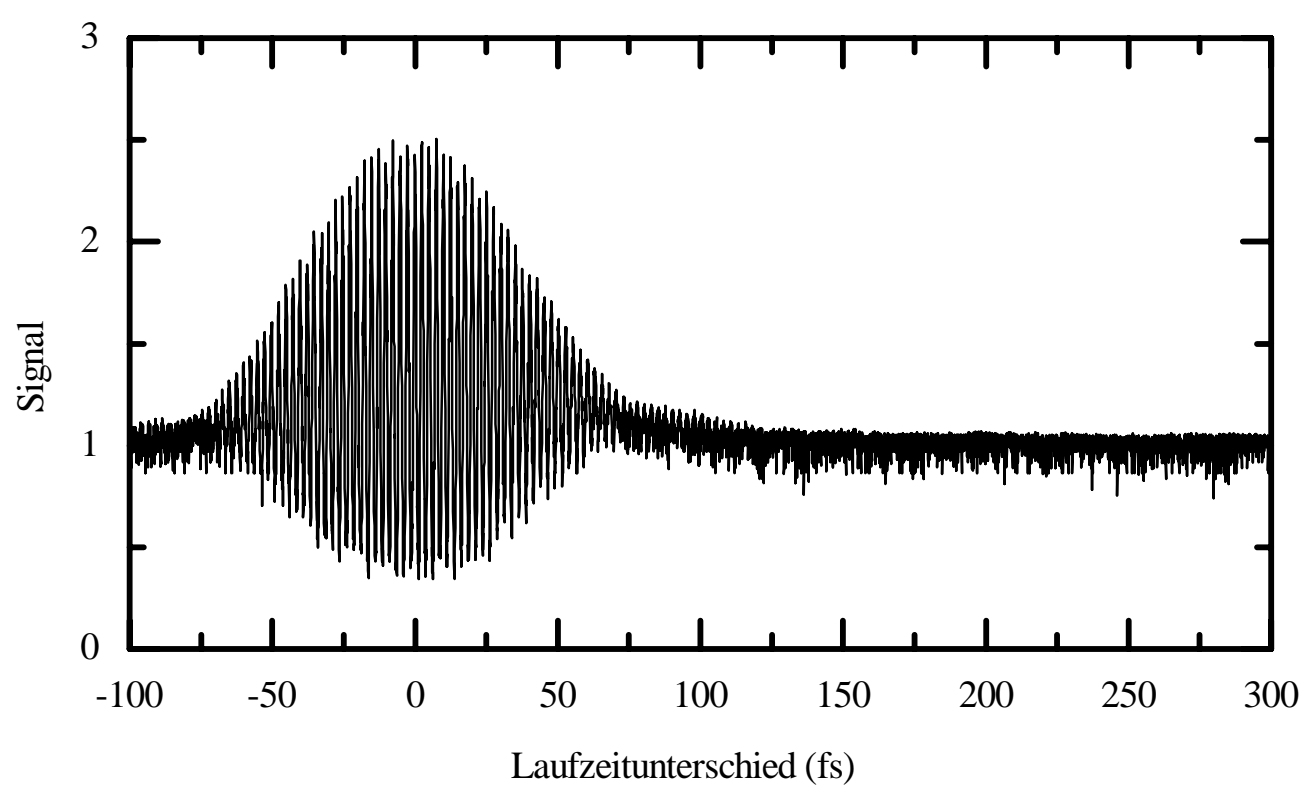

Abbildung 3.6: Autokorrelationskurve des Laserpulses. Die Pulsdauer beträgt ca. 80 fs. Am Anstieg des Signals vor dem Einsetzen des Oszillationen erkennt man einen leichten Chirp. Durch Kompensation des Chirps kann der Puls auf etwa 50 fs komprimiert werden.

Literatur entnommen werden $[87,88]$. An dieser Stelle soll nur insoweit darauf eingegangen werden, als es für den Einsatz eines fs-Lasers in der Zweiphotonenmikroskopie wichtig ist.

Zur Aufnahme einer Autokorrelationskurve wird der eine Arm des Autokorrelators in seiner Länge durchgefahren und die Intensität der frequenzverdoppelten Strahlung für jede Position gemessen. Entscheidend dabei ist, daß die Meßgröße nichtlinear - im Falle der Frequenzverdoppelung quadratisch — von der Intensität der einfallenden Strahlen abhängt.

Abbildung 3.6 zeigt eine Autokorrelationskurve des Lasers. Qualitativ kann man sich den Kurvenverlauf so erklären: So lange sich die Laufwege der Strahlen in den beiden Armen des Autokorrelators um mehr als die Pulslänge unterscheiden, durchlaufen die beiden Pulse den KDP-Kristall zu verschiedenen Zeiten. Die Pulse interferieren nicht miteinander und jeder Puls wird unabhängig vom anderen verdoppelt. Dies ist in den beiden Randbereichen der Kurve in Abbildung 3.6 der Fall.

Die Intensität der frequenzverdoppelten Strahlen ist proportional zum zeitlichen Mittel des Quadrats der Intensität der einfallenden Strahlen. Man bekommt also für den Bereich, in dem sich die Pulse zeitlich nicht überlappen, folgendes Signal:

$$
S_{\text {offset }} \sim \overline{{I_{1}}^{2}}+\overline{I_{2}{ }^{2}} \sim \overline{\left(E_{1}^{2}\right)^{2}}+\overline{\left(E_{2}{ }^{2}\right)^{2}}=2 \overline{\left(E^{2}\right)^{2}}
$$

Sind die beiden Arme des Autokorrelators gleich lang, interferieren die beiden 
Pulse konstruktiv miteinander und man bekommt folgendes Signal:

$$
S_{\max } \sim \overline{\left(\left(E_{1}+E_{2}\right)^{2}\right)^{2}}=16 \overline{\left(E^{2}\right)^{2}}
$$

Sind die Weglängen der beiden Strahlen nur um eine halbe Wellenlänge unterschiedlich, löschen sich die Pulse durch destruktive Interferenz aus und das Signal geht auf Null zurück. In dem Bereich, in dem sich die Pulse zeitlich überlagern, kommt es also durch den Wechsel von konstruktiver und destruktiver Interferenz zu periodischen Schwankungen des Signals. Aus der Breite dieses Bereichs kann daher auf die Pulsdauer zurückgeschlossen werden. Für das maximale Signal gilt $S_{\max }=8 S_{\text {offset }}$.

Damit diese Extremwerte erreicht werden, ist es nötig, daß beide Strahlen exakt gleiche Intensität haben und so justiert sind, daß ihre Wellenfronten parallel sind man spricht dann von interferometrischer Autokorrelation. Anderenfalls kommt es nur zu teilweiser Verstärkung bzw. Auslöschung und das Signalverhältnis von 1:8:0 — für die Fälle keine Überlagerung der Pulse, vollständige konstruktive Interferenz, vollständige Auslöschung — wird nicht erreicht. Alle hier gezeigten Autokorrelationskurven sind so normiert, daß gilt $S_{\text {offset }}=1$.

Das bisher gesagte gilt für nicht gechirpte Pulse. ${ }^{5}$ Sind die Pulse, die mit dem Autokorrelator untersucht werden, gechirpt, so überlagert sich bei unvollständiger Überlappung z. B. der „,rote“ Anfang des einen mit dem „,blauen“ Ende des anderen Pulses. Da die Frequenzen der beiden Pulse im Überlappungsbereich unterschiedlich sind, kann es nicht mehr zu vollständiger Verstärkung oder Auslöschung kommen, so daß man hier keine Oszillationen beobachtet sondern einen Anstieg des Offsetlevels. Die Oszillationen setzen erst ein, wenn sich die lokalen Frequenzen in beiden Pulsen nicht mehr stark voneinander unterscheiden. Durch eine genaue Auswertung der Autokorrelatorkurven können der Betrag des Chirps sowie die Pulsdauer bestimmt werden. Das Vorzeichen des Chirps kann an den Kurven nicht erkannt werden.

Bei genauer Betrachtung von Abbildung 3.6 sieht man, daß die Autokorrelationskurve leicht ansteigt, bevor die Oszillationen einsetzen. Die Pulse sind also etwas gechirpt. Dies entsteht hauptsächlich durch die Justierung und den Auskoppelspiegel des Lasers (5 mm BK 7); die optischen Elemente im Autokorrelator (1.4 mm Suprasil, $0.4 \mathrm{~mm}$ KDP) tragen nur wenig dazu bei.

\subsubsection{Die Dispersionskompensation}

Wie oben bereits ausgeführt (siehe Abschnitt 3.1.2) ist eine kurze Pulsdauer in der Probe vorteilhaft. Durch die Dispersion der optischen Elemente im Strahlengang insbesondere des Mikroskopobjektivs wird der Puls auf dem Weg vom Laser zur Probe zeitlich verlängert.

Die Dispersion kann kompensiert werden; um aber die Größe der benötigten Kompensation zu bestimmen, muß die Pulsdauer in der Probe gemessen werden.

\footnotetext{
${ }^{5}$ Man spricht von gechirpten Pulsen, wenn sich die Momentanfrequenz des elektrischen Feldes im Verlauf des Pulses ändert.
} 


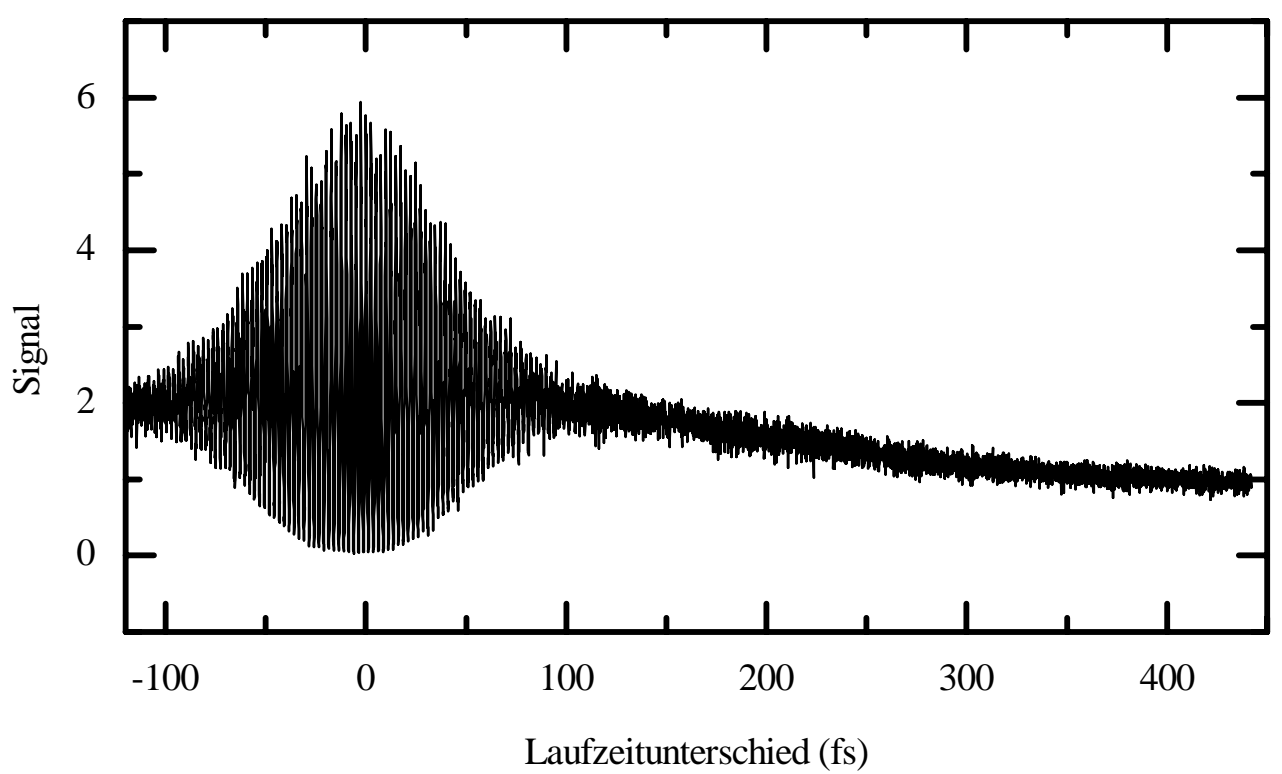

Abbildung 3.7: Autokorrelationskurve des Pulses in der Probe ohne Dispersionskompensation. Die Pulsdauer beträgt 280 fs. Der Anstieg des Signals vor dem Einsetzen der Oszillationen ist charakteristisch für einen gechirpten Puls.

Da es schwer ist, den Strahl in den Autokorrelator zu schicken, nachdem er durch das Objektiv fokussiert wurde, wurde hier ein anderer Weg verfolgt: Der Strahl wurde direkt hinter dem Laser in den Autokorrelator geleitet. Die beiden Strahlen, die aus dem Autokorrelator austraten, wurden in Strahlteiler und Mikroskop eingekoppelt und in eine Probe fokussiert, die sich zur Zweiphotonenfluoreszenz anregen ließ (Coumarin 500 gelöst in Ethylenglycol). Für jede Stellung des Piezotranslators im Autokorrelator wurde der Photomultiplier ausgelesen und ein Bild der Fluoreszenz aufgenommen. Die Fluoreszenz ist als Autokorrelationssignal geeignet, da sie ebenso wie die Intensität der frequenzverdoppelten Strahlung im Autokorrelator vom Quadrat der einfallenden Intensität abhängt. Der Verlauf der Fluoreszenz gibt die Laserpulse in der Probe wieder, während das simultan dazu aufgenommene Photomultipliersignal den Zustand der Pulse, wie sie aus dem Laser kommen, darstellt.

Abbildung 3.7 zeigt eine Autokorrelationskurve der Pulse in der Probe. Man erkennt im linken Teil die starken Oszillationen. Dort, wo die Oszillationen verschwinden, wird allerdings nicht sofort der Wert 1 erreicht, sondern die Kurve klingt erst langsam ab. Das ist ein deutliches Kennzeichen für einen stark gechirpten Puls. Eine genaue Analyse der Daten ergibt eine Pulsdauer von $\approx 280$ fs. Das bedeutet, daß das Mikroskopobjektiv eine Dispersion von $5000 \mathrm{fs}^{2}$ haben muß. Dies deckt sich mit anderen Messungen [89] an ähnlichen Aufbauten.

Durch die Verwendung einer Dispersionskompensation, die aus zwei SF10-Prismen aufgebaut ist, kann die Dispersion des Objektivs vollständig kompensiert wer- 


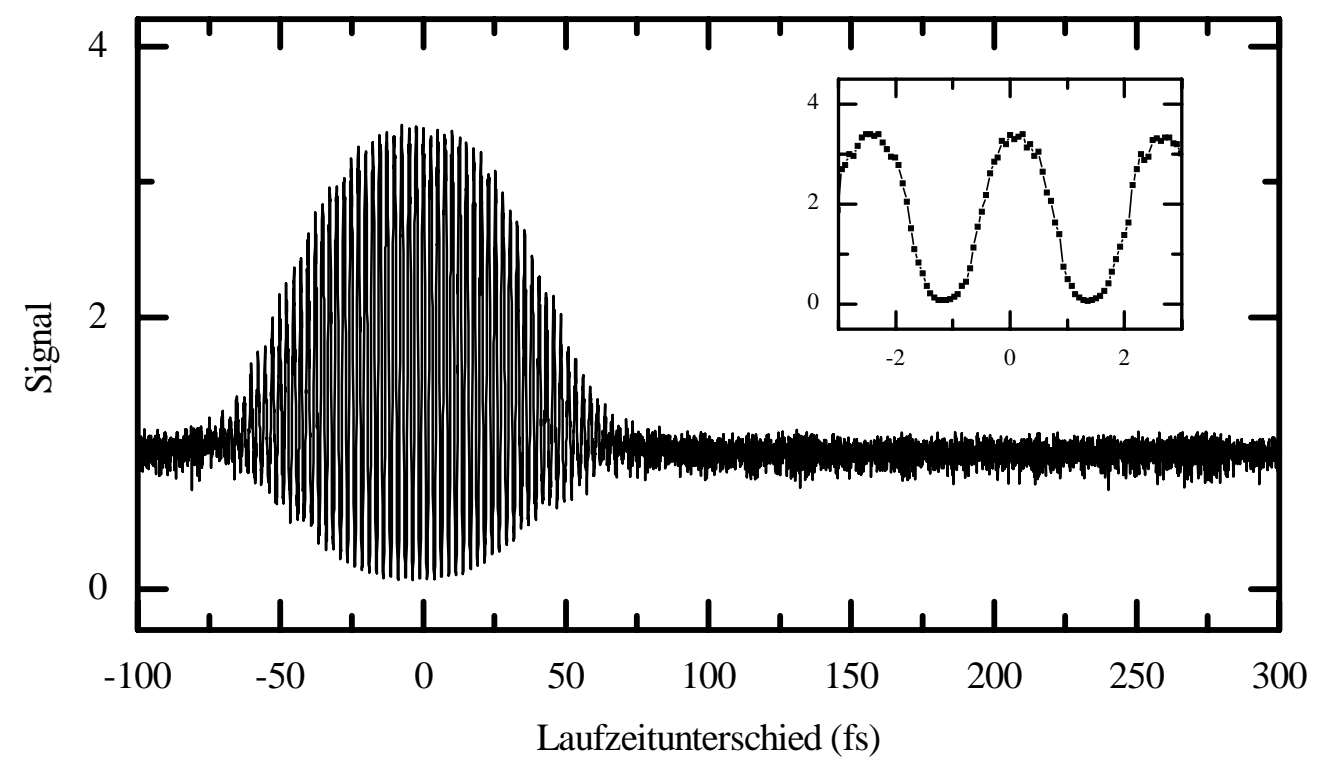

Abbildung 3.8: Autokorrelationskurve des Pulses in der Probe bei optimaler Kompensation der Dispersion. Die Pulsdauer beträgt 46 fs, es ist kein Chirp zu erkennen. Die kleine Graphik zeigt einen Ausschnitt der Oszillationen.

den, wie Abbildung 3.8 zeigt. Hier ist die Autokorrelationskurve in der Probe bei optimalem Abstand der Kompensationsprismen gezeigt. Es wird eine Pulsdauer von 46 fs erreicht. Durch die Verkürzung der Pulse in der Probe steigt das Signal bei gleicher Durchschnittsleistung des Lasers um den Faktor 7 an.

Man kann die Dispersionskompensation auch ohne Autokorrelator einstellen, indem einfach auf maximales Fluoreszenzsignal justiert wird. Dann kann aber nicht überprüft werden, ob die Dispersion vollständig kompensiert wurde, oder ob höhere Ordnungen (quadratischer Chirp) übrig bleiben. Daß dies bei unseren Pulsdauern nicht der Fall ist, konnte anhand der Autokorrelationskurven eindeutig gezeigt werden. Eine genauere Diskussion der Chirpkompensation findet man in [88].

\subsubsection{Der Strahlvervielfacher}

Damit die Probe in vielen Punkten gleichzeitig beleuchtet werden kann, ist es nötig, den Laserstrahl in Teilstrahlen aufzuspalten. Dabei sind folgende Punkte zu beachten:

1. Die einzelnen Teilstrahlen sollten möglichst gleiche Leistung haben, damit sich die Fluoreszenzsignale, die alle mit demselben Detektor aufgenommen werden, nicht zu stark voneinander unterscheiden. Die Signalunterschiede können durch Normierung auf die Anregungswahrscheinlichkeit für jeden Teilstrahl eliminiert werden; die nutzbare Dynamik des Detektors wird dadurch aber reduziert. 


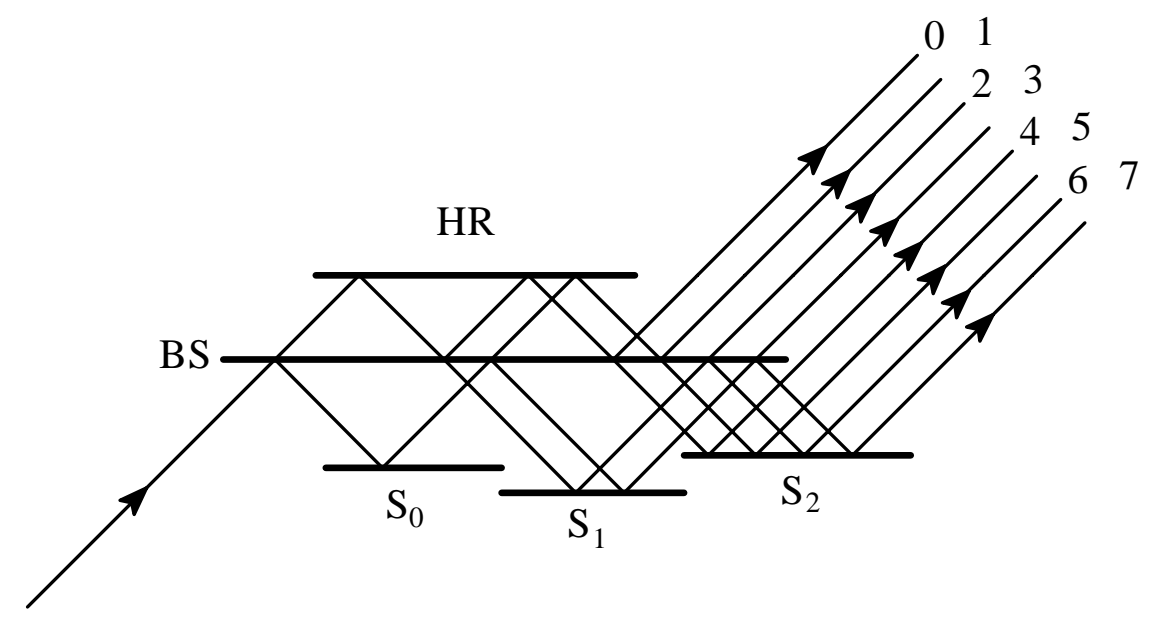

Abbildung 3.9: Prinzip der Strahlaufteilung durch mehrfache Reflexion. Gezeigt ist die Erzeugung von 8 Teilstrahlen.

2. Um einen kleinen Fokus und damit gute Ortsauflösung zu erreichen, sollten die Teilstrahlen ein gutes Strahlprofil besitzen.

3. Die gesamte Laserleistung sollte genutzt werden, um eine gute Effizienz zu erreichen.

4. Um die Zeitauflösung nicht durch Laufzeitunterschiede der Strahlen zu verlieren, sollten sich die Wege der einzelnen Teilstrahlen nicht zu stark voneinander unterscheiden.

5. Damit die Strahlen gut fokussiert werden, müssen sie die Apertur des Mikroskopobjektivs voll ausnutzen. D. h. in der Eintrittspupille des Objektivs müssen sich alle Teilstrahlen überlagern und die Eintrittspupille leicht überstrahlen.

6. Damit die Strahlen an unterschiedliche Orte in der Probe fokussiert werden, müssen sie unter unterschiedlichen Winkeln in das Objektiv einfallen.

Neben dem in dieser Arbeit eingeschlagenen Weg [90], den Laserstrahl aufzuteilen, gibt es noch eine andere Arbeit, in der ein anderes Konzept [91] verfolgt wird. Beide Methoden werden im folgenden beschrieben und miteinander verglichen. 


\subsubsection{Strahlaufteilung durch mehrfache Reflexion}

Das Prinzip der Strahlaufteilung, wie sie in dieser Arbeit realisiert wurde, ist in Abbildung 3.9 gezeigt. Der einfallende Strahl kommt von links unten und fällt unter $45^{\circ}$ auf einen 50\% Spiegel (BS), d. h. er wird in zwei Strahlen gleicher Leistung aufgespalten. Der eine Strahl tritt durch den 50\% Spiegel hindurch und wird an einem hochreflektierenden Spiegel (HR), der parallel zum 50\% Spiegel ausgerichtet ist, reflektiert. Der andere Strahl wird an einem anderen hochreflektierenden Spiegel $\left(\mathrm{S}_{0}\right)$, der sich in einem anderen Abstand zum 50\% Spiegel befindet, reflektiert. So werden die beiden Strahlen wieder auf den 50\% Spiegel geworfen und dort in 4 Strahlen geteilt. Dies kann mehrfach wiederholt werden $\left(S_{1}, \ldots\right)$, wobei sich die Zahl der Strahlen bei jedem Kontakt mit dem 50\% Spiegel verdoppelt. Zum Schluß wird das eine Strahlbündel mit einem Umlenkspiegel $\left(S_{2}\right)$ in die Richtung des anderen Bündels um $90^{\circ}$ abgelenkt. Auf diese Weise lassen sich mit $n+2$ optischen Elementen $2^{n}$ Strahlen erzeugen. Jeder Teilstrahl hat dabei das gleiche Strahlprofil wie der einfallende Strahl. Es wird die gesamte Leistung des einfallenden Strahls genutzt.

Sind alle Spiegel parallel, so sind auch alle Teilstrahlen parallel. Indem die Spiegel 0,1 und 2 verkippt werden, können die Winkel der Teilstrahlen beeinflußt werden. Um die Winkel, die die Strahlen am Ausgang des Strahlvervielfachers gegenüber der Richtung des einfallenden Strahls haben, zu berechnen, ist es zweckmäßig, zunächst die Strahlen zu numerieren.

Die hier verwendete Numerierung der Strahlen ist ebenfalls in Abbildung 3.9 gezeigt. Man bekommt die Binärdarstellung der Strahlnummer $n$, indem man eine 1 für eine Reflektion an Spiegel 0, 1 oder 2 an die entsprechende binäre Stelle der Zahl schreibt:

$$
\begin{aligned}
n & =\sum_{i} b_{i}(n) \cdot 2^{i} \quad \text { mit } \\
b_{i}(n) & =\left\{\begin{array}{ll}
1 & \text { falls Strahl an Spiegel i reflektiert wird } \\
0 & \text { sonst }
\end{array}\right\}
\end{aligned}
$$

Man kann sich leicht davon überzeugen, daß so jeder Strahl eine Nummer erhält und keine Nummer mehr als einmal vergeben wird.

Wird ein Spiegel $i$ z. B. um den Winkel $\delta_{i}$ gegenüber dem $50 \%$ Spiegel gekippt, wird der Strahl bei der Reflektion an diesem Spiegel um den Winkel $2 \delta_{i}$ gegenüber dem Strahl, der durch den 50\% Spiegel hindurchtritt, abgelenkt (siehe Abbildung 3.10). Der Gesamtwinkel, den ein Strahl mit der Nummer $n$ am Ausgang des Strahlvervielfachers hat, kann also aus den Kippwinkeln der Spiegel $\delta_{i}$ so berechnet werden:

$$
\alpha(n)=2 \sum_{i} b_{i}(n) \delta_{i}
$$

Stellt man die Spiegel so ein, daß gilt

$$
\delta_{i}=\frac{\gamma}{2} \cdot 2^{i},
$$




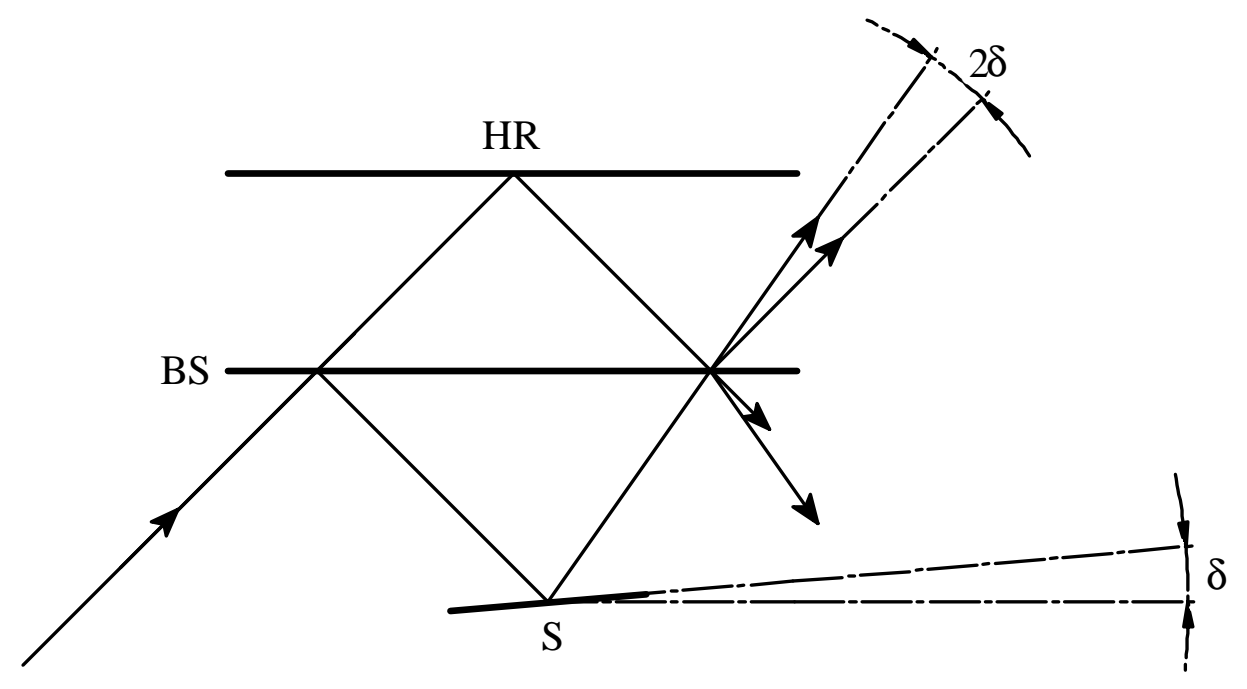

Abbildung 3.10: Drehung des Strahls bei Reflektion.

so erhält man

$$
\alpha(n)=\gamma n,
$$

d. h. die Winkel der Strahlen steigen gleichmäßig an; benachbarte Strahlen unterscheiden sich jeweils um den Winkel $\gamma$. Werden die Teilstrahlen dann mit dem Mikroskopobjektiv fokussiert, ergeben sich Foki in einem gleichmäßigen Abstand voneinander. Die Abstände der Foki in der Probe werden durch die Justierung des Strahlvervielfachers und der Vergrößerung des Objektivs festgelegt. Ein typischer Wert für den Winkel ist $\gamma=2.5 \mathrm{mrad}$, bei dem man mit dem hier verwendeten Objektiv $(V=63)$ einen Abstand der Foki von $\approx 5 \mu \mathrm{m}$ erhält.

Damit sich die Strahlen in der Eintrittspupille des Objektivs überlagern, müssen sie den Strahlvervielfacher mit den richtigen Abständen verlassen. Die Abstände, die die Strahlen am Ausgang des Strahlvervielfachers haben, werden durch die Abstände der Spiegel 0,1,2 zum 50\% Spiegel festgelegt. Dabei ist der Unterschied der Abstände BS - HR bzw. BS - $\mathrm{S}_{i}$ entscheidend. Bei der Erzeugung von 8 Teilstrahlen hat man 3 Freiheitsgrade, so daß man 4 Strahlen perfekt überlagern kann. Die anderen Strahlen treffen nicht exakt im selben Punkt übereinander. Da die Winkel der Strahlen aber klein gegeneinander sind, ist der Fehler vernachlässigbar. Für eine Einstellung, bei der 8 Strahlen mit einem relativen Winkel von 2.5 mrad erzeugt werden, beträgt die Abweichung in der Apertur des Objektivs weniger als $70 \mu \mathrm{m}$.

Ein zweidimensionales Raster von Strahlen kann man erzeugen, wenn man den Laserstrahl zunächst in einer Richtung in Teilstrahlen aufspaltet und dann jeden der Teilstrahlen durch einen zweiten Strahlteiler, der um $90^{\circ}$ gegenüber dem ersten verkippt ist, nochmals zerlegt. Für die praktische Realisierung ist es allerdings einfacher, die Strahlen nach dem ersten Strahlteiler mit einem Periskop um $90^{\circ} \mathrm{zu}$ 


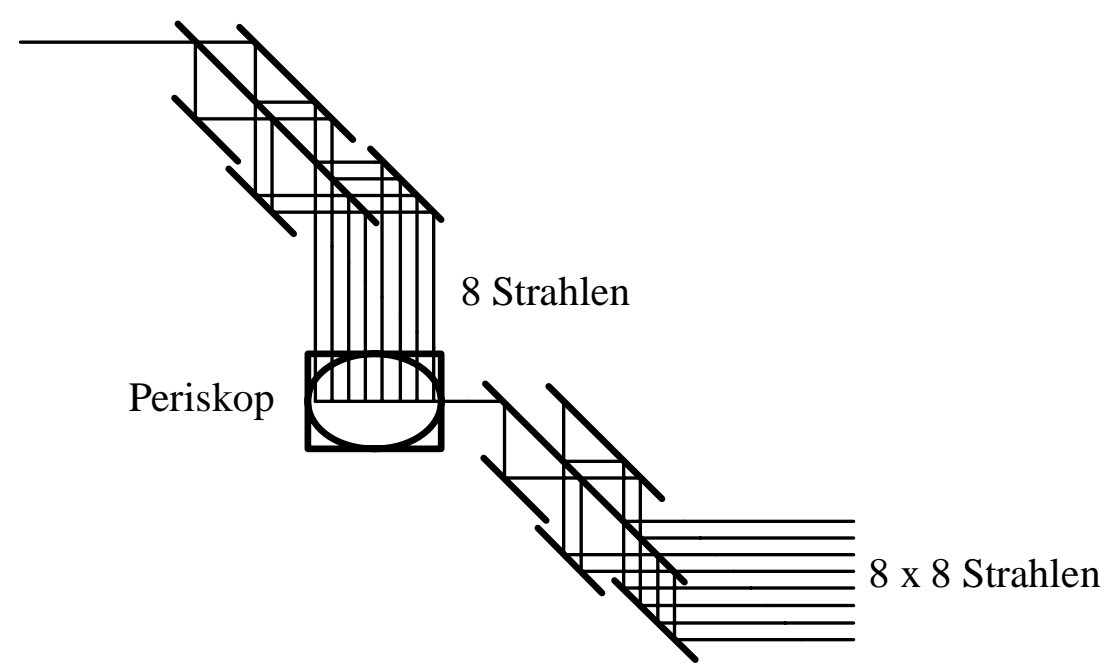

Abbildung 3.11: Der Aufbau des Strahlvervielfachers.

drehen, anstatt den zweiten Strahlteiler zu kippen.

Abbildung 3.11 zeigt den in dieser Arbeit verwendeten Aufbau, mit dem $8 \times 8$ Teilstrahlen erzeugt wurden. Er besteht aus zwei ähnlich aufgebauten Strahlvervielfachern, zwischen denen ein Periskop das Strahlbündel um $90^{\circ}$ dreht. Als $50 \%$ Spiegel wurden dielektrisch bedampfte Suprasilsubstrate $\left(60 \times 30 \times 2 \mathrm{~mm}^{3}\right.$, Laseroptik $\mathrm{GmbH}$ ) verwendet, die auf der Rückseite entspiegelt sind. Da die Reflektivität polarisationsabhängig ist und das Periskop die Polarisationsrichtung dreht, wurde ein Spiegel für P- und ein Spiegel für S-Polarisation verwendet. Die hochreflektierenden Spiegel haben eine Reflektivität von mehr als 99.5\%. Die Gesamttransmission des Strahlvervielfachers betrug 91\%. Die Unterschiede zwischen den Teilstrahlen werden im Abschnitt 3.2.4.5 anhand der Zweiphotonenfluoreszenz, die von den Strahlen ausgelöst wird, diskutiert. Der Abstand des Strahlvervielfachers vom Mikroskopobjektiv betrug etwa $780 \mathrm{~mm}$.

\subsubsection{Strahlaufteilung durch Mikrolinsenraster}

In diesem Abschnitt wird die zweite Methode, die benutzt wird, um den Laserstrahl in Teilstrahlen aufzuspalten, beschrieben. Die Daten sind [93] entnommen.

Das Prinzip ist in Abbildung 3.12 gezeigt. Der Laserstrahl wird aufgeweitet $\left(\mathrm{L}_{1}\right.$, $\mathrm{L}_{2}$ ) und beleuchtet einen Teil einer Scheibe, in die Mikrolinsen geätzt sind. Jede der Mikrolinsen fokussiert den Teil des Strahls, mit dem sie beleuchtet wird, und bildet auf diese Weise einen Teilstrahl aus. Die Linsen haben einen Durchmesser von $460 \mu \mathrm{m}$ und eine Brennweite von $6 \mathrm{~mm}$. In der Brennebene der Linsen erhält man so ein Raster von Foki, die einen Durchmesser von etwa $6 \mu \mathrm{m}$ haben. 


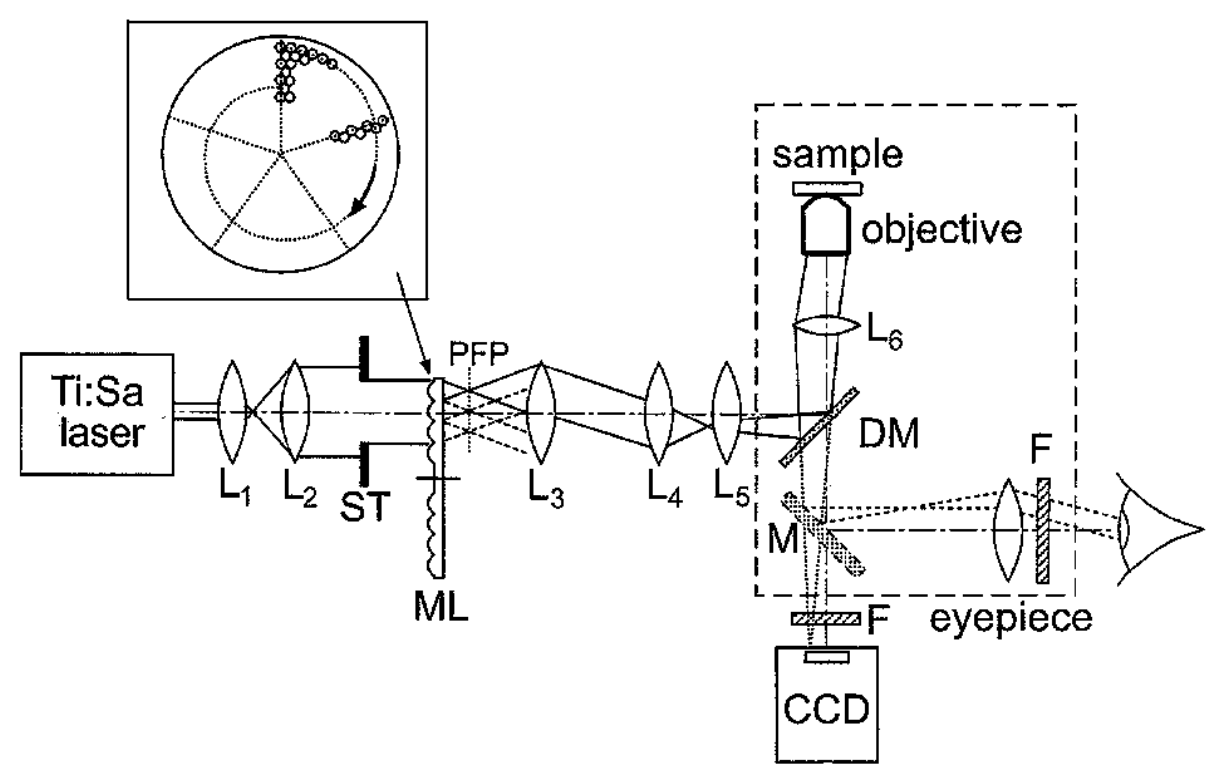

Abbildung 3.12: Aufteilung des Strahls durch Mikrolinsenraster (aus [93]).

Die Teilstrahlen werden über weitere Linsen $\left(\mathrm{L}_{3}-\mathrm{L}_{6}\right)$ zum Mikroskopobjektiv geleitet. Dieses Linsensystem sorgt daür, daß die Teilstrahlen kollimiert sind und die Apertur des Objektivs überstrahlen.

Die Mikrolinsen sind hexagonal angeordnet, um möglichst wenig der Fläche ungenutzt zu lassen. So tragen $90 \%$ der bestrahlten Fläche zur Ausbildung der Teilstrahlen bei. Leicht abweichend von einer exakt hexagonalen Anordnung befinden sich die Linsen auf Spiralen, so daß die Foki, wenn die Scheibe rotiert wird, die Brennebene abrastern. Dabei ist die Steigung der Spiralen so gewählt, daß bei einer Umdrehung der Scheibe fünf Scans durchgeführt werden.

Auf diese Weise wurden mit einem Ti:Sa-Laser mit 1.4 W Ausgangsleistung 25 Strahlen mit einer Leistung von $5-7 \mathrm{~mW}$ in der Probe erzeugt. Die Probe wurde abgerastert, indem die Scheibe mit $75 \mathrm{~Hz}$ rotiert wurde.

Die Fluoreszenz aller Teilstrahlen wurde mit einer CCD-Kamera aufgenommen. Dabei wurde die Belichtungszeit der Kamera so lang eingestellt, daß die Mikrolinsenscheibe mehrere Umdrehungen während der Belichtung des Bildes durchführte. Bei dieser Art der Detektion erzeugt jeder Strahl nicht nur an einem Punkt des Bildes ein Signal, sondern schreibt eine ganze Spur, die den vom Fokus dieses Strahls überstrichenen Bereich des Objekts wiedergibt, auf das Bild. Da bei einer Umdrehung der Scheibe jeder Punkt der Objektebene (mehrmals) von einem Strahl getroffen wird, erhält man ein zweidimensionales Bild des Objekts. 


\subsubsection{Vergleich der beiden Methoden: die Strahlerzeugung}

Die Aufspaltung des Laserstrahls durch Mikrolinsen zeichnet sich durch einen kompakten Aufbau aus, da im wesentlichen nur ein optisches Bauteil benötigt wird. Die Anforderungen an die Präzision des Mikrolinsenrasters sind allerdings hoch, da z. B. die Brennweiten der Linsen genau übereinstimmen müssen, um eine gute Tiefenauflösung zu erreichen. So konnten bei dem in [93] verwendeten Raster zwei der fünf Segmente der Scheibe nicht benutzt werden, weil die Brennweiten zu stark von denen der anderen Segmente abwichen.

Die Mikrolinsen sind nicht chromatisch korrigiert. Dies kann bei kurzen Pulsen, die ein breites Spektrum haben, die Tiefenauflösung reduzieren, wenn die Foki durch die chromatische Aberration verlängert werden.

Das Abrastern der Probe wird durch Rotation der Scheibe erreicht und ist damit deutlich einfacher als die herkömmliche Methode, bei der die Strahlen durch Spiegelscanner oder die Probe durch Piezoscanner bewegt werden.

Der Strahlabstand - d. h. auch die Bildgröße — und die Schrittweite beim Scannen sind beim Mikrolinsenraster durch die Konstruktion vorgegeben. Beim Spiegelaufbau kann der Strahlabstand durch Justieren eingestellt werden, die Schrittweite der Scanner kann frei gewählt werden. In beiden Fällen kann man den Strahlabstand in der Probe allerdings am einfachsten durch die Vergrößerung des Mikroskopobjektivs beeinflussen.

Das größte Problem bei Verwendung der Mikrolinsen ist die unterschiedliche Leistung der Teilstrahlen, die dadurch entsteht, daß das Strahlprofil des Lasers nicht homogen ist. Typischerweise haben die Laser, die in der Mikroskopie eingesetzt werden, ein gaußförmiges Strahlprofil, das nicht trivial zu homogenisieren ist, da es sich um fs-Pulse handelt.

Das gaußförmige Strahlprofil führt dazu, daß nur ein Bruchteil des Strahls verwendet werden kann, wenn die Intensitätsunterschiede der Teilstrahlen nicht zu stark werden sollen. Dadurch ist die Effizienz, die mit dem Mikrolinsenraster erreicht wird, mit $10 \%(\approx 25 \cdot 6 \mathrm{~mW} / 1.4 \mathrm{~W})$ niedrig. Die Effizienz des Spiegelaufbaus ist mit $90 \%$ deutlich höher. Die Erhöhung der Effizienz bei der Zweiphotonenmikroskopie und damit die Steigerung der Meßgeschwindigkeit war ein Hauptziel dieser Arbeit.

Die Signalunterschiede zwischen den Teilstrahlen betragen bei beiden Arten, die Strahlen zu erzeugen, etwa 50\%.

\subsubsection{Vergleich der beiden Methoden: die Datenaufnahme}

Die Integration des Fluoreszenzsignals auf einem Kamerabild (wie in [93]) ist nur bei dünnen Proben, die das Licht nicht streuen, möglich. Wird das Fluoreszenzlicht beim Austritt aus der Probe gestreut, verteilt sich das Signal über einen größeren Ortsbereich. Beim Scannen vermischen sich dann die Signale von unterschiedlichen Punkten der Probe auf dem Bild der Kamera und die Ortsauflösung sinkt.

In diesem Experiment wird für jede Position der Probe ein Kamerabild aufgenommen und aus diesen Bildern ein Gesamtbild errechnet (siehe Abschnitt 3.3.3). 


\begin{tabular}{|r|r|}
\hline Hersteller & Zeiss \\
\hline Typ & P-Apo \\
\hline Vergrößerung & 63 \\
\hline N. A. & 1.4 \\
\hline Immersion & Öl \\
\hline ØEintrittspupille & $7.3 \mathrm{~mm}$ \\
\hline Arbeitsabstand & $90 \mu \mathrm{m}$ \\
\hline
\end{tabular}

Tabelle 3.1: Daten zum Mikroskopobjektiv.

Solange die Signale, die von den einzelnen Teilstrahlen erzeugt werden, noch auf den Einzelbildern getrennt werden können, kann das Signal eindeutig einer Rasterposition zugeordnet werden. D. h. auch wenn die Probe so stark streut, daß das Fluoreszenzlicht im Bild über einige Mikrometer verteilt wird, kann ohne Verlust der Ortsauflösung gearbeitet werden.

\subsubsection{Das Mikroskop}

Das Mikroskop wurde aus mehreren Komponenten, die im folgenden beschrieben werden, aufgebaut. Abbildung 3.13 zeigt schematisch das Mikroskop mit Detektor und Scanner.

Um eine gute Fokussierung der Strahlen und eine hohe Lichtsammeleffizienz zu erreichen, muß ein gut korrigiertes Objektiv mit möglichst hoher numerischer Apertur verwendet werden. In diesen Experimenten wurde ein Zeiss Plan-Apochromat benutzt. Die Daten zum Objektiv sind in Tabelle 3.1 zusammengefaßt. Die numerische Apertur beträgt 1.4; dies ist der größte Wert, der mit einem Objektiv mit Öl-Immersion erreicht werden kann. Das Objektiv wurde an einem Piezotranslator (P-720.00, Physik Instrumente) mit einem Stellweg von $100 \mu \mathrm{m}$ befestigt, durch dessen Stellung die Tiefe der Ebene, die in der Probe abgerastert wurde, festgelegt werden konnte.

Sollen dicke Proben (z. B. Gewebe) untersucht werden, kann es vorteilhaft sein, ein Objektiv mit Wasser-Immersion zu benutzen, da die Proben in der Regel einen ähnlichen Brechungsindex wie Wasser haben. Wird mit einem Öl-Immersions Objektiv tief in eine solche Probe hineinfokussiert, durchläuft das Licht nur eine kurze Strecke durch das Immersionsöl und eine lange Strecke durch die wäßrige Probe. Die Korrektur der Objektive ist allerdings für den umgekehrten Fall, in dem das Licht nur einen kurzen Weg durch die Probe zurïcklegt, berechnet. Daher sinkt die Fokusqualität eines Öl-Immersions Objektivs bei größeren Tiefen. Dieser Effekt tritt bei Wasser-Immersions Objektiven nicht auf, da sich hier sowohl über als auch unter dem Deckglas Wasser befindet. Allerdings erreicht man mit WasserImmersions Objektiven nur eine etwas geringere numerische Apertur von 1.2.

Die Laserstrahlen wurden über einen dielektrischen $45^{\circ}$-Spiegel, der für $800 \mathrm{~nm}$ hochreflektierend beschichtet ist, in das Objektiv eingekoppelt. Dieser Spiegel hat 


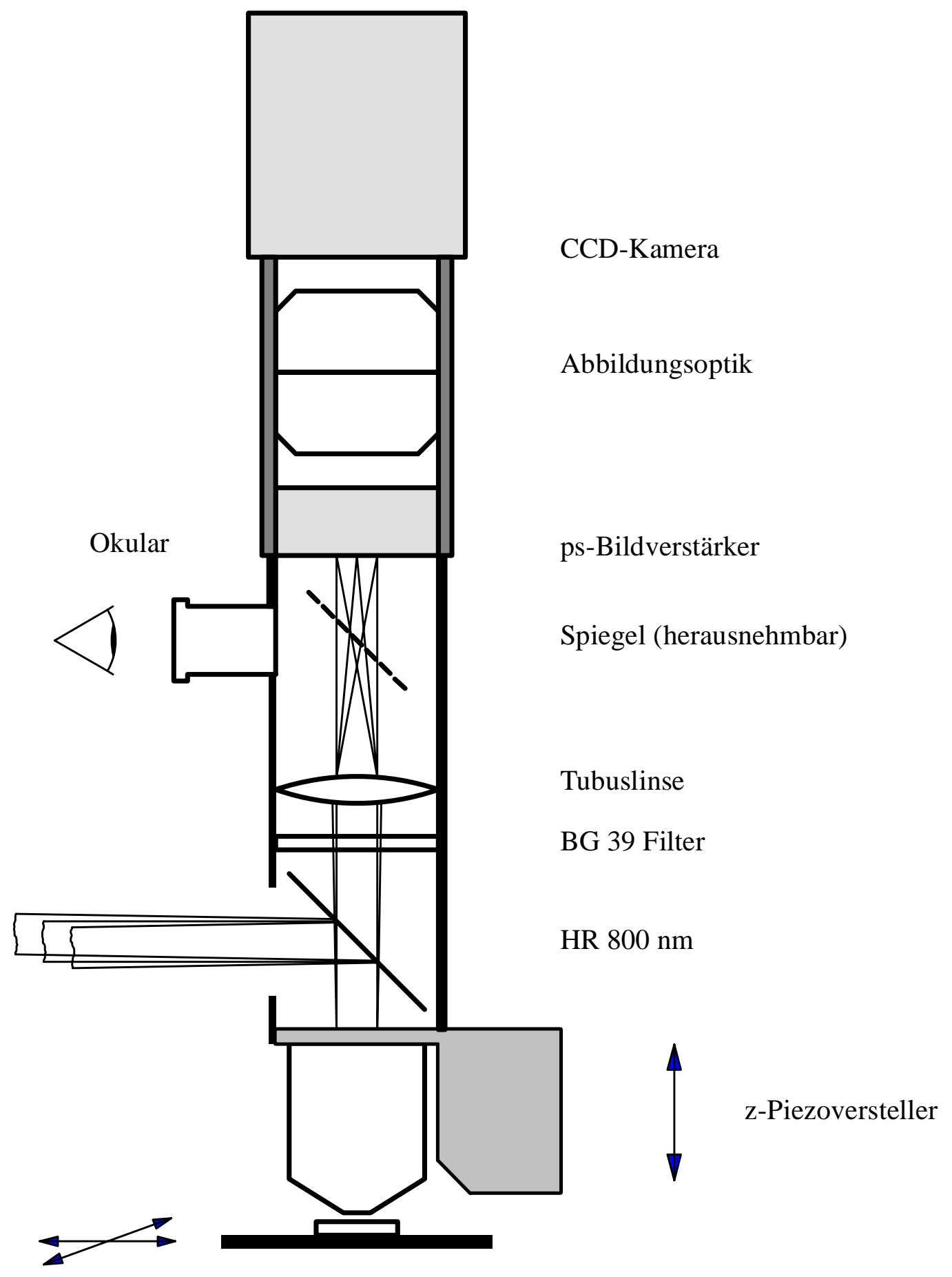

Probenhalter und xy-Scantisch

Abbildung 3.13: Der Aufbau des Mikroskops mit Scanner und Detektor. 


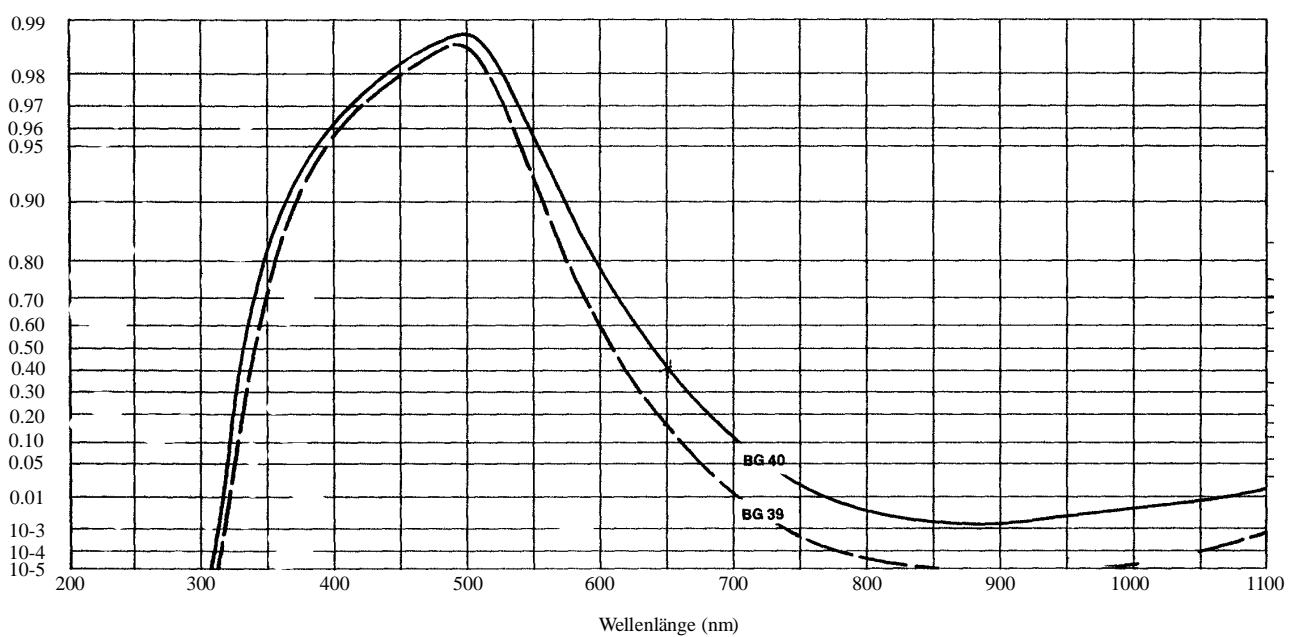

Abbildung 3.14: Die Transmission von 1 mm BG 39 (aus [94]).

eine hohe Transmission bei anderen Wellenlängen, so daß die Fluoreszenz, zu der die Probe angeregt wird, größtenteils durch den Spiegel hindurchtritt.

Das Objektiv ist ein sogenanntes ICS-Objektiv, ${ }^{6}$ bei dem das Bild durch eine Tubuslinse, die sich in einer Entfernung von $100 \mathrm{~mm}$ über dem Objektiv befindet, gebildet wird. Zwischen Tubuslinse und Objektiv verlaufen die Strahlen parallel. In diesem Teil des Strahlengangs wurde über dem Umlenkspiegel ein Filter (2 mm BG39) zur Unterdrückung von Laserstreulicht eingebaut. Dieses Filterglas hat eine hohe Absorption im infraroten Spektralbereich und eine gute Transmission im Bereich zwischen 350 und $600 \mathrm{~nm}$ (siehe Abbildung 3.14). Es wurde kein verbleibendes Laserstreulicht detektiert.

Das Bild konnte wahlweise mit dem Detektor, der in Abschnitt 3.2.4 beschrieben wird, oder über einen Aluminiumspiegel, der in den Strahlengang hineingeklappt wurde, mit einem Okular betrachtet werden. Das Okular ist hilfreich beim groben Justieren der Strahlen und beim Positionieren der Probe.

Abbildung 3.15 zeigt das Bild eines Objektmikrometers (Zeiss), mit dessen Hilfe der Abbildungsmaßstab festgelegt wurde. Die kleinen Teilstriche haben einen Abstand von $10 \mu \mathrm{m}$. Im Kamerabild erscheinen sie mit einem Abstand von 66 Pixel, d. h. ein Kamerapixel entspricht $0.152 \mu \mathrm{m}$. Für die y-Richtung bekommt man den gleichen Faktor. Durch die Positionen der Striche läßt sich sehr gut eine Gerade legen. Lineare Regression liefert einen Korrelationskoeffizienten von $1-10^{-6}$. Das Bildfeld des Objektivs ist im beobachteten Bereich also verzerrungsfrei, was für diesen Objektivtyp aber auch zu erwarten war.

\footnotetext{
${ }^{6}$ infinity corrected system
} 


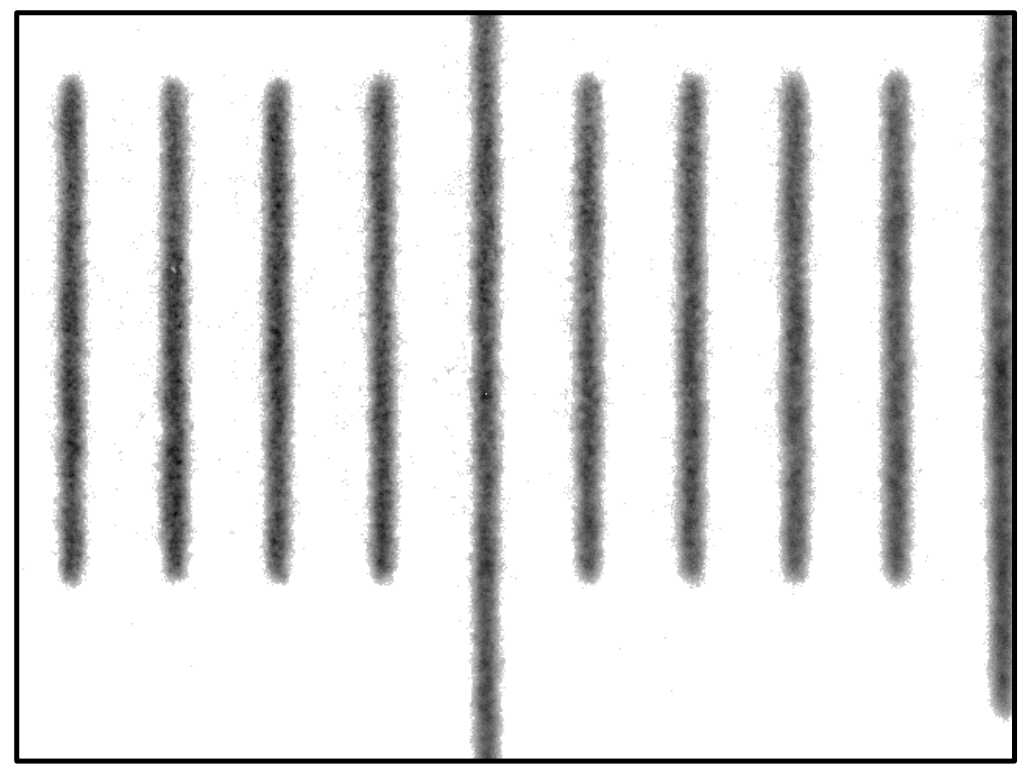

Abbildung 3.15: Bild eines Objektmikrometers zur Festlegung des Abbildungsmaßstabs. Die Teilstriche sind $10 \mu \mathrm{m}$ voneinander entfernt. Ein Kamerapixel entspricht $0.152 \mu \mathrm{m}$.

\subsubsection{Der Scantisch}

Das Objekt wurde nicht durch Strahlscannen, sondern durch Verschieben der Probe abgerastert. Dazu wurde das Objekt auf einem Tisch befestigt, der durch Piezos in der xy-Ebene verschoben werden konnte. Der ganze Tisch konnte über Mikrometerverschiebetische in allen drei Raumrichtungen positioniert werden. Die Piezos (P-286.30, Physik Instrumente) haben einen maximalen Stellweg von etwa $100 \mu \mathrm{m}$. Sie sind rechtwinklig zueinander angeordnet und halten über kurze, steife Federstahlbleche einen Rahmen aus VA-Stahl, auf dem der Objektträger angebracht wird. Sie werden über zwei Hochspannungsnetzteile angesteuert (siehe Abschnitt 3.2.5).

Das Verhalten des Scantisches wurde untersucht, indem das Bild eines bekanntes Objekts im Durchlicht mit dem Detektor aufgenommen wurde und die Position des Objekts für verschiedene Piezo-Spannungen ausgewertet wurde. Dabei kam es einerseits darauf an, die Spannungs/Dehnungs-Charakteristik der Piezos aufzunehmen, und andererseits festzustellen, ob der Scantisch mit der nötigen Geschwindigkeit den angelegten Spannungen folgt.

\subsubsection{Die Positionseichung der Scanner}

Als Objekt wurde ein kleines Stück eines Silizium-Wafers, in den ein quadratisches Loch geätzt war, benutzt. Dieses Objekt wurde gewählt, weil die Kanten des Loches sehr scharf sind, und man leicht Bilder mit gutem Kontrast erhält. Das Loch hatte eine Kantenlänge von $0.5 \mathrm{~mm}$, so daß nur eine Ecke des Lochs im Bild zu sehen 


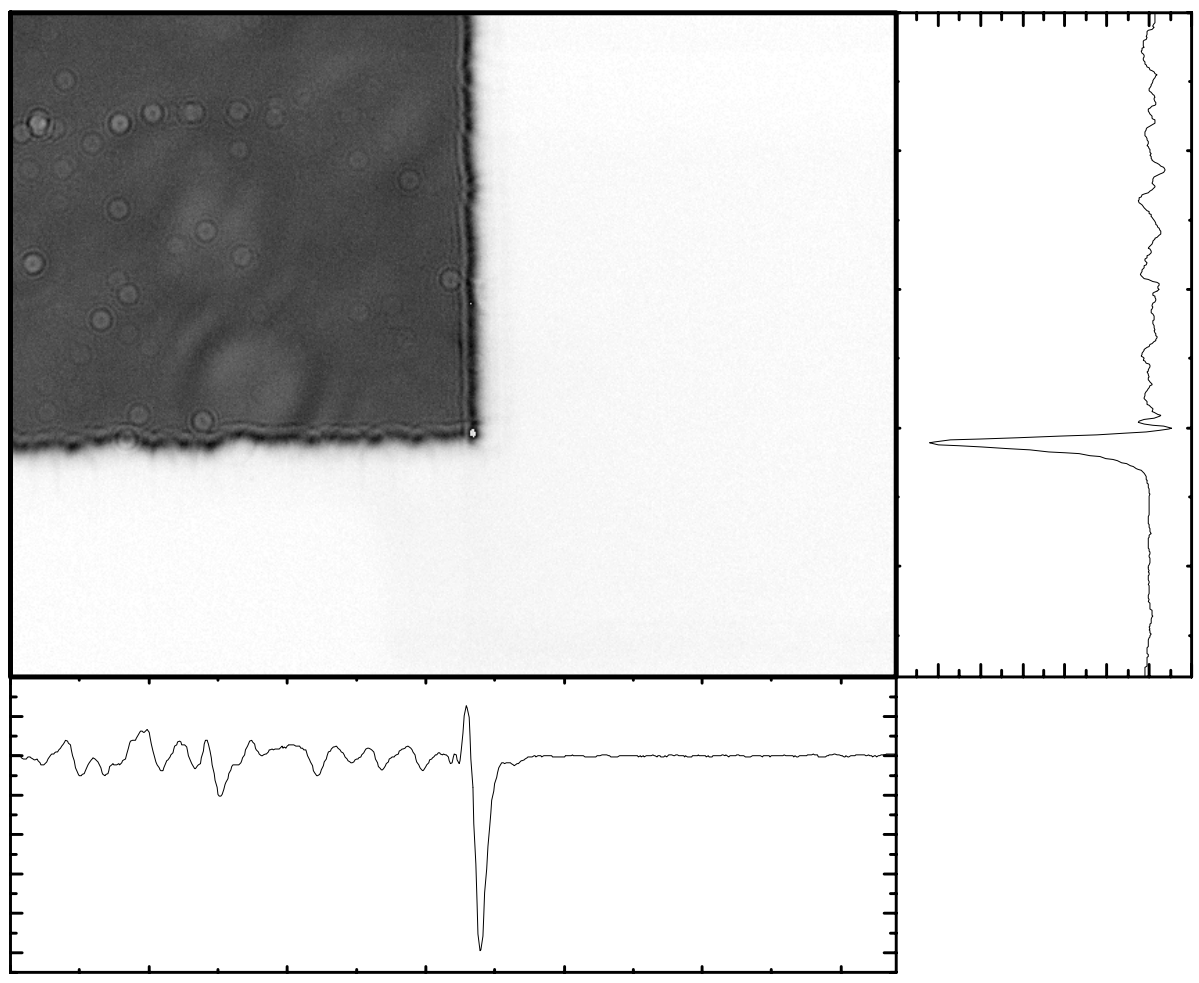

Abbildung 3.16: Typisches Bild des Lochs im Si-Wafer. Zur automatischen Bestimmung der Position der Ecke wurden senkrechte und horizontale Profile ausgewertet. Neben und unter dem Bild sind die differenzierten Profile dargestellt. Die Position der Ecke wurde durch die Orte mit der größten Steigung festgelegt.

war. Die Kanten wurden entlang der Kamera-Pixel ausgerichtet.

Abbildung 3.16 zeigt ein typisches Bild des Lochs. Als Maß für die Position des Objekts wurden die Koordinaten der Ecke benutzt. Die Position der Ecke läßt sich leicht automatisch auswerten, so daß die Eichkurven für den Scantisch weitgehend automatisch aufgenommen werden können.

Die Position der Ecke wurde bestimmt, indem zunächst ein über das ganze Bild gemitteltes, horizontales Profil berechnet wurde. Die Position mit der größten Steigung wurde als Schätzwert für die x-Koordinate der Ecke verwendet. In einem Bereich von \pm 30 Pixeln um diesen Schätzwert herum wurde dann ein gemitteltes, vertikales Profil berechnet. Die Position mit der größten Steigung wurde als $\mathrm{y}$-Position der Ecke benutzt. Die x-Position wurde dann analog aus einem um die y-Position gemittelten Profil bestimmt. Die so gewonnenen Werte schwanken, wenn viele Bilder bei unveränderter Position des Tisches aufgenommen werden, um 1.2 Pixel (rms). Dies entspricht einer Ungenauigkeit bei der Positionsbestimmung von $0.2 \mu \mathrm{m}$. Diese Art der automatischen Positionsbestimmung kann also als hinreichend genau angesehen werden.

Zur Aufnahme der Spannungs/Dehnungs-Charakteristik der Piezos wurde das 

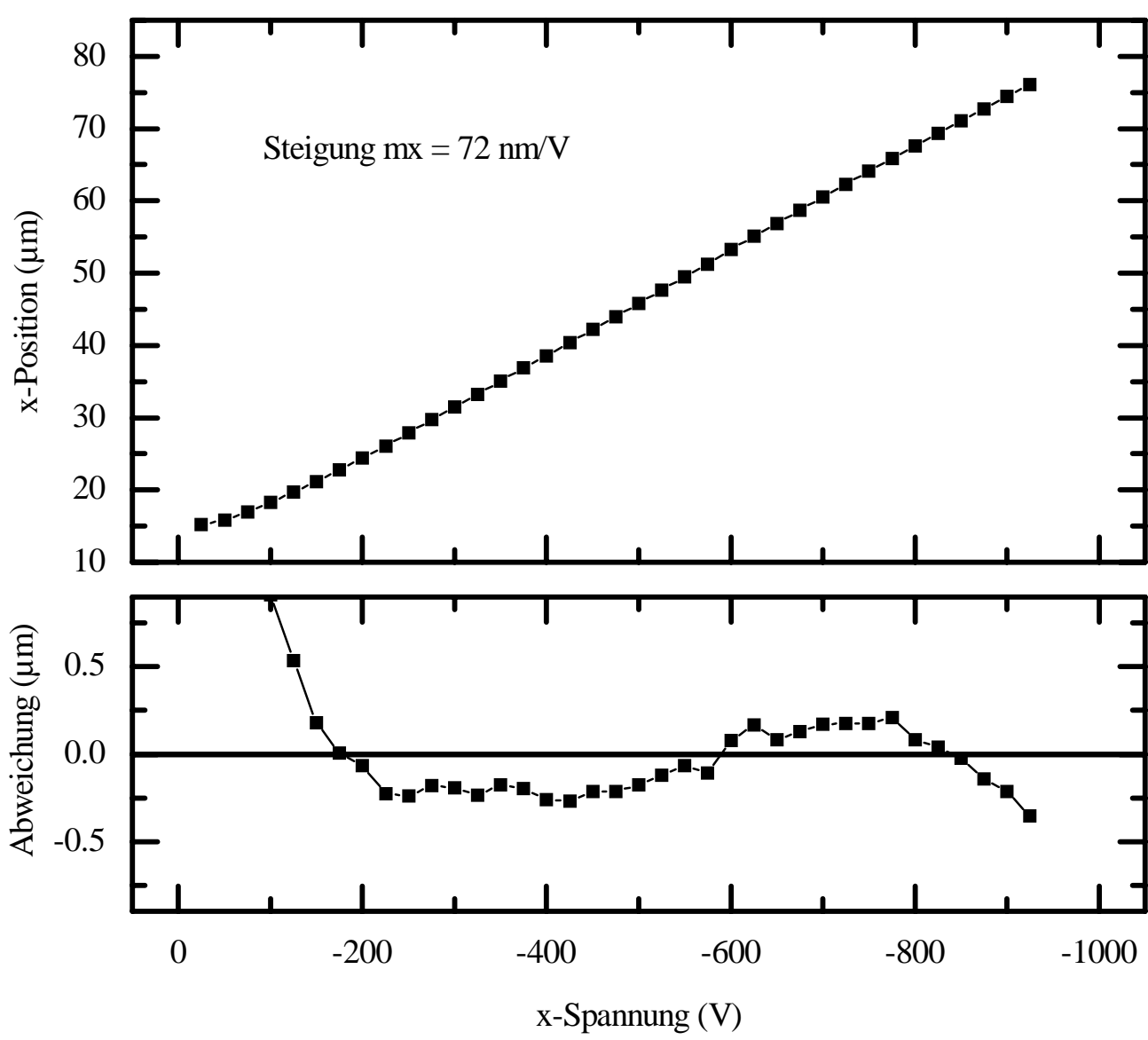

Abbildung 3.17: x-Position in Abhängigkeit von der angelegten Spannung. Die untere Kurve zeigt die Abweichung von der Regressionsgeraden.

Objekt durch Verändern der x/y-Spannungen in einem Raster bewegt und jeweils seine Position bestimmt. Um Hystereseeffekte zu vermeiden, wurden die Scanner dabei immer so bewegt, daß zunächst der x-Piezo vom minimalen auf den maximalen Wert gefahren wurde. Danach wurde er auf Null zurückgefahren und der y-Piezo wurde um einen Schritt erhöht. D. h. es wurde zum Scannen einer Zeile nur der Hin- und nicht der Rückweg ausgenutzt.

Man bekommt so eine Kalibriermatrix, mit deren Hilfe die angelegten Spannungen mit tatsächlichen Positionen des Objekts identifiziert werden können. Diese Matrix wird später bei der Rekonstruktion der Bilder aus den Rohdaten verwendet. Weil die $\mathrm{x}$ - und $\mathrm{y}$-Position für ein zweidimensionales Raster bestimmt wurde, können auch Kreuzkorrelationen zwischen $\mathrm{x}$ - und y-Position, wie sie z. B. auftreten, wenn die Scannerachsen nicht parallel zu den Zeilen und Spalten der Kamerapixel ausgerichtet sind oder die Achsen nicht unabhängig voneinander sind, erkannt werden.

Abbildung 3.17 zeigt eine typische Kurve für die x-Position in Abhängigkeit 
von der Spannung. Man erkennt einen im wesentlichen linearen Zusammenhang. Am Anfang des Scanbereichs treten merkliche Abweichungen auf und auch im zentralen Bereich ist der Verlauf nicht exakt linear, wie in der unteren Graphik zu sehen ist, in der eine Regressionsgerade von den Daten subtrahiert wurde. Zur Kalibrierung der Fluoreszenzcans wurden daher die gemessenen Positionen verwendet; Zwischenwerte wurden interpoliert.

\subsubsection{Die Geschwindigkeit der Scanner}

Da zur Positionsbestimmung ungebinnte Bilder (siehe hierzu Abschnitt 3.2.4.1) verwendet wurden, die sofort ausgewertet wurden, war eine Meßzeit von etwa einer Sekunde pro Bild nötig. Bei der Aufnahme von Fluoreszenzscans wird der Scantisch mit einer deutlich höheren Geschwindigkeit bewegt. Die Zeit zwischen zwei Bildern liegt hier bei etwa $5 \mathrm{~ms}$. Dies ist die minimale Zeit, die benötigt wird, um die CCD-Kamera auszulesen.

Um festzustellen, ob die Scanner diese schnelleren Bewegungen ausführen können, wurde ein xy-Scan des Silizium-Wafers unter den gleichen Bedingungen wie die Fluoreszenzscans durchgeführt. Die Bilder wurden mit maximaler Geschwindigkeit aufgenommen und in einem großen Datenpuffer, der erst nach der Messung ausgewertet wurde, abgelegt. Damit die Kamera mit maximaler Geschwindigkeit ausgelesen werden kann, muß das Bild in y-Richtung allerdings stark gebinnt werden (32fach). Die einzelnen Bilder haben dann eine Größe von $640 \times 15$ Pixel, d. h. die y-Position der Ecke kann nur noch sehr ungenau bestimmt werden. Da die schnelle Bewegung aber in x-Richtung stattfindet, genügt es, wenn die Position in dieser Richtung genau bestimmt werden kann.

Abbildung 3.18 zeigt die Ergebnisse einer solchen Messung. Die x-Positionen werden für jede Zeile gleichmäßig angefahren, wie die gleichmäßigen Rampen zeigen. Jede einzelne Rampe weicht an jeder Stelle des Anstiegs nur um ca. 0.8 Pixel (rms) vom Mittelwert aller Rampen ab.

Die Steigung einer einzelnen Rampe ist im Rahmen der Meßgenauigkeit gleich der, die beim langsamen Durchfahren des Rasters erhalten wurde.

Die y-Auflösung ist durch die kleine Pixelzahl nur sehr grob, die Kurve entspricht aber den Erwartungen aus den Messungen mit ungebinnten Bildern. Abweichungen treten in der ersten Zeile des Scans (Positionen $0 \ldots 29$ ) sowohl in der Xals auch in der y-Position dadurch auf, daß die Wartezeit zwischen Anfahren der Startposition und Beginn des Rasterns noch zu kurz eingestellt war.

Die starken Schwankungen am Ende der Profile entstehen dadurch, daß die Ecke durch den y-Piezo ganz aus dem Sichtbereich der Kamera herausgeschoben wurde, und der Algorithmus zur Positionsbestimmung daher willkürliche Werte liefert.

Zusammenfassend kann man sagen, daß die Piezos der Geschwindigkeit bei einem Fluoreszenzscan folgen können. 


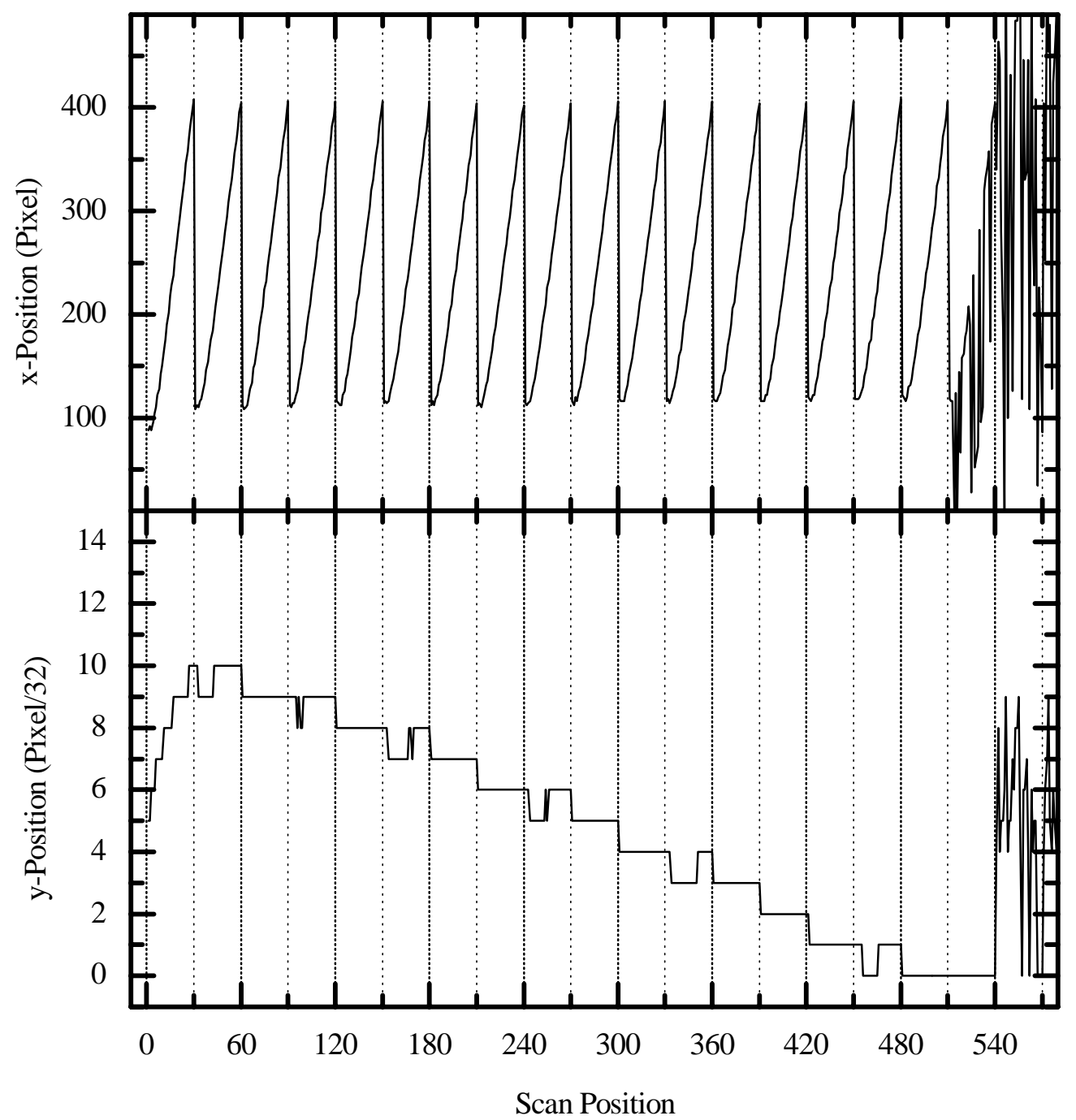

Abbildung 3.18: x- und y-Position der Ecke bei schneller Bewegung der Piezos. 


\begin{tabular}{|l|l|}
\hline Typ & $\begin{array}{l}\text { interline progressive scan mit } \\
\text {,lens-on-chip“ } \\
\text { double-shutter }\end{array}$ \\
\hline Pusführung & $640(H) \times 480(V)$ \\
Pixel & $9.9 \times 9.9 \mu \mathrm{m}^{2}$ \\
\hline Ausleserate & $12.5 \mathrm{MHz}$ \\
hor. Binning & $1 \ldots 8$ \\
ver. Binning & $1 \ldots 32$ \\
\hline AD-Wandler & $12 \mathrm{bit}$ \\
Ausleserauschen & $14 \mathrm{e}^{-}$ \\
Konversionsfaktor & $7.5 \mathrm{e}^{-} /$Count \\
\hline
\end{tabular}

Tabelle 3.2: Ausgewählte technische Daten zur CCD-Kamera.

\subsubsection{Der Detektor}

Der Detektor hat zwei Aufgaben in diesem Experiment. Zum einen soll er zweidimensionale Bilder der Fluoreszenz der einzelnen Teilstrahlen liefern, zum anderen soll er durch extrem kurze Verschlußzeiten die Möglichkeit zur Messung der Fluoreszenzlebensdauer bieten. Dementsprechend besteht der Detektor aus zwei Teilen: einer CCD-Kamera als flächigem Detektor und einem Bildverstärker als Verschluß. Die beiden Teile werden im folgenden beschrieben.

\subsubsection{Die CCD-Kamera}

Bei der CCD-Kamera handelt es sich um eine Imager3 (LaVision). In Tabelle 3.2 sind einige Daten zur Kamera zusammengestellt.

Ein wichtiger Parameter der CCD-Kamera ist die Auslesegeschwindigkeit, da für jede Scanposition ein Bild aufgenommen wird und die maximale Scangeschwindigkeit daher von der Bildaufnahmerate mitbestimmt wird.

Die Kamera ist eine interline-Kamera, d. h. für jede Zeile, die belichtet wird, gibt es eine lichtunempfindliche Zeile, die als Speicher dient. Die lichtunempfindlichen Zeilen liegen dabei zwischen den belichteten Zeilen. Linsen, die direkt auf jedem Pixel angebracht sind, sorgen dafür, daß das Licht auf die lichtempfindlichen Pixel fokussiert wird, damit möglichst viel von der Chipfläche zum Lichtsammeln ausgenutzt wird.

Fällt Licht auf die sensitiven Pixel, werden in ihnen freie Ladungsträger erzeugt. Die Quanteneffizienz hängt von der Wellenlänge des einfallenden Lichts ab und liegt im Bereich von $350-550 \mathrm{~nm}$ zwischen 0.3 und 0.4. Nachdem der Chip belichtet wurde, werden die Ladungen von den lichtempfindlichen Zeilen sehr schnell $(<200 \mathrm{~ns})$ in die Speicherzeilen geschoben.

Zum Auslesen des Chips werden die Speicherzeilen nacheinander in ein Ausleseregister transportiert. Das Ausleseregister kann jeweils eine Zeile aufnehmen und wird Pixel für Pixel über einen Verstärker und einen A/D-Wandler ausgewertet. 


\begin{tabular}{|r|r|r|}
\hline ybin & Zeit [ms] & Bildrate $[\mathrm{Hz}]$ \\
\hline 1 & 33 & 30 \\
2 & 17 & 59 \\
4 & 17 & 59 \\
8 & 9 & 111 \\
16 & 5 & 200 \\
32 & 4.2 & 240 \\
\hline
\end{tabular}

Tabelle 3.3: Auslesezeit der CCD-Kamera in Abhängigkeit vom vertikalen Binningfaktor (ybin).

Das horizontale Verschieben vom Ausleseregister in den Verstärker geschieht dabei mit $12.5 \mathrm{MHz}$ - diese Rate ist wesentlich für die Geschwindigkeit des ganzen Ausleseprozesses.

Das Auslesen der Kamera kann durch sogenanntes Binning beeinflußt werden. Dabei werden die Ladungen mehrerer Pixel vor dem Digitalisieren aufsummiert. ${ }^{7}$ Beim horizontalen Binning, bei dem mehrere Spalten zusammengefaßt werden, geschieht dies direkt im Ausleseverstärker, d. h. der Transport der Ladungen läuft genauso wie ohne Binning ab. Man erhält daher auch keine Geschwindigkeitssteigerung durch horizontales Binning.

Beim vertikalen Binning werden die Ladungen ganzer Zeilen im Ausleseregister aufsummiert bevor das Ausleseregister zum Verstärker geschoben wird. In erster Näherung sinkt daher die Auslesezeit für ein Bild proportional zum vertikalen Binningfaktor. Bei großen Faktoren macht sich jedoch die Dauer für das Transportieren der Zeilen in das Ausleseregister bemerkbar, so daß der Geschwindigkeitsgewinn dann kleiner wird. In Tabelle 3.3 sind die Auslesezeiten für ein Bild für die verschiedenen Binningfaktoren angegeben. Die tatsächlich für die Aufnahme eines Bildes benötigte Zeit ist die Summe aus Belichtungszeit und Auslesezeit.

Neben der Auslesegeschwindigkeit beeinflußt das Binning das Signal/RauschVerhältnis. Daher ist auch horizontales Binning, besonders bei schwachen Signalen, sinnvoll.

\subsubsection{Rauschen und Linearität der Kamera}

Das Rauschen der CCD-Kamera wird durch zwei Größen bestimmt: das konstante Ausleserauschen des Verstärkers und die Schwankung der auf einem Pixel erzeugten freien Elektronen. Die Zahl der Elektronen folgt der Poisson-Statistik, das heißt, wenn im Mittel $n$ freie Elektronen erzeugt werden, schwankt ihre Zahl um $\sqrt{n}$ (rms). Legt man diese zwei Rauschquellen zugrunde, kann man das Signal/Rausch-

\footnotetext{
${ }^{7}$ Dies ist das sogenannte Hardware-Binning. Davon unterschieden werden muß SoftwareBinning, bei dem die Werte mehrerer Pixel nach dem Digitalisieren addiert werden. Vergleiche dazu auch Gl. (3.26) und Gl. (3.28) im nächsten Abschnitt. Ist die Art des Binnings nicht ausdrücklich angegeben, ist immer Hardware-Binning gemeint.
} 
Verhältnis abschätzen.

Das Signal $s$ (in Counts), das ein Pixel liefert, ist die Summe aus konstantem Dunkelbild $u$ und dem Signal der Elektronen:

$$
s=u+c n
$$

Dabei ist $c$ der Konversionsfaktor des A/D-Wandlers (in Counts/Elektron). Die Varianz des Signals ist:

$$
\sigma^{2}=(c \Delta n)^{2}+(c \sqrt{n})^{2}=c^{2}\left(\Delta n^{2}+n\right)
$$

$\Delta n$ ist dabei das Ausleserauschen in Elektronen.

Das Verhältnis von Standardabweichung und Signal, von dem der konstante Untergrund abgezogen wird, ist:

$$
\frac{\sigma}{c n}=\sqrt{\frac{\Delta n^{2}}{n^{2}}+\frac{1}{n}}
$$

Der erste Term in diesem Ausdruck kommt durch das Ausleserauschen, der zweite durch die Poisson-Statistik zustande. Bei großem Signal dominiert die Zählstatistik das Rauschen. Das Ausleserauschen wird erst dann wesentlich, wenn die Zahl der auf einem Pixel freigesetzten Elektronen so klein ist, daß gilt $n<\Delta n^{2}$.

Hardware Binning führt zu einer Verbesserung des Signal/Rausch-Verhältnisses, ${ }^{8}$ indem die Elektronen mehrerer Pixel zusammengefaßt werden.

$$
s_{h b}=u+\sum_{i} c n_{i}=u+c N
$$

Wesentlich ist, daß das Ausleserauschen dabei nicht zunimmt. Man bekommt für das Signal/Rausch-Verhältnis den gleichen Ausdruck wie in Gl. (3.24), nur daß statt der Zahl der Elektronen eines Pixels die Gesamtzahl der Elektronen $N$ auftaucht.

$$
\frac{\sigma_{h b}}{c N}=\sqrt{\frac{\Delta n^{2}}{N^{2}}+\frac{1}{N}}
$$

Software Binning, bei dem nach der Digitalisierung die Werte mehrerer Pixel addiert werden, verbessert ebenfalls das Signal/Rausch-Verhältnis, allerdings nicht so stark wie Hardware Binning, da das Ausleserauschen bei jedem Pixel einen Beitrag liefert.

$$
\begin{gathered}
\sigma_{s b}^{2}=\sum_{i=1}^{m} \sigma_{i}^{2}=\sum_{i=1}^{m}\left((c \Delta n)^{2}+(c \sqrt{n})^{2}\right)=c^{2}\left(m \Delta n^{2}+N\right) \\
\frac{\sigma_{s b}}{c N}=\sqrt{\frac{m \Delta n^{2}}{N^{2}}+\frac{1}{N}}
\end{gathered}
$$

$\mathrm{m}$ gibt hier die Anzahl der Pixel, die addiert werden, an.

Man erkennt an den Formeln, daß die Zählstatistik eine obere Grenze für das Signal/Rausch-Verhältnis vorgibt. Durch Binning kann nur der Einfluß des Ausleserauschens gemildert werden, so daß sich das Signal/Rausch-Verhältnis dem durch 


\begin{tabular}{|r|c|}
\hline Methode & SNR $(\mathrm{cn} / \sigma)$ \\
\hline ohne Binning & 4.5 \\
Poisson-Statistik & 8.7 \\
\hline Software Binning (x8) & 12.9 \\
Hardware Binning (x8) & 21.3 \\
Poisson-Statistik & 24.5 \\
\hline
\end{tabular}

Tabelle 3.4: Der Einfluß des Binnings auf das Signal/Rausch-Verhältnis. Es wurden folgende Werte angenommen: $\Delta n=14, n=75$ (das entspricht 10 counts).

die Poisson-Statistik der Elektronen bestimmten Wert annähert. In Tabelle 3.4 ist ein Beispiel mit für diese Kamera typischen Werten durchgerechnet.

Das bisher gesagte gilt für den Fall, daß die freien Elektronen tatsächlich durch Licht erzeugt wurden und als Signal angesehen werden können. Es werden jedoch auch thermisch freie Elektronen auf den Pixeln erzeugt. Ihre Zahl steigt proportional zur Belichtungszeit an, so daß dieser Effekt nur bei großen Belichtungszeiten wichtig wird. Für das Signal/Rausch-Verhältnis gilt dann:

$$
\begin{aligned}
s & =u+c\left(n+n_{t h}\right) \\
\sigma^{2} & =c^{2}\left(\Delta n^{2}+n+n_{t h}\right) \\
\frac{\sigma}{c n} & =\sqrt{\frac{\Delta n^{2}+n_{t h}}{n^{2}}+\frac{1}{n}}
\end{aligned}
$$

Das heißt, der thermische Untergrund macht sich wie ein erhöhtes Ausleserauschen bemerkbar. Die Rate, mit der die thermischen Elektronen gebildet werden, hängt stark von der Temperatur ab. Daher wird der CCD-Chip in der Kamera auf $-15^{\circ} \mathrm{C}$ gekühlt; dann beträgt die Zahl der thermischen Elektronen $<0.1 \mathrm{~s}^{-1}$ pro Pixel.

Bei den hier verwendeten Belichtungszeiten von wenigen Millisekunden, können die thermischen Elektronen vernachlässigt werden.

Um zu überprüfen, inwieweit das Rauschen der Kamera tatsächlich diesen Gesetzmäßigkeiten folgt, wurde das Signal/Rausch-Verhältnis in Abhängigkeit vom Signal untersucht. Dazu wurden 100 Bilder bei konstanter Beleuchtung aufgenommen und für jedes Pixel der Mittelwert und die Standardabweichung des Signals berechnet. Dies wurde für verschiedene Beleuchtungsstärken wiederholt, um möglichst den gesamten Dynamikbereich der Kamera abzudecken. Diese Messung wurde einmal ohne Binning und einmal mit $8 \times 16$ Binning durchgeführt.

Abbildung 3.19 zeigt das so bestimmte Signal/Rausch-Verhältnis zusammen mit einem Fit der theoretischen Kurve. Als Parameter gehen in das Modell der Untergrund $u$, der direkt aus dem Dunkelbild der Kamera abgelesen wurde, und das Ausleserauschen $\Delta n$ sowie der Konversionsfaktor $c$ ein. Bei der Messung ohne Binning bekommt man eine sehr gute Übereinstimmung zwischen Fit und Messung für die vom Hersteller angegebenen Werte $\Delta n=14$ und $c=1 / 7.5$; bei der Mes-

\footnotetext{
${ }^{8}$ Das Signal/Rausch-Verhältnis SNR ist der Kehrwert von (3.24).
} 

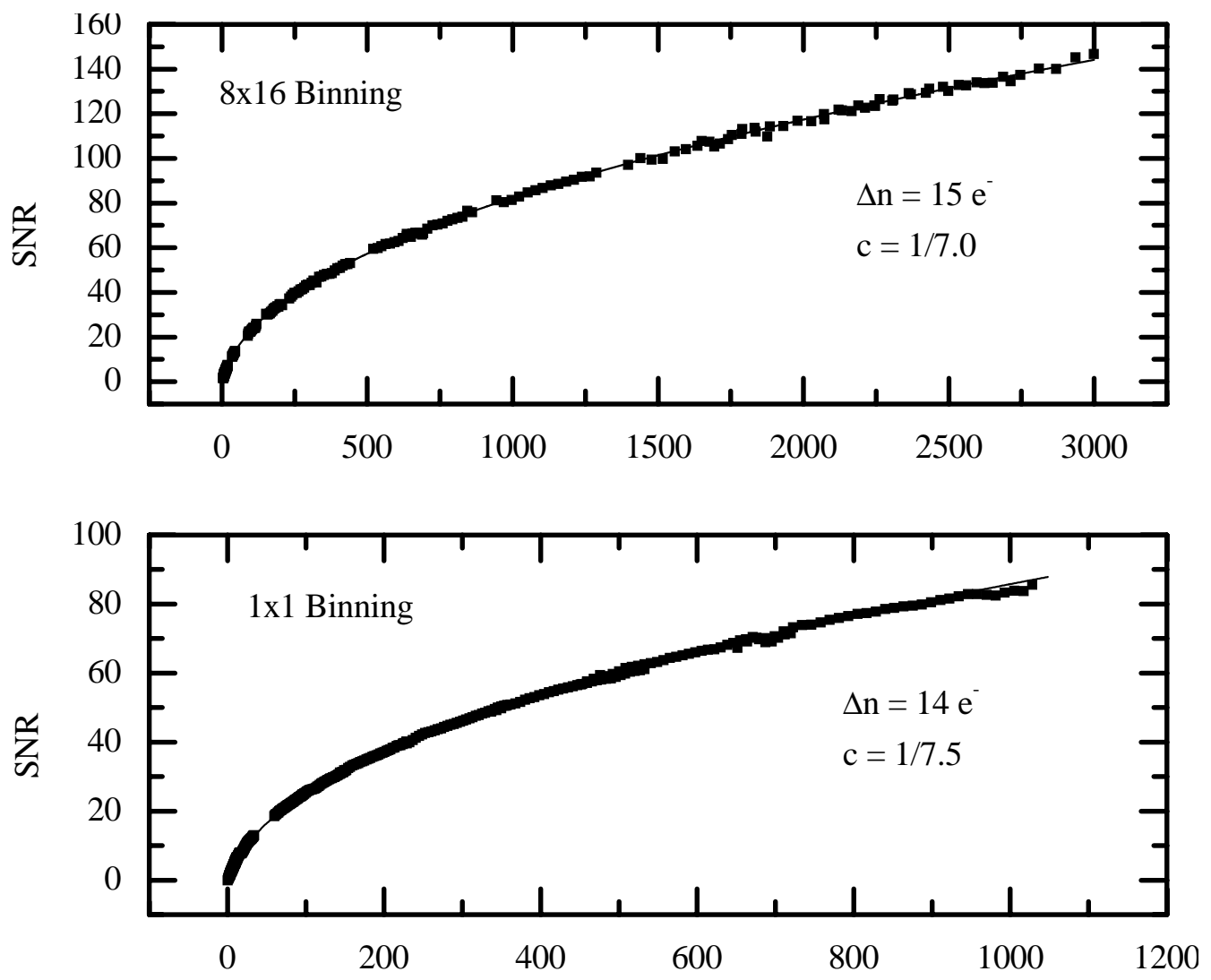

Signal (Counts)

Abbildung 3.19: Experimentell bestimmtes Signal/Rausch-Verhältnis der CCDKamera: 1.) ohne Binning, 2.) mit $8 \times 16$ Binning.

sung mit $8 \times 16$ Binning erhält man die beste Übereinstimmung für etwas andere Werte: $\Delta n=15$ und $c=1 / 7.0$. Beide Kurven stimmen aber sehr gut mit dem theoretischen Modell überein und bestätigen so die obigen Betrachtungen.

Die Linearität der Kamera wurde durch Veränderung der Belichtungszeit bei konstanter Beleuchtung überprüft. Dabei wurde festgestellt, daß die Kamera über den gesamten Dynamikbereich linear reagiert, d. h. es kommt zu keinen Sättigungseffekten durch zu geringe „full-well capacity“ der Pixel.

\subsubsection{Der ps-Bildverstärker}

Die Verschlußzeiten von bis zu $0.2 \mathrm{~ns}$, durch die die Fluoreszenzlebensdauer gemessen werden kann, wurden mit einem speziellen Bildverstärker (HRI, Kentech) realisiert. Er besteht aus einer S20 Photokathode ( $\varnothing 18 \mathrm{~mm})$, einer einstufigen MCP und einem P47 Phosphorschirm. Bei diesem Bildverstärker wird die Photokathode durch einen schnellen Spannungspulser für Zeiten zwischen $0.2-1 \mathrm{~ns}$ freigeschal- 
tet; die maximale Wiederholrate beträgt $100 \mathrm{MHz}$. Da die Laserpulse mit einer Rate von nur $76 \mathrm{MHz}$ emittiert werden, kann der Bildverstärker, synchron zum Laser, für jeden Puls geöffnet werden.

Um Instabilitäten und Drifts beim Öffnen des Bildverstärkers zu vermeiden, wurde die Photokathode kontinuierlich mit $76 \mathrm{MHz}$ getriggert. Ein- und ausgeschaltet wurde der Bildverstärker durch die Hochspannung an der MCP. Dies wurde über einen TTL-Eingang der Bildverstärkerelektronik (inhibit) gesteuert. Die Hochspannung an der MCP konnte zwischen $240 \mathrm{~V}$ (inhibit = high) und $960 \mathrm{~V}$ geregelt werden.

Zur Triggerung des Bildverstärkers wurde ein Reflex des Laserstrahls auf eine schnelle Photodiode (Hamamatsu S5973) gelenkt. Deren Pulse wurden durch einen Hochfrequenzverstärker 16 fach auf eine Amplitude von etwa $1 \mathrm{~V}$ verstärkt und über ein programmierbares passives Kabeldelay der Bildverstärkerelektronik zugeführt.

Das Kabeldelay besteht aus 8 hintereinandergeschalteten Hochfrequenzrelais, die den Triggerpuls je nach Stellung entweder mit minimaler Verzögerung oder durch ein Kabel, das eine Verzögerung des Pulses um eine definierte Zeit bewirkt, weiterleiten. Die Längen der Kabel sind dabei so gewählt, daß sie netto Verzögerungen von 0.1, 0.2, 0.4, 0.8, 1.6, 3.2, 6.4 und 12.8 ns zur Folge haben. Durch Kombinationen der Kabel können dann Verzögerungen von 0 bis 25.5 ns eingestellt werden. ${ }^{9}$ Das Kabeldelay ist mit einer seriellen Schnittstelle ausgerüstet, so daß die Verzögerungszeit mit dem Computer eingestellt werden kann.

Der Phosphorschirm des Bildverstärkers wurde 1:1 über zwei Photoobjektive ( $\left.f=50 \mathrm{~mm}, f_{\#}=1.4\right)$, die mit den Eintrittsöffnungen gegeneinander gerichtet waren, auf den CCD-Chip abgebildet. Dieser Abbildungsmaßstab wurde gewählt, damit die Teilstrahlen auf den Bildern weit genug voneinander entfernt waren, um mit starkem Binning arbeiten zu können, ohne den Abstand der Strahlen in der Probe vergrößern zu müssen. Da der CCD-Chip deutlich kleiner als der Phosphorschirm ist, wurde also nur ein Teil des Bildverstärkers verwendet.

Für den Phosphorschirm des Bildverstärkers wurde P47 verwendet, obwohl dessen Effizienz nur etwa ein Drittel anderer üblicher Phosphore (z. B. P43) beträgt, weil P47 eine relativ kurze Leuchtdauer von 100 ns hat [92]. Bei anderen Phosphoren ist diese Zeit bis zu einige Millisekunden lang.

Ein kurzes Nachleuchten des Phosphors ist nötig, damit das Bild, das die Kamera aufnimmt, tatsächlich der aktuellen Rasterposition entspricht und nicht durch das Nachleuchten des Bildes der vorigen Position gestört wird.

\subsubsection{Die Kalibrierung des Detektors}

Um die absolute Signalstärke aus den Counts der Kamerabilder berechnen zu können, ist es nötig, den Umrechnungsfaktor zwischen der Anzahl der an der Photokathode ausgelösten Elektronen und den Counts zu bestimmen. Dieser Faktor hängt

\footnotetext{
${ }^{9} \mathrm{Zu}$ diesen Zeiten kommt die Durchgangszeit durch das Gerät, die etwa 4 ns beträgt, natürlich noch hinzu. Diese Zeit spielt allerdings in diesem Experiment, wo die Pulse mit hoher Repetitionsrate etwa alle $13 \mathrm{~ns}$ kommen, keine Rolle.
} 
natürlich von der Spannung an der MCP ab, doch es gehen auch noch andere GröBen wie die Effizienz der Abbildungsoptik zwischen Phosphor und CCD-Chip und die Quanteneffizienz des Chips ein.

Um den Umrechnungsfaktor von Counts in Photoelektronen in Abhängigkeit von der MCP-Spannung zu bestimmen, wurden zunächst bei maximaler Spannung Bilder aufgenommen. Die Verstärkung ist dann so groß, daß einzelne Photoelektronen problemlos nachgewiesen werden können. Dabei wurde mit so geringer Beleuchtungsstärke gearbeitet, daß auf jedem Bild nur wenige Ereignisse $(<10)$ detektiert wurden. Um das Verhältnis von Signal zu Untergrundrauschen zu optimieren, wurde mit $8 \times 8$ Binning gearbeitet. Das Signal eines Photoelektrons wird dann auf einem $3 \times 3$ Pixel großen Bereich komprimiert. Durch einen automatischen Auswertealgorithmus wurden für alle Ereignisse des Bildes die Counts bestimmt und in einem Histogramm abgespeichert.

Der Algorithmus suchte jeweils das Maximum im Bild und berechnete die Summe der Counts auf einem um dieses Maximum zentrierten $3 \times 3$ Bereich. Die Summe wurde um das Dunkelbild der Kamera korrigiert und dann als Signal eines Photoelektrons gespeichert. Der $3 \times 3$ Bereich wurde gelöscht, indem die Werte durch die entsprechenden Werte des Dunkelbilds der Kamera ersetzt wurden. Dann wurde wieder das aktuelle Maximum gesucht und ausgewertet, usw. Abgebrochen wurde, wenn das Maximum sich nur noch um weniger als ein Schwellwert (hier 20 Counts) vom Wert des Dunkelbilds unterschied.

Die Wahl des Schwellwerts hat einen Einfluß auf den Teil des Histogramms, der zu den niedrigen Counts gehört. Wird der Schwellwert zu hoch angesetzt, werden schwache Ereignisse nicht erkannt, wird er zu niedrig gewählt, wird das Rauschen der Kamera mit steigender Wahrscheinlichkeit als Ereignis erkannt.

Es ist allerdings besser, einen eher niedrigen Schwellwert zu wählen, da man das Histogramm vom Einfluß des Kamerarauschens bereinigen kann, indem die ganze Messung mit abgeschaltetem Bildverstärker wiederholt wird und das Histogramm von der Messung mit Bildverstärker abgezogen wird. ${ }^{10}$ So wurde hier auch überprüft, daß der Schwellwert von 20 Counts nicht zu hoch war. Für ein Histogramm wurden einige tausend Bilder aufgenommen.

Abbildung 3.20 zeigt das um das Kamerarauschen bereinigte Histogramm der Counts pro Photoelektron bei einer MCP-Spannung von 940 V. Das Histogramm deckt einen breiten Bereich ab, wie es für eine einstufige MCP zu erwarten ist; im Mittel erhält man 110 Counts/PE.

Um den Umrechnungsfaktor für andere MCP-Spannungen zu bestimmen, wurde eine konstante Lichtquelle bei verschiedenen Spannungen und Belichtungszeiten aufgenommen und die Ergebnisse auf den Wert bei 940 V skaliert. Abbildung 3.21 zeigt die so erhaltene Abhängigkeit der Counts pro Photoelektron von der MCPSpannung. Bei einer Spannung von $800 \mathrm{~V}$, die bei den meisten Messungen verwendet wurde, beträgt der Wert 29 Counts/PE.

\footnotetext{
${ }^{10}$ Man kann das Histogramm, das sich durch das Rauschen der Kamera ergibt, auch nach den Formeln in Abschnitt 3.2.4.2 berechnen. Auch hier ergibt sich eine sehr gute Übereinstimmung mit dem gemessenen Histogramm.
} 


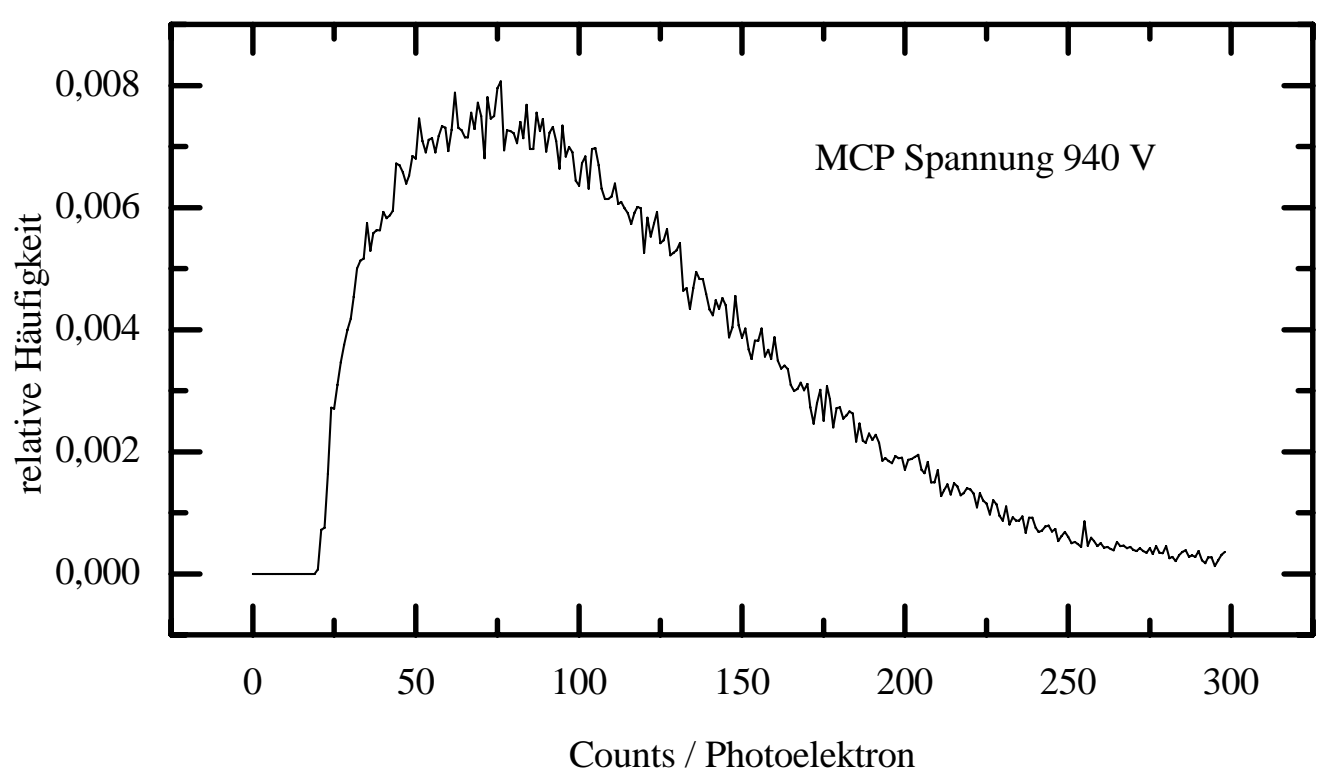

Abbildung 3.20: Histogramm der Counts pro Photoelektron bei einer MCPSpannung von $940 \mathrm{~V}$. Im Mittel bekommt man 110 Counts/PE.

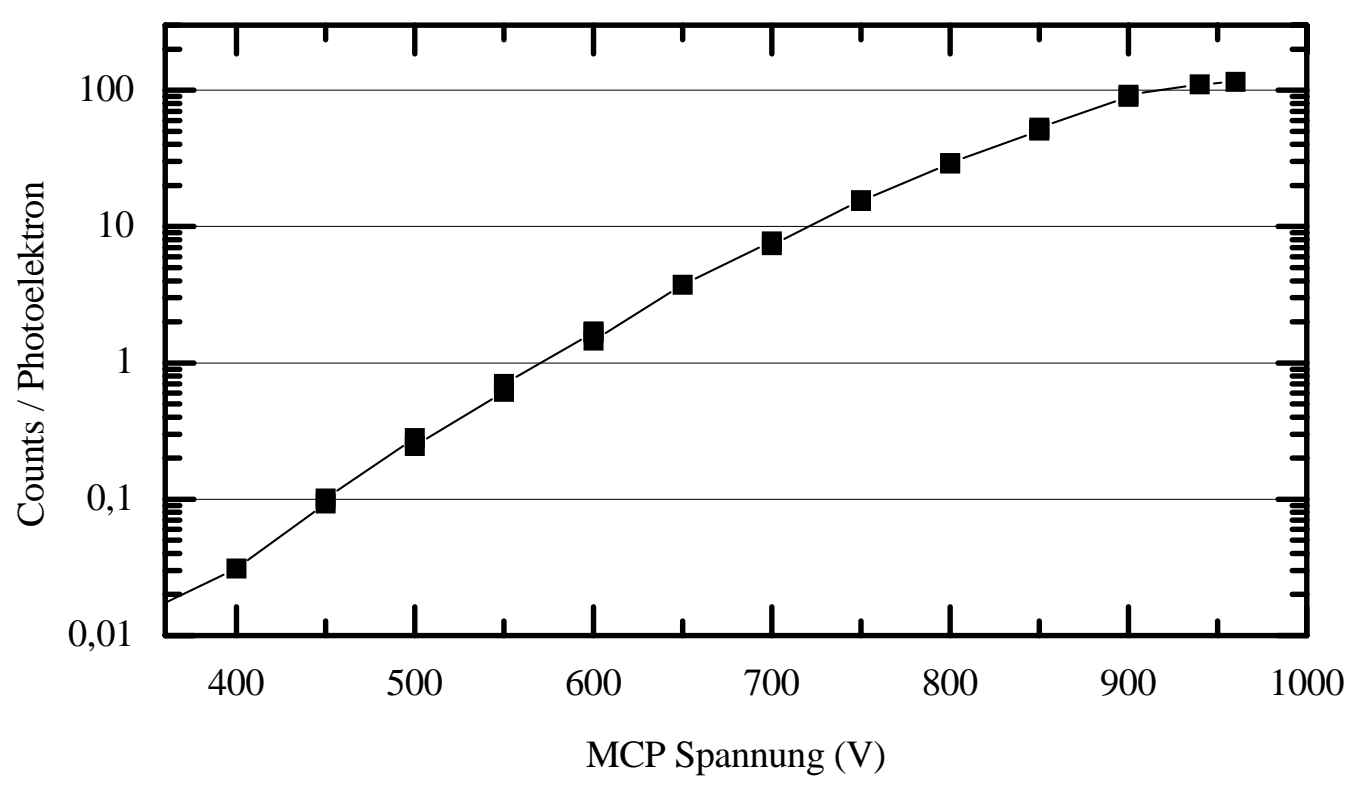

Abbildung 3.21: Abhängigkeit der Counts pro Photoelektron von der MCPSpannung. 

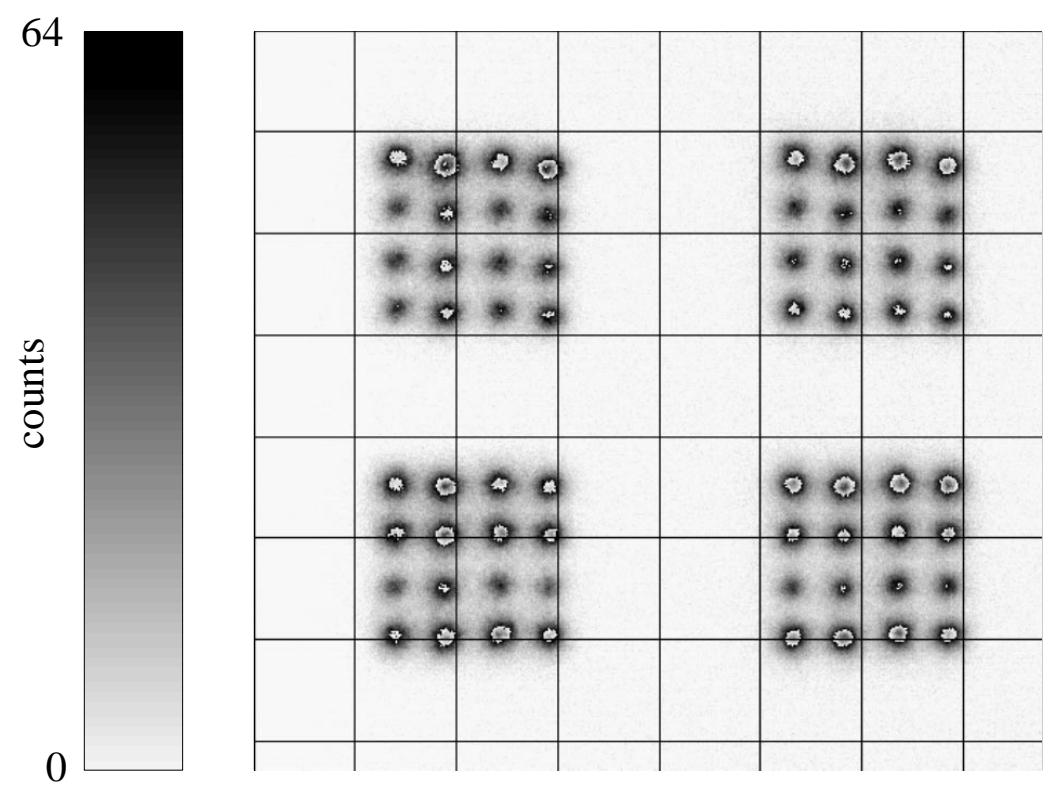

Abbildung 3.22: Typisches Bild der Fluoreszenz aller Teilstrahlen (ohne Binning). Das Raster hat einen Abstand von $10 \mu \mathrm{m}$. Die Spannung an der MCP des Bildverstärkers betrug $740 \mathrm{~V}$, die Belichtungszeit $10 \mathrm{~ms}$.

\subsubsection{Einzelbilder der Fluoreszenz der Teilstrahlen}

Abbildung 3.22 zeigt ein typisches Bild der Fluoreszenz aller Teilstrahlen, das ohne Binning für eine Position der Scanner aufgenommen wurde. Als Probe wurde eine homogene Farbstoffschicht verwendet, daher sind alle Strahlen gleichzeitig zu sehen. Die Spannung an der MCP des Bildverstärkers betrug $740 \mathrm{~V}$, die Belichtungszeit $10 \mathrm{~ms}$, der Abstand zwischen den Strahlen $5 \mu \mathrm{m}$. Daß die Strahlen in 4 Blocks zu je $4 \times 4$ angeordnet sind, hängt mit dem Aufbau des Strahlvervielfachers zusammen: Durch die endliche Dicke des 50\% Spiegels müssen die Strahlenbündel, die links und rechts vom 50\% Spiegel austreten, einen Mindestabstand voneinander haben. Dieses Problem tritt in beiden Stufen der Strahlaufspaltung auf, deshalb bleibt horizontal und vertikal eine Lücke zwischen je 4 Strahlen.

An dem Bild in Abbildung 3.22 läßt sich erkennen, wie groß die Unterschiede zwischen den einzelnen Teilstrahlen sind. Die Fluoreszenzintensitäten der 64 Strahlen schwanken mit einer Standardabweichung von 24\% um den Mittelwert; die größte Abweichung vom Mittelwert beträgt 56\%. Durch Normierung können die Unterschiede zwischen den einzelnen Strahlen und Übersprechen bei der Auswertung von Scans korrigiert werden (siehe Abschnitt 3.3.3).

Die Breite der Peaks beträgt $2.7 \mu \mathrm{m}$ (FWHM). Der Grund für diese große Breite ist die Modulationstransferfunktion (MTF) des Bildverstärkers. Abbildung 3.23 zeigt zum Vergleich zwei horizontale Profile der Fluoreszenzintensität, von denen das eine mit Bildverstärker und das andere direkt mit der CCD-Kamera aufgenom- 


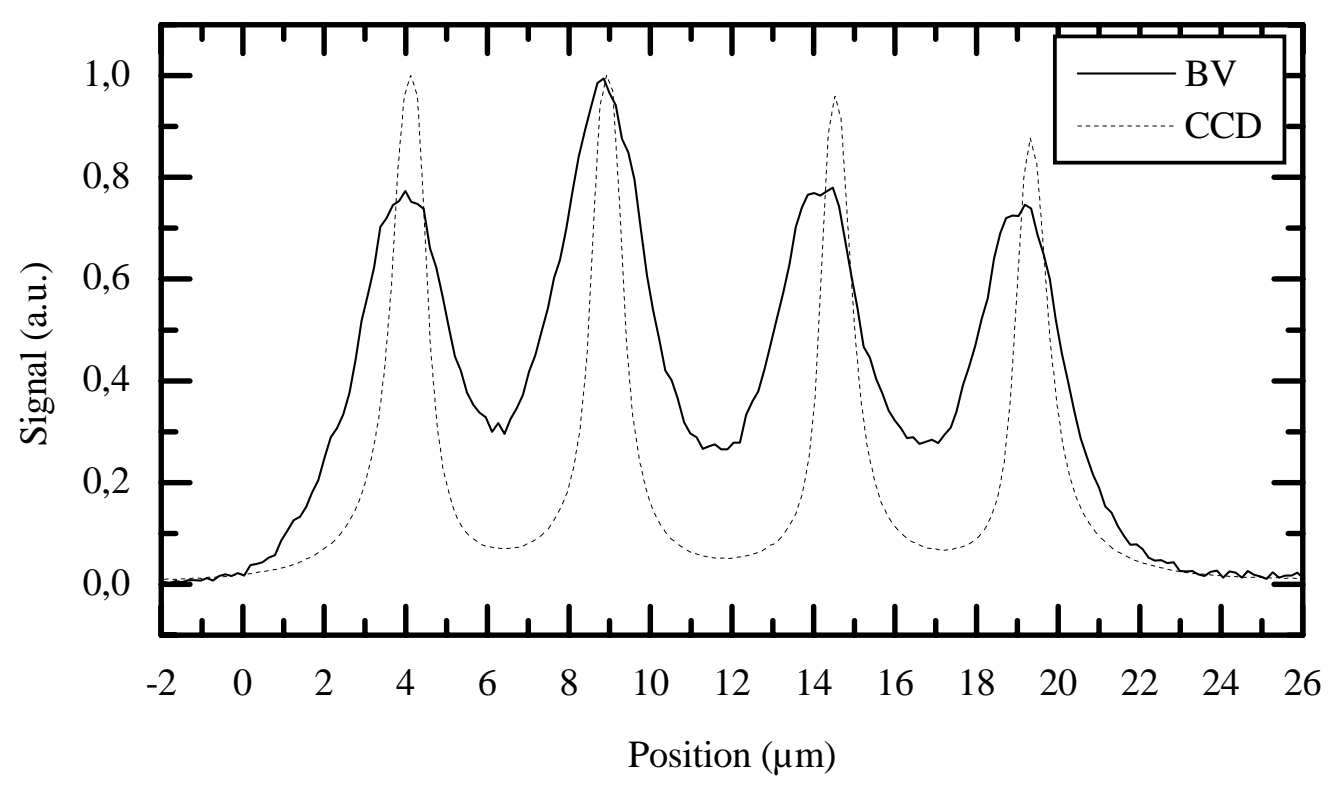

Abbildung 3.23: Horizontale Intensitätsprofile der Fluoreszenz der einzelnen Teilstrahlen. Mit Bildverstärker (-), direkt mit der CCD-Kamera aufgenommen (- $-)$.

men wurde. Ohne den Bildverstärker haben die Peaks eine Breite von nur $0.8 \mu \mathrm{m}$ (FWHM).

Die maximale Bildrate $(240 \mathrm{~Hz})$ erreicht man bei der Kamera mit einem vertikalen Binningfaktor von 32; das resultierende Bild hat dann nur noch 15 Zeilen. Da es schwierig war, die Fluoreszenz der einzelnen Teilstrahlen bei dieser Einstellung voneinander zu trennen, wurde in der Regel mit einem vertikalen Binningfaktor von 16, d. h. einer maximalen Bildrate von $200 \mathrm{~Hz}$, gearbeitet. Der tatsächliche Geschwindigkeitsverlust durch den geringeren Binningfaktor war noch kleiner, da die Belichtungszeit (typ. $1 \mathrm{~ms}$ ) noch berücksichtigt werden muß. Um die anfallende Datenmenge klein zu halten, wurde maximales horizontales Binning ( $8 \mathrm{fach}$ ) verwendet.

Abbildung 3.24 zeigt ein Einzelbild, das mit Binning 8x16 aufgenommen wurde. Die Belichtungzeit betrug $10 \mathrm{~ms}$ die MCP-Spannung $540 \mathrm{~V}$. Bilder dieser Art wurden bei den Scans für jede Position der Probe aufgenommen und dann weiterverarbeitet.

\subsubsection{Die Steuerung der Messungen}

Der gesamte Ablauf eines Scans wurde mittels einer digitalen Ein/Ausgabe-Karte (Bestec buffered PIO) von einem PC automatisch gesteuert. Fünf Ausgabeleitungen wurden verwendet: eine für den Bildverstärker, eine für die CCD-Kamera und drei zur Steuerung der Piezos. 


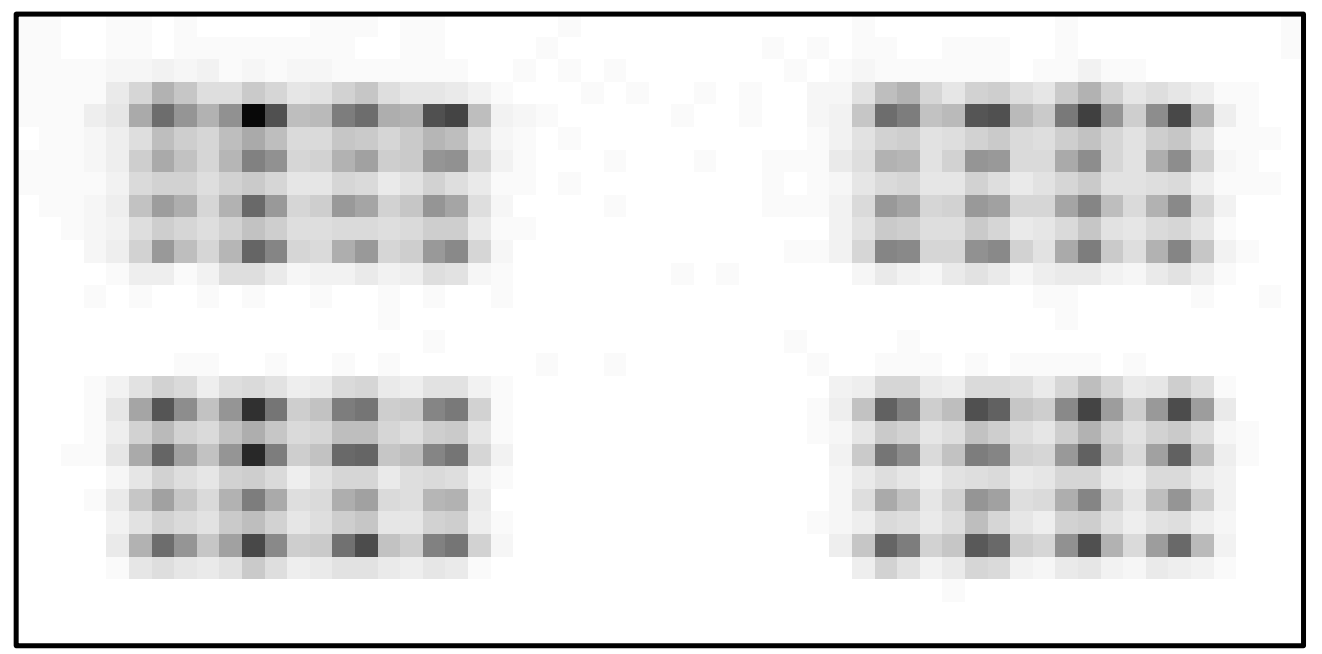

Abbildung 3.24: Typisches Bild der Fluoreszenz aller Teilstrahlen, wie es beim Abrastern der Probe aufgenommen wurde (Binning 8x16). Die Spannung an der MCP des Bildverstärkers betrug $540 \mathrm{~V}$, die Belichtungszeit $10 \mathrm{~ms}$

$\mathrm{Zu}$ Beginn eines Scans wurde die inhibit Leitung des Bildverstärkers auf $0 \mathrm{~V}$ gelegt, d. h. die Hochspannung an der MCP des Bildverstärkers wurde eingeschaltet. Vor Aufnahme des ersten Bildes wurde eine Zeit von $50 \mathrm{~ms}$ abgewartet, damit die MCP voll geladen war. In dieser Zeit wurden die Piezos auf ihre Startpositionen gefahren.

Die Positionen der Piezos wurden seriell als digitale 12bit Werte ausgegeben. Die Daten wurden in drei 12bit Schieberegister, die in Reihe geschaltet sind geladen, und dann simultan an drei D/A-Wandler übergeben. Dazu waren drei digitale Leitungen nötig: Daten, Takt und Wandler laden.

Die analogen Spannungen der D/A-Wandler, die zwischen 0 und $10 \mathrm{~V}$ liegen, wurden dann von Hochspannungsnetzteilen in Spannungen von 0 bis $-1000 \mathrm{~V}$ (x/yPiezos) bzw. 0 bis $+120 \mathrm{~V}$ (z-Piezo) umgesetzt.

Die Kamera wurde über eine weitere Leitung der PIO-Karte, die die Bildaufnahme startete, gesteuert. Die Belichtungszeit wurde entweder per Software (im Bereich $1 \mu \mathrm{s}-50 \mathrm{~ms}$ ) festgelegt oder durch die Steuerleitung vorgegeben.

Nach Abschluß der Belichtung wurde die nächste Scanner-Position ausgegeben bevor das Auslesen der Kamera gestartet wurde. So konnten die Piezos die nächste Position anfahren, während das zuletzt aufgenommene Bild ausgelesen wurde.

Die Daten der Bilder wurden direkt in einen großen Speicherbereich geschrieben, der vor Beginn des Scans reserviert wurde. Erst nach Abschluß des Scans wurde die inhibit Leitung wieder auf $5 \mathrm{~V}$ gelegt und der Bildverstärker damit abgeschaltet. Die Photokathode des Bildverstärkers wurde unabhängig vom Rest des 
Experimentes kontinuierlich mit $76 \mathrm{MHz}$ direkt vom Laser getriggert. Dadurch, daß dieser kritische Teil ohne Unterbrechung arbeitete, wurden Einschwingvorgänge und Drifts vermieden.

\subsection{Die Messungen}

In den folgenden Abschnitten werden einige Messungen, die zur Charakterisierung des Vielstrahlmikroskops dienen, vorgestellt. Dabei geht es insbesondere um die Zeit- und Ortsauflösung sowie um die Rekonstruktion zusammenhängender Bilder aus den Daten der einzelnen Strahlen. Zur Demonstration der Funktionsfähigkeit wurden einige Messungen mit fluoreszenzmarkierten Bakterien, die im letzten Abschnitt dargestellt werden, durchgeführt.

\subsubsection{Zweiphotonenanregung}

Daß es sich bei den beobachteten Signalen tatsächlich um Zweiphotonenfluoreszenz handelt, kann man anhand der Intensitätsabhängigkeit der Fluoreszenz feststellen. Die Intensität der Laserpulse konnte in diesem Experiment auf zwei Arten verändert werden: zum einen durch Abschwächen des Laserstrahls, und zum anderen durch Veränderung der Pulsdauer bei gleichbleibender Durchschnittsleistung, indem die Dispersionskompensation variiert wurde.

Abbildung 3.25 zeigt die Abhängigkeit des Fluoreszenzsignals von der Durchschnittsleistung des Lasers in doppelt-logarithmischer Darstellung. Als Probe diente der blaue Laserfarbstoff Coumarin 500 (Lambda Physik) gelöst in Ethylenglycol $(1.5 \mathrm{mg} / \mathrm{ml})$, von dem ein Tropfen auf einen Objektträger gegeben wurde. Die Meßwerte lassen sich gut durch eine Gerade mit der Steigung 1.96 beschreiben. Man beobachtet also annähernd die quadratische Intensitätsabhängigkeit, die man für Zweiphotonenanregung erwartet.

Verändert man den Abstand der Prismen in der Dispersionskompensation, so ändert sich die Gesamtdispersion des Systems und damit auch die Pulsdauer in der Probe. Die Änderung der Dispersion in Abhängigkeit vom Abstand der Kompensationsprismen ist durch deren Material (SF10) festgelegt. Man kann also bei bekannter Laserpulsdauer und Mikroskopdispersion die Pulsdauer in der Probe für verschiedene Stellungen der Prismen berechnen.

Im Falle von linearer Anregung sollte das Fluoreszenzsignal bei konstanter Durchschnittsleistung überhaupt nicht von der Pulsdauer $t$ abhängen, bei Zweiphotonenanregung proportional $\mathrm{zu} t^{-1}$, bei Dreiphotonenanregung proportional $\mathrm{zu} t^{-2}$ sein.

Abbildung 3.26 zeigt das für verschiedene Prismenabstände aufgenommene Fluoreszenzsignal. Die durchgezogene Kurve wurde mit den Materialkonstanten des Aufbaus unter der Annahme, daß es sich um Zweiphotonenfluoreszenz handelt, berechnet. Auch hier passen die Meßdaten gut zur Theorie. Man erkennt an dieser Abbildung auch den Nutzen der Dispersionskompensation für die nichtlineare 


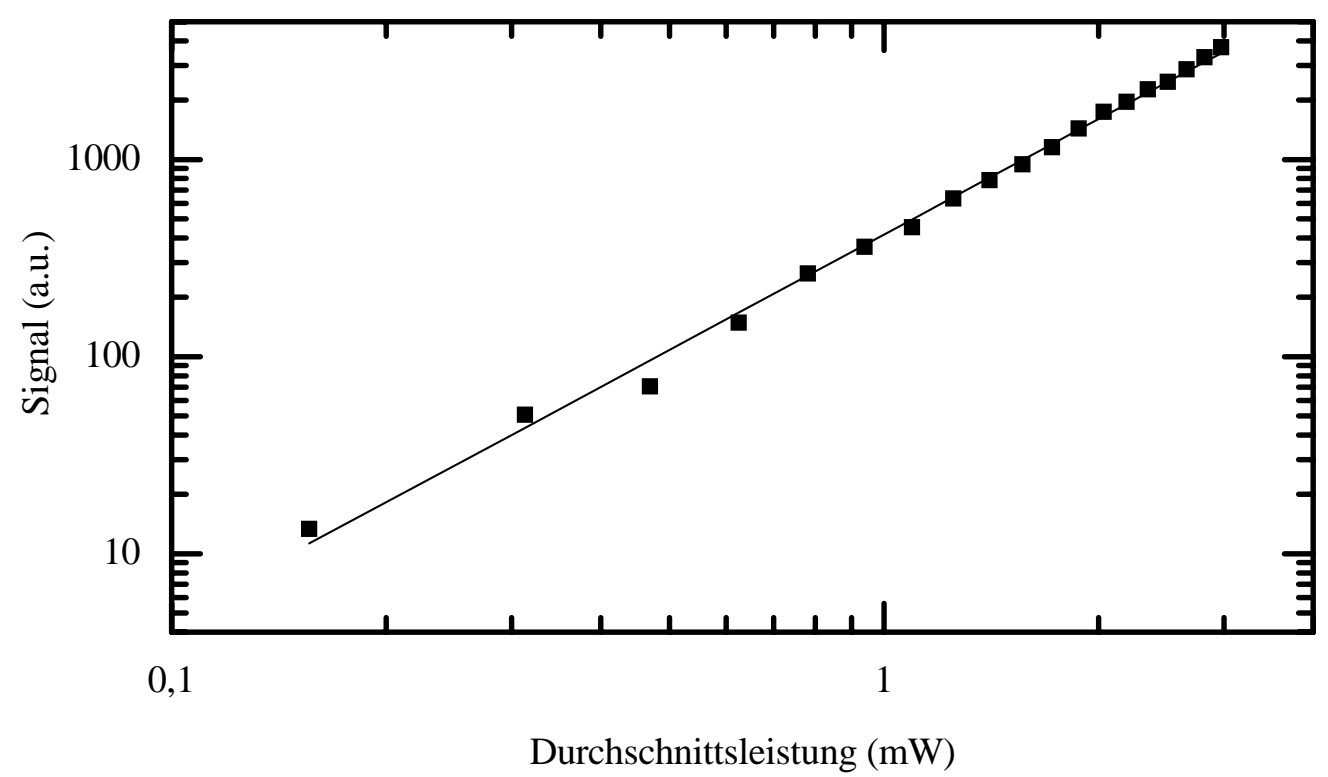

Abbildung 3.25: Die Abhängigkeit des Fluoreszenzsignals von der Durchschnittsleistung des Laserstrahls. Die Steigung der Regressionsgeraden beträgt 1.96.

Mikroskopie, da sie das Signal um einen Faktor 7 steigert bzw. die für einen Strahl benötigte Laserenergie um die Wurzel des Faktors erniedrigt. Damit wird die maximale Anzahl von Teilstrahlen, die mit einer gewünschten Pulsleistung in der Probe erzeugt werden können, erhöht.

\subsubsection{Die Zeitauflösung}

Die Zeitauflösung des Systems wurde untersucht, indem die Fluoreszenzlebensdauern verschiedener Substanzen bzw. der Zeitverlauf des Laserstreulichts aufgenommen wurde. Der Zeitverlauf des Laserstreulichts spiegelt die Öffnungscharakteristik des Detektors wieder, da es sich um Femtosekundenpulse handelt.

Abbildung 3.27 zeigt den Zeitverlauf der Coumarin-Fluoreszenz einmal für den Fall, daß das Coumarin in Ethylenglycol gelöst war, und einmal für den Fall, daß sich das Coumarin als Festsubstanz direkt auf der Glasoberfläche des Objektträgers befand. ${ }^{11}$ Der Zeitverlauf unterschiedet sich in beiden Fällen stark voneinander. Beim gelösten Coumarin beobachtet man eine Lebensdauer von $4.8 \mathrm{~ns}$, während die Fluoreszenz im anderen Fall so kurz andauert, daß mit diesem Aufbau keine Fluoreszenzlebensdauer bestimmt werden kann. Die Breite der Fluoreszenz beträgt im zweiten Fall etwa 200 ps, dies entspricht der minimalen Öffnungsdauer des Bildverstärkers. Auch der Zeitverlauf des Laserstreulichts ergab Meßkurven mit dieser

\footnotetext{
${ }^{11}$ Dazu wurde Coumarin in Ethanol gelöst und auf den Objektträger getropft; das Ethanol verdampft rasch und das Coumarin bleibt auf der Oberfläche zurück. Die Konzentration des Coumarins war so gering gewählt, daß sich weniger als eine Monolage auf dem Objektträger ablagerte.
} 


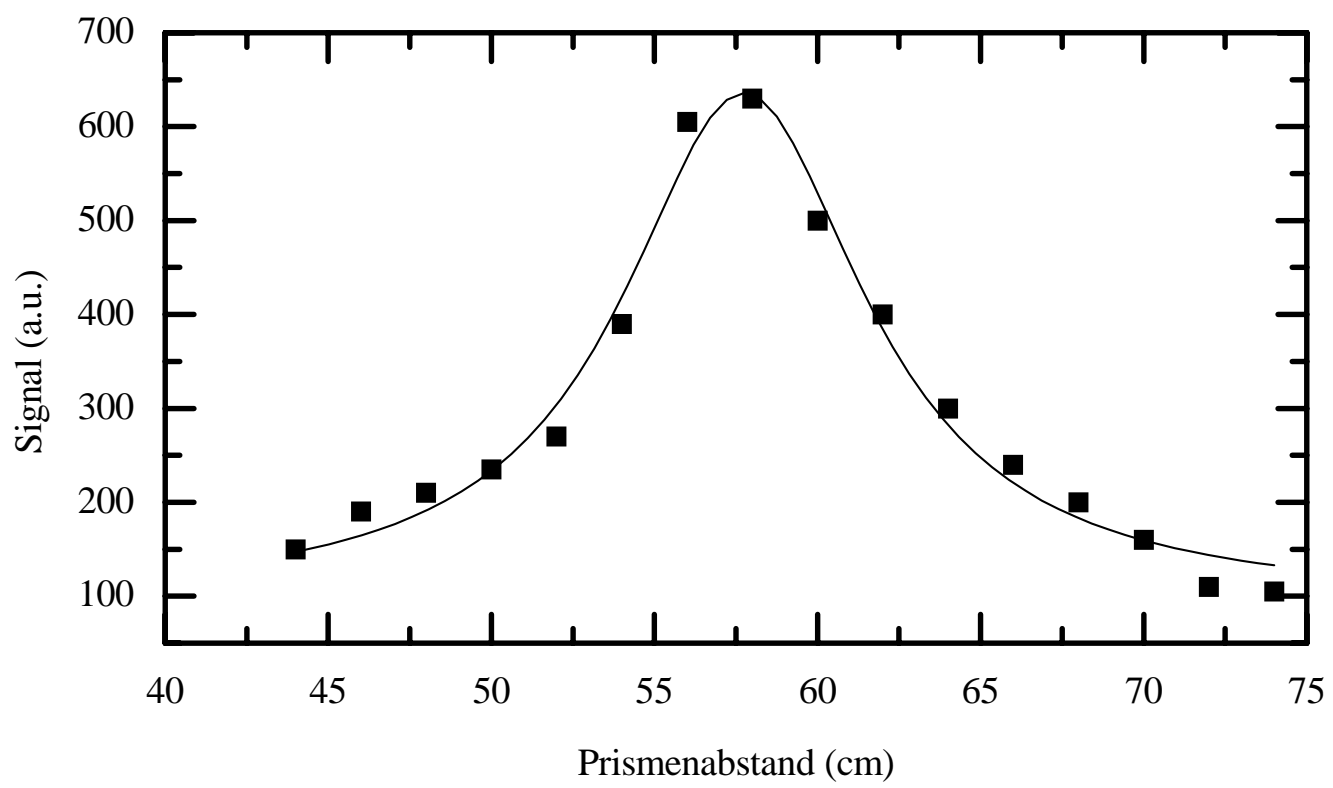

Abbildung 3.26: Die Abhängigkeit des Fluoreszenzsignals vom Abstand der Prismen in der Dispersionskompensation.

Breite.

Die Zeitauflösung des Systems entspricht also den Erwartungen. Gleichzeitig verdeutlicht dieses Beispiel, wie stark die Fluoreszenzlebensdauer von der Umgebung der Moleküle abhängen kann. Der extreme Rückgang der Lebensdauer liegt hier an der starken Wechselwirkung der Coumarin-Moleküle mit der festen Oberfläche des Objektträgers, wo die Energie sehr schnell von Elektronen oder vom Gitter aufgenommen und transportiert werden kann.

\subsubsection{Die Berechnung der Bilder aus den Rohdaten}

Bevor im folgenden Abschnitt die Ortsauflösung des Vielstrahlmikroskops untersucht wird, soll an dieser Stelle zunächst die Rekonstruktion von zusammenhängenden Bildern aus den Daten der einzelnen Strahlen dargestellt werden.

Beim Abrastern wird für jede Position der Probe ein Bild mit dem Detektor aufgenommen und in einem großen Datenpuffer abgelegt (siehe Abbildung 3.24). Die Verarbeitung der Rohdaten eines Scans geschieht in drei Schritten:

1. die Berechnung des Signals für jeden Strahl,

2. die Berechnung der Strahlpositionen,

3. das Zusammensetzen der Daten zu einem Bild. 


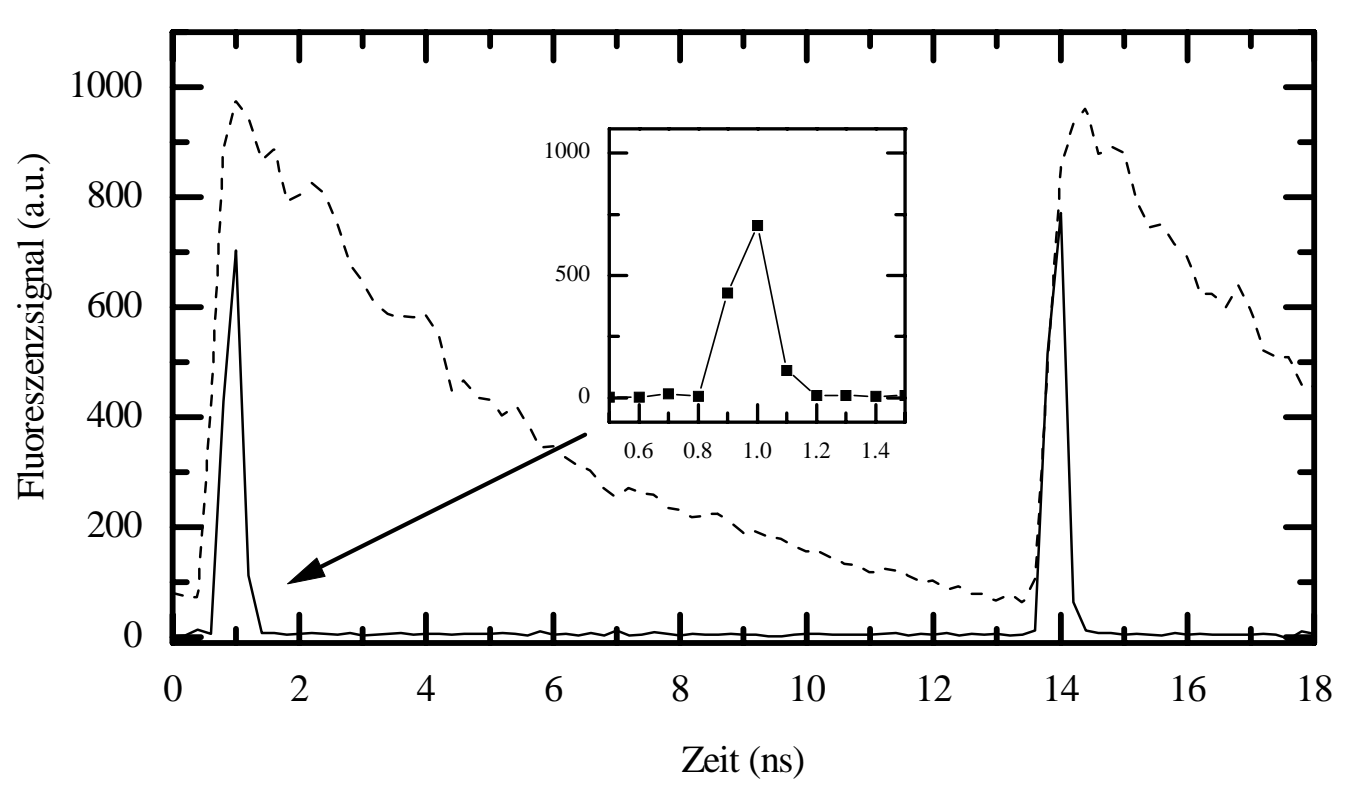

Abbildung 3.27: Zeitverlauf der Coumarin-Fluoreszenz. 1.) gelöst in Ethylenglycol $(---), 2$.) direkt auf der Oberfläche des Objektträgers (-).

\subsubsection{Die Signalberechnung}

Um das Signal, das von jedem Teilstrahl erzeugt wird, zu ermitteln, werden zunächst auf einem rechteckigen Bereich um die Position jedes Strahls die Intensitätswerte des Bildes — um das Dunkelbild der Kamera korrigiert — gemittelt.

Die Größe des Bereichs, über den gemittelt wird, hat einen Einfluß auf die Qualtität des rekonstruierten Bildes. Wird der Bereich zu klein gewählt, wird ein Teil des Signal nicht genutzt und das Signal/Rausch-Verhältnis ist nicht optimal. Wird der Bereich zu groß gewählt, kommt es zum Übersprechen zwischen den einzelnen Strahlen. Bei den durch Binning stark komprimierten Bildern, die hier aufgenommen wurden, genügte es, für die Bestimmung des Signals ein Pixel bzw. die zwei benachbarten horizontalen Pixel zusätzlich zu verwenden.

Wird das Übersprechen nicht korrigiert, kommt es bei großen Kontrasten im Bild zu „Geisterbildern“, d. h. ein helles Objekt erscheint nicht nur in dem Bild des Strahls, der das Objekt tatsächlich getroffen hat, sondern auch schwächer in den Bildern der benachbarten Strahlen. Dieser Effekt kann beseitigt werden, indem Referenzbilder an einer homogenen Farbstoffschicht aufgenommen werden, bei denen das Übersprechen dadurch bestimmt wird, daß zeilen- und spaltenweise die Laserstrahlen im Strahlvervielfacher geblockt werden, so daß sie keine Fluoreszenz anregen können. Mit Hilfe dieser Daten kann das Übersprechen durch eine Inversion korrigiert werden.

Wurde zur Bestimmung des Signals nur ein Pixel verwendet, spielte das Übersprechen keine merkliche Rolle. Bei der Verwendung von drei Pixeln kam es zu 


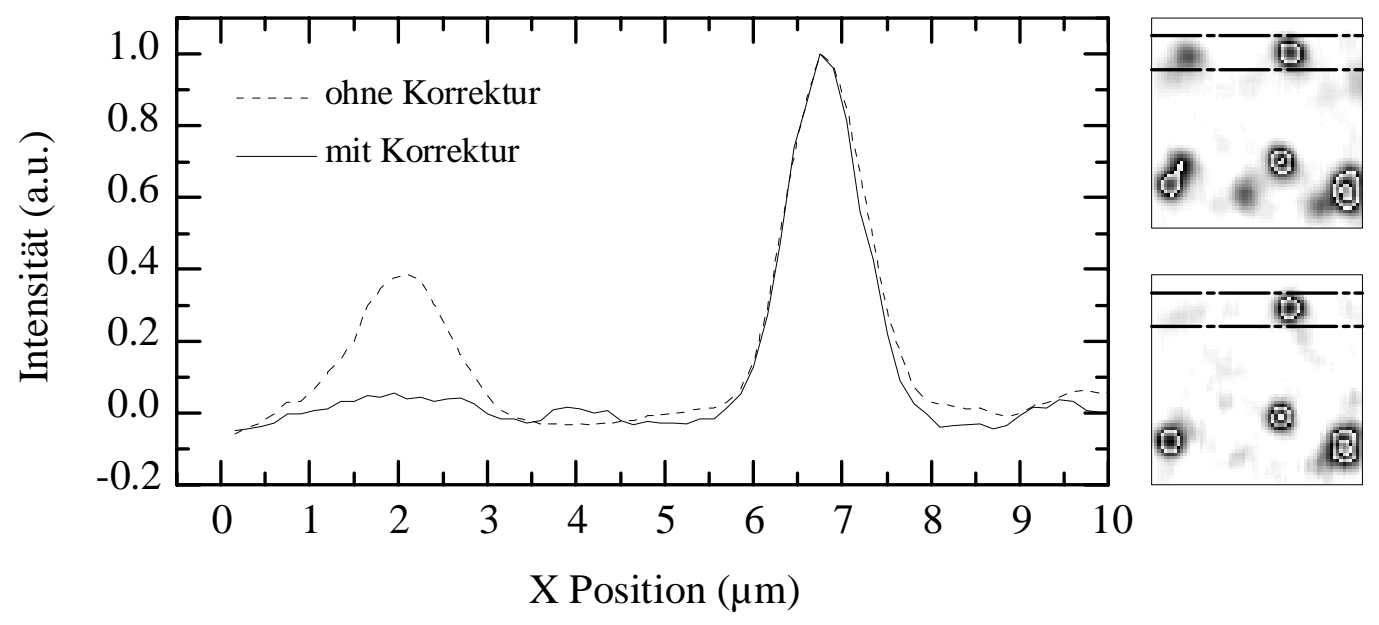

Abbildung 3.28: Der Einfluß des Übersprechens zwischen den einzelnen Strahlen auf das rekonstruierte Bild. Rechts ist ein Ausschnitt eines Scans (ca. $10 \times 10 \mu \mathrm{m}^{2}$ ) gezeigt: oben ohne Korrektur des Übersprechens, unten mit Korrektur. Links sind zwei horizontale Profile dargestellt, die aus den durch Linien gekennzeichneten Bereichen der Bilder berechnet wurden. 
leichtem Übersprechen in das jeweils links benachbarte Bild hinein. Abbildung 3.28 zeigt den Einfluß des Übersprechens auf das Bild sowie das korrigierte Bild.

Zur Klarheit: Die Ursache des Übersprechens ist die Vermischung der Signale der einzelnen Strahlen im Detektor und nicht die Vermischung der Foki in der Probe. Dies kann an den Referenzmessungen und noch deutlicher an einem Vergleich mit Messungen ohne Bildverstärker, bei denen das Übersprechen durch die höhere Ortsauflösung des Detektors viel schwächer ist, erkannt werden. Eine gegenseitige Beeinflussung der Foki in der Probe wurde nicht beobachtet und ist wegen der Laufzeitunterschiede der Strahlen, die im Strahlteiler entstehen, auch nicht zu erwarten.

Nachdem eventuelles Übersprechen korrigiert wurde, wurden die Signalstärken noch mit einem Kalibrierfaktor, der den unterschiedlichen Intensitäten der Teilstrahlen Rechnung trägt, multipliziert.

Nach diesen Rechenoperationen bekommt man einen Datensatz, der die Signalstärke der 64 Teilstrahlen für jede Rasterposition enthält. Dieser Datensatz wird im nächsten Schritt bei der Rekonstruktion eines zweidimensionalen Bildes verwendet.

Bei der Berechnung eines zusammenhängenden Bildes aus den Signalen der einzelnen Strahlen gehen die Positionen der Scanner sowie die Abstände der Foki in der Probe ein.

\subsubsection{Die Positionsbestimmung}

Beim Abrastern der Probe wurde ein bestimmter Bereich der Spannung an den Scanner-Piezos in gleichmäßigen Schritten durchlaufen. Die Nichtlinearität der Piezos sorgt dafür, daß dem gleichmäßigen Raster von Spannungswerten ein verzerrtes Raster von Positionswerten entspricht. Bei der Umrechnung von Spannung in Position wurden die Kalibrierdaten der Scanner, deren Aufnahme in Abschnitt 3.2.3.2 beschrieben wurde, verwendet.

Abbildung 3.29 zeigt den Übergang vom gleichmäßigen Spannungsraster auf das ungleichmäßige Positionsraster anhand der Daten für einen Strahl. Im linken Teil der Abbildung sind die Gitter gezeigt und im rechten Teil die Bilder, die sich ergeben, wenn die gemessenen Signale in dem gleichmäßigen (Spannungs)-Raster bzw. in dem Positionsraster angeordnet werden. Man erkennt den starken Unterschied bei kleinen Spannungswerten, wo eine Änderung der Spannung kaum zu einer Bewegung der Scanner führt.

Außerdem sieht man, daß die beiden Piezos deutlich unterschiedliche Charakteristiken haben, da in y-Richtung bei gleichem Spannungsbereich ein deutlich gröBerer Raumbereich überdeckt wird.

Man bekommt so die Positions-Signal Wertepaare für den ersten Strahl. Die Positionen der anderen Strahlen unterscheiden sich jeweils um einen konstanten Betrag, nämlich den Abstand der Foki in der Probe, von denen des ersten Strahls. Die Abstände der Foki wurden aus einem Bild der Coumarin-Schicht, das ohne Binning aufgenommen wurde (siehe Abbildung 3.22), ermittelt. Mit diesen Werten kann man jedem gemessenen Signal eine Position zuordnen. 

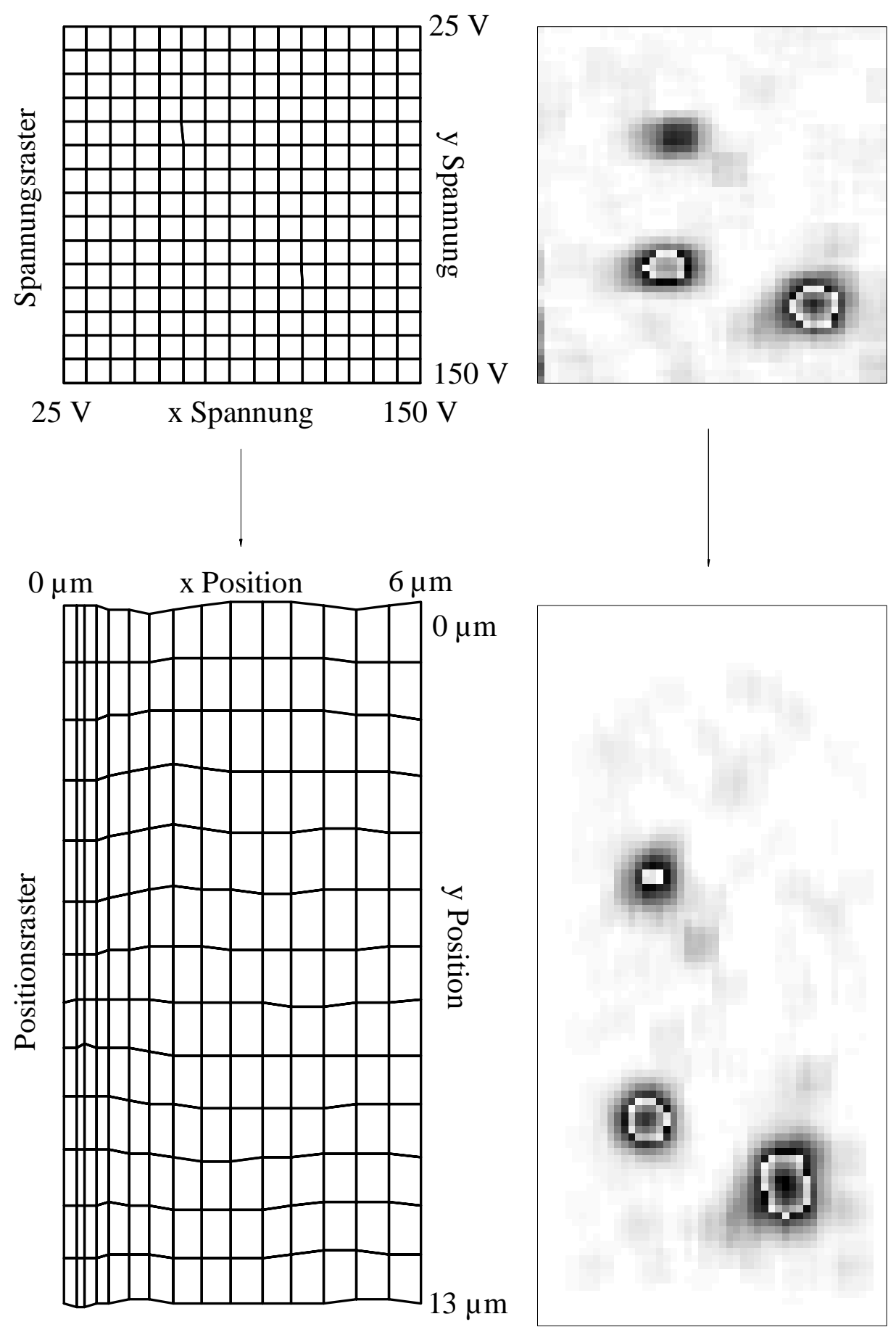

Abbildung 3.29: Der Übergang vom gleichmäßigen Spannungsraster zum Positionsraster. Im linken Teil der Abbildung sind die Gitter gezeigt und im rechten Teil die Bilder, die sich ergeben, wenn die gemessenen Signale in dem gleichmäßigen (Spannungs)-Raster bzw. in dem Positionsraster angeordnet werden. 


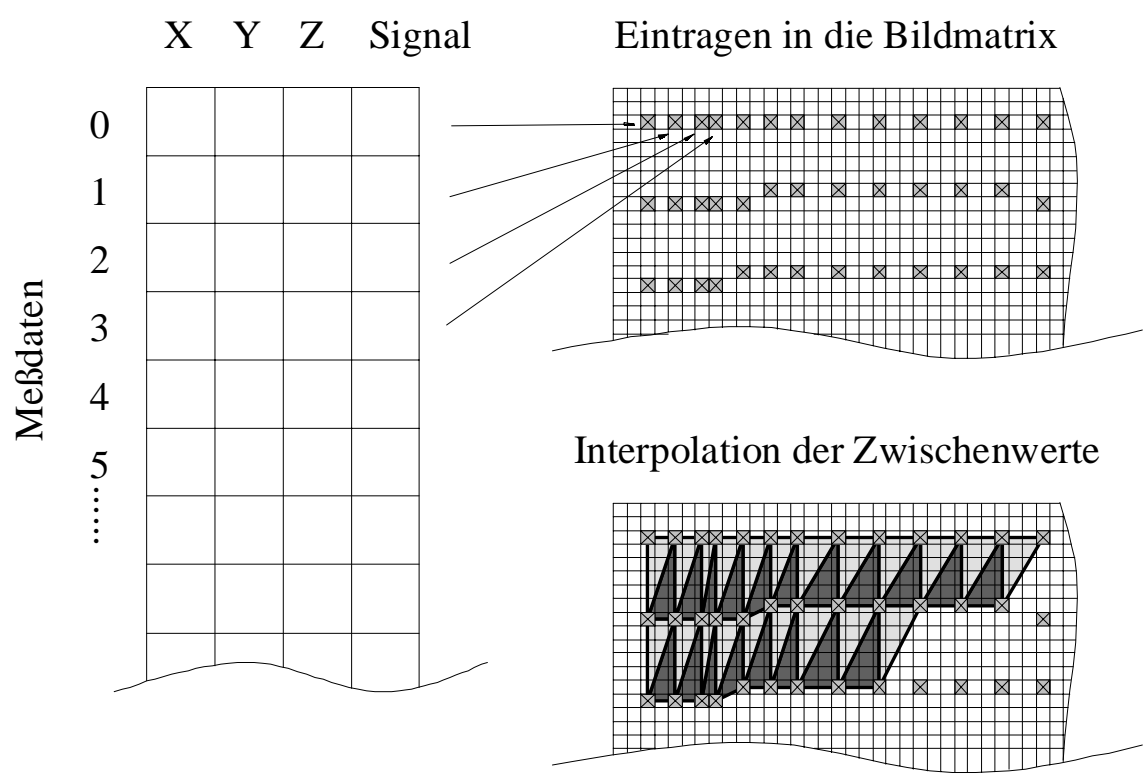

Abbildung 3.30: Die Berechnung der Bilder: 1.) das Eintragen der Daten in die Bildmatrix, 2.) lineare Interpolation der fehlenden Zwischenwerte.

\subsubsection{Die Rekonstruktion eines zusammenhängenden Bildes}

Um ein zusammenhängendes zweidimensionales Bild zu berechnen, wurden die Daten nun wieder auf ein gleichmäßiges Positionsraster umgerechnet. Dabei wurde auch eine eventuelle Überlappung der Scanbereiche berücksichtigt.

Die Daten des Scans sind soweit aufbereitet, daß sie als Positions-Signal Wertepaare vorliegen. Die Aufgabe besteht nun darin eine Fläche durch die $(x, y, z, S)$ Werte zu legen. Stellt man die Konturen (bzw. Höhenlinien) dieser Fläche in Graustufen kodiert dar, bekommt man ein zweidimensionales Bild der üblichen Form. Die Schwierigkeit liegt darin, daß die Punkte, die von einem Strahl geliefert werden, nicht auf einem gleichmäßigen Raster liegen und daß die Raster der einzelnen Teilstrahlen gegeneinander verschoben sind und sich eventuell überlappen.

Es gibt Algorithmen, um Flächen zwischen irregulär verteilten Stützstellen zu interpolieren (siehe z. B. [95, 96]). Die Algorithmen sind allerdings sehr zeitaufwendig, wenn eine große Zahl von Punkten verarbeitet werden soll. Daher wurde hier eine einfachere, schnelle Methode benutzt, die im folgenden beschrieben wird.

Zunächst wird eine Matrix definiert, die das Bild aufnehmen soll. Die Spalten der Matrix repräsentieren die x-Koordinaten und die Zeilen die y-Koordinaten im Bild. Zu Beginn wird jeder Eintrag auf Null gesetzt. Dann wird nacheinander für jedes Position-Signal Wertepaar des Scans ermittelt, welcher Zeile und Spalte der Bildmatrix die Position entspricht und das Signal zum Eintrag der Matrix an dieser Stelle addiert. Nachdem alle Daten verarbeitet sind, wird jeder Eintrag noch durch die Anzahl der Daten, die an dieser Stelle einen Beitrag leisteten, geteilt. Dadurch 
wird automatisch auch eine Überlappung der Scanbereiche berücksichtigt.

Stellt man nun die Matrix als Pixelgrafik so dar, daß jedem Zahlenwert ein Grauwert zugeordnet wird, bekommt man ein Bild des Objekts, das beim Scan abgerastert wurde. Die Auflösung dieses Bildes ist durch die Zahl der Zeilen und Spalten der Bildmatrix vorgegeben.

Dieses Verfahren, ein Bild zu erzeugen, ist sehr schnell. Ein Nachteil des Verfahrens ist, daß die vorgegebene Auflösung passend zur tatsächlichen Auflösung, mit der die Probe abgerastert wurde, gewählt werden muß. Wird die Auflösung zu grob gewählt, werden zuviele Daten in einem Pixel zusammengefaßt und Details gehen verloren. Wird sie zu fein gewählt, werden nicht alle Einträge der Matrix von einem Datenpunkt „getroffen“. Diese Einträge erscheinen dann als Lücken im Bild; im Extremfall werden die Daten so verstreut in die Matrix eingetragen, daß die einzelnen Daten isoliert voneinander liegen.

Dieses Problem kann man beseitigen, indem man die fehlenden Zwischenwerte interpoliert. Dazu wurden die Werte auf den Dreiecksflächen, die von je drei Datenpunkten aufgespannt werden, linear interpoliert (siehe Abbildung 3.30). Die Flächen, die so erzeugt werden, sind im Unterschied zu mit Splines interpolierten Flächen nicht glatt. Solange die Auflösung nicht zu fein gewählt wird, bestehen die Dreiecke allerdings aus wenigen Pixeln, so daß der Unterschied kaum ins Gewicht fällt.

Alle Bilder, die im folgenden gezeigt werden, wurden mit diesem Verfahren erzeugt.

\subsubsection{Die Ortsauflösung}

Zur Bestimmung der dreidimensionalen Ortsauflösung des Mikroskops wurden Scans in der $\mathrm{x} / \mathrm{y}$-Ebene und in z-Richtung durchgeführt.

\subsubsection{Die Tiefenauflösung}

Die Zweiphotonenanregung führt durch die quadratische Intensitätsabhängigkeit der Anregungsrate automatisch zu einer starken Abhängigkeit des Signals in Strahlrichtung. Nur unmittelbar in der Nähe des Fokus kommt es zur effizienten Fluoreszenzanregung.

Fährt man mit dem Fokus durch eine dünne, homogene Farbstoffschicht hindurch und nimmt das Fluoreszenzsignal in Abhängigkeit von der z-Position bei konstanter $\mathrm{x}$ - und y-Position auf, kann man, wenn die Farbstoffschicht deutlich dünner als die Fokuslänge ist, die axiale Abhängigkeit der Anregungsrate messen. Der Zusammenhang zwischen Tiefenauflösung und lateraler Auflösung bzw. numerischer Apertur des Objektivs ist in Abschnitt 3.1.2.2 dargestellt. Nach der Theorie erwartet man für gaußsche Strahlen ein Lorentzprofil; die Halbwertsbreite der Kurve gibt die axiale Auflösung des Systems an.

Zur Vermessung der axialen Auflösung wurde eine dünne Coumarin-Schicht auf einem Objektträger verwendet und die Foki in Schritten von $0.5 \mu \mathrm{m}$ durch diese Schicht hindurch bewegt. Abbildung 3.31 zeigt das dabei erhaltene Signal für einen 


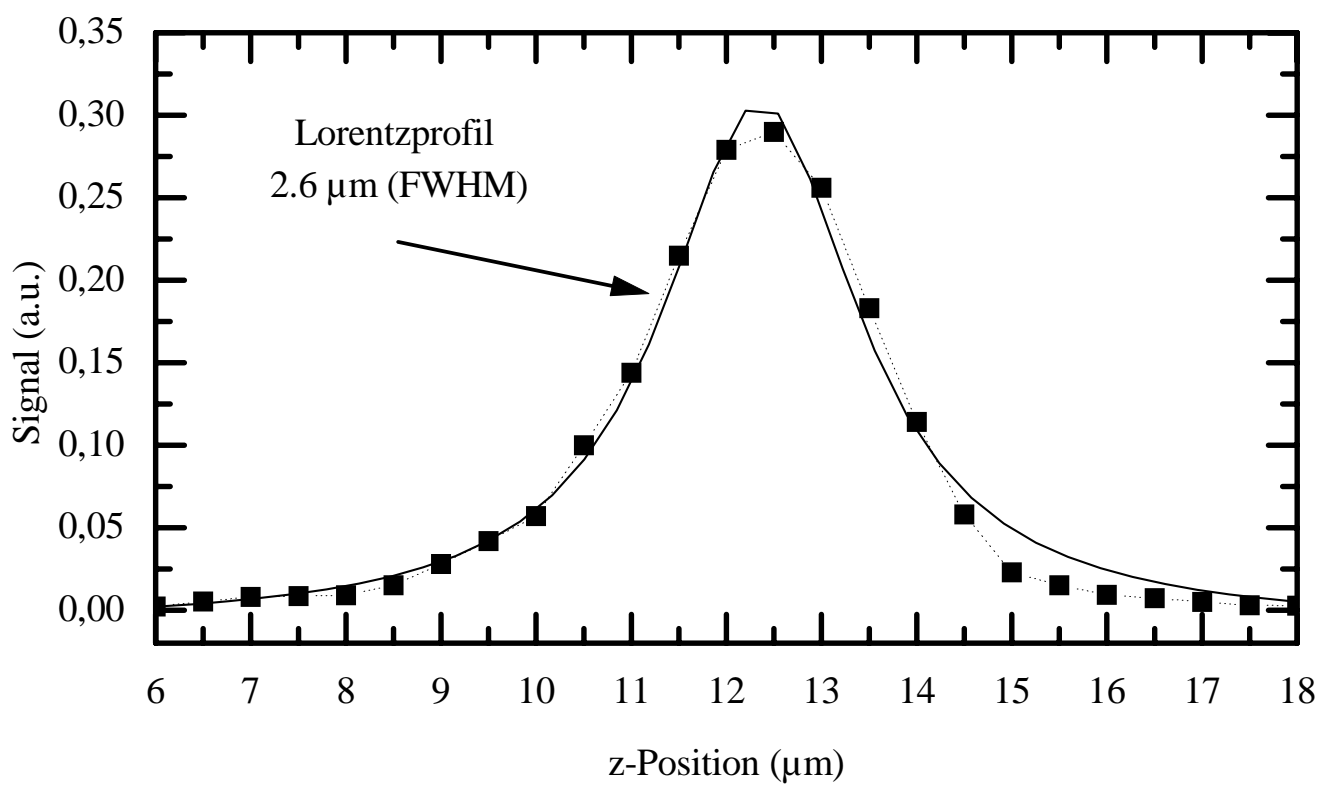

Abbildung 3.31: Die axiale Auflösung des Mikroskops. Signal einer dünnen Coumarin-Schicht zusammen mit einem angepaßten Lorentzprofil.

der Strahlen zusammen mit einem Fit eines Lorentzprofils; die Halbwertsbreite beträgt $2.6 \mu \mathrm{m}$ (FWHM).

Neben der Breite der Profile wurde auch die absolute Position des Peaks für jeden Strahl gemessen. ${ }^{12}$ Dabei zeigte sich, daß es eine deutliche Korrelation zwischen der x/y-Position des Strahls und der z-Position des zugehörigen Peaks gab. Der obere Teil der Abbildung 3.32 zeigt die Fläche, die von den Strahlpositionen und den z-Koordinaten der Peaks aufgespannt wird. Man erkennt, daß es sich im wesentlichen um eine Ebene handelt. Wird mittels linearer Regression eine Ausgleichsebene bestimmt und von den Daten subtrahiert, bekommt man die im unteren Teil der Grafik dargestellte Fläche. Die z-Koordinaten schwanken hier mit einer Standardabweichung von $170 \mathrm{~nm}$ um Null. Eine Schwankung in dieser Größe ist schon aufgrund der Berechnung der z-Koordinaten aus den mit einer Unsicherheit behafteten Meßwerten zu erwarten, so daß man sagen kann, im Rahmen der Meßgenauigkeit liegen die Foki aller Teilstrahlen in einer Ebene.

Die Ausgleichsebene, die vom oberen Graphen subtrahiert wurde, gibt die relative Lage der Fokalebene und der Farbstoffschicht an. Aus der Steigung der Ebene ergibt sich ein relativer Winkel von $2.3^{\circ}$, was bei der verwendeten Probenhalterung nicht auszuschließen ist.

\footnotetext{
${ }^{12}$ Die Position wurde rechnerisch als Schwerpunkt des Profils ermittelt.
} 

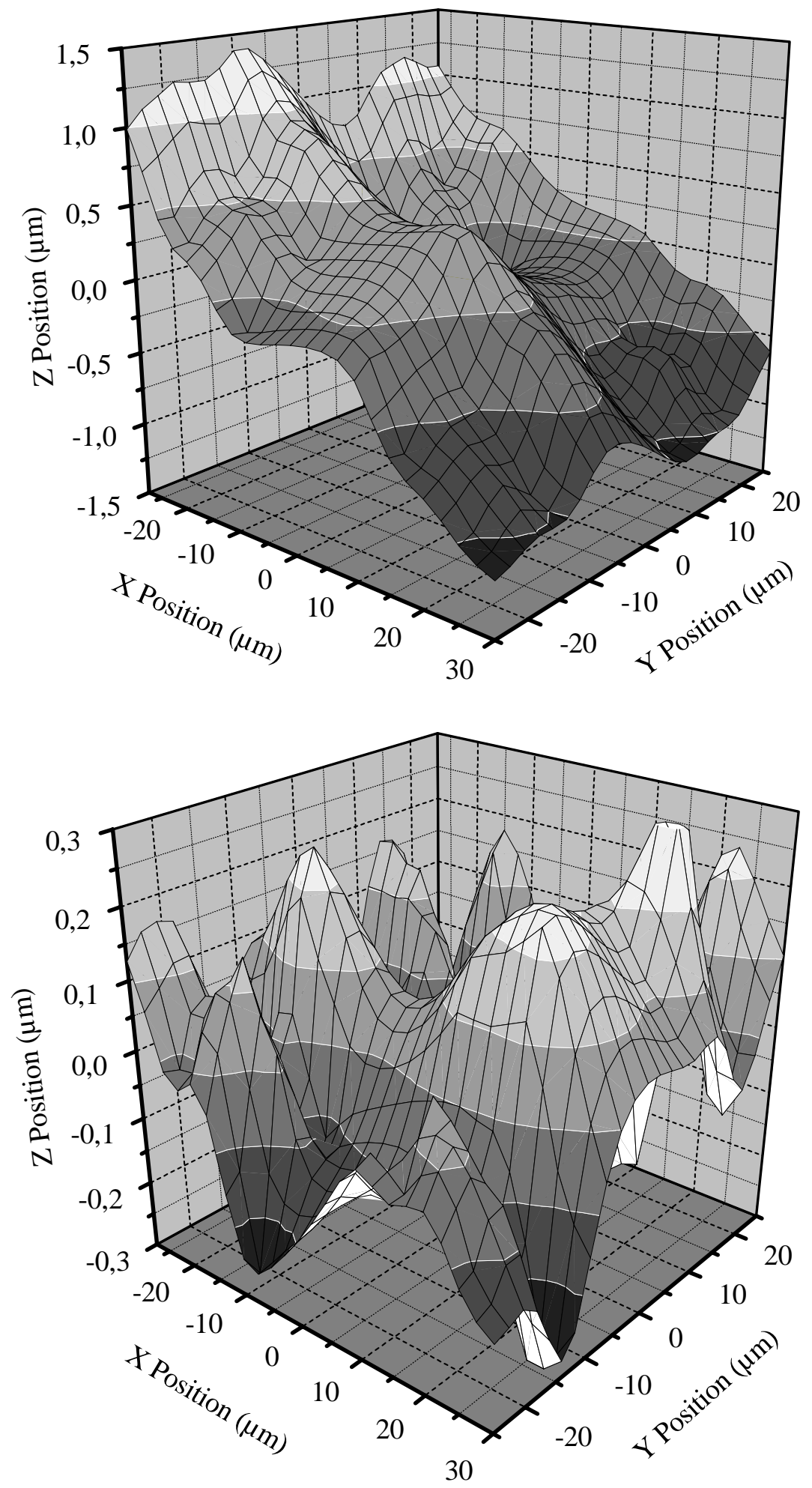

Abbildung 3.32: Oben: Korrelation zwischen der lateralen Position des Strahls und der Lage des Peaks in z-Richtung. Unten: Dieselben Daten, nachdem eine Ausgleichsebene subtrahiert wurde. 


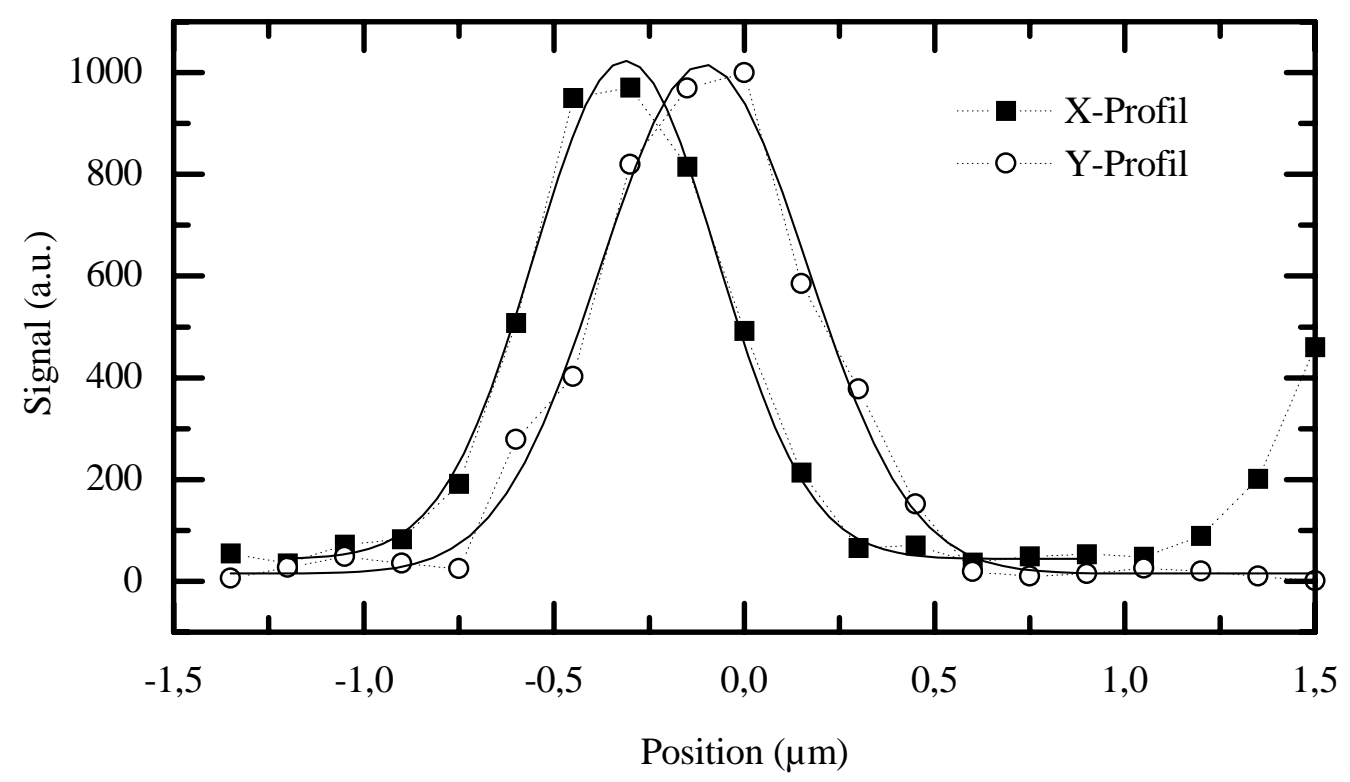

Abbildung 3.33: Horizontale und vertikale Querschnittsprofile durch die Bilder von Farbstoffkügelchen. Die durchgezogenen Kurven sind den Daten angepaßte Gaußprofile. Die Breite der Profile beträgt $0.6 \mu \mathrm{m}$ (FWHM).

\subsubsection{Die laterale Auflösung}

Die laterale Auflösung wurde bestimmt, indem mit Farbstoff gefüllte Latexkügelchen [97] mit einem Durchmesser von $0.4 \mu \mathrm{m}$ abgerastert wurden. Die Kügelchen wurden in Wasser verdünnt und auf einen Objektträger gegeben. Nachdem das Wasser verdunstet war, lagen die Kugeln zum Teil in Haufen, aber auch einzeln auf der Oberfläche des Objektträgers. Abbildung 3.33 zeigt zwei Querschnittsprofile durch die erhaltenen Fluoreszenzbilder einer einzelnen Kugel.

Die Profile haben eine Halbwertsbreite von $0.6 \mu \mathrm{m}$ (FWHM) und lassen sich gut durch Gaußkurven beschreiben (durchgezogene Linien). Die Breite der Profile entspricht tatsächlich der Auflösung des Mikroskops, auch bei Kugeln mit nur 40nm Durchmesser wurden keine schmaleren Profile beobachtet.

Es ist etwas verwunderlich, daß die $0.4 \mu \mathrm{m}$ Kugeln nur mit einer Breite von $0.6 \mu \mathrm{m}$ erscheinen. Man könnte eigentlich eine Breite von $\sqrt{0.6^{2}+0.4^{2}} \mu \mathrm{m}=$ $0.7 \mu \mathrm{m}$ erwarten. Eine mögliche Ursache für die Abweichung ist, daß die Kugeln nicht vollständig, sondern nur im Kern mit Farbstoff gefüllt sind.

\subsubsection{Messungen mit fluoreszenzmarkierten Bakterien}

Um zu demonstrieren, daß das Mikroskop auch tatsächlich zur Untersuchung biologischer Fragen eingesetzt werden kann, wurden einige Scans mit fluoreszenzmarkierten Bakterien durchgeführt. Dabei handelte es sich um kleine Bodenbakterien 
vom Stamm Rhizobium meliloti, die gentechnisch so verändert waren, daß sie das sogenannte Green Fluorescent Protein (GFP) exprimierten. Diese Bakterien spielen eine Rolle bei der Stickstoffaufnahme von Pflanzen, indem sie den Stickstoff der Luft in Verbindungen (meist Nitrate) umsetzen, die von der Pflanze weiterverarbeitet werden können.

Die Bakterien gehen eine Symbiose mit der Pflanze ein, indem sie in die Pflanzenwurzel eindringen und Knoten an den Wurzelhaaren bilden. Der Verlauf einer solchen Infektion ließe sich gut mit dreidimensionalen, zerstörungsfrei aufgenommenen Bildern der Wurzel und der Bakterien verfolgen.

Das GFP dient zur Markierung der Bakterien, die nur etwa $1 \mu \mathrm{m}$ groß sind. Dieses Protein hat Absorptionsmaxima bei $395 \mathrm{~nm}$ und $470 \mathrm{~nm}$ und emittiert Fluoreszenz mit einem Peak bei 509 nm [98]. Es läßt sich mit dem Titan-Saphir Laser zur Zweiphotonenfluoreszenz anregen, über die die Bakterien gut sichtbar gemacht werden können.

Die Markierung mit GFP hat zahlreiche Vorteile gegenüber herkömmlichen Verfahren und gewinnt noch dadurch an Bedeutung, daß es gelungen ist, das GFP gezielt an Organellen oder Proteine zu koppeln, ohne daß diese dabei ihre Funktion einbüßten [99]. Durch gezielte Veränderungen in der DNA-Sequenz, die das GFP kodiert, konnten außerdem ähnliche Proteine erzeugt werden, die andere Emissionsspektren haben, so daß auch mehrfache Markierungen möglich werden [100]. Zwei Messungen werden im folgenden dargestellt:

- Ein 2D-Scan, bei dem der maximale Stellweg der Piezos ausgenutzt wurde, so daß sich die Bereiche, die die Strahlen abrasterten, stark überlappten. Hier wurde überprüft, wie gut sich die Bilder, die von unterschiedlichen Strahlen erzeugt wurden, decken.

- Eine Serie von 2D-Scans in verschiedenen Tiefen, zur Demonstration der 3DAuflösung.

\subsubsection{Scan über einen großen Ortsbereich}

Abbildung 3.34 zeigt das Ergebnis eines Scans mit $100 \times 100$ Schritten, bei dem der maximale Stellweg der Piezos ausgenutzt wurde. Das Bild zeigt einen Bereich von etwa $120 \times 180 \mu \mathrm{m}^{2}$; das Raster hat eine Größe von $10 \mu \mathrm{m}$. Die Belichtungszeit betrug 5 ms, die Öffnungszeit des Bildverstärkers 200 ps; der Detektionszeitpunkt lag im Maximum der Fluoreszenz. Man erkennt einzelne Bakterien, sowie größere Bereiche, in denen sich Tröpfchen aus geplatzten Bakterien gebildet haben.

Da die Strahlen nur etwa $5 \mu \mathrm{m}$ voneinander entfernt waren, der Bereich, den jeder Strahl abrasterte, aber $60 \times 130 \mu \mathrm{m}^{2}$ groß war, überlappen sich die Bilder, die von jedem der Teilstrahlen erzeugt werden, stark. Um zu überprüfen, wie gut sich die Bilder decken, wurde der Korrelationskoeffizient der Bilder auf den Bereichen, wo sie sich überlappen, berechnet. Die Bereiche, die von einzelnen Teilstrahlen abgedeckt wurden, sind in Abbildung 3.34 rechts dargestellt. 

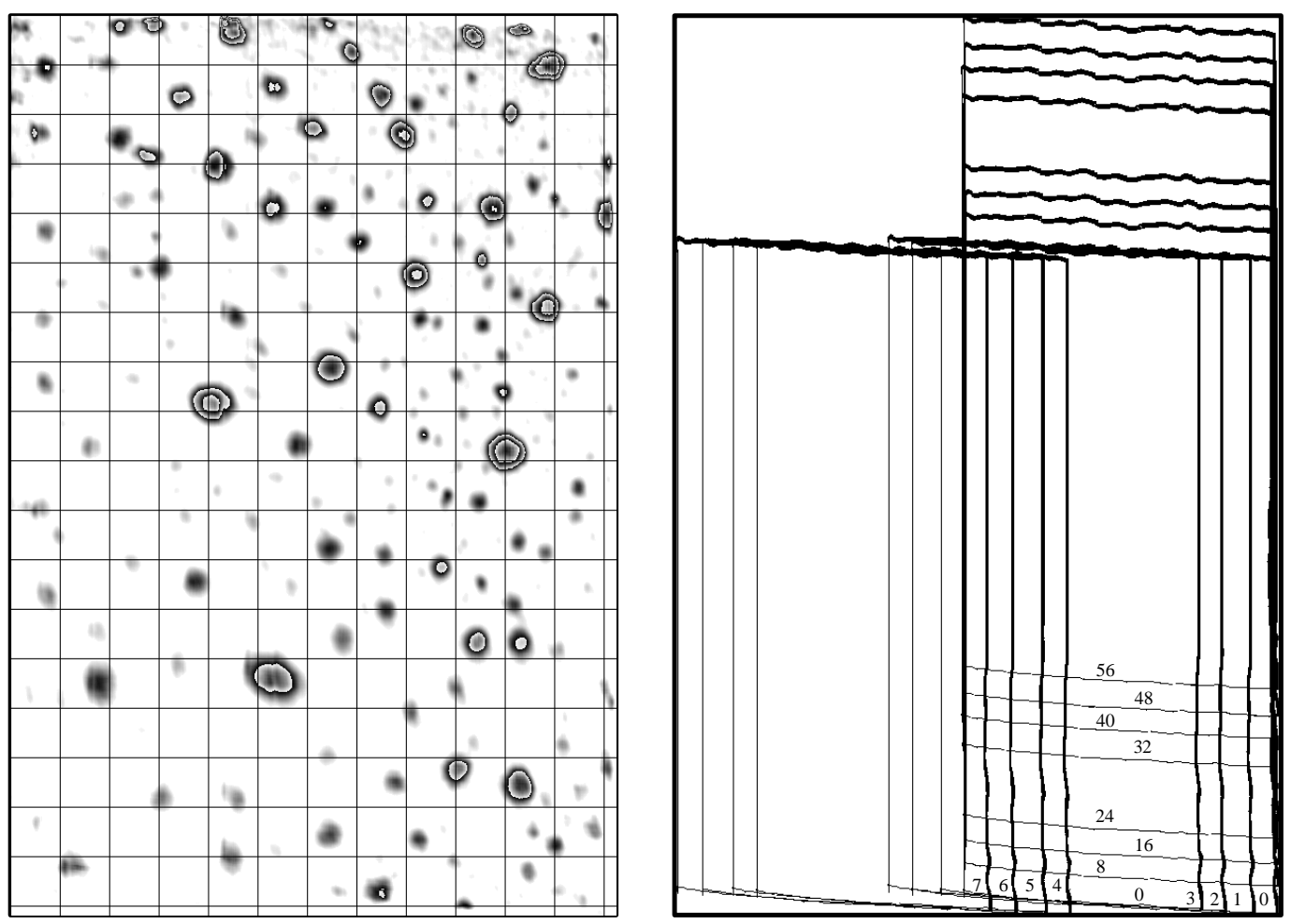

Abbildung 3.34: Scan mit GFP markierten Bakterien. Das Raster, das dem Scan überlagert wurde, hat eine Größe von $10 \mu \mathrm{m}$. Rechts sind die Bereiche, die von einzelnen Strahlen abgedeckt wurden, dargestellt. Die Korrelationskoeffizienten wurden jeweils auf den Überlappungsbereichen berechnet. 


\begin{tabular}{|cc|c||cc|c|}
\hline \multicolumn{3}{|c||}{ vertikale Verschiebung } & \multicolumn{3}{c|}{ horizontale Verschiebung } \\
1. Bild & 2. Bild & c & 1. Bild & 2. Bild & c \\
\hline 0 & 0 & 1 & 0 & 0 & 1 \\
0 & 8 & 0.91 & 0 & 1 & 0.89 \\
0 & 16 & 0.89 & 0 & 2 & 0.88 \\
0 & 24 & 0.90 & 0 & 3 & 0.84 \\
0 & 32 & 0.86 & 7 & 4 & 0.82 \\
0 & 40 & 0.85 & 7 & 5 & 0.85 \\
0 & 48 & 0.82 & 7 & 6 & 0.89 \\
0 & 56 & 0.79 & 7 & 7 & 1 \\
\hline
\end{tabular}

Tabelle 3.5: Korrelationskoeffizienten der Bilder einzelner Teilstrahlen.

In Tabelle 3.5 sind die Korrelationskoeffizienten für vertikal bzw. horizontal gegeneinander verschobene Bilder zusammengefaßt. Sie liegen zwischen 0.79 und 0.91, was zeigt, daß sich die Bilder der einzelnen Teilstrahlen sehr gut decken. Allgemein nimmt die Korrelation ab, wenn der Bereich, in dem sich die Bilder überlappen, kleiner wird. Da sich die Bereiche der Strahlen 4, 5, 6, 7 kaum mit dem des Strahls 0 überdecken, wurde für diese die Korrelation mit dem Bild des Strahls 7 berechnet. Die Korrelation ist für die horizontal verschobenen Bilder etwas kleiner als für die vertikal verschobenen, was aber vermutlich auch den Grund hat, daß die Bereiche in vertikaler Richtung größer sind und daher die Überlappung auch stärker ist.

Bei einer ernsthaften Anwendung des Mikroskop wird man die Scanbereiche natürlich so wählen, daß die Bereiche der einzelnen Strahlen zwar aneinander angrenzen, sich aber möglichst wenig überlappen, damit keine redundanten Daten aufgenommen werden. Die gute Korrelation der einzelnen Bilder zeigt, daß das Aneinanderfügen der Bilder zu einem Gesamtbild gelingt.

\subsubsection{2D-Scans in verschiedenen Tiefen}

Mit höherer Auflösung als bei der obigen Messung wurde eine Serie von Scans in verschiedenen Tiefen durchgeführt. Dazu wurden jeweils $50 \times 50$ Positionen mit einer Belichtungszeit von $10 \mathrm{~ms}$ bei einer Öffnungszeit des Bildverstärkers von $200 \mathrm{ps}$ aufgenommen; der Detektionszeitpunkt lag im Maximum der Fluoreszenz. Der Bereich, der von jedem Strahl abgerastert wurde, hatte eine Größe von ca. $5 \times 10 \mu \mathrm{m}$, so daß die Bereiche benachbarter Strahlen in $\mathrm{x}$-Richtung gerade aneinander stießen. Es wurden insgesamt 14 Ebenen mit einem Abstand von $1.25 \mu \mathrm{m}$ aufgenommen.

Die Bilder sind, bis auf das erste und letzte der Serie, in Abbildung 3.35 und 3.36 mit einem $10 \mu \mathrm{m}$ Gitter dargestellt. Man erkennt, daß man nur dann ein Bild der Bakterien bekommt, wenn die Tiefe, in der das Objekt abgerastert wird, den 

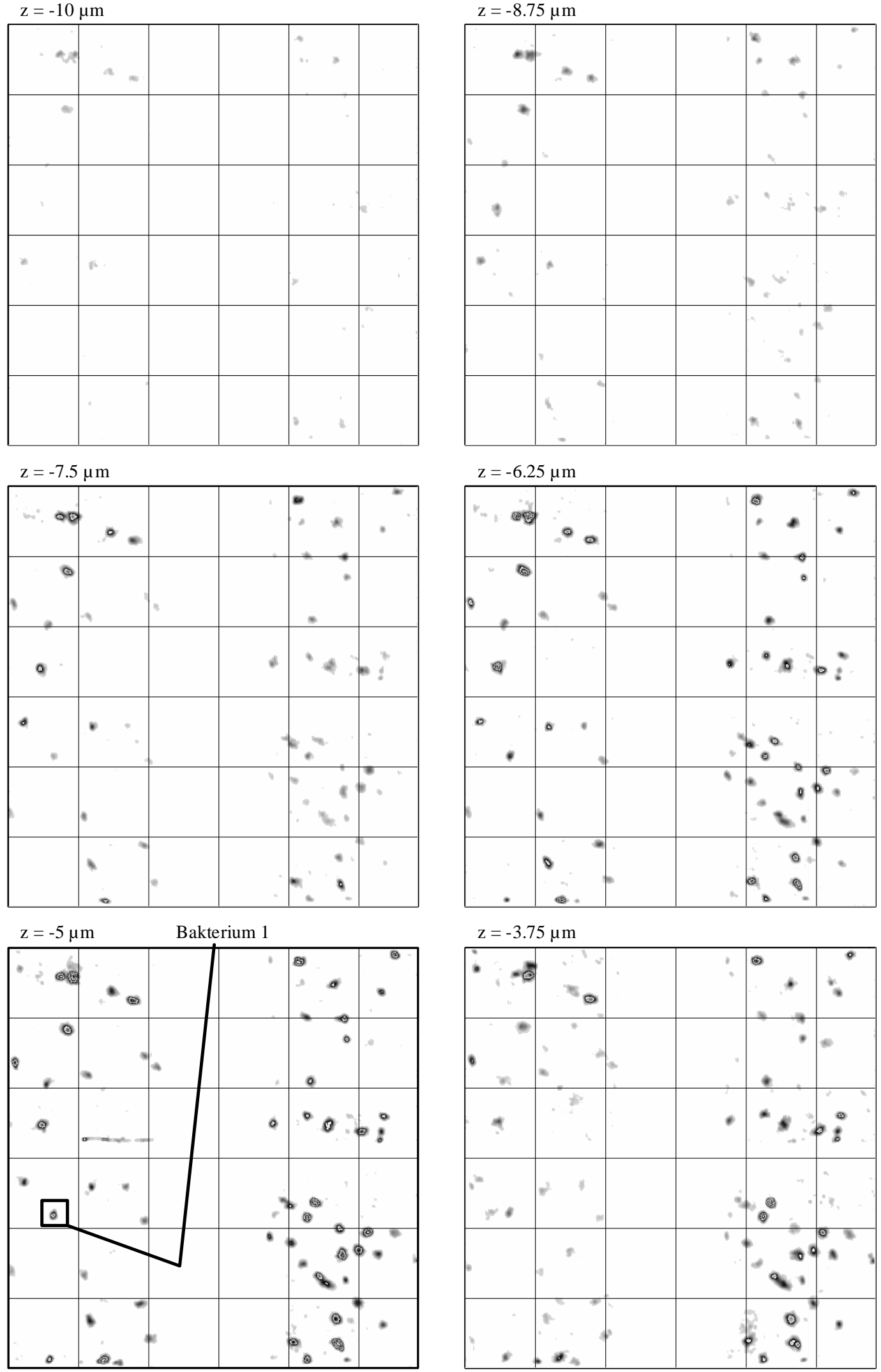

Abbildung 3.35: Mehrere Scans derselben Stelle in verschiedenen Tiefen. Die Ebenen sind jeweils $1.25 \mu \mathrm{m}$ voneinander entfernt. Im Bild für $z=-5 \mu \mathrm{m}$ ist das Bakterium, für das in Abb. 3.38 die z-Abhängigkeit dargestellt ist, mit einem Rechteck gekennzeichnet. 

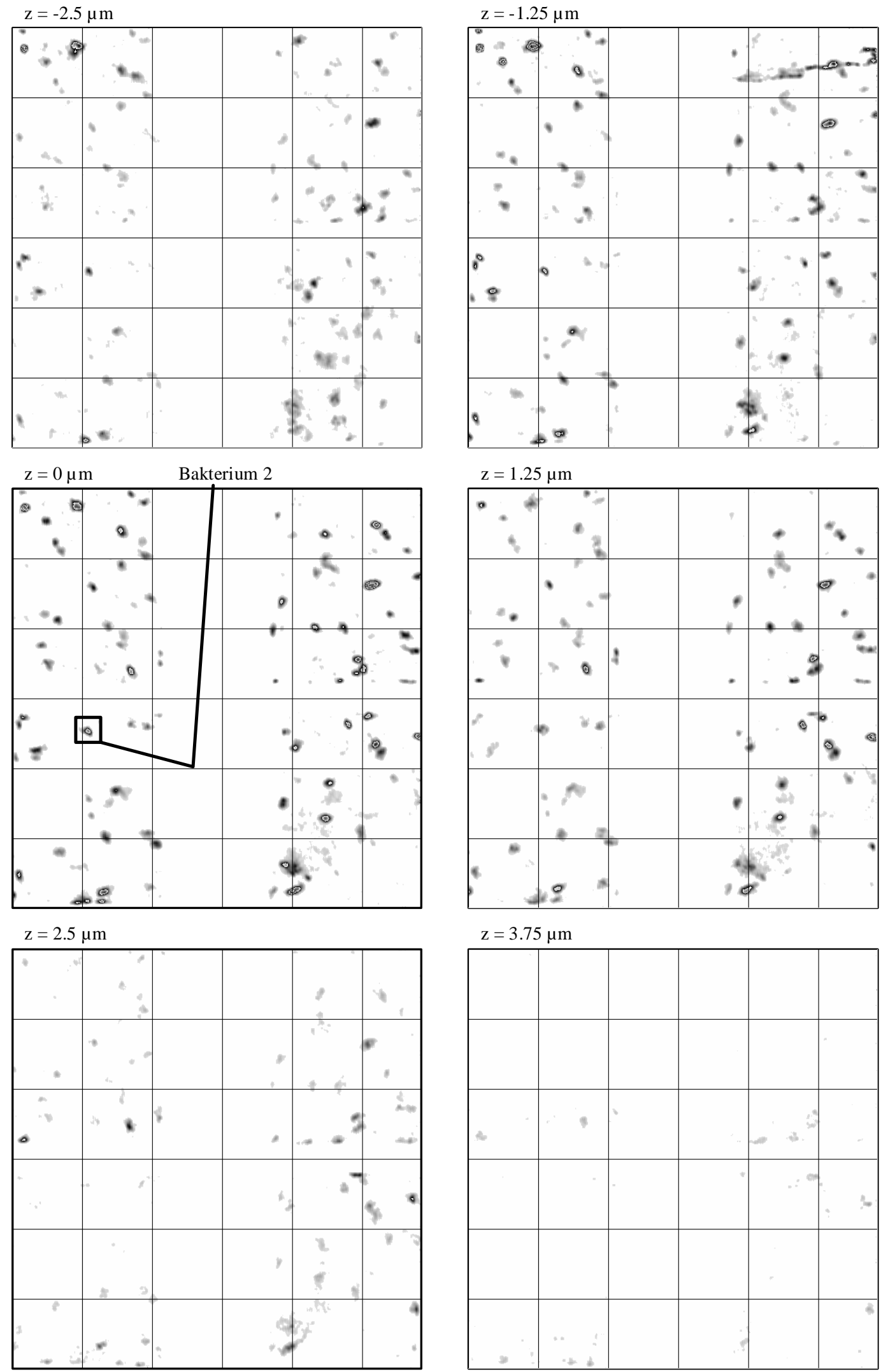

Abbildung 3.36: Mehrere Scans derselben Stelle in verschiedenen Tiefen. Die Ebenen sind jeweils $1.25 \mu \mathrm{m}$ voneinander entfernt. Im Bild für $z=0 \mu \mathrm{m}$ ist das Bakterium, für das in Abb. 3.38 die z-Abhängigkeit dargestellt ist, mit einem Rechteck gekennzeichnet. 


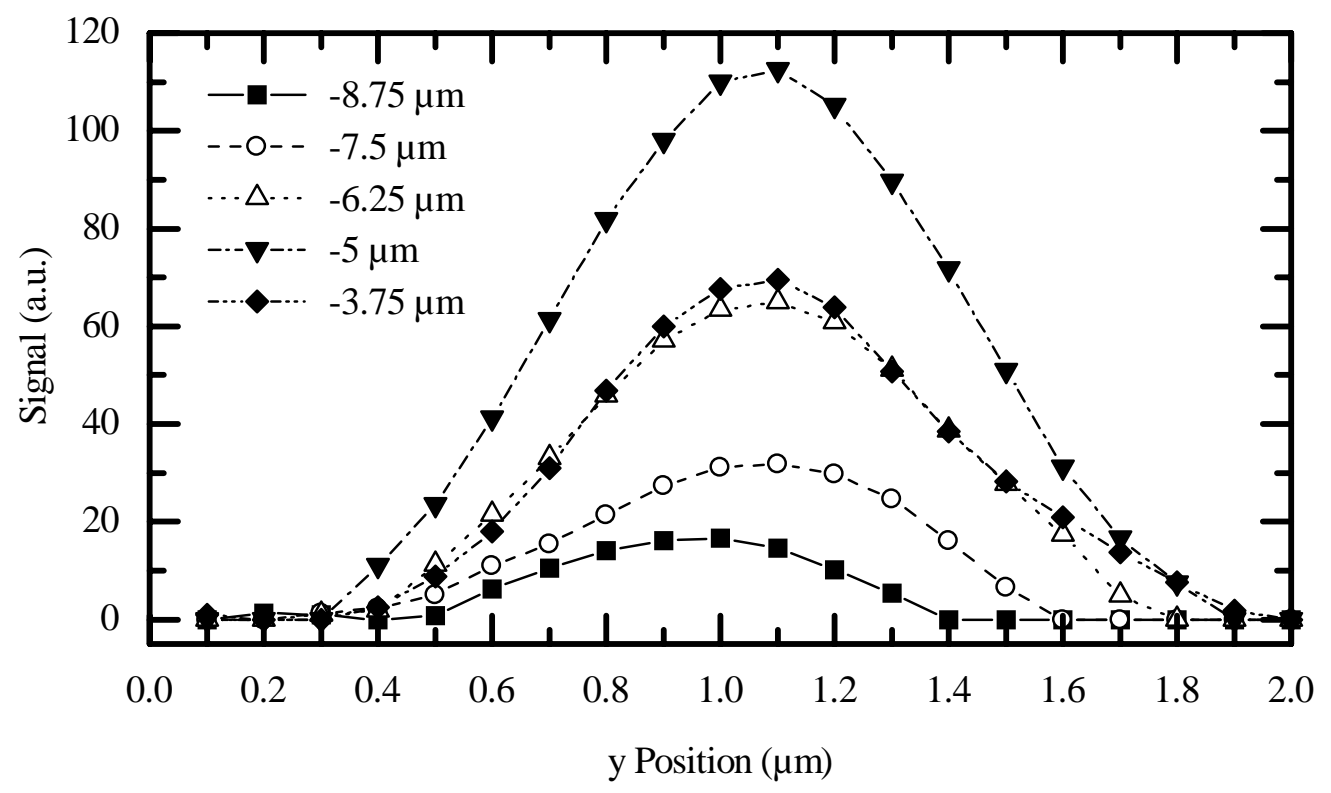

Abbildung 3.37: Querschnittsprofile durch ein Bakterium für verschiedene Tiefen. Man erkennt die Zunahme des Signals, wenn die Fokalebene dem Bakterium näher kommt. Die Halbwertsbreite der Kurven ist annähernd konstant und beträgt $0.75 \mu \mathrm{m}$.

richtigen Wert hat. ${ }^{13}$ Ist der z-Wert zu klein, befinden sich die Bakterien unterhalb der Foki und das GFP wird nicht zur Fluoreszenz angeregt. Nimmt dann der zWert zu, wird das Bild der Bakterien zunehmend klarer, bis es bei zu großem zWert wieder verschwindet. In der Mitte der Bilder bleibt ein kreuzförmiger Bereich wegen der Anordnung der Strahlen in Blöcken zu je $4 \times 4$ frei. In Abbildung 3.37 sind Querschnittsprofile in y-Richtung durch ein Bakterium für verschiedene Tiefen dargestellt.

Bei genauerer Betrachtung fällt auf, daß es tatsächlich zwei z-Positionen ( $z=$ $-5 \mu \mathrm{m}, z=0 \mu \mathrm{m})$ gibt, in denen man ein scharfes Bild bekommt. Die beiden Bilder sind völlig unterschiedlich, was die Lage und Anzahl der Bakterien betrifft. Das heißt, die Bakterien liegen nicht nur in einer Ebene auf dem Objektträger, sondern befinden sich auch noch in einer zweiten Ebene $5 \mu \mathrm{m}$ darüber - an der Unterseite des Deckgläschens.

Die beiden Ebenen können klar voneinander getrennt werden, was bei einem normalen Epifluoreszenzmikroskop nicht möglich wäre. Dies zeigt, auch wenn die Bakterien selbst über keine auflösbare Struktur verfügen, die dreidimensionale Auflösung des Zweiphotonenmikroskops.

In Abbildung 3.38 sind drei Tiefenprofile aus der Bilderserie dargestellt. Das eine Profil zeigt das über das gesamte Bild gemittelte Signal. Hier sieht man die

\footnotetext{
${ }^{13}$ Aus diesem Grund ist auf dem ersten und letzten Bild der Serie gar nichts zu sehen; daher fehlen die Bilder in der Abbildung.
} 


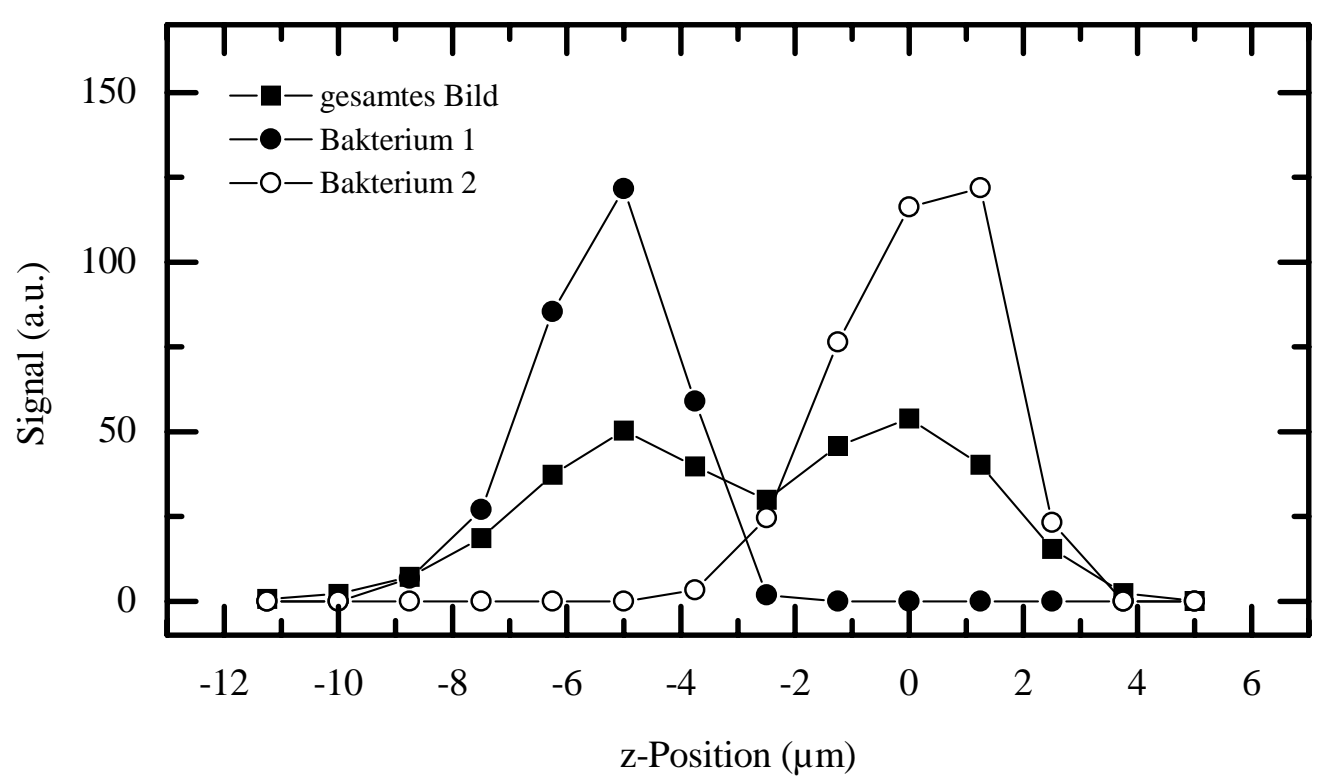

Abbildung 3.38: Tiefenprofile der Bilderserie (siehe Abb. 3.35, 3.36) über unterschiedliche Ortsbereiche gemittelt. Die Bakterien 1 und 2 sind in der Bilderserie durch Rechtecke gekennzeichnet.

Lage der beiden Ebenen als Maxima. Für die anderen beiden Profile wurde das Signal über einen kleinen Bereich gemittelt, in dem sich ein einzelnes Bakterium befand. Dabei wurde einmal ein Bakterium vom Deckglas und beim anderen Profil eins vom Objektträger gewählt. An diesen Profilen erkennt man, daß die Bakterien aus der jeweils anderen Ebene nur sehr wenig Signal liefern, wenn das Mikroskop auf eine der beiden Ebenen scharf gestellt ist.

\section{Quantitative Mikroskopie}

Die Signalstärke, die für ein einzelnes Bakterium gemessen wird, gibt in erster Näherung die Stärke der GFP-Expression wieder. Zur quantitativen Auswertung wurden die Signale auf einem rechteckigen Bereich, der das Bakterium ganz überdeckte aufsummiert. Alle Bakterien der Bilder für $z=-5 \mu \mathrm{m}$ und $z=0 \mu \mathrm{m}$ wurden so ausgewertet. In Abbildung 3.39 ist ein Histogramm der so bestimmten Signale dargestellt. Man erkennt einen breiten Peak bei 9000 counts. Der schwache Peak bei 27000 counts kommt vermutlich dadurch zustande, daß hier das Signal mehrerer Bakterien aufgenommen wurde. Dies kann z. B. passieren, wenn die Bakterien an derselben xy-Position liegen und nur wenig in z-Richtung voneinander entfernt sind.

Die Messung der Gen-Expression ist interessant, weil man so Informationen über den Stoffwechselzustand eines Organismus auf der fundamentalsten Ebene erhalten kann. 


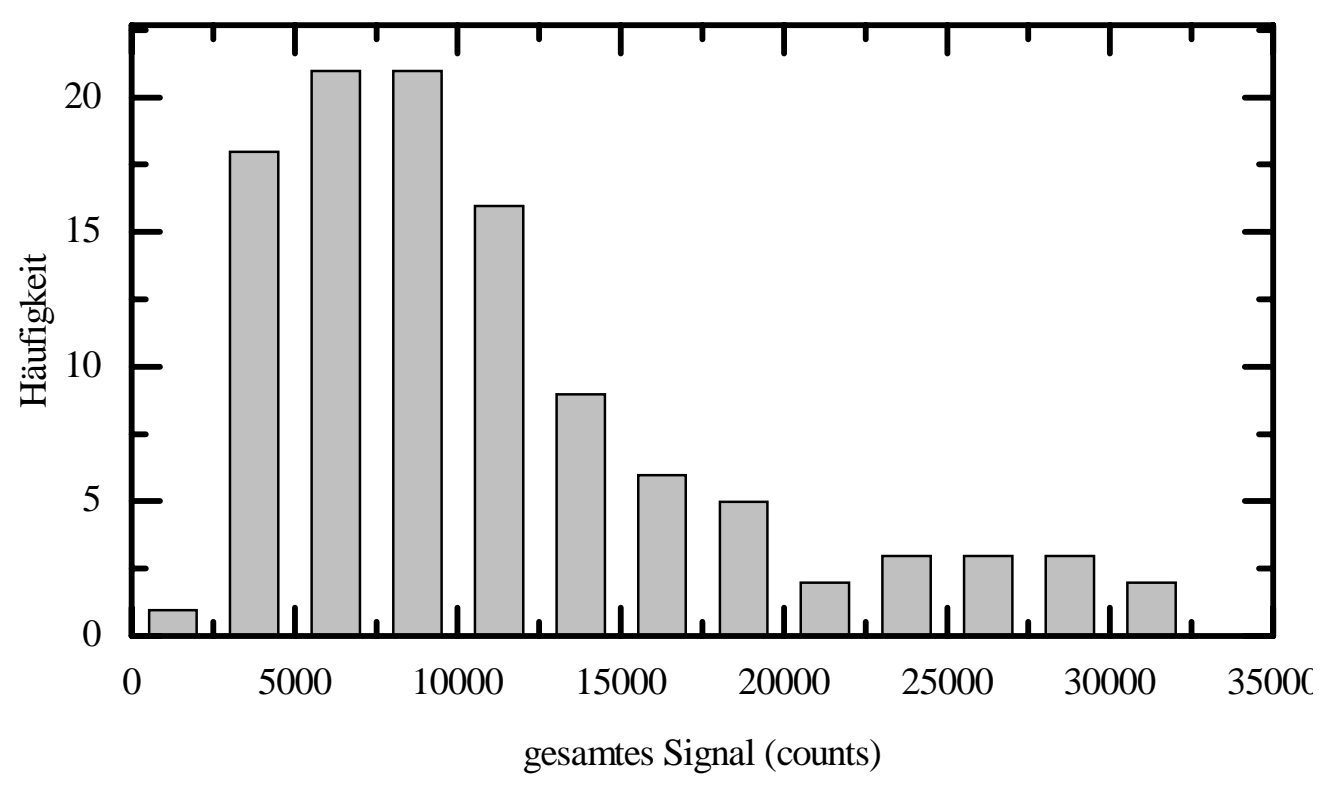

Abbildung 3.39: Histogramm der GFP-Signalstärken der Bakterien.

\subsection{Diskussion}

\subsubsection{Die Auflösung}

Die Auflösung, die bisher erreicht wurde ( $0.6 \mu \mathrm{m}$ lateral, $2.6 \mu \mathrm{m}$ axial), ist geringer, als sie für einen beugungsbegrenzten Fokus zu erwarten wäre. Eine Ursache dafür ist, daß der Durchmesser der Teilstrahlen noch etwas zu gering ist und nicht optimal an den Durchmesser der Eintrittspupille des Objektivs angepaßt ist.

Ein zweiter Grund für die nicht optimale Auflösung ist die Verwendung eines Öl-Immersionsobjektiv bei Objekten, die sich in wässriger Umgebung befinden. In [101] wurde gezeigt, daß schon bei geringen Eindringtiefen eine Verschlechterung der Auflösung eintritt, wenn der Brechungsindex des Mediums nicht an den der Immersion angepaßt ist.

Die Auflösung sollte die optimalen Werte erreichen, wenn die Strahlen etwas aufgeweitet werden und ein Objektiv mit Wasserimmersion verwendet wird.

\subsubsection{Gegenseitige Beeinflussung der Teilstrahlen in der Probe}

Bei der Ausbildung von Teilstrahlen mit Mikrolinsen wurde beobachtet, daß die Tiefenauflösung vom Abstand der Foki abhängt [102]. Dies wurde dadurch erklärt, daß es oberhalb und unterhalb der Fokalebene Bereiche gibt, in denen sich die Kegel der einzelnen Strahlen überlappen und dadurch die Intensität so hoch wird, daß es zu einer merklichen Fluoreszenzanregung kommt. Die gegenseitige Beeinflussung reduzierte die Tiefenauflösung um so stärker, je kleiner der Abstand der Foki war. 
Dieser Effekt wurde hier nicht beobachtet. Der Grund hierfür ist, daß die einzelnen Teilstrahlen im Strahlteiler leicht unterschiedliche Wege zurücklegen, so daß sie die Probe zu verschiedenen Zeiten durchlaufen. Da sich die Zeiten um mehr als die Pulsdauer unterscheiden, können sich die Foki nicht beeinflussen und die Tiefenauflösung ist unabhängig vom Strahlabstand.

\subsubsection{Die Signalstärke}

In diesem Abschnitt soll die beobachtete Signalstärke mit den Erwartungen nach den Abschätzungen in Abschnitt 3.1.2.1 verglichen werden. Als Detektor wurde die CCD-Kamera allein sowie die Kamera mit Bildverstärker benutzt. Als Probe wurde Coumarin 500 in Glycol gelöst verwendet; die Konzentration betrug $1.5 \mathrm{mg} / \mathrm{ml}$ bzw. $105 \mu \mathrm{M}$.

\subsubsection{Detektion mit der CCD-Kamera}

Bei der Messung ohne Bildverstärker wurde bei einer Laserleistung von $2 \mathrm{~mW}$ und einer Belichtungszeit von $60 \mu$ s ein Signal von 6000 counts (42000 Elektronen) registriert. Berechnet man mit Hilfe der Gleichungen (3.9) und (3.10), welche Zeit zur Aufnahme dieses Signal benötigt werden sollte, kommt man auf $t=31 \mu \mathrm{s}$. Dabei wurde für die Quanteneffizienz der CCD-Kamera $q=0.3$ und für die Sammeleffizienz $\epsilon=0.3$ angenommen. Trotz der Unsicherheit, die durch die geschätzten Werte für die Quanteneffizienz des Farbstoffs und den ZweiphotonenAbsorptionsquerschnitt entsteht, liefert die Abschätzung also realistische Werte für die Signalstärke.

\subsubsection{Detektion mit dem Bildverstärker}

Bei einer entsprechenden Messung mit dem Bildverstärker wurden bei einer MCPSpannung von $540 \mathrm{~V}$ und 200 ps Öffnungsdauer in $10 \mathrm{~ms}$ Belichtungszeit 9000 counts gemessen; das entspricht bei 0.5 counts/Photoelektron (siehe Abb. 3.21) 18000 Photoelektronen $\left(1.8 \cdot 10^{6}\right.$ Photoelektronen/s). Aus der Messung mit der Kamera kann der Photonenfluß, der den Detektor erreicht, berechnet werden:

$\Phi^{\prime}=42000 /(0.3 \cdot 60 \mu \mathrm{s})=2 \cdot 10^{9} \mathrm{~s}^{-1}$. Daraus ergibt sich eine Nachweiswahrscheinlichkeit des Bildverstärkers von $q=9 \cdot 10^{-4}$.

Die Nachweiswahrscheinlichkeit $q$ setzt sich aus zwei Faktoren zusammen: der Quanteneffizienz der Photokathode $q_{p c}$ und einem Faktor $c_{d c}$, der die Öffnungsdauer $\Delta t$ des Bildverstärkers berücksichtigt.

Der zweite Faktor kann so berechnet werden:

$$
c_{d c}=\frac{\int g\left(t-t_{0}\right) \Phi(t) d t}{\int_{0}^{1 / f} \Phi(t) d t}
$$

Dabei steht $g$ für die Öffnungscharakteristik des Bildverstärkers und $t_{0}$ für den Beginn der Detektion relativ zum Laserpuls. $1 / f$ ist der zeitliche Abstand der Laserpulse. Nimmt man an, daß die Fluoreszenz einfach-exponentiell abklingt, im 


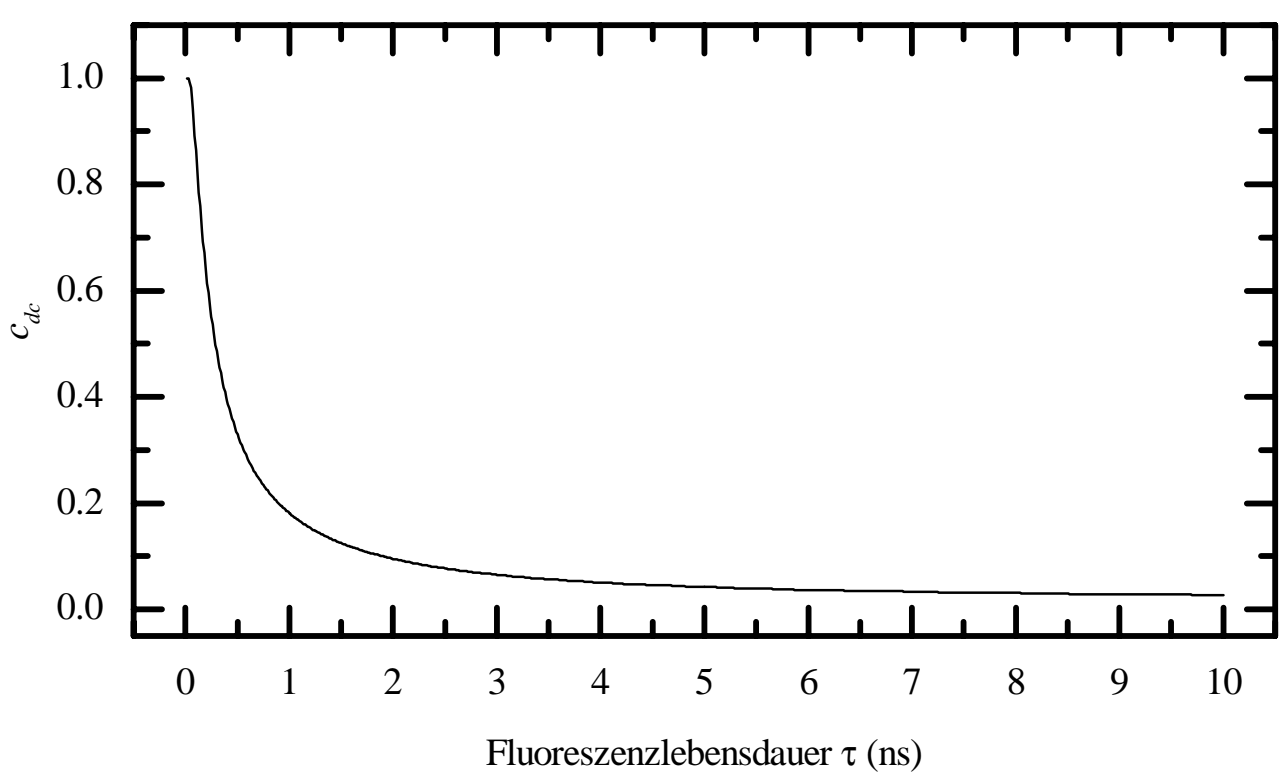

Abbildung 3.40: Die Abhängigkeit des Faktors $c_{d c}$ von der Fluoreszenzlebensdauer $\tau$. Die Kurve wurde für $f=76 \mathrm{MHz}$ und $\Delta t=200$ ps berechnet.

Maximum detektiert wird und die Öffnungscharakteristik $g$ eine Rechteckfunktion der Breite $\Delta t$ ist, ergibt sich daraus

$$
c_{d c}=\frac{\int_{0}^{\Delta t} \exp (-t / \tau) d t}{\int_{0}^{1 / f} \exp (-t / \tau) d t}=\frac{1-\exp (-\Delta t / \tau)}{1-\exp (-1 / f \tau)} .
$$

Die Abhängigkeit von $c_{d c}$ von der Fluoreszenzlebensdauer $\tau$ ist für $f=76 \mathrm{MHz}$ und $\Delta t=200 \mathrm{ps}$ in Abbildung 3.40 dargestellt. Für große Werte von $\tau$ nähert sich $c_{d c}$ dem Grenzwert $f \cdot \Delta t$ an (hier 0.015). Für $\tau=4.8 \mathrm{~ns}$ (Coumarin in Glycol) ergibt sich $c_{d c}=0.044$; damit ist die Quanteneffizienz der Photokathode $q_{p c}=0.020$.

Dieser Wert ist fünfmal niedriger als erwartet - für kontinuierlichen Betrieb wird vom Hersteller ein Wert von 0.1 angegeben. Der Grund für die niedrigere Ausbeute liegt in der Ansteuerung des Bildverstärkers: Bei den kurzen Öffnungsdauern wird an der Photokathode nicht die Spannung erreicht, die für einen optimalen Betrieb nötig ist. Die Spannung zwischen Photokathode und MCP hat dann im geöffneten Zustand nicht einen Wert von -120 V sondern nur von -20 V [103], d. h. die Photoelektronen werden nicht so stark auf die MCP beschleunigt. Dies führt dazu, daß die Wahrscheinlichkeit, Sekundärelektronen auszulösen, sinkt und die Photoelektronen effektiv nicht zum Signal beitragen.

Die Nachweiswahrscheinlichkeit der CCD-Kamera ist etwa dreihundertfach größer als die des Bildverstärkers (so wie er in diesem speziellen Fall betrieben wurde). Dazu tragen mehrere Faktoren bei, die im folgenden aufgelistet werden:

1. Die kurze Öffnungsdauer des Bildverstärkers $\left(c_{d c}\right)$ : Dieser Faktor ist unvermeidlich und ist der Preis, den man für die Messung der Fluoreszenzlebens- 
dauer zahlen muß. Man kann $c_{d c}$ durch Anpassen der Öffnungszeit an die Lebensdauer, die gemessen werden soll, steigern. Dabei muß man einen Kompromiß zwischen Reduktion der Zeitauflösung und Erhöhung der Nachweiseffizienz eingehen. Arbeitet man z. B. mit einer Öffnungsdauer, die halb so groß ist, wie die Lebensdauer, erhält man einen Wert von $c_{d c} \approx 0.4$.

2. Die geringere Quanteneffizienz der Photokathode: Die cw-Quanteneffizienz der Photokathode ist um einen Faktor 3 geringer als die Quanteneffizienz der CCD-Kamera.

3. Die Erniedriegung der effektiven Quanteneffizienz durch die Ansteuerung des Bildverstärkers: Dies reduziert die Nachweiswahrscheinlichkeit um einen Faktor 5. Dieser Effekt könnte durch eine bessere Bildverstärkerelektronik soweit verringert werden, daß die Quanteneffizienz den cw-Wert erreicht.

Selbst bei optimalen Bedingungen (Anpassung von $c_{d c}$, verbesserte Ansteuerung des Bildverstärkers) ist die Nachweiswahrscheinlichkeit mit Bildverstärker etwa achtmal geringer als ohne; d. h. die Kamera ist dem Bildverstärker vorzuziehen, wenn auf die Messung der Fluoreszenzlebensdauer verzichtet werden kann.

Die Nachweiswahrscheinlichkeit ist ein wesentlicher Faktor für das erreichbare Signal/Rausch-Verhältnis. Allgemein haben CCD-Kameras (bzw. Halbleiterdetektoren) eine höhere Quanteneffizienz als Photokathoden — auch im Vergleich mit Photomultipliern sind die Kameras daher in diesem Punkt überlegen. Das Problem der CCD-Kameras ist das hohe Ausleserauschen, das den Nachweis kleiner Signale verhindert (siehe Gl. (3.24)).

\subsubsection{Die Scangeschwindigkeit}

Die maximale Scangeschwindigkeit wird durch die Zeit, die zur Integration des Signals nötig ist, bestimmt. Bei Verwendung des Bildverstärkers sind $\approx 1 \mathrm{~ms}$, bei Verwendung der Kamera $\approx 100 \mu$ s Belichtungszeit pro Scanposition nötig. In dem hier verwendeten Aufbau ist die Auslesegeschwindigkeit der CCD-Kamera der zweite begrenzende Faktor, da für jede Scanposition ein Bild aufgenommen wird. Bei gleichzeitiger Aufnahme von 64 Signalen und einer Bildrate von $200 \mathrm{fps}$ (fps $=$ frames per second) ist die Pixelrate $1.3 \cdot 10^{4} \mathrm{~s}^{-1}$. Dieser Wert entspricht dem, was bei einem herkömmlichen Mikroskop mit einem Strahl ohne Messung der Fluoreszenzlebensdauer erreicht wird.

Die Pixelrate kann durch mehr Teilstrahlen und eine schnellere Kamera gesteigert werden. Kommerzielle fs-Laser ${ }^{14}$ liefern eine Leistung von $1 \mathrm{~W}$ bei einer Pulsdauer von $30 \mathrm{fs}$, d. h. mit einem solchen Laser lassen sich einige hundert Teilstrahlen erzeugen. Hochgeschwindigkeitskameras sind in der Lage, bis zu $5000 \mathrm{fps}$ zu liefern. ${ }^{15}$ Mit einem optimierten Aufbau sollte daher eine Pixelrate von ca. $5 \cdot 10^{5} \mathrm{~s}^{-1}$

\footnotetext{
${ }^{14}$ Die Daten beziehen sich auf einen Coherent Vitesse.

${ }^{15}$ PixelVision: Fast One
} 
(mit BV) bzw. $2 \cdot 10^{6} \mathrm{~s}^{-1}$ erreicht werden; dies ist etwa hundertmal schneller als bei herkömmlichen Zweiphotonenmikroskopen.

Das Problem der Auslesegeschwindigkeit der Kamera entfällt ganz, wenn die Strahlen gescannt werden und die Fluoreszenzsignale auf der Kamera integriert werden (sog. non de-scanned detection). Der Nachteil dieser Methode besteht darin, daß die Auflösung reduziert wird, wenn das Fluoreszenzlicht beim Austreten aus der Probe gestreut wird. Dieses Verfahren ist im allgemeinen nur bei dünnen Objekten geeignet.

\subsection{Zusammenfassung}

In diesem Kapitel wurde der Aufbau eines Zweiphotonen-LSM beschrieben. Mit diesem Mikroskop ist es möglich, dreidimensionale Bilder dicker Objekte mit hoher Ortsauflösung zu gewinnen. Im Unterschied zu herkömmlichen Verfahren arbeitet das Mikroskop mit 64 Teilstrahlen simultan. Die Aufteilung des Laserstrahls wurde durch ein neues Verfahren - die mehrfache Reflektion an einem teildurchlässigen Spiegel — realisiert. Diese Art der Strahlaufteilung zeichnet sich durch folgende Eigenschaften aus:

- Die Effizienz ist sehr hoch (90\%).

- Unabhängig vom Strahlprofil des Lasers werden Teilstrahlen mit annähernd gleicher Leistung erzeugt.

- Alle Teilstrahlen haben dasselbe Strahlprofil wie der Ausgangsstrahl.

Die Fluoreszenzsignale wurden mit einer intensivierten CCD-Kamera nachgewiesen. Durch extrem kurze Verschlußzeiten des Bildverstärkers konnte die Fluoreszenzlebensdauer gemessen werden.

Die Probe wurde punktweise vermessen, wobei für jede Scanposition ein Bild aufgenommen wurde. Zur Rekonstruktion eines zusammenhängenden Bildes aus den Daten der einzelnen Teilstrahlen wurde ein einfacher aber schneller Algorithmus implementiert. Diese Art der Datenaufnahme ist erstmalig realisiert worden.

Die Funktionsfähigkeit des Mikroskops wurde an Testobjekten sowie an fluoreszenzmarkierten Bakterien überprüft. Dabei wurde die dreidimensionale Ortsauflösung (0.6 $\mu \mathrm{m}$ lateral, $2.6 \mu \mathrm{m}$ axial) sowie die Zeitauflösung (0.2 ns) des Mikroskops bestimmt.

Aus den Messungen ergeben sich folgende Punkte, die in Zukunft optimiert werden können:

- Mehr Teilstrahlen durch Verwendung eines leistungsstärkeren Lasers,

- Datenaufnahme mit einer schnelleren Kamera,

- Abrastern der Probe durch Scannen der Laserstrahlen und nicht durch Bewegen des Objekts, 
- Optimierung des Strahlteilers, so daß die Strahlen in einem gleichmäßigen Raster angeordnet sind,

- Adaption des Aufbaus an ein kommerzielles Mikroskop.

Die Meßzeit für ein mikroskopisches Bild ist umgekehrt proportional zur Zahl der verwendeten Teilstrahlen. Daher führt eine Erhöhung der Anzahl der Strahlen zu einer höheren Bildrate des Mikroskops und damit zu einer Erweiterung der Einsatzmöglichkeiten der Zweiphotonenmikroskopie.

Das Scannen des Laserstrahls hat gegenüber dem Bewegen des Objekts den Vorteil, daß die Probenhalterung viel einfacher und robuster konstruiert sein kann. Die Art der Objekte, die dann untersucht werden kann, ist weniger Einschränkungen (z. B. bezüglich Größe und Gewicht) ausgesetzt als beim Scannen der Probe.

Die Adaption des parallel arbeitenden Zweiphotonenmikroskops an ein kommerzielles Labormikroskop bietet den Vorteil, daß zusätzlich zur Zweiphotonenmikroskopie die Standardverfahren der Mikroskopie verwendet werden können.

Die Meßdaten, die mit diesem Aufbau erhalten wurden, sowie Abschätzungen zeigen, daß durch diese Maßnahmen die Bildrate um einen Faktor hundert gegenüber einem herkömmlichen Zweiphotonen-LSM gesteigert werden kann. Damit werden die Möglichkeiten der Zweiphotonenmikroskopie drastisch erweitert.

Mögliche Anwendungen sind u. a. die Untersuchung der Reizleitung in intaktem Nervengewebe, die Verfolgung der Aufnahme von Medikamenten in Zellen und deren Reaktionen in der Zelle, in vivo Gewebeuntersuchungen an Patienten während einer Operation (optische Biopsie). 


\section{Zusammenfassung}

In dieser Arbeit wurde der Einsatz der zeitaufgelösten Laserspektroskopie in drei Experimenten demonstriert. Dabei wurde jeweils LIF mit einem ps- bzw. fsLaser angeregt und mit einer intensivierten CCD-Kamera mit hoher Zeitauflösung $(\leq 200 \mathrm{ps})$ nachgewiesen. Aus dem Zeitverlauf der Fluoreszenz konnten Informationen über die Umgebung, in der sich die angeregten Moleküle befanden, erhalten werden.

\section{ps-LIF an zweiatomigen Molekülen}

Im ersten Kapitel wurden OH-Moleküle in atmosphärischen Flammen untersucht. Mit einem an der Universität Bielefeld entwickelten, schmalbandigen und abstimmbaren ps-UV-Laser konnten einzelne Rotationsübergänge des OH-Moleküls selektiv angeregt werden. Die Fluoreszenzemission wurde mit hoher zeitlicher und spektraler Auflösung detektiert. Durch eine detaillierte Analyse der Spektren konnte die durch Stöße mit umgebenden Molekülen induzierte Dynamik in einem Vibrationszustand des elektronisch angeregten Zustands verfolgt werden. Mit diesem Aufbau war es erstmalig möglich, einige RET Raten direkt in einer atmosphärischen Flamme zu messen. Es konnte die totale RET Rate für das angeregte Rotationsniveau bestimmt werden. Desweiteren konnte die Rotationsverteilung innerhalb des angeregten Vibrationszustands durch ein einfaches Modell für zustandsspezifischen RET beschrieben werden.

Die im ersten Kapitel vorgestellten Messungen demonstrieren, wie Prozesse, die von den lokalen Gegebenheiten in der Flamme abhängen, wie z. B. Depolarisation und RET die Fluoreszenzemission beeinflussen. Die stoßinduzierten Prozesse haben Konsequenzen für quantitative LIF-Experimente, in denen Molekülkonzentrationen oder über Zwei-Linien-Thermometrie (TLT = two-line-thermometry) Temperaturen gemessen werden sollen. In theoretischen Betrachtungen wurde stoBinduzierten Effekten eine große Bedeutung für das Ergebnis von TLT-Messungen, die üblicherweise mit ns-Lasern durchgeführt werden, beigemessen [46, 47, 48]. Bisher hat sich dies aber noch nicht in systematischen, experimentellen Untersuchungen ausgewirkt.

Es bleibt zu hoffen, daß diese Messungen dazu beitragen, die Schwierigkeiten, die bei der Quantifizierung von LIF unter nicht stoßfreien Bedingungen auftreten, ins Bewußtsein der Anwender der in letzter Zeit auch in technischen Problemen populärer werdenden Lasermeßverfahren zu rücken. 


\section{ps-LIF in Flüssigkeiten}

Im zweiten Kapitel wurde die Bindung von fluoreszenzmarkiertem GTP an ein GProtein mit spektroskopischen Methoden untersucht. Das Bindungsereignis konnte sowohl an einer Änderung der Fluoreszenzintensität als auch an einer Änderung der Fluoreszenzlebensdauer festgestellt werden. Die untersuchte Reaktion stellt ein Modellsystem für ein Screening-System dar. Die durchgeführten Messungen zeigen, daß sich der Aufbau zu einem leistungsfähigen HTS-System erweitern läßt, das sich gegenüber bestehenden Systemen durch einige Vorteile auszeichnen würde: Die Analyse der beim Screening in großer Zahl eingesetzten Testsubstanzen könnte parallelisiert werden, so daß viele Reaktionen simultan untersucht werden könnten. Außerdem wären bei dem Verfahren keine Waschschritte erforderlich, d. h. die Durchführung der Reaktion (das liquid handling) wäre äußerst einfach. Da diese Schritte bei bisher üblichen Enzym-Assays sogar mehr Zeit beanspruchen als das Überprüfen, ob eine Reaktion stattgefunden hat, kann man bei einem Screening-System auf Basis der Experimente in Kapitel 2 einen sehr hohen Durchsatz erwarten.

Es zeichnet sich ab, daß optische Screening-Systeme mit paralleler Verarbeitung der Proben in Zukunft ein wichtiges Instrument in der Pharmaforschung sein werden [70]. Die zeitaufgelöste Spektroskopie bietet sich zum Einsatz in diesem Bereich an, da der Zeitverlauf der Fluoreszenz etwas über die Umgebung des Moleküls aussagt.

Die Experimente in Kapitel 2 könnten auch in eine andere Richtung weiterentwickelt werden: Die Untersuchung komplizierter Reaktionssysteme, wie sie z. B. bei der Signaltransduktion in Zellen auftreten. Anhand der Eigenfluoreszenz des G-Proteins könnten Rückschlüsse auf Konformationsänderungen gezogen werden. Durch Versuche, in denen mehrere, verschieden markierte Komponenten (z. B. GTP und GEF) simultan verwendet werden, könnten die Wechselwirkungen zwischen den verschiedenen Molekülen untersucht werden.

Obwohl einzelne Reaktionsketten bei der Signaltransduktion schon gut erforscht sind, ist die gegenseitige Beeinflussung der Reaktionswege (sog. cross talk) ein hoch aktuelles Thema in der biologischen Grundlagenforschung. Die zeitaufgelöste Laserspektroskopie bietet die Möglichkeit, sich diesen Fragen zu nähern.

\section{fs-LIF mit hoher Ortsauflösung}

Im dritten Kapitel wurde der Aufbau und die Erprobung eines Zweiphotonenmikroskops dargestellt. Im Unterschied zu üblichen Zweiphotonenmikroskopen, die mit einem Strahl arbeiten, wurden zur Anregung der Fluoreszenz 64 Laserstrahlen simultan verwendet. Diese Art der Parallelisierung ist sehr jung und wird zur Zeit nur von zwei anderen Arbeitsgruppen durchgeführt [93, 102].

In dieser Arbeit wurde ein neues Verfahren der Strahlaufteilung vorgestellt, das sich durch folgende Vorteile gegenüber der Aufteilung mit Mikrolinsen (ML), die von den anderen beiden Gruppen verwendet werden, auszeichnet: Die vorhandene 
Laserleistung wird sehr effizient genutzt (90\% gegenüber 10\% mit ML). Die Leistung der einzelnen Teilstrahlen ist unabhängig vom Strahlprofil des Lasers, d. h. auch bei einem gaußförmigen Strahlprofil werden Teilstrahlen mit annähernd gleicher Leistung erzeugt. Beide Eigenschaften führen dazu, daß bei gegebener Laserleistung eine größere Anzahl von brauchbaren Teilstrahlen erzeugt werden kann.

Zur Detektion der Fluoreszenz wurde eine (intensivierte) CCD-Kamera verwendet. Für jede Raster-Position wurde ein Bild der Kamera ausgelesen. Die Daten der einzelnen Strahlen wurden anschließend für jede Raster-Position ausgewertet und zu einem Gesamtbild zusammengesetzt. Diese Art der Datenaufnahme ist ebenfalls eine Neuerung in der Zweiphotonenmikroskopie. Sie hat den Vorteil, daß, auch wenn die Fluoreszenz beim Austritt aus dem untersuchten Objekt gestreut wird, ohne Einschränkung der Auflösung gearbeitet werden kann, solange die Signale der einzelnen Strahlen noch voneinander getrennt werden können.

Abschätzungen, die auf den mit diesem Aufbau erhaltenen Daten beruhen, zeigen, daß die Geschwindigkeit der Bildaufnahme um einen Faktor 100 gegenüber einem herkömmlichen Zweiphotonenmikroskop gesteigert werden kann, wenn ein leistungsstärkerer Laser und eine Hochgeschwindigkeitskamera verwendet werden. Damit wird dreidimensional auflösende Mikroskopie mit Videobildrate möglich, die sicherlich zahlreiche Anwendungen in Biologie und Medizin finden wird. Ein optimiertes Mikroskop befindet sich zur Zeit im Aufbau. Eine Anwendung zur Krebsdiagnostik ist in Vorbereitung. 


\section{Anhang A}

\section{Der Einfluß der Mittelung auf die Lösung der Ratengleichung}

Gleichung (1.4) enthält einen nicht-linearen Term, $\gamma(t) X$, die Laseranregung. Als Folge dieses Terms ist es nicht dasselbe, ob

a) ein gemittelter Laserpuls benutzt wird, um die Gleichung einmal zu lösen, oder

b) viele Lösungen für viele Laserpulse gemittelt werden.

In den hier beschriebenen Messungen wurde die Fluoreszenz vieler Laserpulse gemittelt und so ein Emissionsspektrum aufgenommen — dies entspricht Fall b). Bei der Modellierung der Besetzung wurde allerdings nur ein gemittelter Laserpuls, in den Pulsdauer, Jitter, die Öffnungszeit der Kamera und Intensitätsschwankungen eingingen, verwendet - dies entspricht Fall a). Die Frage ist jetzt, welche Unterschiede ergeben sich durch diese zwei Arten der Mittelung in den Ergebnissen, den RET Raten? Um dies quantitativ zu untersuchen, wurde ein einfacheres drei Niveau System, das aus einem Niveau im Grundzustand $n_{x}$ und zwei Niveaus im angeregten Zustand $n_{l}$ und $n_{\mathrm{Bad}}$ besteht, gewählt. RET findet zwischen $n_{l}$ und $n_{\mathrm{Bad}}$ statt, beide Niveaus sind dem Quenching ausgesetzt. In diesem Fall kann Gleichung (1.4) so geschrieben werden:

$$
\frac{d n}{d t}=\left(\begin{array}{ccc}
0 & 0 & 0 \\
0 & -Q-R & R_{b} \\
0 & R & -Q_{b}-R_{b}
\end{array}\right)\left(\begin{array}{c}
n_{x} \\
n_{l} \\
n_{\mathrm{Bad}}
\end{array}\right)+\gamma(t) X
$$

Für die Parameter wurden typische Werte angenommen: $R=3.0303 \mathrm{~ns}^{-1}, R_{b}=$ $0.4 \mathrm{~ns}^{-1}, Q=Q_{b}=1.48 \mathrm{~ns}^{-1}$.

Diese Gleichung wurde jetzt auf zwei Arten gelöst:

1. Es wurden 500 verschiedene Laserpulse verwendet, die Schwankungen ähnlich denen im Experiment hatten, um 500 Lösungen der Gleichung zu berechnen. Diese Lösungen wurden gemittelt und mit der Charakteristik des Detektors gefaltet. (Fall b) 


\begin{tabular}{|c|c|c|c|c|}
\hline $\begin{array}{c}\text { Pulsenergie } \\
\mathrm{mJ}]\end{array}$ & $\begin{array}{c}n_{x} \text { nach der } \\
\text { Anregung }\end{array}$ & $\begin{array}{c}\text { RET Rate } \\
\text { (Fall a) }\left[10^{9} \mathrm{~s}^{-1}\right]\end{array}$ & $\begin{array}{c}\text { RET Rate } \\
\text { (Fall b) }\left[10^{9} \mathrm{~s}^{-1}\right]\end{array}$ & $\begin{array}{c}\text { relative } \\
\text { Differenz }\end{array}$ \\
\hline 0.5 & 0.86 & 3.03382 & 3.03388 & $2 \cdot 10^{-5}$ \\
5 & 0.34 & 3.03380 & 3.03385 & $2 \cdot 10^{-5}$ \\
25 & 0.12 & 3.03114 & 3.03116 & $7 \cdot 10^{-6}$ \\
\hline
\end{tabular}

Tabelle A.1: Berechnete RET Raten für verschiedene Arten der Mittelung.

2. Der Mittelwert der Laserpulse wurde mit der Detektorcharakteristik gefaltet und zur einmaligen Lösung der Gleichung benutzt. (Fall a)

Die beiden Lösungen für $n_{l}$ und $n_{\text {Bad }}$ sind in Abbildung A.1 für verschiedene Werte der Pulsenergie dargestellt. Die Pulsenergie in dem Experiment $(0.5 \mathrm{~mJ})$ war an der Grenze zur Sättigung, d. h. 25 mJ steht für sehr starke Sättigung — also maximalen Effekt der Nichtlinearität.

Unterschiede in den Zeitverläufen erkennt man am Anfang der Profile; das Abklingen ist im wesentlichen identisch oder nur zeitlich verschoben, selbst bei starker Sättigung. Aus den Lösungen wurden RET Raten berechnet. Die Ergebnisse sowie die relative Differenz zwischen der Lösung für Fall a) und b) sind in Tabelle A.1 dargestellt. Die relative Differenz ist in der Größenordnung von $10^{-5}$ und damit bei weitem kleiner als andere Meßfehler. Der Grund für diese kleinen Differenzen selbst für große Nichtlinearitäten liegt darin, daß die Raten die Dynamik innerhalb des angeregten Zustands beschreiben, während die Laseranregung nur die Art, wie der angeregte Zustand bevölkert wird, angibt. Die RET Rate wird mehr vom Verhältnis $n_{l}$ zu $n_{\text {Bad }}$ beeinflußt als vom absoluten Wert von $n_{l}$. 

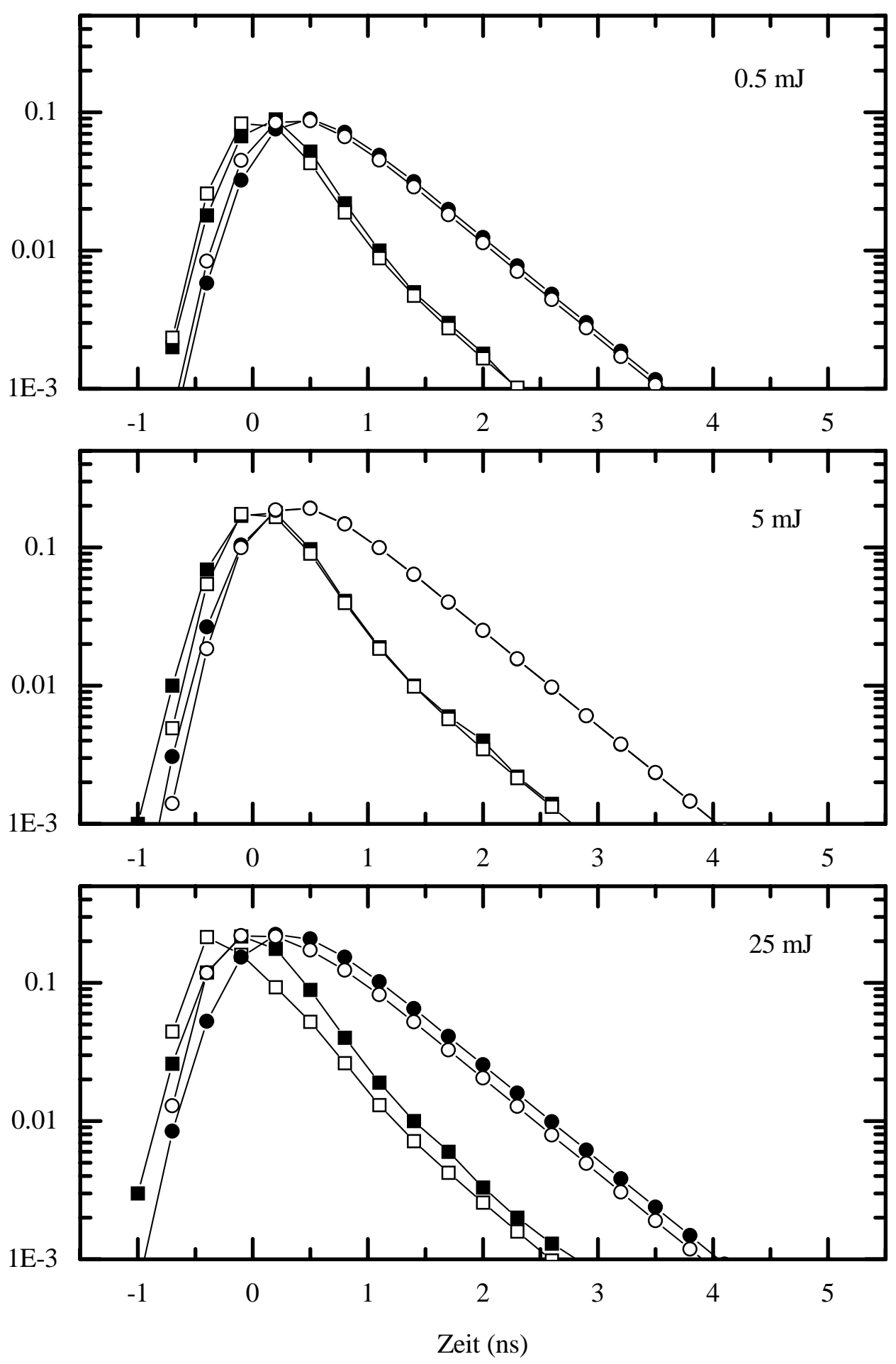

$-\square-n_{l}$ Fall $\mathrm{a}-\bullet-n_{B a d}$ Fall a
$-\square-n_{l}$ Fall $\mathrm{b}-\mathrm{O}-n_{B a d}$ Fall $\mathrm{b}$

Abbildung A.1: Lösungen des Ratengleichungsmodells für verschiedene Arten der Mittelung. Die Pulsenergie beeinflußt die Größe des nicht-linearen Terms. 


\section{Literaturverzeichnis}

[1] W. Demtröder, Laserspektroskopie: Grundlagen und Techniken, 3. Auflage, Springer Verlag, Berlin (1993).

[2] G. Herzberg, Spectra of Diatomic Molecules, 2. Auflage, Van Nostrand Reinhold Company, New York (1950).

[3] D. R. Crosley, R. K. Lengel, JQSRT 15, 579 - 591 (1975).

[4] T. Nielsen, F. Bormann, M. Burrows, P. Andresen, Appl. Opt. 36, 7960 - 7969 (1997).

[5] K. Kohse-Höinghaus, Prog. Energy Combust. Sci. 20, 203-279 (1994).

[6] E. W. Rothe, P. Andresen, Appl. Opt. 36, 3971 - 4033 (1997).

[7] E. W. Rothe, Y. W. Gu, G. P. Reck, Appl. Opt. 35, 934-947 (1996).

[8] A. Dreizler, R. Tadday, P. Monkhouse, J. Wolfrum, Appl. Phys. B 57, 85-87 (1993).

[9] M. Köllner, P. Monkhouse, Appl. Phys. B 61, 499-503 (1995).

[10] F. Bormann, T. Nielsen, M. D. Burrows, P. Andresen, Appl. Phys. B 62, 601607 (1996).

[11] F. Bormann, T. Nielsen, M. D. Burrows, P. Andresen, Appl. Opt. 36, 6129 6140 (1997).

[12] R. Kienle, M. P. Lee, K. Kohse-Höinghaus, Appl. Phys. B 62, 583-599 (1996).

[13] R. Goldflam, S. Green, D. J. Kouri, J. Chem. Phys. 67, 4149 - 4161 (1977).

[14] M. H. Alexander, J. Chem. Phys. 76, 3637 - 3645 (1982).

[15] A. E. DePristo, S. D. Augustin, R. Ramaswamy, H. Rabitz, J. Chem. Phys. 71, 850-865 (1979).

[16] M. D. Burrows, F. Bormann, P. Andresen, Appl. Phys. B 61, 451-460 (1995).

[17] F. Bormann, Dissertation, Universität Bielefeld (1996). 
[18] T. Nielsen, Diplomarbeit, Universität Bielefeld (1995).

[19] R. W. Boyd, Nonlinear Optics, Academic Press, London (1992).

[20] P. E. Young, J. D. Hares, J. D. Kilkenny, D. W. Phillion, E. M. Campbell, Rev. Sci. Instr. 59, 1457-1460 (1988).

[21] T. Nielsen, F. Bormann, S. Wolbeck, H. Spiecker, M. D. Burrows, P. Andresen, Rev. Sci. Instr. 67, 1721-1724 (1996).

[22] J. Luque, D. R. Crosley, SRI Internatinal Report MP 99-001 (1996).

[23] G. H. Golub, V. Pereyra, SIAM J. Numerical Analysis 10, 413-432 (1973).

[24] W. H. Press, S. A. Teukolsky, W. T. Vetterling, B. P. Flannery, Numerical Recipes in C, Second Edition, Cambridge University Press (1992).

[25] C. H. Greene, R. N. Zare, J. Chem. Phys. 78, 6741-6753 (1983).

[26] P. P. Feofilov, The physical basis of polarized emission, Consultants Bureau, New York (1961).

[27] W. Schade, J. Walewski, A. Offt, A. Knaack, Phys. Rev. A 53, R2921-R2924 (1996).

[28] P. M. Doherty, D. R. Crosley, Appl. Opt. 23, 713-721 (1984).

[29] M. H. Alexander, J. E. Smedley, G. C. Corey, J. Chem. Phys. 84, 3049-3058 (1986).

[30] A. Jörg, U. Meier, K. Kohse-Höinghaus, J. Chem. Phys. 93, 6453-6462 (1990).

[31] L. R. Williams, D. R. Crosley, J. Chem. Phys. 104, 6507 - 6514 (1996).

[32] R. A. Copeland, M. L. Wise, D. R. Crosley, J. Phys. Chem. 92, 5710-5715 (1988).

[33] I. J. Wysong, J. B. Jeffries, D. R. Crosley, J. Chem. Phys. 92, 5218-5222 (1990).

[34] C. B. Cleveland, J. R. Wiesenfeld, Chem. Phys. Lett. 144, 479-485 (1988).

[35] R. J. Cattolica, T. G. Mataga, Chem. Phys. Lett. 182, 623-631 (1991).

[36] J. B. Jeffries, K. Kohse-Höinghaus, G. P. Smith, R. A. Copeland, D. R. Crosley, Chem. Phys. Lett. 152, 160-166 (1988).

[37] T. Hartlieb, D. Markus, W. Kreutner, K. Kohse-Höinghaus, Appl. Phys. B 65, 81 - 91 (1997).

[38] R. Kienle, M. P. Lee, K. Kohse-Höinghaus, Appl. Phys. B 63, 403-418 (1996). 
[39] S. Gordon and McBride, NASA Spec. Publ. SP-273 (Washington, D. C. 1971).

[40] R. Kienle, Dissertation, Universität Bielefeld (1994).

[41] R. K. Lengel, D. R. Crosley, J. Chem. Phys. 67, 2085-2101 (1977).

[42] J. Burris, J. J. Butler, T. J. McGree, W. S. Heaps, Chem. Phys. 124, 251-258 (1988).

[43] A. Joerg, U. Meier, R. Kienle, K. Kohse-Höinghaus, Appl. Phys. B 55, 305310 (1992).

[44] D. Stepowski, M. J. Cottereau, J. Chem. Phys. 74, 6674-6679 (1981).

[45] R. P. Lucht, D. W. Sweeney, N. M. Laurendeau, Appl. Opt. 25, 4086-4095 (1986).

[46] J. W. Daily, E. W. Rothe, Appl. Phys. B 68, 131 - 140 (1999).

[47] E. W. Rothe, Y. Gu, A. Chryssostomou, P. Andresen, F. Bormann, Appl. Phys. B 66, 251 - 258 (1998).

[48] E. W. Rothe, Y. Gu, Proc. of SPIE 3172, 462 - 466 (1997).

[49] G. McGall, J. Labadie, P. Brock, G. Wallraff, T. Nguyen, W. Hinsberg, Proc. Natl. Acad. Sci. 93, 13555 - 13560 (1996).

[50] B. Alberts, D. Bray, J. Lewis, M. Raff, K. Roberts, J. D. Watson, Molecular Biology of the Cell, 3rd ed., Garland, NewYork (1994).

[51] R. C. West edt., CRC Handbook of Chemistry and Physics E-206, 1st Student Edition, CRC Press, Inc. Florida (1987).

[52] Y. Takai, K. Kaibuchi, A. Kikuchi, M. Kawata, Int. Rev. of Cytology 133, 187 - 232 (1992).

[53] A. Hall, Science 249, 635 - 640 (1990).

[54] M. Zerial, L. A. Huber, Guidebook to the Small GTPases, Oxford University Press (1994).

[55] K. Simons, M. Zerial, Neuron 11, 789 - 799 (1993).

[56] T. Hiratsuka, Biochimica et Biophysica Acta 742, 496-508 (1983).

[57] S. E. Neal, J. F. Eccleston, M. R. Webb, Proc. Natl. Acad. Sci. USA 87, 3562 - 3565, (1990).

[58] W. Troz, J. K. Reed, FEBS Lett. 127, 196 - 200 (1981).

[59] S. Udenfriend, P. Zaltzman, Analytical Biochemistry 3, 49 - 59 (1962). 
[60] A. E. Remmers, R. Posner, R. R. Neubig, J. of Biological Chemistry 269, 13771 - 13778 (1994).

[61] M. Baumert, G. Fischer von Mollard, R. Jahn, T. C. Südhof, Biochem. J. 293, 157 - 163 (1993).

[62] J. F. Eccleston, K. J. M. Moore, G. G. Brownbridge, M. R. Webb, P. N. Lowe, Biochem. Soc. Trans. 19, 432 - 436 (1991).

[63] E. Faurobert, A. Otto-Bruc, P. Chardin, M. Chabre, EMBO J. 12, 4191 - 4198 (1993).

[64] T. L. Hazlett, K. J. M. Moore, P. N. Lowe, D. M. Jameson, J. F. Eccleston, Biochemistry 32, 13575 - 13583 (1993).

[65] J. R. Lacowicz, Principles of Fluorescence Spectroscopy, Plenum Press, New York (1983).

[66] K. J. M. Moore, M. R. Webb, J. F. Eccleston, Biochemistry 32, 7451 - 7459 (1993).

[67] T. Higashijima, K. M. Ferguson, P. C. Sternweis, E. M. Ross, M. D. Smigel, A. G. Gilman, J. of Biological Chemistry 262, 752 - 756 (1987).

[68] bezogen von Calbiochem, Cat. No. 552100

[69] bezogen von Molecular Probes, Cat. No. M-12415

[70] Innovation Lambda 3, 16 - 21, Carl Zeiss Mikroskopie (1999).

[71] P. T. C. So, T. French, W. M. Yu, K. M. Berland, C. Y. Dong, E. Gratton, Bioimaging 3, 49 - 63 (1995).

[72] R. Yuste, W. Denk, Nature 375, 682-684 (1995).

[73] Handbook of biological confocal microscopy, edited by J. B. Pawley, 2nd ed. Plenum Press, New York (1995).

[74] T. R. Corle, C.-H. Chou, G. S. Kino, Optics Letters 11, 770 - 772 (1986).

[75] C. J. R. Sheppard, T. Wilson, Optics Letters 3, 115 - 117 (1978).

[76] H. Giloh, J. W. Sedat, Science 217, 1252 - 1255 (1982).

[77] J. P. Reyftmann, E. Kohen, P. Morliere, R. Santus, C. Kohen, W. F. Mangel, L Dubertret, J. G. Hirschberg, Photochem. Photobiol. 44, 461 - 469 (1986).

[78] W. Denk, J. Strickler, W. W. Webb, Science 248, 73 - 76 (1990).

[79] K. König, P. T. C. So, W. Mantulin, E. Gratton, Optics Letters 22, 135 - 136 (1997). 
[80] P. E. Hänninen, S. W. Hell, J. Salo, E. Soini, C. Cremer, Appl. Phys. Lett. 66, $1698-1700(1995)$.

[81] E. H. K. Stelzer, S. Lindek, Opt. Commun. 111, 536 - 547 (1994).

[82] S. W. Hell, M. Kroug, Appl. Phys. B 60, 495 - 497 (1995).

[83] S. W. Hell, J. Wichmann, Opt. Lett. 19, 780 - 782 (1994).

[84] D. L. Wokosin, V. E. Centonze, J. G. White, S. N. Hird, S. Sepsenwol, G. P. A. Malcolm, G. T. Maker, A. I. Ferguson, Proc. SPIE 2678, 38 - 49 (1996).

[85] S. W. Hell, M. Booth, S. Wilms, C. M. Schnetter, A. K. Kirsch, D. J. ArndtJovin, T. M. Jovin, Optics Letters 23, 1238 - 40 (1998).

[86] D. L. Wokosin, V. E. Centonze, J. G. White, D. Armstrong, G. Robertson, A. I. Ferguson, IEEE J. sel. topics in Quantum Electronics 2, 1051 - 1065 (1996).

[87] J. Borkowski, Dissertation, Universität Bielefeld (1996).

[88] D. Hellweg, Diplomarbeit, Universität Bielefeld (1999).

[89] R. Wolleschensky, T. Feurer, R. Sauerbrey, U. Simon, Appl. Phys. B 67, 87 94 (1998).

[90] Deutsches Patentamt Nr. DE 19904592.5 (1999).

[91] Deutsches Patentamt Nr. DE 19653413 A1 (1996).

[92] E. Ott, Wissenswertes über CCD-Kameras, PCO CCD Imaging (1997).

[93] J. Bewersdorf, R. Pick, S. W. Hell, Optics Letters 23, 655 - 657 (1998).

[94] Schott Glas Katalog.

[95] R. J. Renka, ACM Trans. Math. Softw. 10, 440 - 442 (1984).

[96] H. Späth, Zweidimensionale Spline-Interpolations-Algorithmen, Oldenbourg Verlag, München (1991).

[97] bezogen von Molecular Probes, Cat. No. F-8887

[98] W. W. Ward, C. W. Cody, R. C. Hart, Photochem. Photobiol. 31, 611 - 615 (1980).

[99] F. De Giorgi, M. Brini, C. Bastianutto, R. Marsault, M. Montero, P. Pizzo, R. Rossi, R. Rizutto, Gene 173, 113 - 117 (1996).

[100] R. Heim, R. Tsien, Current Biol. 6, 178 - 182 (1996). 
[101] S. Hell, G. Reiner, C. Cremer, E. H. K. Stelzer, J. of Microscopy 169, 391 405 (1993).

[102] A. H. Buist, M. Müller, J. Squier, G. J. Brakenhoff, J. of Microscopy 192, 217 - 226 (1998).

[103] T. Seelemann, La Vision GmbH, persönliche Mitteilung (1999). 


\section{Danksagung}

Diese Arbeit entstand am Lehrstuhl für Angewandte Laserphysik der Universität Bielefeld unter der Leitung von Prof. Peter Andresen, dem ich für die interessante Aufgabenstellung und hilfreiche Diskussionen danke.

Ebenso danke ich allen Mitgliedern der Arbeitsgruppe für die gute Arbeitsatmosphäre. Besonders erwähnen möchte ich Frank Bormann, mit dessen Unterstützung der ps-Excimer-Laser aufgebaut wurde, Grigorius Tsilimis, der mich in die Eigenheiten von fs-Lasern einführte, und Matthias Fricke und Dirk Hellweg, die bei der Arbeit am Mikroskop mitwirkten.

Die Messungen zum G-Protein wurden in Kooperation mit dem Lehrstuhl für Genetik der Universität Bielefeld durchgeführt. Auch die fluoreszenzmarkierten Bakterien wurden mir freundlicherweise von dort zur Verfügung gestellt. Für die Unterstüzung bei diesen Messungen danke ich Holger Densow, Karin Schiene und Karsten Niehaus vom Lehrstuhl für Genetik der Universität Bielefeld.

Bei den Mitarbeitern der Firma La Vision bedanke ich mich für die technische Unterstützung sowie für Ratschläge zur Programmierung der Kamera. 